$$
\begin{aligned}
& \text { Universidade de São Paulo } \\
& \text { Instituto de Física de São Carlos }
\end{aligned}
$$

Marcos de Oliveira Junior

\title{
Ambientes de coordenação de heteropolioxometalatos de Keggin em xerogeis fotocrômicos analisados por espectroscopia de RMN e RPE em sólidos
}



Marcos de Oliveira Junior

\section{Ambientes de coordenação de heteropolioxometalatos de Keggin em xerogeis fotocrômicos analisados por espectroscopia de RMN e RPE em sólidos}

Tese apresentada ao Programa de PósGraduação em Física do Instituto de Física de São Carlos da Universidade de São Paulo, para obtenção do título de Doutor em Ciências.

Área de Concentração: Física aplicada

Orientador: Prof. Dr. José Fabian Schneider

Versão Corrigida

(versão original disponível na Unidade que aloja o Programa)

São Carlos 
AUTORIZO A REPRODUÇÃO E DIVULGAÇÃO TOTAL OU PARCIAL DESTE TRABALHO, POR QUALQÜER MEIO CONVENCIONAL OU ELETRÔNICO PARA FINS DE ESTUDO E PESQUISA, DESDE QUE CITADA A FONTE.

Ficha catalográfica elaborada pelo Serviço de Biblioteca e Informação do IFSC, com os dados fornecidos pelo(a) autor(a)

Oliveira Junior, Marcos

Ambientes de coordenação de heteropolioxometalatos de Keggin em xerogeis fotocrômicos analisados por espectroscopia de RMN e RPE em sólidos / Marcos Oliveira Junior; orientador José F. Schneider versão corrigida -- São Carlos, 2014.

$182 \mathrm{p}$.

Tese (Doutorado - Programa de Pós-Graduação em Física Aplicada) -- Instituto de Física de São Carlos, Universidade de São Paulo, 2014.

1. Fotocromismo. 2. Xerogel. 3. Tungstofosfato. 4. RMN. 5. RPE. I. F. Schneider, José, orient. II. Título. 




\section{AGRADECIMENTOS}

Ao meu orientador, José Fabian Schneider, por estar sempre preocupado com a formação de seus alunos não só no ambiente de pesquisa, mas de modo geral. E também por ser sempre paciente e compreensivo comigo.

Ao professor Ubirajara e seus alunos do grupo de química inorgânica da USP de São Carlos pela preparação das amostras e pelo auxílio na discussão dos resultados.

Ao técnico de laboratório Edson Vidoto, tanto pelo auxílio técnico prestado no conserto de sondas e componentes do espectrômetro de RMN quanto pelas explicações.

Aos meus pais por sempre acreditarem em mim e nunca me deixarem desistir de minhas metas. Sem o apoio deles com certeza eu não estaria aqui hoje apresentando este trabalho.

Ao amor da minha vida, Syrilla, por ter me dado forças e por ser a minha principal razão para seguir em frente.

Aos meus sogros, Amauri e Lúcia, por estarem sempre dispostos a me ajudar, e que não pouparam esforços para me amparar após um acidente de trânsito durante o período em que me dedicava à escrita desta tese.

Aos meus amigos: Matheus, pelo companheirismo desde meus três anos de idade; Leonardo, pelas dicas de LaTeX e pela amizade e companheirismo; Ricci, pelas dicas de química e churrascos animados; Amanda e André, por não faltarem aos churrascos; Tiago, Moema e Marcos, por terem proporcionado bons momentos durante a condução deste doutorado, e a todas as outras pessoas que foram importantes durante o período em que estive dedicado a este trabalho.

A todos aqueles que diretamente ou indiretamente me ajudaram nesta trajetória, e que por falta de espaço ou de memória não foram citadas neste agradecimento.

À CAPES e ao CNPq pelo apoio financeiro. 

Guardar rancor de alguém é como tomar um copo de veneno e esperar que o outro morra.

Fonte: autor desconhecido. 



\section{RESUMO}

OLIVEIRA JUNIOR., M. Ambientes de coordenação de heteropolioxometalatos de Keggin em xerogeis fotocrômicos analisados por espectroscopia de RMN e RPE em sólidos. 2014. $182 \mathrm{p}$. Tese (Doutorado em Ciências) - Instituto de Física de São Carlos, Universidade de São Paulo, São Carlos, 2014.

Neste trabalho, é analisada a estrutura de materiais híbridos contendo poliânions de ácido 12tungstofosfórico $\left(\mathrm{H}_{3} \mathrm{PW}_{12} \mathrm{O}_{40}, \mathrm{HPW}\right)$ inseridos em uma matriz de silicatos orgânico-inorgânica (ormosil). Estes materiais apresentam propriedade reversível de fotocromismo na faixa do UV (200-400nm), sendo cogitados como possíveis candidatos para aplicação como dosímetros pessoais UV. A metodologia sol-gel possibilita a obtenção destes compostos por vias relativamente simples e de baixo custo para a combinação dos componentes orgânicos e inorgânicos formadores da matriz ormosil. As propriedades do efeito fotocrômico, como intensidade e tempo de vida, ser alteradas variando-se a concentração e a natureza dos grupos presentes na matriz ormosil. Outras propriedades também podem ser ajustadas, como porosidade, adesão dos filmes, resistência mecânica, homogeneidade e transparência. No entanto uma correlação clara entre o processo de fotocromismo e a estrutura local ao redor do poliânion ainda não foi estabelecida. O objetivo geral da pesquisa é a caracterização estrutural e dinâmica destes compostos, a fim de se avançar no entendimento do processo fotocrômico e na otimização de métodos de preparação para o controle das propriedades fotocrômicas. Resultados preliminares mostram que o ambiente de coordenação do HPW nos ormosils é complexo, envolvendo diversas espécies de prótons, e os níveis de hidratação parecem desempenhar importante papel estrutural. Portanto, o objetivo específico deste trabalho é obter uma descrição da estrutura/dinâmica das espécies no ambiente de coordenação do poliânion, como espécies de hidratação e/ou grupos da matriz ormosil, e da interação entre estas espécies e o HPW. Para tal, foram utilizadas técnicas de ressonância magnética nuclear (RMN) para analisar amostras de composição simplificada, como uma amostra modelo HPW $6 \mathrm{H}_{2} \mathrm{O}$ e xerogeis contendo tetraetilortosilicato (TEOS) e no máximo dois organosilanos na composição, dentro do conjunto: 3-aminopropiltrietóxisilano 
(APTS), butironitrilatrietoxisilano (BUT) e 3-glicidoxipropilltrimetóxisilano (GLYMO). Embora a estrutura do HPW. $6 \mathrm{H}_{2} \mathrm{O}$ seja extensamente discutida na literatura, ainda existem questões estruturais a serem discutidas, para as quais as técnicas de RMN podem fornecer importante contribuição. Diferentes tratamentos térmicos sobre o $\mathrm{HPW} \cdot \mathrm{nH}_{2} \mathrm{O}$ foram testados para a obtenção do HPW. $6 \mathrm{H}_{2} \mathrm{O}$, e os resultados de RMN mostram que o controle de atmosfera durante o processo de secagem é determinante para a estrutura final das espécies de hidratação. No caso dos xerogeis, diferentes atmosferas foram testadas durante o preparo, estudando-se o efeito desta variável sobre a estrutura das espécies no ambiente de coordenação do HPW. Adicionalmente, tratamentos térmicos para a secagem das amostras também foram realizados. Após a irradiação das amostras com luz UV é formado um centro paramagnético $\mathrm{W}^{V}$ no poliânion, que foi estudado por ressonância paramagnética eletrônica (RPE). A técnica de ${ }^{31} \mathrm{P}$ permitiu avaliar a estrutura no ambiente mais local da molécula de HPW. Utilizando técnicas de ${ }^{1} \mathrm{H}$ RMN, polarização cruzada $(\mathrm{CP})\left\{{ }^{1} \mathrm{H}\right\}{ }^{31} \mathrm{P}$, correlação heteronuclear (HETCOR) $\left\{{ }^{1} \mathrm{H}\right\}-{ }^{31} \mathrm{P}$, $\left\{{ }^{1} \mathrm{H}\right\}-{ }^{29} \mathrm{Si}$ e $\left\{{ }^{1} \mathrm{H}\right\}-{ }^{13} \mathrm{C}$, e medidas de tempos de relaxação spin-rede de ${ }^{1} \mathrm{H}$ no sistema rotante $\left(T_{1 \rho}\right)$, foi constatado que o ambiente de coordenação do HPW nos xerogeis é basicamente constituído de espécies de hidratação, como $\mathrm{H}_{2} \mathrm{O}, \mathrm{H}_{3} \mathrm{O}^{+}, \mathrm{H}_{5} \mathrm{O}_{2}+$ e $\mathrm{H}^{+}\left(\mathrm{H}_{2} \mathrm{O}\right)_{n}$, e espécies $\mathrm{OH}$, que provavelmente pertencem a grupos na matriz de ormosil. Os experimentos de RPE permitiram identificar a existência de uma processo termicamente ativado, em que o elétron excitado realiza saltos entre os diferentes sítios $\mathrm{WO}_{6}$. Dois tipos de centros paramagnéticos $\mathrm{WO}_{6}$, ambos com simetria ortorrômbica, foram resolvidos em $20 \mathrm{~K}$. Um deles pôde ser atribuído a sítios $\mathrm{WO}_{6}$ interagindo fortemente com $\mathrm{H}_{2} \mathrm{O}$, com a elongação da ligação $\mathrm{W}=0$ em $\mathrm{WO}_{6}$. Este sítio é dominante para amostras mais hidratadas. Além deste, outro sítio é observado em amostras mais secas, atribuído a centros $\mathrm{WO}_{6}$ interagindo mais fracamente com os $\mathrm{H}$ no ambiente do HPW. Estes resultados mostram que as espécies de hidratação desempenham um importante papel no processo de fotocromismo.

Palavras-Chave: Fotocromismo. Xerogel. Tungstofosfato. RMN. RPE 


\section{ABSTRACT}

OLIVEIRA JUNIOR, M. Keggin heteropolyoxometalates coordination environments in photochromic xerogels studied by solid state NMR and EPR spectroscopy. 2014. 182 p. Tese (Doutorado em Ciências) - Instituto de Física de São Carlos, Universidade de São Paulo, São Carlos, 2014.

The local structure of hybrid organic-inorganic (ormosils) materials based on 12-phosphotungstic acid $\left(\mathrm{H}_{3} \mathrm{PW}_{12} \mathrm{O}_{40}, \mathrm{HPW}\right)$ was analyzed. These materials have reversible photochromic response in the range of ultraviolet $(200-400 \mathrm{~nm})$, and may found application in personal UV dosimeters. These ormosils can be prepared in a simple way using the sol-gel method, allowing the possibility of film depositions. It is known that properties such as the intensity of the photochromic response and the life-time in this state can be controlled changing the organic functional groups in the silane precursors. Other general properties can be also adjusted with these organic functionalities, such as film adhesion, mechanical response, homogeneity and transparency. However, the relation between the photochromic response, the chemical species (including water molecules) around the polyanion, and the local structure is still an open problem. The objective of this work was to analyze the effect of the preparation conditions of the ormosils (composition, atmosphere and thermal treatments) on the chemical environment around the polyanion and their possible influence in the photochromic response. The analysis of the interaction between the polyanion and the chemical species in the ormosil network and hydration species was carried out using nuclear magnetic resonance spectroscopy (NMR) in the solid-state for ${ }^{1} \mathrm{H},{ }^{31} \mathrm{P},{ }^{13} \mathrm{C}$, and ${ }^{29} \mathrm{Si}$. A set of simple photochromic ormosils were considered in this study, prepared with tetraethilorthosilicate (TEOS) and a maximum of two organosilane precursors from the set aminopropyltriethoxysilane (APTS), butyronitriletriethoxysilane (BUT) and 3-Glycidoxypropyltrimethoxysilane (GLYMO). Also, the HPW hexahydrate $\left(\mathrm{HPW} \cdot 6 \mathrm{H}_{2} \mathrm{O}\right)$ was analyzed as a model system to test the response of the NMR technique to the structural and dynamical process known in this crystal. The effects of thermal treatments and atmosphere in the preparation of the hexahydrate were analyzed. New information concerning the $\mathrm{H}$ 
dynamics and the thermal transformations observed in this system was gathered in this study. For the photochromic ormosils, preparations under three different atmospheres (uncontrolled ambient, N2 flow, and Ar glove-box) were carried out, as well thermal treatments to remove loosely bound water. Electronic paramagnetic resonance (EPR) experiments were carried out in UV-irradiated ormosils, were paramagnetic centers in $\mathrm{W}^{V}$, related with the photochromic process, were observed. The chemical environment around the polyanion was probed using the techniques of ${ }^{1} \mathrm{H}-\mathrm{NMR},\left\{{ }^{1} \mathrm{H}\right\}-{ }^{31} \mathrm{P}$ cross-polarization, heteronuclear correlations $\left\{{ }^{1} \mathrm{H}\right\}-{ }^{31} \mathrm{P}$, $\left\{{ }^{1} \mathrm{H}\right\}-{ }^{29} \mathrm{Sie}\left\{{ }^{1} \mathrm{H}\right\}-{ }^{13} \mathrm{C}$, and the measurement of the proton spin-lattice relaxation in the rotating frame $\left(\mathrm{T}_{1 \rho}\right)$. The results revealed the presence of close hydration species such as $\mathrm{H}_{2} \mathrm{O}, \mathrm{H}_{3} \mathrm{O}^{+}$, $\mathrm{H}_{5} \mathrm{O}_{2}{ }^{+}$and $\mathrm{H}^{+}\left(\mathrm{H}_{2} \mathrm{O}\right)_{n}$, and $\mathrm{OH}$ groups from the ormosil network. No evidence of interaction between the polyanion and the organic functionalities was found. In the irradiated samples, the EPR experiments revealed a thermally activated hopping process for the excited unpaired electron between $\mathrm{WO}^{6}$ octahedra. Two kinds of paramagnetic sites at the $\mathrm{WO}^{6}$ octahedra, both with orthorrombic symmetry, were resolved at $20 \mathrm{~K}$. One of them corresponds to $\mathrm{WO}^{6}$ strongly interacting with water species, with an elongated $\mathrm{W}=\mathrm{O}$ bond length. This site is dominant for higher hydrated samples. The other site corresponds to $\mathrm{WO}^{6}$ with a weak interaction with protons in the polyanion environment and is observed in higher amounts in less hydrated samples. These results show that the hydrate species in the polyanion coordination environment plays an important role in the photochromic process.

KEYWORDs: Photochromism. Xerogel. Tungstophosphate. NMR. EPR. 


\section{LISTA DE FIGURAS}

Figura 2.1 Estrutura do HPW $\ldots \ldots \ldots \ldots \ldots \ldots \ldots \ldots$

Figura 2.2 Representação de parte da estrutura cristalográfica do HPW. $6 \mathrm{H}_{2} \mathrm{O}$. $\mathrm{Na}$ figura estão representadas as duas orientações possíveis (perpendiculares) para o íon $\mathrm{H}_{5} \mathrm{O}_{2}{ }^{+}$. Fonte: Elaborada pelo autor. . . . . . p. p.34

Figura 2.3 Processo de formação do complexo de transferência de carga entre um POM e um grupo amina. . . . . . . . . . . . . . . . . . p. 40

Figura 2.4 Espectros de RPE de monocristais irradiados de alquilamônio de Mo. p.41

Figura 2.5 Processo de formação do complexo de transferência de carga entre um POM e uma molécula de água. . . . . . . . . . . . . . . p.41

Figura 3.1 Movimento de precessão do vetor magnetização sob a influência de um campo magnético estático. . . . . . . . . . . . . . . . p.46

Figura 3.2 Decomposição de um campo oscilante linear em duas componentes rotantes. . . . . . . . . . . . . . . . . . . . . p. . . . . .

Figura 3.3 Movimento de precessão do vetor magnetização em torno de um campo oscilante $\mathrm{H} 1$ em ressonância, visto no sistema rotante. . . p.49

Figura 3.4 llustração representativa do tensor de blindagem, e definição dos ângulos que indicam a orientação do campo magnético no SEP. . . p.54

Figura 3.5 Espectros de pó para uma amostra policristalina, considerando apenas a interação Zeeman e de desvio químico. . . . . . . . . p. 56

Figura 3.6 Efeito das interações Zeeman e Zeeman mais dipolar nos níveis de energia de um sistema de sois spins $1 / 2 . \ldots \ldots$. . . . . . . . p.59

Figura 3.7 Padrão de pó para um sistema policristalino com vários pares de spin interagindo via interação dipolar homonuclear. . . . . . . . . p.60 
Figura 3.8 Esquema da condição de rotação do porta amostras em um experimento de MAS. . . . . . . . . . . . . . . . . . . . . . . . p.62

Figura 3.9 Sequencia de pulsos do experimento de RMN utilizando a técnica de polarização cruzada e sequência de pulsos utilizada nos experimentos TORQUE e SLCP. . . . . . . . . . . . . . . . . . . . . . . . $\quad$ p.65

Figura 3.10 Dependência temporal da transferência de magnetização no experimento de CP convencional e no experimento de TORQUE. . . . . . . p.67

Figura 3.11 Sequencia de pulsos do experimento HETCOR. . . . . . . . . . . p. p p

Figura 3.12 Processo de evolução da magnetização em um experimento de RMN utilizando técnica de spin-eco. . . . . . . . . . . . . . . . . p.70

Figura 3.13 Sequência de pulsos convencional para o experimento de SEDOR, e sequência modificada, com um ciclo de CP substituindo o pulso de preparação. . . . . . . . . . . . . . . . . . . . p.72

Figura 3.14 Diagrama de blocos que ilustra de forma simplificada o funcionamento do espectrômetro de RMN de dupla ressonância. . . . . . . . p.73

Figura 3.15 Espectros simulados RPE de uma amostra na forma de pó, para um sistema de spin $S=1 / 2$ com simetria cúbica, axial e ortorrômbica. . p.77

\begin{tabular}{llll}
\hline Figura 5.1 & Representações estruturais dos precursores orgânicos. & . . . . . . . . & p.82
\end{tabular}

Figura 5.2 Filme obtido por método dip-coating à partir do gel de composição HGT preparado em condições ambientes. . . . . . . . . . . . . . . p.84

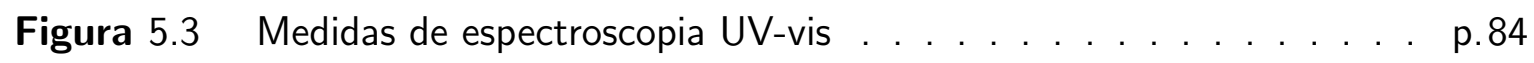

Figura 6.1 Espectros estáticos de ${ }^{31} \mathrm{P}-\mathrm{RMN}$ para o $\mathrm{HPW} \cdot \mathrm{nH}_{2} \mathrm{O}$ em diferentes temperaturas. . . . . . . . . . . . . . . . . . . . . . . . . . . p.87

Figura 6.2 Sinal da magnetização de ${ }^{1} \mathrm{H}$ em função do tempo de spin-lock para uma amostra de $\mathrm{HPW} \cdot \mathrm{nH}_{2} \mathrm{O}$ a temperatura ambiente. . . . . . . p p.88

Figura 6.3 Curvas de TGA desde temperatura ambiente até $350^{\circ} \mathrm{C}$, para uma amostra de HPW comercial e para a mesma amostra, após passar por diferentes tratamentos térmicos em forno com fluxo constante de $\mathrm{N}_{2} . \ldots \ldots \ldots \ldots$. . . . . . . . . . . . . . . . . . . . . . .

Figura 6.4 Curva de TGA para uma amostra de HPW comercial, desde temperatura ambiente até $350^{\circ} \mathrm{C}$, com isoterma em $105^{\circ} \mathrm{C}$. . . . . . . . . p. 91 
Figura 6.5 Espectros de ${ }^{31} \mathrm{P}$ MAS RMN e CP $\left\{{ }^{1} \mathrm{H}\right\}-{ }^{31} \mathrm{P}$ MAS RMN para amostra de $\mathrm{HPW} \cdot \mathrm{nH}_{2} \mathrm{O}$ submetidas a diferentes tratamentos térmicos em forno mufla sob fluxo de $\mathrm{N}_{2}$. . . . . . . . . . . . . . . . . . . . p.92

Figura 6.6 Espectros de ${ }^{1} \mathrm{H}$ MAS RMN para amostra de $\mathrm{HPW} \cdot \mathrm{nH}_{2} \mathrm{O}$ submetidas a diferentes tratamentos térmicos em forno mufla sob fluxo de $\mathrm{N}_{2}$. p.93

Figura 6.7 Espectro HETCOR $\left\{{ }^{1} \mathrm{H}\right\}-{ }^{31} \mathrm{P}$ RMN para a amostra HPW.6 $\mathrm{H}_{2} \mathrm{O}$. .

Figura 6.8 Espectro de HETCOR $\left\{{ }^{1} \mathrm{H}\right\}-{ }^{31} \mathrm{P}$ RMN para a amostra HPW.2,6 $\mathrm{H}_{2} \mathrm{O}$. p. 96

Figura 6.9 Curvas de TGA desde temperatura ambiente até $350^{\circ} \mathrm{C}$, para amos-

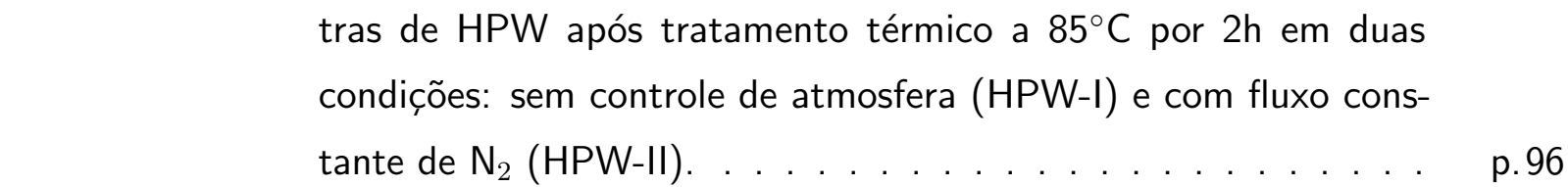

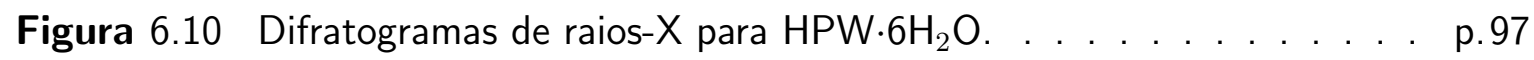

Figura 6.11 Espectros de ${ }^{31} \mathrm{P}$ MAS RMN medidos em temperatura ambiente para amostras de HPW submetidas a diferentes secagens e ciclagens térmicas. . . . . . . . . . . . . . . . . . . . . . . . . . . p.98

Figura 6.12 Espectros de ${ }^{31} \mathrm{P}$ MAS RMN medidos em função da temperatura \begin{tabular}{|l|}
\hline durante ciclos de aquecimento (a) e resfriamento (b) sobre a amostra \\
\hline HPW-I, e durante o aquecimento para a amostra HPW-II (c). . . p. 100
\end{tabular}

Figura 6.13 Parâmetros espectrais do experimento de ${ }^{31} \mathrm{P}$ RMN sobre a amostra HPW-I.

Figura 6.14 Espectros de ${ }^{31} \mathrm{P}$ RMN para a amostra HPW-II medidos em diferentes temperaturas. . . . . . . . . . . . . . . p. 102

Figura 6.15 Parâmetros espectrais do experimento de ${ }^{31} \mathrm{P}$ RMN sobre a amostra HPW-II. .

Figura 6.16 Espectros de ${ }^{1} \mathrm{H}$ MAS RMN medidos em temperatura ambiente para amostras de HPW submetidas a diferentes secagens e ciclagens térmicas. . . . . . . . . . . . . . . . . . . . . . . . . . . . p.104

Figura 6.17 Espectros de ${ }^{1} \mathrm{H}$ MAS RMN medidos em função da temperatura durante ciclos de aquecimento (a) e resfriamento (b) sobre a amostra HPW-I, e durante o aquecimento para a amostra HPW-II (c). . . p.105 
Figura 6.18 Experimentos de inversão e recuperação ${ }^{1} \mathrm{H}$ RMN realizados em $20^{\circ} \mathrm{C}$ e $85^{\circ} \mathrm{C}$, sobre a amostra HPW-II. . . . . . . . . . . . . . p. 106

Figura 6.19 Espectros de ${ }^{1} \mathrm{H}$ MAS RMN medidos em função da temperatura para a amostra HPW-II. . . . . . . . . . . . . . . . . . . . . . p.107

Figura 6.20 Parâmetros espectrais do experimento de ${ }^{1} \mathrm{H}$ RMN sobre a amostra HPW-II. . . . . . . . . . . . . . . . . . . p. 108

Figura 6.21 Espectros de ${ }^{31} \mathrm{P}$ RMN e $\mathrm{CP}\left\{{ }^{1} \mathrm{H}\right\}-{ }^{31} \mathrm{P}$ para as amostras HPW-I e HPW-II. . . . . . . . . . . . . . . . . . p.110

Figura 6.22 Curvas TORQUE $\left\{{ }^{1} \mathrm{H}\right\}-{ }^{31}$ Ppara as amostras HPW-I e HPW-II. . . . p. p.111

Figura 6.23 Curvas de relaxação spin-rede no sistema rotante para ${ }^{1} \mathrm{H}$ medidas em temperatura ambiente para HPW-I e HPW-II. . . . . . . . . . $\quad$ p.112

Figura 6.24 Decaimentos SEDOR $\left\{{ }^{1} \mathrm{H}\right\}-{ }^{31} \mathrm{PRMN}$, para as amostras HPW-I e HPW-II. . . . . . . . . . . . . . . . . . . . p.115

Figura 6.25 Espectros de $\mathrm{CP}\left\{{ }^{1} \mathrm{H}\right\}-{ }^{13} \mathrm{C}$ MAS RMN obtidos para a amostra HGT-N2. p. 117

Figura 6.26 Espectros de ${ }^{29} \mathrm{Si}$ MAS RMN para as amostras HGT-Amb, HGT-N2 e HT-N2, antes e após tratamento térmico a $150^{\circ} \mathrm{C}$ por $2 \mathrm{~h}$, sob fluxo contínuo de $\mathrm{N}_{2}$. . . . . . . . . . . . . . . . . . . . . p.118

Figura 6.27 Espectros de ${ }^{29} \mathrm{Si}$ MAS RMN para a amostra HGT preparada em diferentes condições de atmosfera. . . . . . . . . . . . . . . . . p.119

Figura 6.28 Espectros de ${ }^{31} \mathrm{P}$ MAS RMN para as amostras de xerogeis preparadas em diferentes condições de atmosfera. . . . . . . . . . . . . . . . p. 120

Figura 6.29 Espectros de ${ }^{1} \mathrm{H}$ MAS RMN medidos em $85^{\circ} \mathrm{C}$ para as amostras de xerogeis preparadas em diferentes condições de atmosfera. . . . . . p.124

Figura 6.30 Espectros de CP $\left\{{ }^{1} \mathrm{H}\right\}-{ }^{31} \mathrm{P}$ e ${ }^{31} \mathrm{P}$ MAS RMN para as amostras de xerogeis preparadas em diferentes condições de atmosfera. . . . . p. 125

Figura 6.31 Espectros de $\mathrm{CP}\left\{{ }^{1} \mathrm{H}\right\}-{ }^{31} \mathrm{P}$ (linhas contínuas) e ${ }^{31} \mathrm{P}$ MAS RMN (linhas tracejadas) para a amostra HT-N2 submetida a tratamento térmico em $85^{\circ} \mathrm{C}$ por $2 \mathrm{~h}$ sob fluxo de $\mathrm{N}_{2}$. . . . . . . . . . . . . p. 126

Figura 6.32 Curvas TORQUE $\left\{{ }^{1} \mathrm{H}\right\}-{ }^{31} \mathrm{P}$ RMN para os xerogeis preparados em diferentes condições de atmosfera. 
Figura 6.33 Curvas SLCP $\left\{{ }^{1} \mathrm{H}\right\}{ }^{31} \mathrm{P}$ RMN para os xerogeis preparados em diferentes condições de atmosfera. . . . . . . . . . . . . . . . . . . p. 128

Figura 6.34 Espectros de polarização direta ${ }^{31} \mathrm{P}$ MAS RMN em função da temperatura, para amostras HGAT-N2 e HGAT-Box.

Figura 6.35 Parâmetros espectrais do experimento de ${ }^{31} \mathrm{P}$ RMN sobre amostras HGAT-N2 e HGAT-Box.

Figura 6.36 Espectros de ${ }^{1} \mathrm{H}$ RMN em função da temperatura para os xerogeis preparados em atmosfera saturada com $\mathrm{N}_{2}$.

Figura 6.37 Espectros de ${ }^{1} \mathrm{H}$ RMN em função da temperatura, para a amostra HGAT preparada em glove-box.

Figura 6.38 Espectros de ${ }^{1} \mathrm{H}$ RMN em função da temperatura, para a amostra HGAT preparadas em câmara com fluxo de $\mathrm{N}_{2}$.

Figura 6.39 Curvas SLCP $\left\{{ }^{1} \mathrm{H}\right\}-{ }^{31} \mathrm{P}$ e spin-lock ${ }^{1} \mathrm{H}$ RMN para as amostras HGATN2 e HGAT-Box.

Figura 6.40 Curvas SEDOR $\left\{{ }^{1} \mathrm{H}\right\}{ }^{31} \mathrm{P}$ RMN, para os xerogeis preparados em diferentes condições de atmosfera.

Figura 6.41 Espectro de HETCOR $\left\{{ }^{1} \mathrm{H}\right\}{ }^{29}{ }^{29} \mathrm{Si}$ RMN para a amostra HT-N2 tratada a $85^{\circ} \mathrm{C}$.

Figura 6.42 Espectro HETCOR $\left\{{ }^{1} \mathrm{H}\right\}{ }^{13} \mathrm{C}$ RMN para a amostra HGAT-Box . . . p. p. 141

Figura 6.43 Espectro de HETCOR $\left\{{ }^{1} \mathrm{H}\right\}{ }^{31} \mathrm{P}$ RMN medido em $85^{\circ} \mathrm{C}$, para a amostra HGAT preparada em condições ambientes. . . . . . . . . p. 142

Figura 6.44 Comparações entre a projeção de ${ }^{1} \mathrm{H}$ do espectro de $\operatorname{HETCOR}\left\{{ }^{1} \mathrm{H}\right\}$ -

${ }^{31} \mathrm{P}$ (preto) e o espectro de PD ${ }^{1} \mathrm{H}$ MAS RMN (vermelho) para as
amostras HGAT-Amb, HGAT-N2, HGAT-Box e HT-N2. . . . . . . p. p.143

Figura 6.45 Espectro de HETCOR $\left\{{ }^{1} \mathrm{H}\right\}{ }^{31} \mathrm{P}$ RMN medido em $85^{\circ} \mathrm{C}$, para a

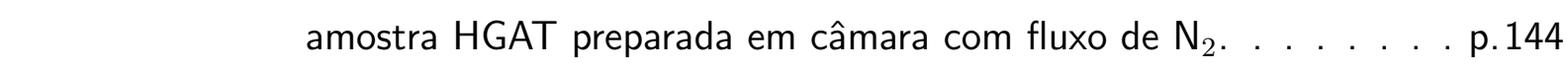

Figura 6.46 Espectro de HETCOR $\left\{{ }^{1} \mathrm{H}\right\}-{ }^{31} \mathrm{P}$ RMN medido em $85^{\circ} \mathrm{C}$, para a amostra HGAT preparada em glove-box. . . . . . . . . . . . . . p. 145

Figura 6.47 Espectro de HETCOR $\left\{{ }^{1} \mathrm{H}\right\}-{ }^{31} \mathrm{P}$ RMN medido em $20^{\circ} \mathrm{C}$, para a amostra HT preparada em câmara com fluxo de $\mathrm{N}_{2}$. . . . . . . p. 145 
Figura 6.48 Espectro de RPE para a amostra HGT preparada em glove-box. . p.146

Figura 6.49 Espectros de RPE para xerogeis preparados em condições ambientes. p. 147

Figura 6.50 Ambiente local de um átomo de tungstênio em um poliânion de HPW.p. 147

Figura 6.51 Espectros de RPE para xerogeis preparados em condições ambientes e submetidos a secagem. . . . . . . . . . . . . . . . . . . . . . . p.150

Figura 6.52 Espectros de RPE para os xerogeis preparados em câmara com fluxo de $\mathrm{N}_{2} . \ldots \ldots \ldots \ldots \ldots$. . . . . . . . . . . . . . . . . . . . . . . . . .

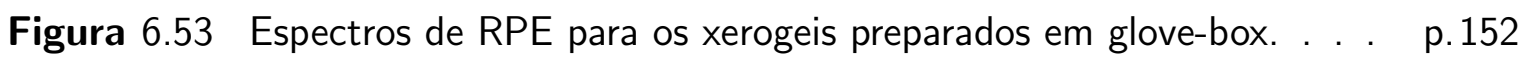

Figura 6.54 Espectros de RPE em função da temperatura para as amostras HGT preparadas em diferentes condições. . . . . . . . . . . . . . . . . p.155

Figura 6.55 Espectros de RPE em função da temperatura para as amostras HGBT preparadas em diferentes condições. . . . . . . . . . . . . p. 155

Figura 6.56 Espectros de RPE em função da temperatura para as amostras HGAT preparadas em diferentes condições. . . . . . . . . . . . . p.156

Figura 6.57 Espectros de RPE medidos em 20K e 100K para as amostras HGT (a), HGBT (b) e HGAT (c) preparadas em glove-box. . . . . . . . . . p.157

Figura 6.58 Espectros de ${ }^{31} \mathrm{P}$ RMN para a amostra HGAT-N2 antes e após irradiação com lâmpada de Xe. Fonte: Elaborada pelo autor. . . . p. p.158

Figura 6.59 Espectros de ${ }^{1} \mathrm{H}$ RMN em polarização direta (a) e spin-eco com $\tau=800 \mu s$ (b) para a amostra HGAT-Amb, antes e após passar por irradiação com lâmpada de Xe. Fonte: Elaborada pelo autor. . . . p.159

Figura 6.60 Espectros de ${ }^{1} \mathrm{H}$ RMN em polarização direta (a) e spin-eco com $\tau=800 \mu s$ (b) para a amostra HGAT-N2, antes e após passar por irradiação com lâmpada de Xe. . . . . . . . . . . . . . . . . p. 160

Figura 7.1 Representação esquemática de SiOH isolados e adjacentes . . . . p. p.166 


\section{LISTA DE TABELAS}

Tabela 5.1 Porcentagens molares dos precursores envolvidos na preparação dos diferentes xerogeis. . . . . . . . . . . . . . . . . . . . . . . p.83

Tabela 6.1 Numero médio de moléculas de água por poliânion de HPW (n) após diferentes tratamentos térmicos. $\ldots \ldots$. . . . . . . . . p.90

Tabela 6.2 Desvios químicos de ${ }^{31} \mathrm{P}$ e ${ }^{1} \mathrm{H}$ RMN para as amostras de HPW-I antes e após ciclagem térmica e HPW-II. . . . . . . . . . . . . . p.99

Tabela 6.3 Valores de $\mathrm{T}_{1 \rho}$ medidos nos experimentos de spin-loch ${ }^{1} \mathrm{H}$ e SLCP $\left\{{ }^{1} \mathrm{H}\right\}-{ }^{31} \mathrm{P}$ e valores de $\mathrm{T}_{H P}$ determinados nos experimentos de TOR-

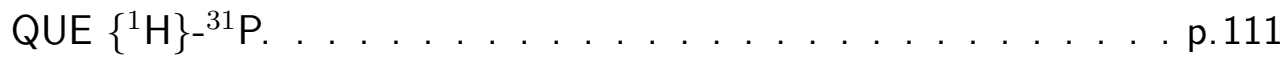

Tabela 6.4 Distribuição dos grupos silicato em diferentes xerogeis. $\quad \ldots$. . . . . p. p.118

\begin{tabular}{|ll|l|l|}
\hline Tabela 6.5 Desvios químicos isotrópicos para os espectros da figura 6.28 , refe-
\end{tabular} rentes aos xerogeis sem tratamento térmico. . . . . . . . . . . . . . p.121

Tabela 6.6 Desvios químicos para os picos observados nos espectros de ${ }^{1} \mathrm{H}$ RMN (figura 6.29) para os diversos xerogeis. . . . . . . . . . . . . . . p. 123

Tabela 6.7 Valores de $\mathrm{T}_{H P}, \mathrm{~T}_{1 \rho}$ e $\mathrm{M}_{2 H P}$ para diferentes xerogeis antes e após tratamento térmico. . . . . . . . . . . . . . . . . . . . . p.129

Tabela 6.8 $\quad$ Valores de $\mathrm{T}_{1 \rho}$ para amostras de HGAT-N2 e HGAT-Box. . . . . . p p.136

Tabela 6.9 Valores de desvio químico para as linhas observadas nas projeções de ${ }^{1} \mathrm{H}$ dos espectros HETCOR para diferentes amostras e experimentos. p. 139

Tabela 6.10 Valores para os valores principais do tensor $\stackrel{\leftrightarrow}{g}$ obtidos por meio de simulação dos espectros de RPE medidos para o conjunto de xerogeis preparados em diferentes condições de controle de atmosfera. 
Tabela 6.11 Valores para os parâmetros do tensor $\stackrel{\leftrightarrow}{g}$ obtidos por meio de simulação dos espectros de RPE medidos para o conjunto de xerogeis preparados em diferentes condições de controle de atmosfera. . . . . . . . . . p. p.153 


\section{SUMÁRIO}

\begin{tabular}{lll}
\hline 1 & Introdução & p. 25
\end{tabular}

\begin{tabular}{lll}
\hline 2 & Revisão da literatura & p. 31
\end{tabular}

2.1 Heteropoliânions do tipo Keggin . . . . . . . . . . . . . . . . . p.31

2.2 Estrutura do ácido 12-tungstofosfórico hidratado

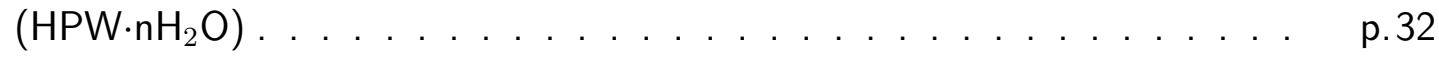

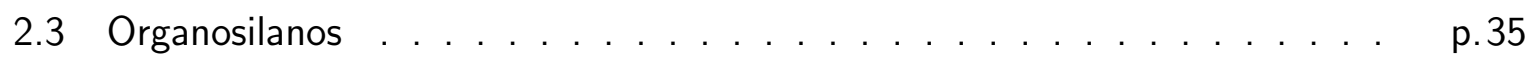

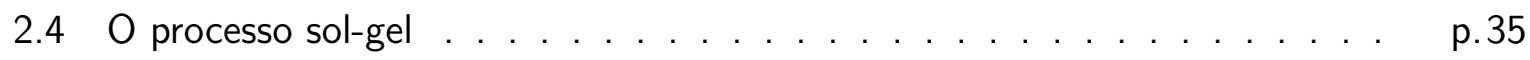

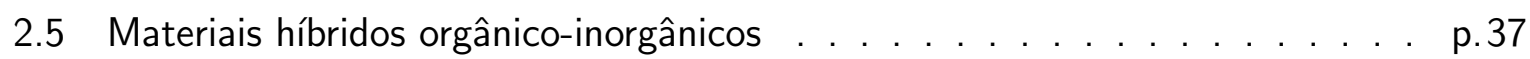

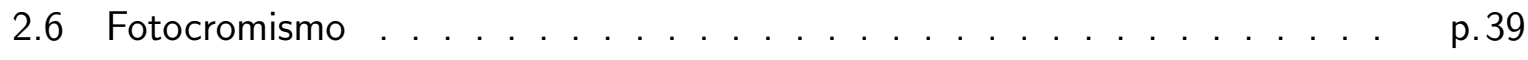

3 Técnicas experimentais p.43

3.1 Espectroscopia por ressonância magnética nuclear $\ldots \ldots \ldots \ldots$. . . . . . .

3.1 .1 Teoria básica . . . . . . . . . . . . . . . . . . . . . p. 43

3.1.2 Dinâmica clássica do vetor magnetização e o sistema rotante . . . p. p.45

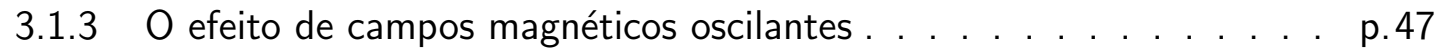

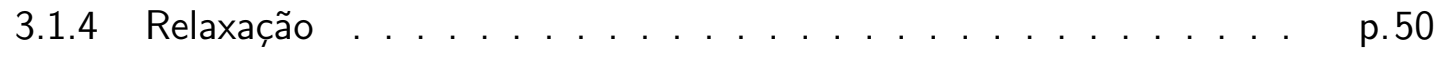

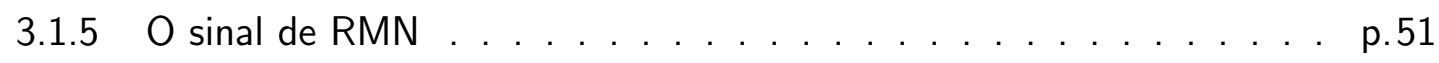

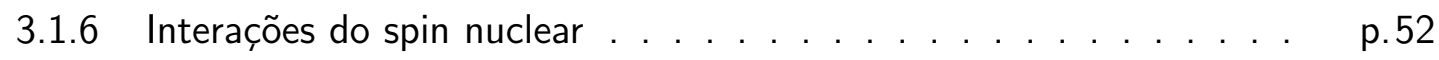

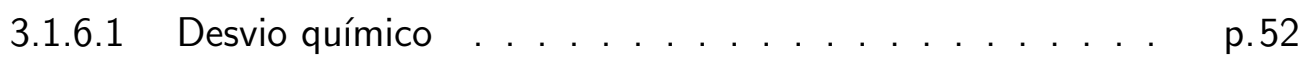

3.1 .6 .2 Interação dipolar . . . . . . . . . . . . . . . p.57 
3.1 .7 Técnicas de RMN pulsada de alta resolução . . . . . . . . . . . . . p.61

3.1.7.1 Rotação em torno do ângulo mágico (MAS) . . . . . . . . . p. p.61

3.1.7.2 Desacoplamento por irradiação contínua de alta potência $(\mathrm{CW}) \ldots \ldots \ldots \ldots \ldots \ldots$ p. 63

3.1.7.3 Polarização cruzada (CP) . . . . . . . . . . . . . . . p. 63

3.1.7.4 Dinâmica de CP . . . . . . . . . . . . . . . . . p. 65

3.1.7.5 Correlação Heteronuclear (HETCOR) . . . . . . . . . . . p. p8

3.1 .8 Técnicas de RMN pulsada de baixa resolução . . . . . . . . . . . . . p. p 69

3.1.8.1 Spin-eco de Hahn . . . . . . . . . . . . . . . . . p. 69

3.1.8.2 Ressonância dupla de eco de spin (SEDOR) . . . . . . . . . p.71

3.1.9 Aspectos básicos de um espectrômetro de ressonância magnética nuclear p.72

3.2 Ressonância paramagnética do elétron (RPE) $\ldots \ldots \ldots$. . . . . . . . . . . . . . p.74

\begin{tabular}{lll}
\hline 4 & Parâmetros experimentais & p.79
\end{tabular}

$\begin{array}{lll}5 & \text { Preparação das amostras } & \text { p.81 }\end{array}$

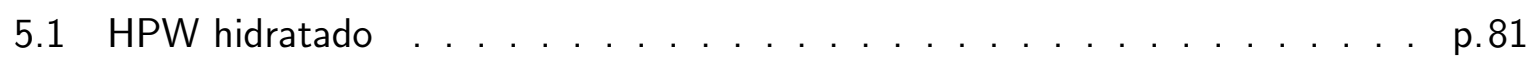

5.2 Xerogeis fotocrômicos . . . . . . . . . . . . . . . . . . . p.81

\begin{tabular}{lll}
\hline 6 & Resultados & p. 87
\end{tabular}

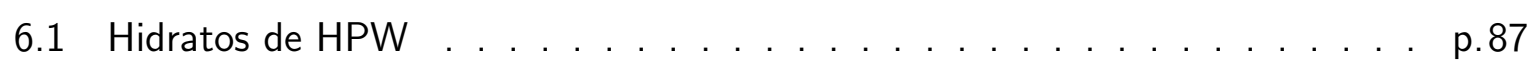

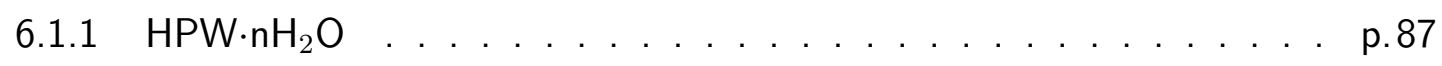

6.1 .2 Efeito de secagens sobre o HPW·nH $\mathrm{H}_{2} \mathrm{O} \ldots \ldots$. . . . . . . . . 88

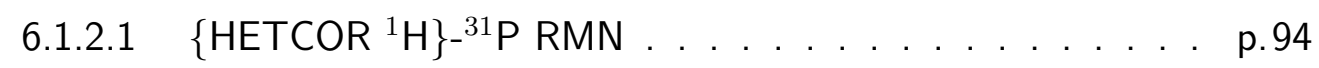

6.1 .3 HPW hexahidratado $\left(\mathrm{HPW} \cdot 6 \mathrm{H}_{2} \mathrm{O}\right)$. . . . . . . . . . . . . p.95

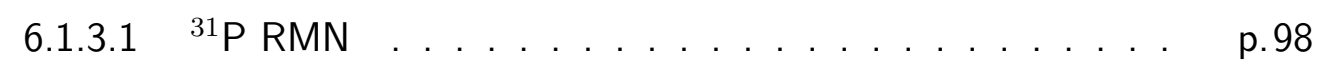

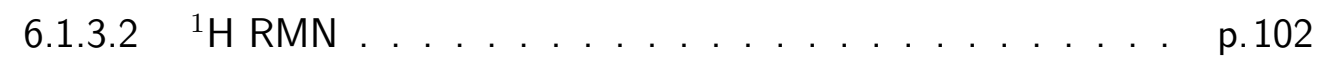

6.1.3.3 Polarização cruzada $\left\{{ }^{1} \mathrm{H}\right\}-{ }^{31} \mathrm{P}$ RMN e analise de tempos de relaxação . . . . . . . . . . . . . . . . . p.109 


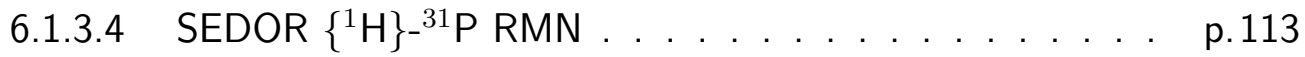

6.2 Xerogeis . . . . . . . . . . . . . . . . . . . . p. 116

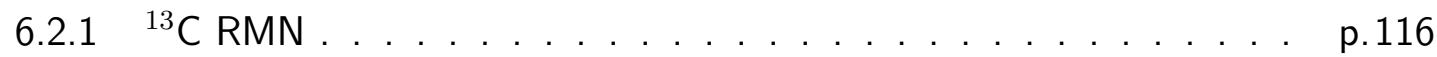

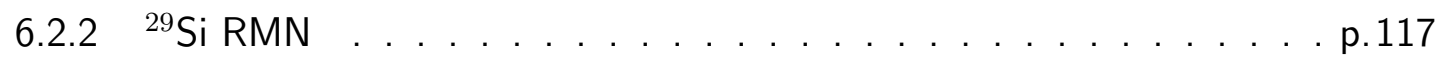

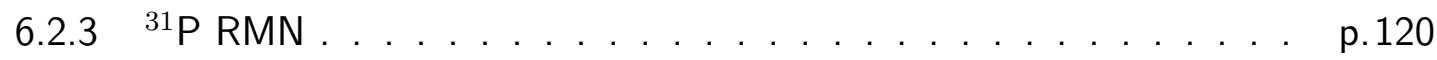

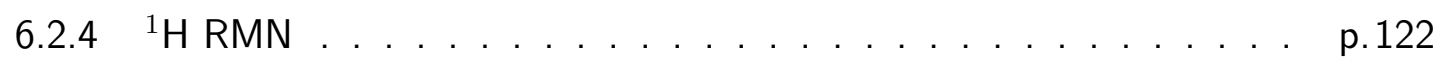

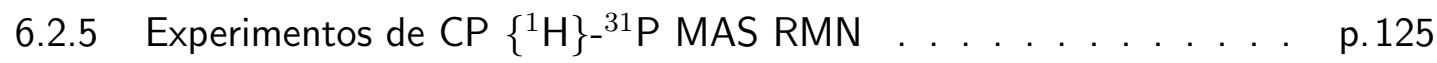

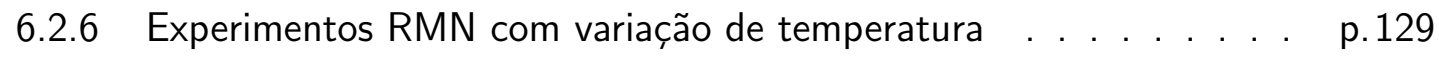

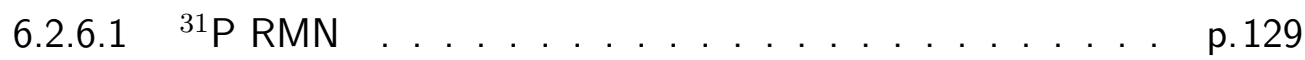

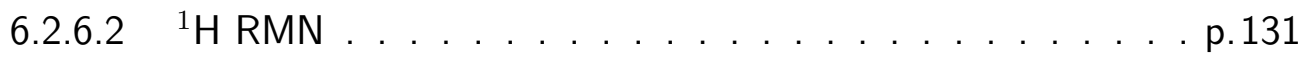

6.2.6.3 Tempo de relaxação spin-rede no sistema rotante $-\mathrm{T}_{1 \rho}$. p.135

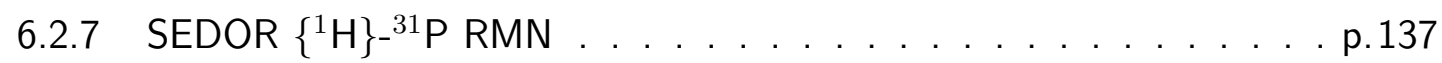

6.2.8 Experimentos de correlação heteronuclear (HETCOR) $\left\{{ }^{1} \mathrm{H}\right\}-{ }^{31} \mathrm{P},\left\{{ }^{1} \mathrm{H}\right\}-$

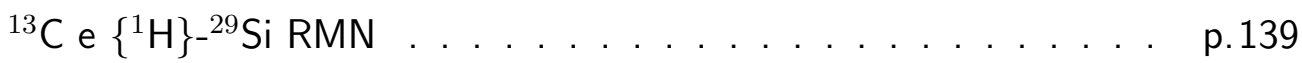

6.2.9 Experimentos de ressonância paramagnética eletrônica (RPE) . . . p.146

$6.2 .10{ }^{31} \mathrm{Pe} \mathrm{e}^{1} \mathrm{H}$ MAS RMN em amostras irradiadas . . . . . . . . . . . . . p. 157

\begin{tabular}{lll}
\hline 7 & Discussão & p. 161
\end{tabular}

7.1 HPW hidratado . . . . . . . . . . . . . . . . . . . . p. 161

7.2 Xerogeis . . . . . . . . . . . . . . . . . . . . p. . 163

\begin{tabular}{llr}
\hline C Conclusão & p. 169
\end{tabular}

\begin{tabular}{ll}
\hline REFERÊNCIAS & p.173
\end{tabular} 

Capítulo 1

\section{Introdução}

A exposição à radiação UV solar ou artificial é origem de diversas patologias da pele, tais como eritemas, queimaduras, e em casos mais comprometedores, o desenvolvimento de câncer.(1) Existem diversos tipos de radiômetros eletrônicos disponíveis, entretanto estes dispositivos têm custo elevado e inviáveis para serem utilizados como dosímetros pessoais de UV. A fim de remediar esta situação vários esforços têm sido feitos para desenvolver dosímetros UV passivos de baixo custo, que possam ser aplicados, por exemplo, em substratos flexíveis.(2-5) Uma das formas de se produzir estas fitas dosimétricas é baseada na utilização de materiais fotocrômicos. Estes materiais apresentam a propriedade de alterar sua coloração mediante a irradiação de luz em determinada faixa de frequência, e podem ser utilizados em diversas aplicações além de dosimetria, tais como máquinas fotográficas auto-ajustáveis, materiais de proteção, actinômetros, armazenamento de dados, processamento de sinal ótico, catalisadores controlados por irradiação, entre outras.(6) Embora em sua maioria os materiais fotocrômicos sejam orgânicos, os materiais inorgânicos podem apresentar certas vantagens sobre estes, como resistência química e estabilidade térmica.(7) Dentre os compostos inorgânicos que apresentam atividade fotocrômica podem ser citados os óxidos de metais de transição (OMT), e em particular os polioxometalatos (POM), cuja importância ganhou destaque após o trabalho pioneiro de Deb et al.(8) As principais vantagens dos POM são: redução multivalente reversível, resposta fotoquímica, condutividade, estabilidade com relação à umidade e à temperatura, polaridade e distribuição de cargas na superfícies, habilidade para armazenamento/transferência de prótons e elétrons, entre outras.(9-12) Por outro lado, como espécies inorgânicas unitárias estes materiais exibem certas desvantagens, tais como pouca reversibilidade do fotocromismo, pequenas alterações de densidade ótica após irradiação, resposta para um espectro estreito de radiação (majoritariamente azul e UV), baixa reprodutibilidade (perda das propriedades em função do número de ciclos de irradiação), coloração única e alto custo quando preparados na forma de filmes. (6, 7)

Através do processo sol-gel, é possível integrar as vantagens de compostos orgânicos e inorgânicos. Este processo permite a mistura de compostos orgânicos e inorgânicos a nível molecular, resultando nos chamados materiais híbridos orgânico-inorgânicos.(13) Os materiais estudados neste trabalho são preparados na forma de xerogeis. Estes materiais combinam as propriedades das classes orgânica e inorgânica, oferecendo uma gama de possibilidades para 
a preparação de materiais com diferentes propriedades físico-químicas. Por estas vantagens, inúmeros materiais híbridos orgânico-inorgânicos baseados em siloxano ou silicato (ormosil) vêm sendo desenvolvidos nos últimos anos.(13) O processo sol-gel permite a deposição destes ormosils em forma de filmes, através de processos relativamente simples e de baixo custo. As propriedades destes materiais não dependem apenas da natureza química de cada componente, mas também do sinergismo entre elas. Desta forma, a princípio, o comportamento fotocrômico pode ser "sintonizado". De particular interesse são os materiais estudados por ZAIAT para dosimetria UVA e UVB.(14) Estes materiais são constituídos por compostos da classe das oxiranas $\left(\mathrm{C}_{2} \mathrm{H}_{4} \mathrm{O}\right)$, responsáveis pelo fotocromismo, inseridos em uma matriz ormosil através do processo sol-gel. A atividade fotocrômica (sensibilidade e tempo de resposta) é controlada através de mudanças na polaridade da superfície dos poros internos do ormosil.(14)

Uma classe de POM promissores para utilização como pigmentos fotocrômicos em xerogeis são os heteropolioxometalatos (HPOM). Nestes materiais o fotocromismo está intimamente ligado à presença de compostos coadjuvantes no processo, como por exemplo compostos com agrupamentos aminas.(15) As aminas agem como contra-íons, atuam como agente direcionador da estrutura dos filmes através da formação de pares iônicos e ligações de hidrogênio, e exercem, segundo Yamase (15), um papel fundamental no processo fotoquímico responsável pelo fotocromismo. De particular interesse para este trabalho são os xerogeis formulados a partir de uma classe de HPOM, os heteropoliácidos do tipo Keggin, como o ácido 12-tungstofosfórico $\left(\mathrm{H}_{3} \mathrm{PW}_{12} \mathrm{O}_{40}, \mathrm{HPW}\right)$, que apresenta resposta fotocrômica na faixa do UV (200nm a $\left.400 \mathrm{~nm}\right)$. A estrutura destes materiais híbridos é relativamente complexa, mas quatro constituintes estruturais principais podem ser destacados: (i) a matriz inorgânica de silicatos, responsável pelas propriedades mecânicas macroscópicas, (ii) os grupos orgânicos conectados à matriz de silicato, que interagem fracamente com o poliânion HPW, e fornecem elétrons para a redução do mesmo, (iii) moléculas de $\mathrm{H}_{2} \mathrm{O}$ no ambiente de coordenação do poliânion e (iv) o poliânion de HPW, responsável pela atividade fotocrômica. As propriedades relevantes para aplicação em dispositivos (sensibilidade, duração do efeito, reversibilidade) dependem criticamente dos ambientes de coordenação ao redor do poliânion de HPW. A dependência das propriedades fotocrômicas com a composição das amostras é diferente para xerogeis na forma de pó ou para filmes depositados por dip-coating. Para amostras preparadas na forma de filmes, a natureza e a fração dos grupos orgânicos na composição alteram as propriedades fotocrômicas.(16-19) Por outro lado, para amostras na forma de pó, apenas o tempo de vida do fotocromismo é dependente da composição da amostra. Esta diferença nas propriedades do pó e dos filmes é devido às diferenças na eficiência da incorporação de moléculas de HPW no filme em função dos funcionais orgânicos presentes na matriz.(19) Os autores propõem que a interação entre 
- HPW e grupos polares, como por exemplo os grupos amina em aminopropiltrietóxisilano (APTS), durante a formação da matriz ormosil, afeta a morfologia do produto final.(19) Por outro lado, estudos preliminares mostram que tanto em xerogeis na forma de filme, quanto na forma de pó, o efeito fotocrômico depende do nível de hidratação das amostras. Portanto as espécies de hidratação no ambiente de coordenação do poliânion de HPW desempenha um importante papel para o fotocromismo. Desta forma, um dos desafios a serem levados em conta para a preparação de materiais com propriedades estáveis e reprodutíveis é o controle das condições de atmosfera durante o preparo e manuseio. A possibilidade de preparação de filmes com controle mínimo de atmosfera é uma questão importante, uma vez que o baixo custo de produção é uma das principais vantagens do processo sol-gel. Por outro lado, a compreensão dos mecanismos físico-químicos envolvidos no processo de fotocromismo em materiais contendo HPW é primordial para determinação de rotas de preparo visando as formulações e condições de preparo ideais. Para esta compreensão, é essencial a analise da interação entre o poliânion de HPW e as espécies ao seu redor, como grupos orgânicos e $\mathrm{H}_{2} \mathrm{O}$.

A natureza local do fenômeno da RMN, sensível às diferenças no ambiente eletrônico ao redor da espécie nuclear ressonante, é especialmente apropriada para estudar os ambientes locais nestes materiais. A possibilidade de discriminar e quantificar espécies não equivalentes (química ou estruturalmente) permite à RMN fornecer informação potencialmente valiosa para determinar as propriedades estruturais dos complexos. A RMN de ${ }^{13} \mathrm{C}$ permite avaliar a extensão das reações na matriz ormosil, determinando o estado dos grupos moleculares orgânicos e ligações à rede de silicatos. A RMN de ${ }^{29} \mathrm{Si}$ é especialmente adequada para descrever o estado de condensação da rede de silicatos.

A possibilidade de realização de experimentos de dupla ressonância permite analisar a proximidade entre pares de espécies ressonantes, tais como ${ }^{1} \mathrm{H}_{-}{ }^{31} \mathrm{P},{ }^{1} \mathrm{H}_{-}{ }^{29} \mathrm{Si}$ e ${ }^{1} \mathrm{H}-{ }^{13} \mathrm{C}$, o que potencialmente permite estabelecer correlações entre os diferentes componentes do material. Estudos recentes de ressonância magnética nuclear (RMN) para caracterização estrutural e dinâmica destes materiais revelam que o poliânion de HPW está rodeado por muitos prótons $(>50)$, indicando a presença de moléculas de $\mathrm{H}_{2} \mathrm{O}$, além dos grupos orgânicos. (18, 20) Estes estudos também revelam poucas diferenças do ponto de vista estrutural para o ambiente de coordenação do HPW, considerando-se materiais com diferentes grupos orgânicos,(18, 20) mas parece haver certa correlação entre a intensidade da interação poliânion/ambiente e o fotocromismo. De forma geral, em amostras onde o HPW apresenta maior mobilidade reorientacional, o efeito é menos intenso.(18, 20) Este comportamento pode estar relacionado ao nível de hidratação na amostra, visto que em cristais de HPW em níveis altos de hidratação, a dinâmica do poliânion é mais rápida do que em amostras menos hidratadas, como será mostrado 
na seção 6.1. Portanto, as moléculas de água no ambiente de coordenação do poliânion têm um importante papel estrutural, e talvez também no próprio processo de fotocromismo.

O objetivo geral da pesquisa em desenvolvimento é a caracterização estrutural e dinâmica destes compostos baseados em HPW utilizando técnicas de RMN, a fim de se avançar no entendimento do processo fotocrômico e na otimização de métodos de preparação para o controle da atividade fotocrômica. Como estes materiais híbridos apresentam estrutura relativamente complexa, antes de se avançar no estudo do processo fotocrômico, é de suma importância o estudo detalhado da organização estrutural destes materiais. Portanto, o objetivo específico deste trabalho é estudar a estrutura das espécies no ambiente de coordenação do HPW e a influência das condições de preparo e composições das amostras sobre estas estruturas. Os resultados obtidos neste trabalho servirão como base para futuros estudos a respeito do mecanismo do processo fotocrômico.

Devido à complexidade estrutural dos xerogeis, o entendimento dos ambientes de hidratação nestes sistemas requer conhecimento prévio da estrutura de materiais mais simples, como os cristais de HPW hidratado (HPW. $\left.\mathrm{nH}_{2} \mathrm{O}, n=29,21,14,6,0\right) .(12$, 21) Estes cristais podem constituir importantes modelos sobre como a estrutura, dinâmica e estado de hidratação influenciam nos resultados obtidos por técnicas de RMN. Dentre os cristais de $\mathrm{HPW} \cdot \mathrm{nH}_{2} \mathrm{O}$, o HPW hexahidratado (HPW. $6 \mathrm{H}_{2} \mathrm{O}$ ) é o mais simples, que tem sido alvo de muitos estudos.(2231) Portanto, o HPW. $6 \mathrm{H}_{2} \mathrm{O}$ foi escolhido como ponto de partida para o estudo dos ambientes de coordenação do poliânion. Apesar dos vários estudos e informações teóricas a respeito da estrutura do HPW. $6 \mathrm{H}_{2} \mathrm{O}$, ainda existem questões de interesse para as quais a técnica de RMN pode oferecer contribuição importante, como uma transição de fase não-convergente ocorrendo por volta de $47^{\circ} \mathrm{C} .(23,24)$

Neste trabalho foi realizado um estudo sobre a eficiência de diferentes tratamentos térmicos sobre $\mathrm{HPW} \cdot \mathrm{nH}_{2} \mathrm{O}$, com vista à obtenção do cristal $\mathrm{HPW} \cdot 6 \mathrm{H}_{2} \mathrm{O}$. Uma vez obtido, foi realizada a caracterização estrutural e dinâmica das espécies protônicas no ambiente de coordenação do poliânion, e sua interação com o mesmo. Em seguida, foram estudados xerogeis com composições modelo, a fim de facilitar a atribuição e caracterização das espécies de prótons. Para analisar o impacto da hidratação da amostra na estrutura e dinâmica das espécies protônicas no ambiente de coordenação do HPW, foram estudadas amostras preparadas em diferentes condições de atmosfera, submetidas ou não à tratamentos térmicos.

Informações a respeito da estrutura primária do poliânion (estrutura e estado de oxidação ou redução), e de seu ambiente de coordenação podem ser obtidas através do desvio químico isotrópico de ${ }^{31} \mathrm{P} .(30,32,33) \mathrm{A}$ RMN de ${ }^{1} \mathrm{H}$ permite identificar as diferentes espécies de prótons 
presentes na estrutura, e identificar seu comportamento com a temperatura. Experimentos de ressonância dupla de correlação heteronuclear (HETCOR) (34), permitem a identificação das espécies de ${ }^{1} \mathrm{H}$ acopladas com ${ }^{31} \mathrm{P},{ }^{13} \mathrm{C}$ e/ ou ${ }^{29} \mathrm{Si}$. Para obtenção de informação a respeito das interações entre as espécies de prótons e o poliânion, podem ser utilizadas técnicas baseadas no acoplamento dipolar heteronuclear entre ${ }^{1} \mathrm{H}$ e ${ }^{31} \mathrm{P}$, como polarização cruzada (CP) e experimentos de ressonância dupla de eco de spin (Spin Echo Double Resonance SEDOR).(35, 36) Diferenças na dinâmica das diferentes espécies de ${ }^{1} \mathrm{H}$ foram analisadas medindo-se o tempo de relaxação spin-rede no sistema rotante $\left(\mathrm{T}_{1 \rho}\right)$ para ${ }^{1} \mathrm{H}$, utilizando experimentos de excitação direta sobre todos os ${ }^{1} \mathrm{H}$ ou selecionando apenas aqueles na vizinhança do HPW, via experimentos de $\mathrm{CP}\left\{{ }^{1} \mathrm{H}\right\}-{ }^{31} \mathrm{P}$.

Foram realizados experimentos de ressonância paramagnética eletrônica (RPE) para caracterizar o estado das amostras após a irradiação, e a influência do nível de hidratação das amostras sobre o centro paramagnético formado. O estado reduzido dos poliânions de HPW é caracterizado pela transferência de carga óxido-metal, desde os $\mathrm{O}$ até o $\mathrm{W}$, alterando a valência do tungstênio de $W^{6+}$ (estado eletrônico $d^{0}$ ) para $W^{5+}$ (estado eletrônico $d^{1}$ ).(7, 15) Neste estado, o $\mathrm{W}^{5+}$ possui um elétron desemparelhado, que pode ser analisado via experimentos de RPE.

Finalmente, foram realizados experimentos de ${ }^{31} \mathrm{P}$ e ${ }^{1} \mathrm{H}$ RMN de forma preliminar, para se avaliar a sensibilidade da técnica de RMN frente às mudanças estruturais ocorrendo na amostra após a redução do poliânion via irradiação com luz UV.

No capítulo 2 deste trabalho serão apresentados alguns conceitos gerais sobre a formação dos complexos híbridos orgânico-inorgânicos, detalhes estruturais a respeito dos componentes e uma descrição do processo fotocrômico. Na seção 3.1 do capítulo 3 são discutidos os princípios básicos de RMN e as técnicas experimentais de RMN utilizadas, como rotação em torno do ângulo mágico (MAS), polarização cruzada, ressonância dupla de eco de spin (SEDOR) e correlação heteronuclear (HETCOR). Na seção 3.2 são discutidos os princípios básicos de RPE em modo de onda contínua. No capítulo 4 é apresentada a montagem experimental utilizada nas medidas de RMN e RPE. No capítulo 5 é descrito o processo de preparação do conjunto de amostras analisadas. A descrição dos resultados experimentais sobre os hidratos de HPW e sobre os xerogeis são apresentados respectivamente nas seções 6.1 e 6.2 do capítulo 6 . A discussão dos resultados é apresentada no capitulo 7 . 


\section{Revisão da literatura}

\subsection{Heteropoliânions do tipo Keggin}

Alguns metais de transição (como $\mathrm{V}, \mathrm{Nb}, \mathrm{Mo}, \mathrm{W}$ ), em seus estados de mais alta oxidação, podem formar clusters de ânions do tipo metal-oxigênio, comumente chamados de polioxometalatos (POM's) (11). As aplicações dos POM's são ligadas principalmente à sua propriedade de redução multivalente reversível, resposta fotoquímica, condutividade, alta acidez, estabilidade com relação à umidade e à temperatura, dentre outras (11, 12). Uma classe de POM's vastamente explorada na literatura são os heteropoliácidos, ou hetropoliânions do tipo Keggin, com fórmula geral $\left[\mathrm{XM}_{12} \mathrm{O}_{40}\right]^{3-}(\mathrm{X}=\mathrm{P}$ ou Si e $\mathrm{M}$ é um metal de transição bivalente). Estes compostos apresentam simetria tetragonal (grupo pontual $\mathrm{T}_{d}$ ), e são constituídos de tetraedros $\mathrm{XO}_{4}$ que se encontram circundados por 12 octaedros $\mathrm{MO}_{6}$ ( simetria $\mathrm{C}_{S}$ ), os quais compartilham vértices e arestas, formando quatro estruturas agrupadas do tipo $\mathrm{M}_{3} \mathrm{O}_{13}$ (simetria $\mathrm{C}_{3 v}$ ). O heteropoliânion considerado neste trabalho é o ácido 12-tungstofosfórico

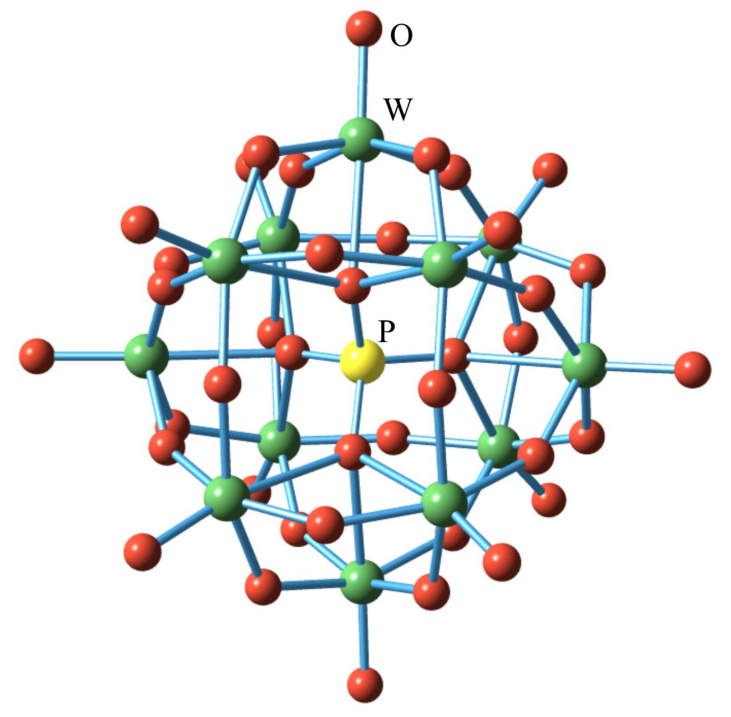

Figura 2.1-Estrutura do heteropoliânion $\left[\mathrm{PW}_{12} \mathrm{O}_{40}\right]^{3-}$. Fonte: Elaborada pelo autor.

$\left(\mathrm{H}_{3} \mathrm{PW}_{12} \mathrm{O}_{40}\right.$, abreviado como HPW), cuja estrutura é exibida na figura 2.1 (22, 29, 32). O HPW é o heteropoliânion de acidez mais forte dentre os poliânions de Keggin (37). Os POM's, 
particularmente o HPW, devido a suas propriedades, são amplamente utilizados como aditivos em matrizes orgânico-inorgânicas obtidas pelo processo sol-gel. Estes complexos híbridos apresentam diversas propriedades, como condutividade iônica, eletrocromismo e fotocromismo (12). Devido a estas propriedades estes complexos são utilizados em diversas aplicações, fotoe eletro-catalizadores, compostos fotocrômicos e eletrocrômicos, filmes resistentes à corrosão, modificação de superfícies de eletrodos, sensores, dentre outras (12).

\subsection{Estrutura do ácido 12-tungstofosfórico hidratado $\left(\mathrm{HPW} \cdot \mathrm{nH}_{2} \mathrm{O}\right)$}

Na forma hidratada, os poliânions de HPW são interconectados por moléculas de água, realizando ligações de hidrogênio com os oxigênios do poliânion, formando cristais com diferentes níveis de hidratação (HPW· $\mathrm{nH}_{2} \mathrm{O}$, com $\mathrm{n}=29,21,13-14,6$ ). O nível de hidratação depende fortemente da temperatura e os níveis mais baixos de hidratação $(n=21,14,6)$ são facilmente obtidos por tratamentos térmicos do $\mathrm{HPW} \cdot 29 \mathrm{H}_{2} \mathrm{O}\left(26\right.$, 30). Entre $28^{\circ} \mathrm{C}$ e $31^{\circ} \mathrm{C}$ ocorre a transformação de $n=29$ para $n=21$, entre $35^{\circ} \mathrm{C}$ e $42^{\circ} \mathrm{C} n=14$ ou 13 é obtido, entre $42^{\circ} \mathrm{C}$ e $60^{\circ} \mathrm{C} \mathrm{n}=6$ é obtido, e entre $175^{\circ} \mathrm{C}$ e $230^{\circ} \mathrm{C}$ toda a água é removida, $\mathrm{n}=0$, e três átomos de $\mathrm{H}$ se ligam quimicamente aos átomos $\mathrm{O}$ do poliânion (25, 26).

Estudos espectroscópicos de infravermelho (IR), Ramam, espalhamento incoerente inelástico de nêutrons (Incoherent Inelastic Neutron Scattering - IINS) e simulações computacionais fornecem uma primeira aproximação sobre os constituintes da estrutura secundária do HPW $\cdot \mathrm{nH}_{2} \mathrm{O}$ (25, 38, 39). A partir destes resultados foi possível identificar diferentes espécies protônicas, como grupos $\mathrm{OH}$, moléculas $\mathrm{H}_{2} \mathrm{O}$ e íons $\mathrm{H}_{3} \mathrm{O}^{+}$e $\mathrm{H}_{5} \mathrm{O}_{2}{ }^{+}$. Essayen e colaboradores também demonstraram via experimentos de ${ }^{2} \mathrm{H}$ MAS RMN, que existem várias espécies protônicas no $\mathrm{HPW} \cdot \mathrm{nD}_{2} \mathrm{O}$, e que a população destas espécies varia com a temperatura (30). Medidas dielétricas também confirmam a existência de diferentes espécies, como $\mathrm{H}_{2} \mathrm{O}, \mathrm{H}_{3} \mathrm{O}^{+}, \mathrm{H}_{5} \mathrm{O}_{2}{ }^{+}$ e/ou $\mathrm{H}^{+}$realizando saltos $(26,28)$.

Diversos estudos de RMN em HPW são reportados na literatura, para diferentes hidratos (30, 32, 35), sais (40, 41), e complexos de sílica (42). Essayem et al. aplicaram técnicas de ${ }^{31} \mathrm{P}$ e ${ }^{1} \mathrm{H}$-RMN para analisar os estágios de desidratação do $\mathrm{HPW} \cdot 6 \mathrm{H}_{2} \mathrm{O}$ até $500^{\circ} \mathrm{C}$, e a subsequente re-hidratação em temperatura ambiente. Durante o aquecimento sob fluxo de 
$\mathrm{N}_{2}$, desde temperatura ambiente até $200^{\circ} \mathrm{C}$, as espécies de hidratação passam por uma série de transformações, surgindo espécies que foram identificadas pelos autores como clusters $\mathrm{H}^{+}\left(\mathrm{H}_{2} \mathrm{O}\right)_{n}$.

Dentre os hidratos de HPW, o hexahidrato é o mais estável em condições ambientes. Sua estrutura cristalina apresenta empacotamento bcc entre poliânions $\mathrm{PW}_{12} \mathrm{O}_{40}{ }^{3-}$ e íons dioxônio $\left(\mathrm{H}_{5} \mathrm{O}_{2}{ }^{+}\right)$, que são rígidos e praticamente planos (22,-26, 28, 29). O íon dioxônio pode assumir duas orientações perpendiculares, ocorrendo aleatoriamente na estrutura com igual probabilidade (24). A figura 2.2 exibe parte da estrutura do $\mathrm{HPW} \cdot 6 \mathrm{H}_{2} \mathrm{O}$, onde estão representadas as duas orientações para o íon dioxônio. Em geral, poucos estudos foram realizados em compostos contendo íons do tipo dioxônio.(22-24, 43-48) 0 íon dioxônio é constituído por duas moléculas de $\mathrm{H}_{2} \mathrm{O}$ interconectadas por um próton central. A distância O-O é em média $2,40 \AA \AA$ a $2,46 \AA$. O próton reside no eixo formado pelos dois oxigênios das moléculas de água e o ângulo O-H-O é em torno de $172^{\circ}$ a $180^{\circ}$.(43-48) Em amostras de HPW.6 $\mathrm{H}_{2} \mathrm{O}$, espectros de espectroscopia no infra-vermelho (IR) e Ramam mostram a existência de bandas características para as espécies $\mathrm{H}_{5} \mathrm{O}_{2}{ }^{+}, \mathrm{H}_{3} \mathrm{O}^{+}$e $\mathrm{H}_{2} \mathrm{O}$.(25) Com base nestes resultados, Mioc et al. propõem o seguinte equilíbrio dinâmico entre as espécies ao redor do poliânion (25)

$$
\mathrm{H}_{5} \mathrm{O}_{2}^{+} \Longleftrightarrow \mathrm{H}_{3} \mathrm{O}^{+}+\mathrm{H}_{2} \mathrm{O} \Longleftrightarrow \mathrm{H}^{+}+2 \mathrm{H}_{2} \mathrm{O}
$$

resultado da associação/dissociação do íon dioxônio em espécies menores. Experimentos de espalhamento inelástico de nêutrons e IR com temperatura variável mostram que em temperaturas mais altas, o equilíbrio da equação 2.2.1 se desloca para a direita (24, 28). Recentemente, cálculos ab initio suportam existência do equilíbrio acima, descrevendo o íon dioxônio como duas moléculas de $\mathrm{H}_{2} \mathrm{O}$ com um íon $\mathrm{H}^{+}$realizando saltos entre posições próximas aos $O$ de cada molécula.(29) As várias espécies observadas experimentalmente são resultado de diferenças na distância e no tipo de interação entre o próton central e as moléculas de água. Resultados de difração de raios-X (DRX) e difração de nêutrons (DN) para o HPW $6 \mathrm{H}_{2} \mathrm{O}$, em função da temperatura, mostram alterações estruturais por volta de $47^{\circ} \mathrm{C}$, atribuídas a uma transição de fase não convergente (sem alteração no empacotamento cristalino) por volta de $47^{\circ} \mathrm{C}\left(\mathrm{T}_{C}\right)$. Esta transição de fase apresenta diferentes processos interconectados (23, 24):

1. Contração do tetraedro $\mathrm{PO}_{4}$ - experimentos de DRX detectaram encurtamento das distâncias P-O $\left(1,61(1) \AA ̊ e m ~ 25^{\circ} \mathrm{C}\right.$ para $1,44(2) \AA ̊$ em $\left.100 \AA ̊\right)$. Em experimentos de Ramam, a frequência de vibração $\nu_{1}(\mathrm{P}-\mathrm{O})$ cresce com a temperatura, e uma descontinuidade é observada na temperatura $\mathrm{T}_{C}$.

2. Descontinuidades na expansão térmica do espaçamento interplanar $\left(\mathrm{d}_{400}\right)$ por volta de 

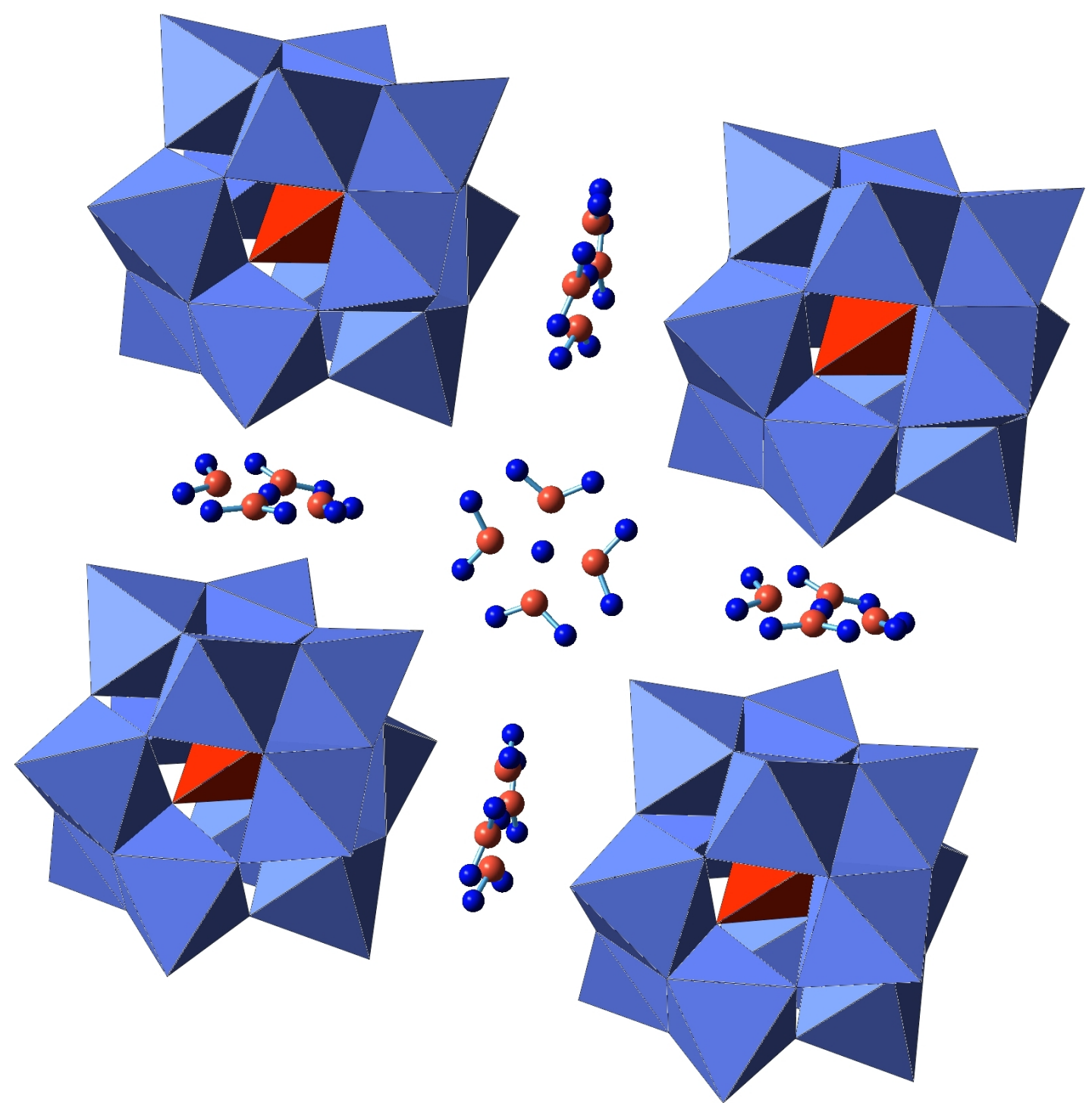

Figura 2.2-Representação de parte da estrutura cristalográfica do HPW $6 \mathrm{H}_{2} \mathrm{O}$. Na figura estão representadas as duas orientações possíveis (perpendiculares) para o íon $\mathrm{H}_{5} \mathrm{O}_{2}{ }^{+}$. Fonte: Elaborada pelo autor. 
$47^{\circ} \mathrm{C}$ e $67^{\circ} \mathrm{C}$

3. Mudanças no equilíbrio das espécies protônicas - como consequência das mudanças no equilíbrio da equação 2.2.1, resultados de DN mostram que o íon dioxônio assume uma conformação praticamente plana na temperatura $T_{C}$, com alteração no ângulo de torção $\mathrm{H}-\mathrm{O}-\mathrm{H}-\mathrm{O}-\mathrm{H}$ de $20(3)^{\circ}$ para $3(3)^{\circ}$, e a distância O-O entre os oxigênios do dioxônio sofre um aumento, o que está de acordo com o deslocamento do equilíbrio da equação 2.2 .1 para a direita.

Kremenovic et al. atribuem esta transição de fase à mudança no equilíbrio dinâmico da equação 2.2.1 e à redução parcial de alguns $\mathrm{W}^{6+}$ em $\mathrm{W}^{5+}$, baseados na alteração da coloração da amostra, de branco para azul, e ao alargamento da banda Ramam $\nu_{1}(\mathrm{P}-\mathrm{O}) .(23,24)$.

\subsection{Organosilanos}

Os compostos com estrutura do tipo $\mathrm{XRSiY}_{3}$, onde $\mathrm{X}$ é um grupo organofuncional, $\mathrm{R}$ é uma cadeia alquílica e $Y$ um grupo hidrolisável do tipo OR', são conhecidos como organosilanos. Estes compostos são amplamente utilizados para a síntese de materiais pelo processo sol-gel, devido à facilitação da incorporação de grupos orgânicos em uma matrizes de silicatos, devido à reatividade dos seus grupos $Y$, que levam à produção de grupos silanois que, por sua vez, podem reagir com silanois pré-formados no ambiente de reação (provenientes de outros organossilanos, ou de grupos silicato), via reação de condensação.

Neste trabalho os grupos organofuncionais dos precursores utilizado para preparação das amostras são do tipo amina, nitrila e epóxi. Os grupos $Y$ destes precursores são grupos metóxi ou etóxi, realizando uma ligação do tipo Si-O-C.

\section{4 processo sol-gel}

O interesse na utilização do processo sol-gel para a síntese de materiais inorgânicos começou com os estudos de Ebelmanl (49) e Graham (50) em géis de sílica, em meados do século 
XIX. Nestes estudos, os autores observaram que a hidrólise de tetraetilortosilicato (TEOS) em condições ácidas dava origem a $\mathrm{SiO}_{2}$ com estrutura amorfa.(49, 51) A obtenção de materiais por meio do processo sol-gel é atualmente uma metodologia bem estabelecida, e amplamente utilizada para uma variedade de aplicações. Estes materiais incluem:

1. diversos derivados híbridos baseados em sílica e/ou siloxanos,

2. materiais funcionais orgânico-inorgânicos,

3. materiais mesoporosos sintetizados na presença de surfactantes ou blocos co-poliméricos,

4. sistemas hóspede-hospedeiro envolvendo moléculas imobilizadas em estruturas porosas.

Todos estes sistemas podem ser considerados como nanocompósitos, cujas propriedades físicas e químicas estão relacionadas a homogeneidade da matriz de óxidos dos complexos e à natureza química da interface entre os nanocomponentes presentes no material. (52)

Sols são dispersões de partículas coloidais (partículas com diâmetro entre 1nm e 100nm) em um líquido. Um gel é uma rede rígida interconectada, com poros de dimensões submicrométricas e cadeias poliméricas, as quais apresentam comprimento médio maior do que um micrômetro. A transição sol-gel, ou gelatinização, ocorre quando se estabelecem ligações entre as partículas do sol, ou espécies moleculares, o que leva à formação de uma rede sólida tridimensional, o gel. A secagem do gel resulta em um complexo chamado xerogel.(51) Dependendo da natureza do precursor utilizado, o processo sol-gel se divide em duas classes, a dos sais (cloretos, nitratos, sulfetos) e a dos alcóxidos, principalmente alcóxidos de silício(16), sendo a última classe utilizada para a obtenção dos complexos deste trabalho.

O processo sol-gel envolvendo alcóxi-silanos, pode ser dividido em três etapas: hidrólise, condensação (policondensação) e secagem. Um precursor alcóxido líquido, como $\mathrm{Si}(\mathrm{OR})_{4}$ (sendo R um grupo orgânico), é hidrolisado na presença de água, levando à formação de silanois, como segue:

$$
\equiv S i-O R+H_{2} O \Longrightarrow S i-O R+R-O H \text { (Hidrólise). }
$$

Estes silanois reagem via reações de condensação, formando ligações do tipo Si-O-Si, como segue (51, 53):

$$
\begin{array}{llr} 
& \equiv S i-O H+\equiv S i-O R \Longrightarrow S i-O-S i+R-O H & \text { (Condensação) } \\
\equiv S i-O H+\equiv S i-O H \Longrightarrow S i-O-S i+H_{2} O & \text { (Condensação). }
\end{array}
$$


À medida que mais alcóxi-silanos são hidrolisados, ocorrem reações de policondensação entre os grupos, que dá início à formação da rede silicato, formadora do gel.(51, 53) Após a secagem do gel, obtem-se o produto final, chamado de xerogel.(51, 53)

\subsection{Materiais híbridos orgânico-inorgânicos}

Existem três tipos de materiais híbridos orgânico-inorgânicos. No primeiro tipo os componentes orgânicos e inorgânicos interagem fracamente, através de interações de Van der Walls ou pontes de hidrogênio. O segundo tipo abrange materiais cujas partes orgânicas e inorgânicas interagem via ligações covalentes. Um terceiro tipo de materiais é uma mistura dos dois primeiros, sendo materiais que apresentam interações covalentes entre um grupo orgânico e outro inorgânico, e ao mesmo tempo interações fracas entre o grupo orgânico e um segundo grupo inorgânico.(17) Os materiais estudados neste trabalho pertencem à última classe, e o seu processo de formação será explicado nesta seção.

Uma forma de se obter materiais híbridos orgânico inorgânicos, é através da combinação de presursores organosilanos por meio do processo sol-gel. Organosilanos são compostos com estrutura do tipo $\mathrm{XRSiY}_{3}$, onde $X$ é um grupo organofuncional, $R$ é uma cadeia alquílica e $Y$ um grupo hidrolisável do tipo $O R^{\prime}$. A aplicabilidade destes organossilanos é determinada pela reatividade dos seus grupos $Y$, que levam à produção de grupos silanois que, por sua vez, podem reagir com silanois pré-formados no ambiente de reação (provenientes de outros organossilanos, ou de grupos silicato), via reação de condensação, como descrito na seção 2.4 . A partir da combinação destes organosilanos, são formadas matrizes híbridas orgânico-inorgânicas, ou ormosil (do inglês "Organically Modified Silica". Os ormosils são constituídos de uma rede de silicatos rígida, que interage através de ligações covalentes, com cadeias orgânicas.(16) Estes materiais são extremamente estáveis cinética e termodinamicamente, mesmo em meios fortemente ácidos ou fortemente básicos. Além disso, o grupo organofuncional $X$ pode ser escolhido de acordo com a aplicação desejada.(54) O grau de porosidade destes ormosils é tal que eles podem ocluir vários tipos de compostos, como enzimas, catalisadores, sondas fluorescentes, fármacos e compostos como os POM (17), gerando assim materiais híbridos orgânico-inorgânico que conjugam as propriedades estruturais e funcionais dos ormosils com as propriedades específicas dos compostos incorporados. Além disso, a interação entre a parte orgânica e inorgânica pode gerar novas propriedades, diferentes das encontradas nos 
precursores.(55) De particular interesse para este trabalho são os materiais híbridos contendo POM, mais particularmente o HPW. A fim de se melhorar as propriedades desejadas nos materiais híbridos, a escolha dos organossilanos utilizados para a formação do xerogel é de fundamental importância.

Estudos revelam que um aumento no tamanho da cadeia alquílica dos organossilanos leva a um decréscimo no grau de condensação, ou seja, os átomos de silício realizam menos pontes do tipo Si-O-Si.(56) A adição de tetraetóxisilano (TEOS) durante o processo de hidrolise aumenta o grau de condensação do ormosil, compensando a redução causada pelo aumento nas cadeias alquílicas e melhorando a conectividade da rede.(56) Vários tipos de trialcóxisilanos podem ser incorporados na matriz ormosil para que haja melhoras em propriedades específicas, como hidrofobicidade, reatividade e flexibilidade na rede inorgânica.(16)

Nos complexos analisados neste estudo, incorpora-se o HPW em uma matriz ormosil, que contém grupos amina ou nitrila. Yamase et al. constataram que em xerogéis contendo HPW, os grupos aminas atuam como fornecedores de contra-íons para o processo de redução do HPW, e consequentemente, como será visto na seção 2.6, são de fundamental importância para a geração de materiais fotocrômicos.(15) No entanto, em trabalhos anteriores nestes mesmos materiais, foi constatado que o poliânion de HPW se encontra inserido em um ambiente com muitos prótons ( $>50$ ), pertencentes a espécies de hidratação. Devido a predominância destes grupos, não foi possível observar via RMN grandes diferenças na estrutura local do poliânion de HPW.(20)

A matriz ormosil dos diferentes complexos foi extensamente caracterizada em trabalhos anteriores (20), e apresenta estrutura amorfa, com diferentes grupos de silicatos puros $\mathrm{SiO}_{4}$ e grupos de organosilicatos $\mathrm{C}_{-} \mathrm{SiO}_{3}$. A matriz ormosil em geral é constituída de frações aproximadamente iguais de silicatos puros e silicatos ligados a grupos orgânicos, e estes grupos apresentam proximidade uns com os outros, não havendo então aglomerações de silicatos puros ou organosilicatos. Para os complexos contendo grupos fenila, é constatada a presença de grupos $\mathrm{Q}_{4}$ distorcidos, com ângulos médios da ligação Si-O-Si da ordem de $20^{\circ}$ maiores do que os ângulos observados nos grupos $Q_{4}$ dos xerogeis contendo grupos amina e nitrila. Provavelmente esta distorção dos tetraedros está associada a agrupamentos destes $Q_{4}$ com grupos fenilsiloxanos. 


\subsection{Fotocromismo}

Fotocromismo refere-se ao fenômeno reversível no qual um material altera sua coloração quando irradiado com luz (UV, visível ou IR). O processo reverso pode ocorrer através da exposição do material a luz em diferentes frequências, por aquecimento na ausência de luz, por polarização eletroquímica ou por oxidação química.(7) Os materiais fotocrômicos preparados a partir da incorporação de POM, particularmente o HPW, são de grande interesse tecnológico, pois as propriedades obtidas não dependem somente das propriedades dos compostos individuais, mas também da interface e do sinergismo entre eles. A princípio, esta última característica torna possível a "sintonia" do comportamento fotocrômico através de alterações na interface de interação entre os componentes do material.

O HPW pode ser fotoquimicamente reduzido, formando espécies azuladas, sem perder sua estrutura e integridade, devido à sua geometria especial. No estado oxidado os átomos de tungstênio apresentam configuração eletrônica $\mathrm{d}^{0}$, e o nível molecular de mais baixa energia do HPW encontram-se basicamente concentrado no orbital $2 p$ do oxigênio (banda de valência no modelo de bandas). Assim, o HPW apresenta bandas de transferência de carga oxigênio-metal $(\mathrm{O} \rightarrow$ ) (em inglês "ligand to metal charge transfer" - LMCT) aparecendo na faixa do UV.(15) Quando materiais híbridos contendo HPW são irradiados com luz na faixa do UV, os elétrons são excitados, passando dos orbitais $2 \mathrm{p}$ do oxigênio, para níveis de energia mais elevados, que são principalmente os orbitais d do metal. Consequentemente a configuração eletrônica do metal deixa de ser $d^{0}$ e passa a ser $d^{1}$, alterando a valência do tungstênio de $W^{6+}$ para $W^{5+}$. Os elétrons no nível $d^{1}$ facilitam a absorção na faixa do visível via transições $d$-d entre os sítios metálicos vizinhos que apresentam diferentes estados de valência.(7, 15)

Existem diversos estudos de ressonância paramagnética eletrônica (RPE) reportados na literatura, focados na caracterização dos estados metaestáveis gerados depois da irradiação, para alquilamônio polioxomolibidatos (APMo).(15, 157-60) No estado oxidado, átomos $\mathrm{H}$ de $\mathrm{NH}_{3}{ }^{+}$dos grupos alquilamônio, realizam ponte de hidrogênio com os átomos $\mathrm{O}$ pertencentes aos octaedros $\mathrm{MO}_{6}$. Os estudos de RPE mostram que a fotoexcitação da banda $\mathrm{O} \rightarrow \mathrm{M}$ LMCT dos APMo, induz a transferência do hidrogênio-ponte, que passa a realizar ligação covalente com o oxigênio pertencente ao octaedro $\mathrm{MO}_{6}$, e ponte de hidrogênio com $\mathrm{N}$. Este processo é seguido pela interação entre o elétron excitado, no nível $\mathrm{d}^{1}$ do metal, com o próton transferido para o $\mathrm{O}$. Simultaneamente, o buraco deixado no sítio do O como resultado da transição $\mathrm{O} \rightarrow \mathrm{M}$ LMCT interage com elétrons não ligantes do $\mathrm{N}$ em $\mathrm{NH}_{2}$, formando um 
complexo de transferência de carga, como mostrado no esquema da figura 2.3.(15) A separação entre elétrons e buracos, após a transição $\mathrm{O} \rightarrow \mathrm{M}$ LMCT descrita acima, é responsável pela permanência do estado colorido. O processo pode ser revertido pela interação com moléculas de oxigênio; um elétron é transferido desde o metal até a molécula $\mathrm{O}_{2}$.
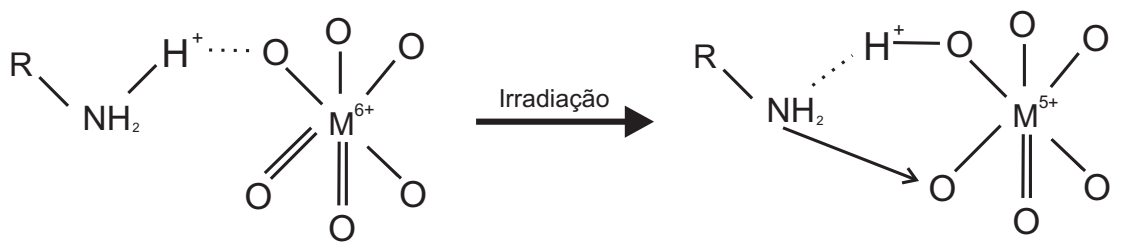

Figura 2.3-Processo de formação do complexo de transferência de carga entre um POM e um grupo amina. Fonte: OLIVEIRA JUNIOR.(20)

A figura 2.4 mostra espectros de RPE obtidos por Yamase et al..(15) O espectro em temperatura ambiente apresenta desdobramentos devido ao acoplamento hiperfino $\operatorname{com}{ }^{1} \mathrm{H}$, indicando que o elétron desemparelhado gerado pela irradiação encontra-se localizado em um sítio $\mathrm{MoO}_{5}(\mathrm{OH})$.(15) A análise dos tensores do acoplamento hiperfino do centro paramagnético com ${ }^{95} \mathrm{Mo} \mathrm{e}{ }^{97} \mathrm{Mo}$ do acoplamento superhiperfino com ${ }^{1} \mathrm{H}$, com base nos espetros de RPE, indica a existência de dois prótons equivalentes interagindo com o elétron paramagnético localizado no octaedro distorcido $\mathrm{MoO}_{5}(\mathrm{OH})$. Um dos prótons corresponde ao próton original da estrutura do polioxometalato, enquanto o outro corresponde ao próton-ponte transferido para o polioxometalato após irradiação.(15, 61)

Por outro lado, muitos estudos mostram que as moléculas de água ao redor de polioxotungstatos desempenham um papel importante no processo de fotocromismo, atuando da mesma forma que os grupos amina nos compostos estudados por Zayat et al..(63-65) Chen et al. (62) estudaram compostos baseados em politungstatos encapsulados em magadiita que apresentam fotocromismo na faixa do visível. Nestes compostos, o $\left[\mathrm{H}_{2} \mathrm{~W}_{12} \mathrm{O}_{40}\right]^{6-}$ se coordena com moléculas de água na interface com a mangadiita. Baseando-se no trabalho de Yamase (15), os autores propõem a reação esquematizada na figura 2.5. (62) A irradiação de espécies $\left[\mathrm{H}_{2} \mathrm{~W}_{12} \mathrm{O}_{40}\right] \cdot \mathrm{nH}_{2} \mathrm{O}$ com luz visível da origem ao processo (i) devido a uma transição $\mathrm{O} \rightarrow \mathrm{M}$ LMCT formando o complexo (1). O complexo ativo (1) pode ser capaz de oxidar moléculas de água, resultando em radicais $\bullet \mathrm{OH}$, em processo similar ao mostrado por Bernardini et al.(66) 

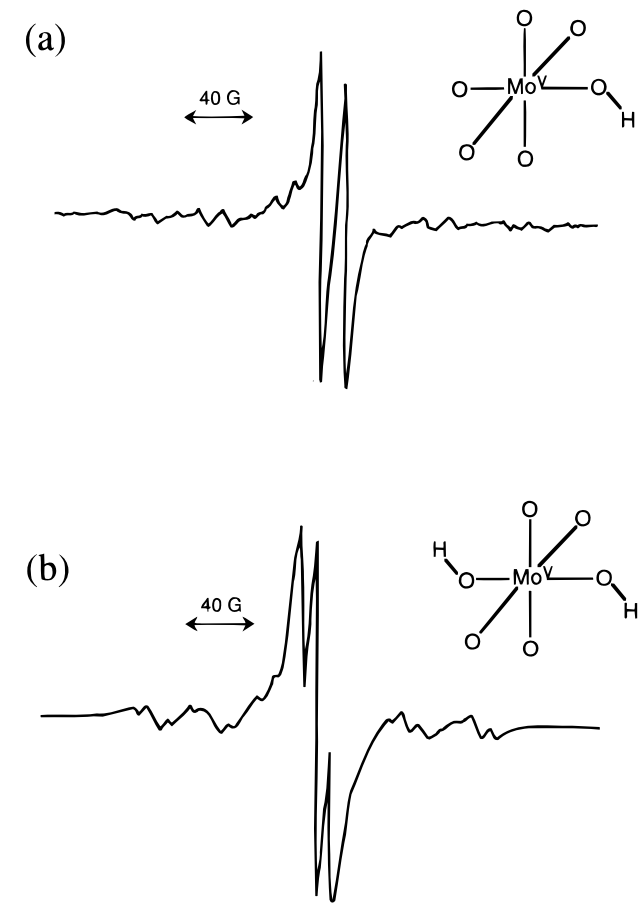

Figura 2.4-Espectros de RPE de monocristais irradiados de $\left[\mathrm{NH}_{3} \mathrm{Pr}\right]_{6}\left[\mathrm{Mo}_{7} \mathrm{O}_{24}\right] \cdot 3 \mathrm{H}_{2} \mathrm{O}(\mathrm{a})$ e $\left[\mathrm{NH}_{3} \mathrm{Pr}\right]_{6}\left[\mathrm{Mo}_{8} \mathrm{O}_{26}(\mathrm{OH})_{2}\right] \cdot 2 \mathrm{H}_{2} \mathrm{O}(\mathrm{b})$ em temperatura ambiente. Fonte: YAMASE (15)
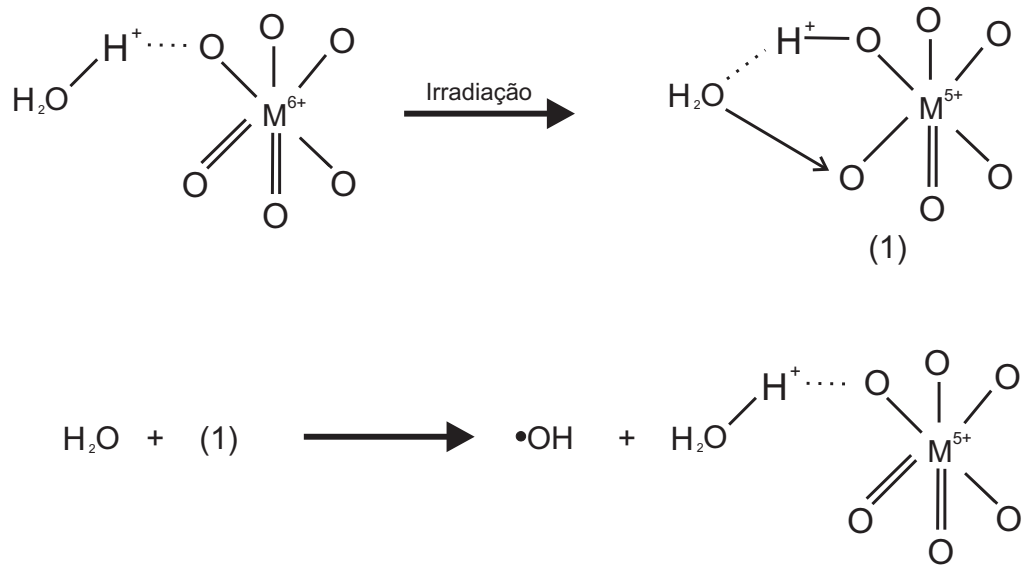

(i)

Figura 2.5-Processo de formação do complexo de transferência de carga entre um POM e uma molécula de água. Fonte: Adaptada de CHEN (62) 
Capítulo 3

\section{Técnicas experimentais}

\subsection{Espectroscopia por ressonância magnética nuclear}

A interação fundamental na técnica de RMN é o acoplamento entre o momento magnético do núcleo atômico com um campo magnético externo. A condição necessária para a utilização da técnica é que o núcleo em estudo possua momento de spin diferente de zero. Na presença de campos magnéticos os estados de energia para uma determinada espécie nuclear são discretos. Em linhas gerais, um experimento de RMN consiste na excitação do sistema de spins com radiação eletromagnética. A absorção da radiação ocorre de forma ressonante, quando a frequência coincide com a frequência de transição entre os possíveis estados de energia do sistema de spins. Esta frequência de ressonância está relacionada ao valor do campo magnético na posição do núcleo, com contribuição do campo magnético externo aplicado e dos campos magnéticos locais devido à vizinhança química e à distribuição eletrônica do núcleo. Esta dependência determina que a técnica de RMN seja sensível à mudanças químicas, estruturais e dinâmicas ocorrendo na vizinhança do átomo cujo núcleo analisado.

Neste capítulo serão apresentados resumidamente alguns dos fundamentos da espectroscopia de RMN em estado sólido, assim como a descrição das técnicas utilizadas para a caracterização dos materiais em estudo.

\subsubsection{Teoria básica}

O núcleo atômico possui um momento angular de spin $\vec{J}$ e um momento magnético $\vec{\mu}$ que satisfazem a relação

$$
\vec{\mu}=\gamma \vec{J}
$$

onde $\gamma$ é um escalar chamado de constante giromagnética, e apresenta um valor específico para cada núcleo.(67) Em mecânica quântica estes momentos são tratados como operadores 
que obedecem à álgebra de momento angular. Pode-se definir um operador momento angular $(\hat{\vec{I}})$ obedecendo a relação

$$
\hat{\vec{J}}=\hbar \hat{\vec{I}}
$$

sendo $\hat{\vec{I}}$ um operador adimensional, conhecido como momento de spin, e $\hbar$ a constante de Plank.(67)

Considerando um núcleo com momento magnético $\vec{\mu}$, na presença de um campo magnético $\vec{H}$, o operador Hamiltoniano de interação do momento magnético com o campo é

$$
\hat{H}_{Z}=-\hat{\vec{\mu}} \cdot \vec{H}
$$

Escolhendo um sistema de coordenadas tal que $\vec{H}=H_{0} \hat{z}$, temos

$$
\hat{H}_{z}=-\gamma \hbar H_{0} \hat{I}_{z}
$$

A Hamiltoniana da equação 3.1 .4 é conhecida como Hamiltoniana de interação Zeeman. Os autovalores desta Hamiltoniana são proporcionais aos autovalores do operador de spin $\hat{I}_{z}$, e as energias possíveis do sistema são:

$$
E=-\gamma \hbar H_{0} m, \quad \operatorname{com} \quad m=I, I-1, \cdots,-I,
$$

sendo $I(I+1)$ os autovalores do operador $\hat{I}^{2} \cdot(67)$

Para o caso de um núcleo com spin $I=1 / 2$, que é o caso dos isótopos estudados neste trabalho $\left({ }^{1} \mathrm{H},{ }^{31} \mathrm{P},{ }^{29} \mathrm{Si} \mathrm{e}{ }^{13} \mathrm{C}\right), m= \pm 1 / 2$, resultando em dois níveis de energia, $E_{+}$para $m=+1 / 2$ e $E_{-}$para $m=-1 / 2$. A separação entre estes níveis de energia é

$$
\Delta E=\gamma \hbar H_{0}
$$

De acordo com a relação de Planck $(\Delta E=\hbar \omega)$ é possível provocar transições entre os níveis de energia através da aplicação de ondas eletromagnéticas de frequência

$$
\omega_{0}=-\gamma H_{0}
$$

conhecida como frequência de Larmor. (67, 68) Para valores de campo $H_{0}$ típicos usados em laboratório $(\approx 1 T)$ essa frequência se situa na faixa de radiofrequência $(r f)$.

Até aqui foram considerados sistemas com apenas um núcleo. No caso de sistemas macroscópicos, o sinal de RMN é resultado da contribuição de vários spins. No equilíbrio térmico um sistema de $\mathrm{N}$ spins ( $I=1 / 2$ e não interagentes) pode ser descrito pela estatística de 
Boltzman, existindo $N_{-}$spins no estado com $m=-1 / 2$ e $N_{+}$spins no estado com $m=+1 / 2$, com $N_{-}$e $N_{+}$dados por

$$
N_{ \pm}=\frac{N e^{E_{ \pm} H_{0} / k_{B} T}}{e^{E_{-} / k_{B} T}+e^{E_{+} / k_{B} T}}
$$

onde $k_{B}$ é a constante de Boltzman.(67) A razão entre as populações nos dois estados de energia, considerando núcleos com $\gamma>0$, fica então dada por

$$
\frac{N_{-}}{N_{+}}=e^{-\frac{\Delta E}{k_{B} T}}=e^{-\frac{\gamma \hbar H_{0}}{k_{B} T}}
$$

Como pode ser observado na equação 3.1.9, a população no nível de mais baixa energia $\left(N_{+}\right)$ é ligeiramente maior do que a população no nível de mais alta energia. Este desbalanço de populações da origem a uma magnetização macroscópica de equilíbrio dada por

$$
\vec{M}=\sum_{i} \overrightarrow{\mu_{i}}=\vec{\mu} N\left(1-\frac{N_{-}}{N_{+}}\right) .
$$

A existência deste desbalanço de populações e de uma magnetização mensurável na direção do campo magnético, que torna possível a realização de experimentos de RMN.

\subsubsection{Dinâmica clássica do vetor magnetização e o sistema rotante}

Na descrição clássica, um vetor magnetização $\vec{M}$ na presença de um campo magnético está submetido a um torque $\vec{N}$ dado por:

$$
\vec{N}=\vec{M} \times \vec{H}
$$

De acordo com a equação 3.1.1. para um sistema de momentos magnéticos nucleares idênticos pode-se escrever

$$
\vec{M}=\gamma \vec{L}
$$

onde $\vec{L}$ é o momento angular obtido da soma dos momentos angulares devido a cada núcleo.(69) O torque $\vec{N}$ e o momento angular $\vec{L}$ se relacionam por:

$$
\vec{N}=\frac{d}{d t} \vec{L}
$$

Agora juntando as equações 3.1.11, 3.1.12 e 3.1.13, obtem-se a equação de movimento 
para o vetor magnetização

$$
\frac{d}{d t} \vec{M}=\gamma \vec{M} \times \vec{H}
$$

Considerando a direção $\hat{z}$ como a direção do campo magnético, $\vec{H}=H_{0} \hat{z}$, obtem-se o conjunto de equações

$$
\begin{aligned}
\frac{d}{d t} M_{x} & =\gamma M_{y} H_{0} \\
\frac{d}{d t} M_{y} & =-\gamma M_{x} H_{0} \\
\frac{d}{d t} M_{z} & =0 .
\end{aligned}
$$

Estas equações descrevem o fenômeno da precessão do vetor magnetização em torno do campo magnético $\vec{H}$ com a frequência de Larmor, $\omega_{0}=-\gamma H_{0}$, conforme ilustra a figura 3.1. Isto ocorre pois o torque $\vec{N}$ é sempre perpendicular ao plano formado pelo campo magnético $\vec{H}_{0}$ e o vetor $\vec{M}$.

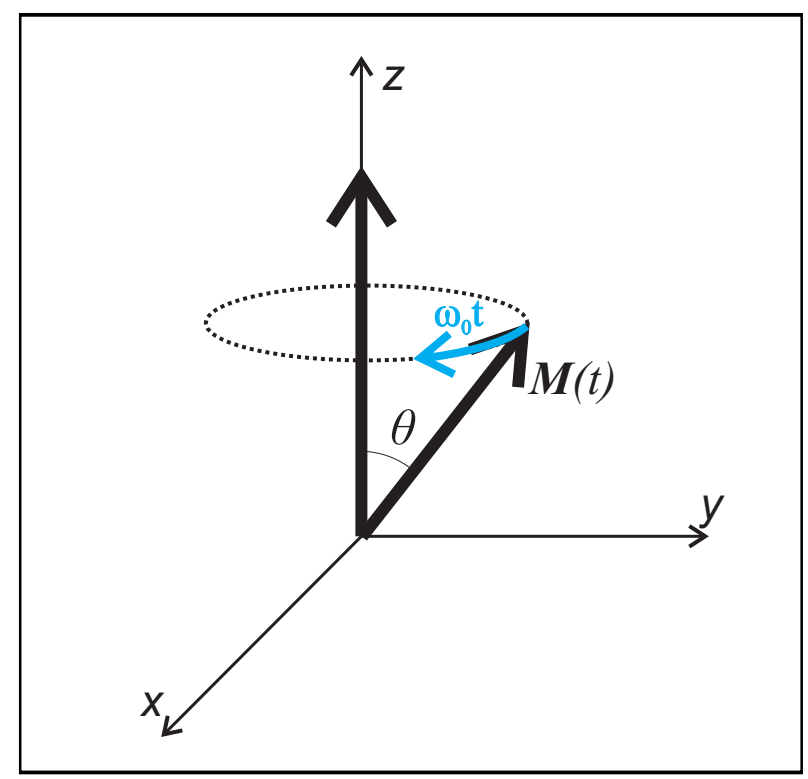

Figura 3.1-Movimento de precessão do vetor magnetização sob a influência de um campo magnético estático. Fonte: OLIVEIRA JUNIOR. (20)

Muitas vezes em RMN é conveniente descrever o vetor magnetização em um sistema de coordenadas rotante (SR), que gira em torno do eixo $\vec{z}$ com velocidade angular $\Omega$. No referido sistema, a equação 3.1 .15 deverá sofrer a seguinte correção:(67)

$$
\frac{d}{d t} \vec{M}=\vec{M} \times \hat{z}\left(\gamma H_{0}+\Omega\right) .
$$

A equação 3.1 .16 é análoga à equação 3.1.14 com a diferença de que neste novo sistema de 
coordenadas a magnetização precessiona em torno de um campo efetivo dado por

$$
\vec{H}_{e}=\left(H_{0}+\frac{\Omega}{\gamma}\right) \hat{z}
$$

Escolhendo convenientemente o valor de $\Omega$ igual à frequência de Larmor, $\Omega=-\gamma H_{0}$, o torque magnético no SR é nulo, e o vetor magnetização se mantém constante no tempo, ou seja, o SR acompanha o movimento da magnetização.

\subsubsection{O efeito de campos magnéticos oscilantes}

O princípio básico dos experimentos de RMN é a perturbação da magnetização por meio de campos magnéticos oscilantes e a subsequente observação da evolução da magnetização no retorno ao estado de equilíbrio térmico. Classicamente, na condição de equilíbrio a orientação do vetor magnetização é paralela ao campo estático aplicado $\vec{H}_{0}$. Para retirar a magnetização de sua condição de equilíbrio é preciso aplicar algum torque sobre esta, que a afaste de sua orientação inicial. Para gerar este torque aplica-se um campo magnético na direção transversal à magnetização. Uma vez afastada de certo ângulo da direção $\hat{z}$ a magnetização passa a precessionar em torno de $\vec{H}_{0}$, como mostrado na seção anterior. A maneira mais efetiva de provocar deflexão na magnetização é através da aplicação de um campo transversal rotatório, que acompanhe o movimento de precessão da magnetização em torno de $\vec{H}_{0}$. Nesta seção será discutida a geração deste campo rotatório e o seu efeito sobre o vetor magnetização. $O$ princípio básico dos experimentos de RMN é a perturbação da magnetização por meio de campos magnéticos oscilantes e a subsequente observação da evolução da magnetização no retorno ao equilíbrio. Classicamente, na condição de equilíbrio a orientação do vetor magnetização é paralela ao campo estático aplicado $\vec{H}_{0}$. Para retirar a magnetização de sua condição de equilíbrio é preciso gerar algum torque sobre esta, que a afaste de sua posição inicial. Para gerar este torque aplica-se um campo magnético na direção transversal à magnetização. Uma vez afastada de certo ângulo da direção $\hat{z}$ a magnetização passa a precessionar em torno de $\vec{H}_{0}$, como mostrado na seção anterior. A maneira mais efetiva de provocar deflexão na magnetização é através da aplicação de um campo transversal rotatório, que acompanhe o

movimento de precessão da magnetização em torno de $\vec{H}_{0}$. Nesta seção será discutida a geração deste campo rotatório e o seu efeito sobre o vetor magnetização.

Experimentalmente, o campo oscilante para a excitação da amostra é gerado utilizando-se 
uma bobina orientada perpendicularmente ao campo magnético $\vec{H}_{0}$ (mais adiante será mostrado que, para certos experimentos, a orientação pode não ser perpendicular). Na bobina é gerado um campo dado por

$$
\vec{H}_{x}(t)=H_{x 0} \cos (\omega t) \hat{x}
$$

Este campo pode ser escrito como a soma de duas componentes de módulo $H_{1}$ que giram com sentidos opostos no plano xy, como ilustrado na figura 3.2, satisfazendo as equações:

$$
\begin{aligned}
\vec{H}_{R} & =H_{1}(\hat{x} \cos (\omega t)+\hat{y} \operatorname{sen}(\omega t)) \\
\vec{H}_{L} & =H_{1}(\hat{x} \cos (\omega t)-\hat{y} \operatorname{sen}(\omega t))
\end{aligned}
$$

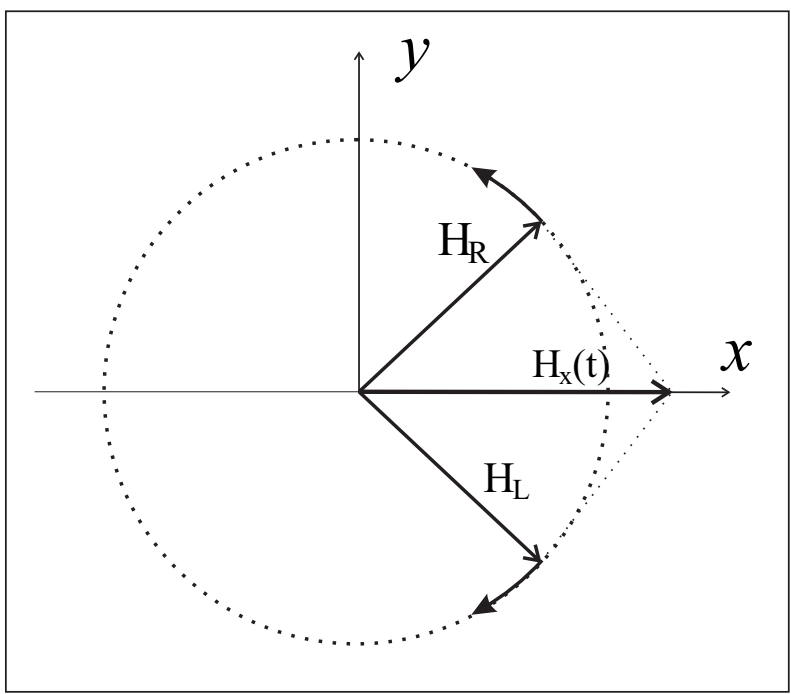

Figura 3.2-Decomposição de um campo oscilante linear em duas componentes rotantes. Fonte: Adaptada de SLICHTER.(67)

As equações 3.1 .20 podem ser escritas como uma única expressão, substituindo a constante positiva $\omega$ por um valor $\omega_{z}$, que pode tomar valores tanto positivos quanto negativos. Sendo assim, o campo oscilante no plano xy pode ser escrito como

$$
\vec{H}_{1}(t)=H_{1}\left(\hat{x} \cos \left(\omega_{z} t\right)+\hat{y} \operatorname{sen}\left(\omega_{\mathrm{z}} \mathrm{t}\right)\right)
$$

Considerando que o módulo de $\omega_{z}$ coincida com a frequência de Larmor do sistema de spins, uma das componentes de $\vec{H}_{1}(t)$ está em ressonância com o sistema $\left(\omega_{z}=-\omega\right)$, enquanto a outra está com frequência relativa duas vezes maior $\left(\omega_{z}=+\omega\right)$. Pode-se demonstrar que a os efeitos devido à componente fora de ressonância são insignificantes comparados aos efeitos provocados pela componente em ressonância, e a componente $\vec{H}_{R}\left(\omega_{z}=+\omega\right)$ pode ser desprezada.(67) Agora, considerando $\omega_{z}=-\omega$, e $H_{1}$ em ressonância com o sistema de spins 
( $\left.\omega=\omega_{0}\right)$, o campo efetivo para o $\mathrm{SR}$ em fase com $H_{1}$ é simplesmente $\vec{H}_{e}=H_{1} \hat{x}^{\prime}$ (onde $\hat{x}^{\prime}$ é o versor na direção $x$ do SR) e a equação da evolução temporal da magnetização fica:

$$
\frac{d}{d t} \vec{M}(t)=\gamma(\vec{M}(t) \times \hat{x}) H_{1}
$$

A equação 3.1 .22 é análoga a equação 3.1.15. Considerando a condição inicial com o sistema de spins em equilíbrio, $\vec{M}(t=0)=M_{0} \hat{k}$, a solução é um vetor magnetização precessionando em torno do eixo $x^{\prime}$ do sistema rotante, formando um ângulo $\theta$ com o eixo $z$ dado por:

$$
\theta(t)=\gamma H_{1} t \equiv-\omega_{1} t
$$

conforme ilustrado na figura 3.3. Quando este campo oscilante $\vec{H}_{1}(t)$ tem um tempo de duração finito, em RMN ele é comumente chamado de pulso de rf. O tempo de duração deste pulso pode ser controlado, de forma a girar a magnetização de um determinado ângulo. Para as intensidades de campos de rf usados em sondas de RMN, as durações destes pulsos são da ordem de microssegundos. Dois pulsos comumente utilizados são os pulsos de $\pi / 2$, que tem o efeito de zerar a componente $z$ da magnetização e $\pi$, que tem o efeito de inverter o sentido da magnetização, com durações $t_{90}=\frac{\pi}{2 \omega_{1}}$ e $t_{180}=\frac{\pi}{\omega_{1}}$.

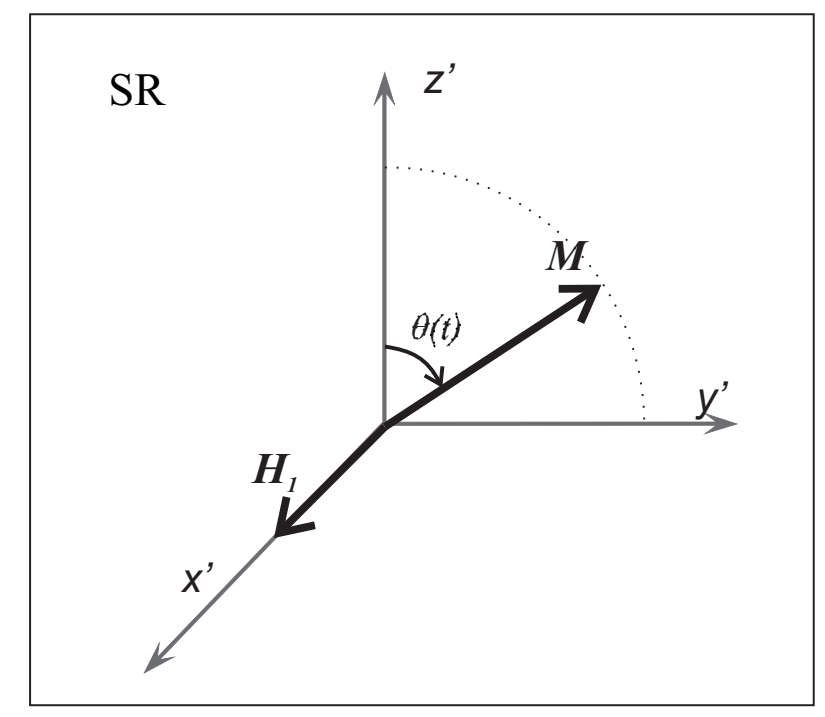

Figura 3.3-Movimento de precessão do vetor magnetização em torno de um campo oscilante $\mathrm{H} 1 \mathrm{em}$ ressonância, visto no sistema rotante. Fonte: Adaptada de OLIVEIRA JUNIOR. (20) 


\subsubsection{Relaxação}

Na equação 3.1.9, é possível notar que conforme a temperatura tende ao infinito, a diferença de populações entre os estados de spin tende a zero. Pode-se então utilizar esta diferença de populações para definir o conceito de temperatura de spin.(67, 70) A temperatura do sistema de spins não é necessariamente a mesma que a temperatura do reservatório, a menos que o sistema esteja em equilíbrio. Uma inversão nas populações leva a uma mudança de sinal na temperatura de spin, sendo definidas assim temperaturas negativas, e a equalização das populações leva a uma temperatura de spin infinita.(67, 70) Com exceção do sistema considerado, todos os graus de liberdade externos ao sistema (por exemplo, oscilações, rotações, translações, campos externos, etc.) são chamados de rede. Pode-se pensar na rede como um reservatório térmico em contato com o sistema de spins. No equilíbrio a temperatura do spin é igual à temperatura da rede. Uma vez fora do equilíbrio, o sistema tende a retornar ao equilíbrio, trocando energia com a rede. Como os estados de spin são quantizados, essa troca de energia só é possível através de transições induzida por flutuações nos campos locais com componentes de frequência coincidentes com a frequência de Larmor.(67, 70) Considerando um estado inicial com campo nulo, se o campo magnético $\vec{H}_{0}$ for ligado no instante $t=0$, as populações entre os níveis de energia (iguais em $t=0$ ) tenderão a se reorganizar, através de trocas de energia entre os spins e a rede, até atingir a condição de equilíbrio da equação 3.1.9. Este processo de evolução pode ser descrito pela equação

$$
n=n_{0}\left(1-e^{-\frac{t}{T_{1}}}\right)
$$

onde $\mathrm{n}$ é a diferença entre as populações fora do equilíbrio, $n=N_{+}(t)-N_{-}(t)$, e $n_{0}$ é a diferença no equilíbrio. A constante de tempo $T_{1}$ é conhecida como tempo de relaxação spin-rede.

Na prática, em um experimento de RMN o campo magnético $H_{0}$ é sempre constante, e o sistema é retirado do equilíbrio por meio de pulsos de rf, como descrito na seção anterior. Por exemplo, após um pulso de $\pi / 2$ sobre a magnetização, inicialmente no eixo $\hat{z}$, esta é transferida para o plano transversal. Após o pulso, a magnetização volta a crescer na direção $\hat{z}$ até atingir o equilíbrio, como explicado acima. No estado de equilíbrio a magnetização no plano transversal é nula, logo deve haver um processo pelo qual a magnetização perde intensidade no plano transversal. Este processo é conhecido como como relaxação transversal, ou relaxação spin-spin, e ocorre devido às defasagens irreversíveis entre as frequências de precessão individuais de cada spin, originadas da presença de campos magnéticos locais flutuantes que se somam ao campo 
externo $H_{0} \cdot(67,70)$

É possível corrigir as equações de precessão 3.1 .15 , considerando termos responsáveis pelos processos de relaxação, obtendo

$$
\begin{aligned}
\frac{d}{d t} M_{x} & =\gamma M_{y} H_{0}-\frac{M_{x}}{T_{2}} \\
\frac{d}{d t} M_{y} & =-\gamma M_{x} H_{0}-\frac{M_{y}}{T_{2}} \\
\frac{d}{d t} M_{z} & =\frac{M_{0}-M_{z}}{T_{1}}
\end{aligned}
$$

que são chamadas equações de Bloch.(67, 69) As equações de Bloch constituem um modelo fenomenológico para explicar a evolução do vetor magnetização para spins não interagentes sob a influência de um campo aplicado, e não são validas para todo sistema de spins. Em particular, em sólidos estas equações podem não ser válidas, devido à existência de interações entre os spíns, como as que serão discutidas na seção 3.1.6. Mesmo sendo limitadas, as equações de Bloch permitem obter uma visão qualitativa de um experimento de RMN pulsada.(67)

\subsubsection{O sinal de RMN}

Um magneto de campo uniforme e constante na região da amostra gera o campo $\vec{H}_{0}=H_{0} \hat{z}$. A bobina utilizada para aplicar o pulso de rf, orientada na direção x, é utilizada também como antena para a obtenção do sinal de resposta do sistema de spins. Após o pulso, a magnetização evolui conforme as equações 3.1.25. Ao executar o movimento de precessão, a componente $M_{x}$ da magnetização oscila na direção do eixo da bobina. De acordo com a lei de Faraday, uma força eletromotriz é induzida na bobina, oscilando com a frequência de precessão do vetor magnetização, e decaindo com o tempo de relaxação $T_{2}$. Esta tensão induzida na bobina é chamada de "free induction decay" (FID). Para um sistema de spins que está sujeito apenas à interação Zeeman, onde a magnetização precessiona com frequência $\omega_{0}$, o FID terá um decaimento exponencial do tipo:

$$
V(t) \propto-\frac{d}{d t} M_{x}(t)=V_{0} \operatorname{sen}\left(\omega_{0} \mathrm{t}\right) \mathrm{e}^{-\frac{t}{T_{2}}} .
$$

Em sólidos, cada núcleo está sob campos locais diferentes, e o FID é uma superposição de várias oscilações amortecidas como a da equação 3.1.26. Para identificar as frequências presentes no FID, é realizada uma transformada de Fourier, obtendo-se assim o espectro de RMN, de 
onde podem ser obtidas informações a respeito da distribuição de frequências de ressonância presentes na amostra. A técnica de RMN pulsada de polarização direta (PD) consiste em aplicar um pulso de $\pi / 2$ e registrar o FID. Nas seções 3.1 .7 e 3.1 .8 serão discutidas outras sequências de pulso, que foram utilizadas neste trabalho.

\subsubsection{Interações do spin nuclear}

Nesta seção serão apresentadas de forma sucinta as principais interações do spin nuclear em sólidos, que serão relevantes para este trabalho. Na abordagem semiclássica da seção 3.1.2. o comportamento dos spins nucleares foi descrito levando-se em conta apenas a interação Zeeman $\left(\hat{H}_{Z}\right)$, cuja Hamiltoniana é dada pela equação 3.1.4. Usualmente, a interação Zeeman domina o comportamento do sistema de spins nucleares, mas não contém informação a respeito do ambiente ao redor do núcleo. Para as aplicações de RMN em espectroscopia, os campos locais sentidos pelos núcleos devido às interações internas são cruciais.(70) Em sólidos, o acoplamento dipolar entre spins, a blindagem do campo $\vec{H}_{0}$ pela nuvem eletrônica, e a interação entre o momento quadrupolar do núcleo com o gradiente de campo elétrico são particularmente importantes.(69) Como a interação Zeeman é usualmente dominante, as interações internas aqui consideradas serão tratadas como perturbações de $\hat{H}_{Z}$.

\subsubsection{Desvio químico}

Sob a influência de um campo externo aplicado $\vec{H}_{0}$, a nuvem eletrônica do átomo gera um campo local adicional $\vec{H}_{L}$. existem duas contribuições diferentes para este campo:

1. Contribuição diamagnética: gerada pelo movimento circular dos elétrons devido ao campo magnético aplicado. Este movimento produz um campo magnético que se opõe ao campo aplicado. Esta contribuição varia com o inverso do cubo da distância do elétron até o núcleo, e tem o efeito de blindar o campo sentido pelo núcleo.(68, 71, 72)

2. Contribuição paramagnética: o campo aplicado causa a mistura dos estados eletrônicos excitados, que possuem propriedades paramagnéticas, com o estado fundamental, criando 
assim paramagnetismo no estado fundamental da molécula. Esta contribuição tem o efeito de diminuir a blindagem do campo magnético sentido pelo núcleo.(68, 71, 72)

Como em geral a nuvem eletrônica não apresenta simetria esférica, o campo local $\vec{H}_{L}$ se relaciona com o campo aplicado através de um tensor $\stackrel{\leftrightarrow}{\sigma}$

$$
\vec{H}_{L}=\stackrel{\leftrightarrow}{\sigma} \cdot \vec{H}_{0}
$$

com

$$
\stackrel{\leftrightarrow}{\sigma}=\left[\begin{array}{ccc}
\sigma_{x x} & \sigma_{x y} & \sigma_{x z} \\
\sigma_{y x} & \sigma_{y y} & \sigma_{y z} \\
\sigma_{z x} & \sigma_{z y} & \sigma_{z z}
\end{array}\right] .
$$

Assim, a Hamiltoniana de desvio químico é escrita como:

$$
\hat{H}_{D Q}=-\gamma \hbar \hat{\vec{I}} \cdot \stackrel{\leftrightarrow}{\sigma} \cdot \vec{H}_{0}
$$

Como explicado anteriormente, a interação Zeemam é a interação dominante, e podemos considerar a Hamiltoniana de desvio químico segundo a teoria de perturbação de primeira ordem com respeito a $\hat{H}_{0}=\omega_{0} \hat{I} \hat{z}$. Como a correção dos níveis de energia é dada em primeira ordem pelos elementos diagonais da Hamiltoniana perturbativa, na base dos autovalores de $\hat{I}_{z}$, $E_{m}^{(1)}=\left\langle m\left|\hat{H}_{D Q}\right| m\right\rangle$, apenas os elementos diagonais nesta base $|m\rangle$ precisam ser mantidos. Assim, a Hamiltoniana truncada de desvio químico é dada por (67, 69):

$$
\hat{H}_{D Q}=-\gamma \hbar \hat{I}_{z} \sigma_{z z} H_{0} .
$$

Considerando as equações 3.1 .30 e 3.1.4, a Hamiltoniana total relevante para o cálculo do espectro do sistema fica então dada por

$$
\hat{H}=\hat{H}_{0}+\hat{H}_{D Q}=\omega_{0}\left(1-\sigma_{z z}\right) \hat{I}_{z},
$$

que representa uma leve correção na frequência de precessão da magnetização

$$
\omega_{D Q}=-\omega_{0} \sigma_{z z}
$$

O elemento $\sigma_{z z}$ do tensor de blindagem, expresso no sistema de referência do laboratório, depende da orientação do segmento molecular com relação a $\vec{H}_{0}$, pois o tensor de blindagem $\overleftrightarrow{\sigma}$ é uma propriedade local do segmento molecular onde o núcleo está inserido, e está portanto fixo com relação ao sistema de coordenadas do segmento. Podemos definir um vetor unitário na direção do campo $\vec{H}_{0}$, dado por $\vec{h}_{0}=\vec{H}_{0} / H_{0}$. Utilizando este versor, o elemento $\sigma_{z z}$ do 
tensor de blindagem pode ser escrito na forma

$$
\sigma_{z z}=\left(\begin{array}{lll}
0 & 0 & 1
\end{array}\right) \stackrel{\leftrightarrow}{\sigma}\left(\begin{array}{l}
0 \\
0 \\
1
\end{array}\right)=\hat{h}_{0}^{s} \cdot \stackrel{\leftrightarrow}{\sigma^{s}} \cdot \hat{h}_{0}^{s} .
$$

Esta expressão é valida para tanto $\hat{h}_{0}$ quanto $\stackrel{\leftrightarrow}{\sigma}$ expressos em qualquer sistema de coordenadas $s .(69)$

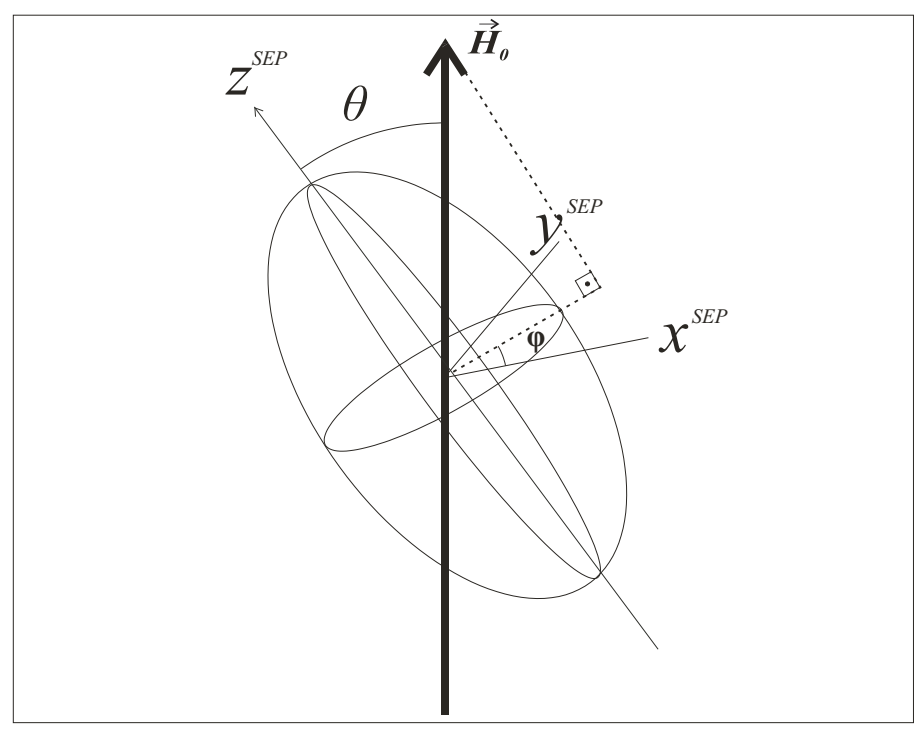

Figura 3.4-llustração representativa do tensor de blindagem, e definição dos ângulos que indicam a orientação do campo magnético no SEP. Fonte: Adaptada de OLIVEIRA JUNIOR. (20)

Um sistema de coordenadas conveniente para continuar a análise deste problema, seria um sistema onde o tensor $\stackrel{\leftrightarrow}{\sigma}$ fosse diagonal, ou seja, um sistema de coordenadas cuja base seja composta pelos auto-vetores da matriz 3.1.28. Este sistema de coordenadas especial é chamado de sistema de eixos principais (SEP), e neste sistema a representação do tensor de blindagem é uma matriz diagonal, cujos termos $\sigma_{i i}^{S E P}(i=x, y, z)$ são os auto-valores da matriz do tensor de blindagem, chamados de valores principais do tensor.(72) $O$ tensor de blindagem no SEP pode ser ilustrado como um elipsoide cujos eixos de simetria coincidem com os eixos principais da interação, e têm comprimento proporcional aos valores principais do tensor de blindagem (figura 3.4).(72) $\mathrm{O}$ versor $\vec{h}_{0}$ no SEP é dado por

$$
\vec{h}_{0}^{S E P}=(\operatorname{sen} \theta \cos \varphi \quad \operatorname{sen} \theta \operatorname{sen} \varphi \quad \cos \theta)
$$

Usando a equação 3.1 .34 na equação 3.1.33, e a definição de $\omega_{D Q}$ da equação 3.1 .32 resulta:

$$
\omega_{D Q}=-\omega_{0}\left(\sigma_{x x}^{S E P} \operatorname{sen}^{2} \theta \cos ^{2} \varphi+\sigma_{\mathrm{yy}}^{\mathrm{SEP}} \operatorname{sen}^{2} \theta \operatorname{sen}^{2} \varphi+\sigma_{\mathrm{zz}}^{\mathrm{SEP}} \cos ^{2} \theta\right),
$$

$\operatorname{com} \varphi$ e $\theta$ definidos na figura 3.4 . 
Para o caso particular de um tensor de blindagem com simetria axial no SEP, temos $\sigma_{x x}^{S E P}=\sigma_{y y}^{S E P}$, e a equação 3.1 .35 pode ser escrita como (72):

$$
\omega_{D Q}=-\omega_{0} \sigma_{z z}^{S E P} \frac{1}{2}\left(3 \cos ^{2} \theta-1\right) .
$$

Em RMN, é usual definir o tensor de blindagem com relação à blindagem isotrópica, $\sigma_{i s o}$, que é a média dos elementos diagonais do tensor de blindagem (como é proporcional ao traço do tensor, é invariante frente ao sistema de referência adotado). Então

$$
\sigma_{i s o}=\frac{1}{3}\left(\sigma_{x x}^{s}+\sigma_{y y}^{s}+\sigma_{z z}^{s}\right)
$$

e a parte anisotrópica do tensor de blindagem, quando o tensor é representado no sistema de referências $s$ é

$$
{\stackrel{\leftrightarrow}{\sigma^{s}}}_{\text {aniso }}=\stackrel{\leftrightarrow}{\sigma^{s}}-\mathbb{1} \cdot \sigma_{i s o}
$$

Onde $\mathbb{1}$ é a matriz identidade. Assim, a frequência de desvio químico anisotrópico para um tensor de blindagem com simetria axial é dada por (72):

$$
\omega_{D Q}^{\text {aniso }}=-\omega_{0}\left(\sigma_{z z}^{S E P}-\sigma_{i s o}\right) \frac{1}{2}\left(3 \cos ^{2} \theta-1\right) .
$$

Para o caso geral, a frequência de desvio químico é escrita na forma

$$
\omega_{D Q}^{\text {aniso }}=-\omega_{0} \sigma_{\text {iso }}-\frac{\omega_{0} \Delta}{2}\left[3 \cos ^{2} \theta-1+\eta \operatorname{sen}^{2} \theta \cos 2 \varphi\right],
$$

onde os termos $\Delta$ e $\eta$ são parâmetros que estão relacionados com os valores principais do tensor de blindagem no SEP pelas equações 3.1.41, e são chamados respectivamente de parâmetro de anisotropia e parâmetro de assimetria.

$$
\begin{gathered}
\Delta=\sigma_{z z}^{S E P}-\sigma_{i s o} \\
\eta=\frac{\sigma_{x x}^{S E P}-\sigma_{y y}^{S E P}}{\sigma_{z z}^{S E P}} .
\end{gathered}
$$

Para o caso axial $\eta=0$, recuperando o desvio apresentado na equação 3.1.39. Já para o caso onde o tensor de blindagem é isotrópico $\Delta=0$.

O efeito causado pela interação de blindagem, como dito anteriormente, é a de provocar um desvio na frequência de ressonância para um núcleo com uma certa orientação do tensor $\stackrel{\leftrightarrow}{\sigma}$, que é da ordem de $\mathrm{KHz}$. Através dos deslocamentos observados pode-se retirar informações a respeito da vizinhança química dos átomos observados, como por exemplo as ligações químicas 
que realizam, ou até interações fracas com outros átomos.(73)

Em uma amostra em pó, o SEP assume todas as orientações possíveis com relação ao campo externo, ou seja, todos os valores de $\varphi$ e $\theta$ são possíveis. Desta maneira, o espectro de RMN resultante é dado pela soma dos diferentes valores de frequência devido a cada orientação do tensor de desvio químico. Este espectro é chamado de padrão de pó, e sua forma depende da simetria do tensor de desvio químico. A figura 3.5 exibe o padrão de pó teórico para os casos isotrópico (figura 3.5.a), axial (figura 3.5.b) e ortorrômbico (figura 3.5.c).

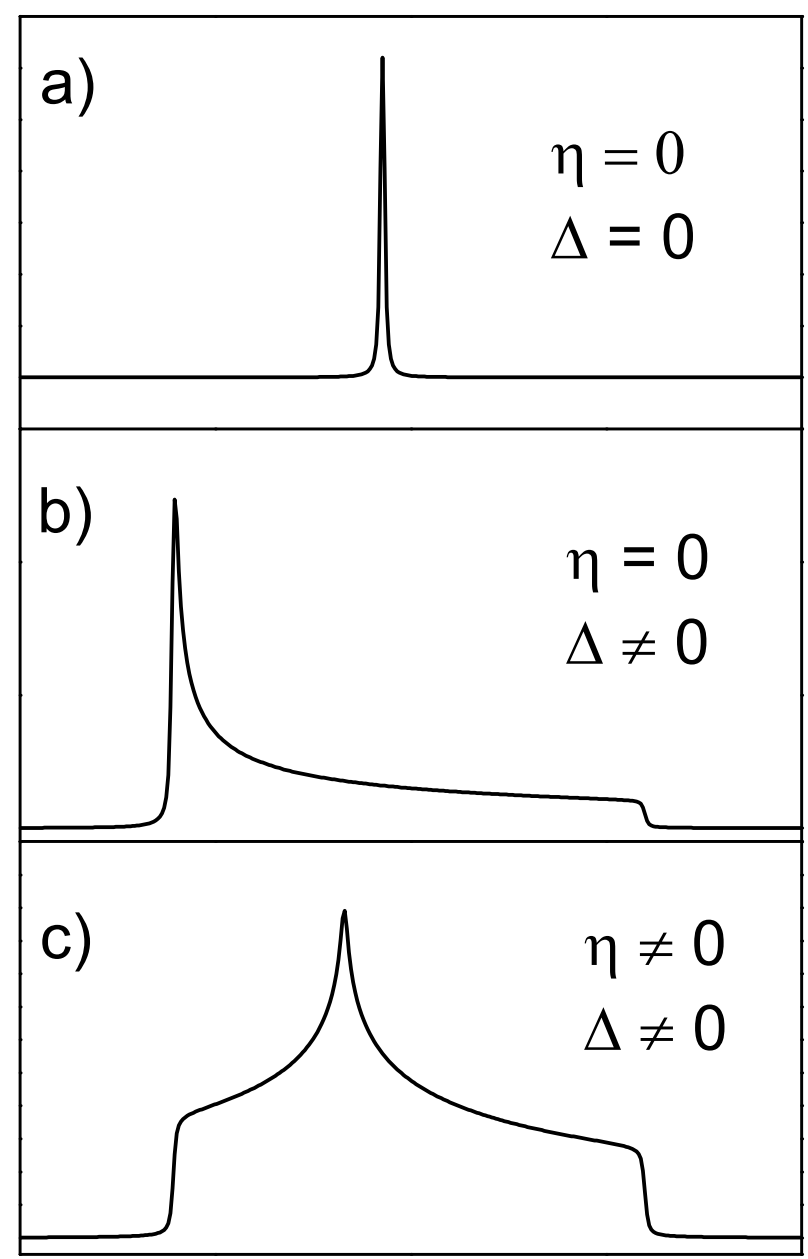

Figura 3.5-Espectros de pó para uma amostra policristalina, considerando apenas a interação Zeeman e de desvio químico para tensores de blindagem com simetria isotrópica (a), axial (b) e ortorrômbica (c). Fonte: Elaborada pelo autor.

Usualmente as frequências de ressonância em RMN não são reportados em unidades de frequências absolutas. O que se faz é tomar valores de desvio isotrópico relativos aos valores experimentais de frequências de ressonância para substâncias de referência $\left(\nu_{r e f}\right)$. O desvio de frequência $\delta$ é definido como

$$
\delta=\frac{\nu-\nu_{r e f}}{\nu_{r e f}} \cdot 10^{6}
$$


onde $\nu$ é a frequência espectral absoluta da substância em estudo, e $\nu_{r e f}$ é a frequência absoluta da substância de referência. Os valores típicos de $\delta$ produzidos pela interação de desvio químico são pequenos, da ordem de partes por milhão. A grande vantagem de se usar o valor de desvio $\delta$ reside no fato dos valores não dependerem do campo magnético utilizado, facilitando assim a comparação entre resultados obtidos em diferentes condições.

\subsubsection{Interação dipolar}

Como explicado na seção 3.1.2, ao spin nuclear está associado um momento magnético. Quando dois ou mais spins se encontram próximos, os momentos magnéticos de ambos interagem mutuamente através de interação do tipo dipolo-dipolo. Em líquidos, as interações dipolares são promediadas ao valor isotrópico, zero, devido às reorientações moleculares rápidas com relação a escala de tempos da RMN $\left(10^{-6} s\right) .(72,174)$ Por outro lado, em sólidos a interação dipolar é a principal responsável pelo alargamento espectral observado.

A energia de interação clássica entre dois dipolos magnéticos $\overrightarrow{\mu_{1}}$ e $\overrightarrow{\mu_{2}}$ separados por uma distância $r$ é dada por (67)

$$
U=\frac{\mu_{0}}{4 \pi}\left[\frac{\overrightarrow{\mu_{1}} \cdot \overrightarrow{\mu_{2}}}{r^{3}}-3 \frac{\left(\overrightarrow{\mu_{1}} \cdot \vec{r}\right)\left(\overrightarrow{\mu_{2}} \cdot \vec{r}\right)}{r^{5}}\right] .
$$

Pelo princípio de correspondência, a Hamiltoniana da interação dipolar para o caso de dois núcleos com spins $\overrightarrow{I_{1}}$ e $\overrightarrow{I_{2}}$, e posição relativa $\vec{r}=\left(\overrightarrow{r_{2}}-\overrightarrow{r_{1}}\right)$ será então dada por

$$
\hat{H}_{12}^{D}=-\frac{\mu_{0}}{4 \pi} \gamma_{1} \gamma_{2} \hbar\left(\frac{\hat{\overrightarrow{I_{1}}} \cdot \hat{\overrightarrow{I_{2}}}}{r^{3}}-3 \frac{\left(\hat{\overrightarrow{I_{1}}} \cdot \vec{r}\right)\left(\hat{\overrightarrow{I_{2}}} \cdot \vec{r}\right)}{r^{5}}\right),
$$

onde $\gamma_{1}$ e $\gamma_{2}$ são as constantes giromagnéticas dos spins $\overrightarrow{I_{1}}$ e $\overrightarrow{I_{2}}$ respectivamente. Expressando a equação 3.1 .44 em coordenadas esféricas, e expandindo os produtos escalares e rearranjando os termos, obtém-se a seguinte expressão

$$
\hat{H}_{12}^{D}=-\frac{\mu_{0}}{4 \pi} \frac{\gamma_{1} \gamma_{2} \hbar}{r^{3}}[A+B+C+D+E+F]
$$


onde

$$
\begin{aligned}
A & =\hat{I}_{1 z} \hat{I}_{2 z}\left(3 \cos ^{2} \theta-1\right) \\
B & =-\frac{1}{4}\left[\hat{I}_{1+} \hat{I}_{2-}+\hat{I}_{1-} \hat{I}_{2+}\right]\left(3 \cos ^{2} \theta-1\right) \\
C & =-\frac{3}{2}\left[\hat{I}_{1 z} \hat{I}_{2+}+\hat{I}_{1+} \hat{I}_{2 z}\right] \operatorname{sen} \theta \cos \theta \mathrm{e}^{-\mathrm{i} \varphi} \\
D & =-\frac{3}{2}\left[\hat{I}_{1 z} \hat{I}_{2-}+\hat{I}_{1-} \hat{I}_{2 z}\right] \operatorname{sen} \theta \cos \theta \mathrm{e}^{+\mathrm{i} \varphi} \\
E & =-\frac{3}{2}\left[\hat{I}_{1+} \hat{I}_{2+}\right] \operatorname{sen}^{2} \theta \mathrm{e}^{-2 \mathrm{i} \varphi} \\
F & =-\frac{3}{2}\left[\hat{I}_{1-} \hat{I}_{2-}\right] \operatorname{sen}^{2} \theta \mathrm{e}^{-2 \mathrm{i} \varphi}
\end{aligned}
$$

, $\hat{I}_{i}+$ e $\hat{I}_{i}-$, com $i=1,2$, são operadores de criação e destruição de spin (68, 72), e os ângulos $\theta$ e $\varphi$ são as coordenadas esféricas do vetor $\vec{r}$. A interação dipolar é fraca comparada com a interação Zeeman, podendo ser tratada segundo a teoria de perturbação de primeira ordem. A Hamiltoniana truncada da interação leva em conta apenas os termos A e B para interação entre spins da mesma espécie (interação dipolar homonuclear) e o termo A para interação entre spins de espécies distintas (interação dipolar heteronuclear). Assim, as Hamiltonianas relevantes de interação homonuclear, $\hat{H}_{I I}$, e heteronuclear, $\hat{H}_{I S}$, ficam dadas por (72):

$$
\begin{aligned}
& \hat{H}_{I I}=-\frac{\mu_{0}}{4 \pi} \frac{\gamma_{I}^{2} \hbar}{r^{3}}\left(3 \cos ^{2} \theta-1\right)\left[\hat{I}_{1 z} \hat{I}_{2 z}-\frac{1}{2}\left(\hat{I}_{1 x} \hat{I}_{2 x}+\hat{I}_{1 y} \hat{I}_{2 y}\right)\right] \\
& \hat{H}_{I S}=-\frac{\mu_{0}}{4 \pi} \frac{\gamma_{I} \gamma_{S} \hbar}{r^{3}}\left(3 \cos ^{2} \theta-1\right) \hat{I}_{z} \hat{S}_{z} .
\end{aligned}
$$

O termo $-\frac{\mu_{0}}{4 \pi} \frac{\gamma_{I} \gamma_{S} \hbar}{r^{3}}$ é chamado de constante de acoplamento dipolar, e é simbolizado por $\Omega_{I S}$.

O efeito da Hamiltoniana de interação dipolar sobre um sistema de dois spins é o de alterar os níveis de energia, conforme mostrado no diagrama da figura 3.6. O valor de $\Delta$ na figura 3.6 é $3 \Omega_{I I}$ para a interação homonuclear, e $2 \Omega_{I S}$ para a interação heteronuclear. 0 novo espectro de frequências terá duas linhas nas posições $\omega_{0}+\Delta$ e $\omega_{0}-\Delta$ correspondentes às novas diferenças entre os níveis de energia. Por depender da constante de acoplamento dipolar (equação 3.1.46), o parâmetro $\Delta$ depende do ângulo $\theta$ da posição relativa entre os núcleos. Sendo assim, para um par de spins pertencente a um sistema policristalino, ou seja, que apresenta cristalitos com múltiplas orientações, todos os valores de $\Delta$ para $\theta$ entre 0 e $\pi$ são possíveis, e o espectro torna-se um padrão de pó como o ilustrado na figura 3.7.a, para o caso de interação dipolar homonuclear entre pares de spins I.(20) 
Considerando os núcleos ${ }^{1} \mathrm{H},{ }^{13} \mathrm{Ce}{ }^{31} \mathrm{P}$, com

$$
\begin{aligned}
& \gamma_{H}=42,576 \cdot 10^{6} H z \cdot T^{-1} \\
& \gamma_{C}=10,705 \cdot 10^{6} H z \cdot T^{-1} \\
& \gamma_{P}=17,235 \cdot 10^{6} H z \cdot T^{-1},
\end{aligned}
$$

é possível estimar os valores para a constante $\Omega_{I S}$ considerando diferentes núcleos acoplados para distâncias típicas encontradas na natureza. A distância ${ }^{1} \mathrm{H}-{ }^{1} \mathrm{H}$ em uma molécula de $\mathrm{H}_{2} \mathrm{O}$, por exemplo, é de $1,6 \AA ̊$, resultando em $\Omega_{H H} \approx 75 \mathrm{KHz}$. Para uma amostra de HPW.n $\mathrm{n}_{2} \mathrm{O}$, $r_{H P}>6 \AA$, resultando em acoplamentos $\Omega_{H P}$ menores do que $8 \mathrm{KHz}$ para pares ${ }^{1} \mathrm{H}_{-}{ }^{31} \mathrm{P}$. Para uma ligação covalente $\mathrm{CH}$ típica, $r_{H P} \approx 0,9 \AA$, resultando em $\Omega_{H C} \approx 30 \mathrm{KHz}$. Como pode ser observado, o acoplamento dipolar homonuclear ${ }^{1} \mathrm{H}-{ }^{1} \mathrm{H}$ é uma ordem de grandeza mais intenso do que os acoplamentos heteronucleares ${ }^{1} \mathrm{H}_{-}{ }^{13} \mathrm{C}{ }^{1} \mathrm{H}_{-}{ }^{31} \mathrm{P}$, devido ao maior valor de $\gamma$, resultando em um alargamento considerável para espectros de ${ }^{1} \mathrm{H}$.

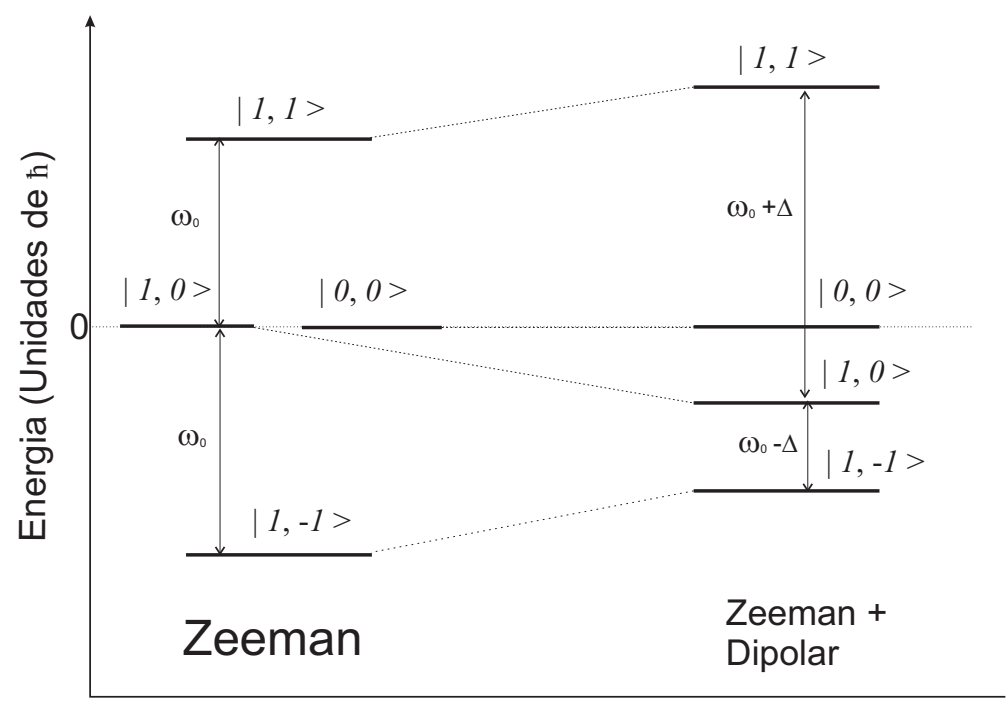

Figura 3.6-Efeito das interações Zeeman e Zeeman mais dipolar nos níveis de energia de um sistema de sois spins $1 / 2$. Os estados correspondentes aos níveis de energia estão representados pelos kets $|I, m\rangle$, onde $I$ e $m$ são os autovalores do operador soma dos momentos de spin. Fonte: Adaptada de OLIVEIRA JUNIOR.(20)

Para o caso de uma amostra não cristalina, onde existe a interação entre múltiplos spins, tem-se uma distribuição estatística de posições relativas entre cada spin e seus vizinhos. Esta distribuição resulta de diferentes valores de $\vec{r}$, e consequentemente diferentes valores para a constante de interação dipolar. Neste caso o espectro de RMN será a superposição de vários padrões de pó como o da figura 3.7.a, resultando em um espectro alargado como o ilustrado na figura 3.7.b.(71) Nos casos como o da figura 3.7.c, onde existem múltiplos spins acoplados, não é possível extrair do espectro os valores para as constantes de acoplamento dipolar envolvidas 


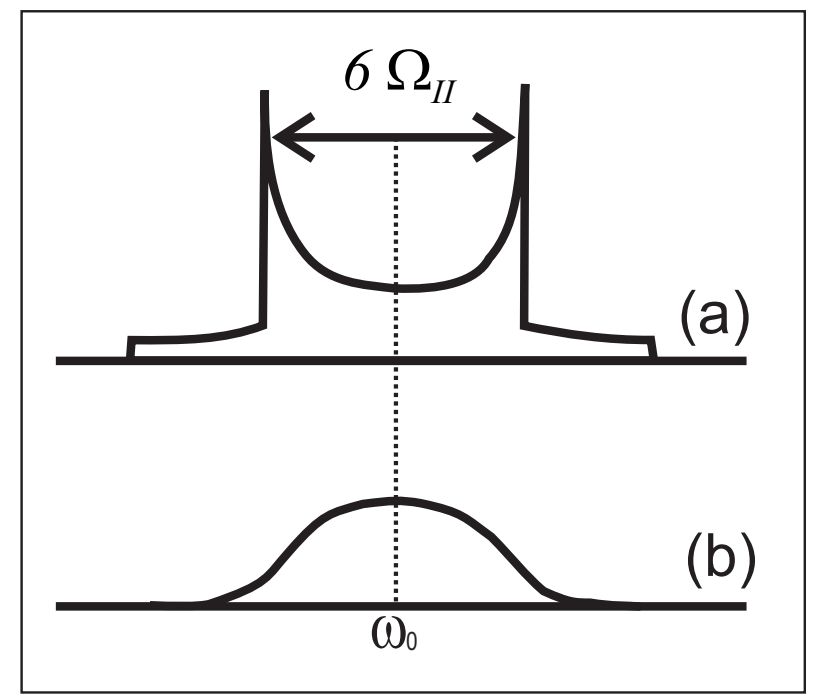

Figura 3.7-Padrão de pó para um sistema policristalino com vários pares de spin interagindo via interação dipolar homonuclear (a), e para um sistema de spins não cristalino, com múltiplos spins acoplados (b). Fonte: Elaborada pelo autor.

no problema, como acontece com o caso de sistemas monocristalinos. Para solucionar este problema, Van Vleck (75) desenvolveu uma teoria para analisar a distribuição de frequências, levando em conta a forma da linha espectral $f(\omega)$. Esta técnica é chamada de método dos momentos. O enésimo momento da função $f(\omega)$ é definido por (67, 68)

$$
M_{n}=\left\langle\Delta \omega^{n}\right\rangle=\frac{\int_{0}^{\infty}(\omega-\langle\omega\rangle)^{n} f(\omega) d \omega}{\int_{0}^{\infty} f(\omega) d \omega}
$$

Para $n=1$ na equação 3.1.47, $M_{1}$ é simplesmente a frequência central $\omega_{0}$, e não contem nenhuma informação acerca da interação dipolar. Para $n=2$ a equação 3.1.47 resulta no segundo momento da interação dipolar, $M_{2}$, e seu valor é da ordem do quadrado da largura espectral. Experimentalmente, para spins $1 / 2$ é verificado que para o acoplamento dipolar a contribuição dos momentos de ordens maiores é muito pequena comparada à contribuição do segundo momento, portanto apenas será considerado neste trabalho o segundo momento da interação dipolar.(68) Para duas espécies de spins interagentes I e S, o segundo momento da interação dipolar em um sistema de muitos spins interagindo, para uma amostra policristalina ou amorfa(67, 68)

$$
M_{2(I S)}=\frac{4}{15}\left(\frac{\mu_{0}}{4 \pi}\right)^{2} I(I+1) \gamma_{I}^{2} \gamma_{S}^{2} \hbar^{2} N^{-1} \sum_{i, j} \frac{1}{r_{i j}{ }^{6}}
$$

onde $r_{i j}$ é a distância entre pares de spins $I$ e $S$ e N é o número total de spins $I$. O segundo momento da equação 3.1 .48 pode ser determinado experimentalmente através de técnicas que 
serão descritas na seção 3.1.8.2. O conhecimento deste parâmetro é útil para a caracterização estrutural, pois o segundo momento carrega informações a respeito das distâncias médias internucleares, e do número de núcleos interagentes.

\subsubsection{Técnicas de RMN pulsada de alta resolução}

A técnica mais simples em RMN é a técnica de polarização direta (PD). Em sólidos, a técnica de PD usualmente é utilizada em conjunto com as técnicas de rotação da amostra em torno do ângulo mágico ("Magic Angle Spinning", MAS) e, no caso da RMN de núcleos de uma espécie $S$ próximos a hidrogênio, o desacoplamento dipolar heteronuclear de alta potência. Estas técnicas, que serão apresentadas nas próximas seções, são utilizadas com a finalidade de remover o alargamento espectral provocado por interações anisotrópicas, como as interações de desvio químico e dipolar. Por este motivo as técnicas que utilizam MAS e desacoplamento são chamadas de técnicas de alta resolução.

\subsubsection{Rotação em torno do ângulo mágico (MAS)}

As interações de spin nuclear descritas nas seções anteriores apresentam uma dependência com a orientação espacial da molécula com relação ao campo local $H_{0}$, ou seja, são anisotrópicas. Como consequência disso o espectro de RMN de amostras em pó é alargado. O objetivo principal da técnica de MAS é remover os efeitos da anisotropia de desvio químico, e reduzir os efeitos da interação dipolar, obtendo linhas espectrais mais estreitas. A técnica de MAS consiste em rodar a amostra em torno de um eixo orientado a um ângulo $\theta_{R}$ com relação ao campo aplicado $H_{0}$, conforme ilustra a figura 3.8. Nesta situação, o ângulo $\theta$ que define o SEP do tensor de blindagem varia com o tempo. De acordo com a equação 3.1 .40 , a anisotropia de interação de desvio químico tem uma dependência angular dada por $\left(3 \cos ^{2} \theta-1+\eta \cos (2 \phi) \sin ^{2} \theta\right)$. Calculando a média temporal sobre um período de rotação tem-se (72, 76):

$$
\left\langle 1-3 \cos ^{2} \theta(t)\right\rangle=\frac{1}{2}\left(1-3 \cos ^{2} \theta_{R}\right)\left(3 \cos ^{2} \gamma-1\right)
$$


onde $\theta_{R}$ é o ângulo que o eixo de rotação faz com o campo $H_{0}$, e $\gamma$ é o ângulo entre o eixo $z$ do SEP do tensor de blindagem e o eixo de rotação. O ângulo $\theta_{R}$ pode ser escolhido de forma a minimizar o desvio anisotrópico da equação 3.1.40, resultando em um estreitamento do espectro de RMN. Para $\theta=54,74^{\circ}$ o termo $\left(1-3 \cos ^{2} \theta_{R}\right)$ é nulo, e desta forma o desvio provocado pela interação de blindagem passa a ser o termo isotrópico $\delta_{i s o}$, idêntico para todos os núcleos, independente da orientação do tensor de blindagem com o campo magnético externo.

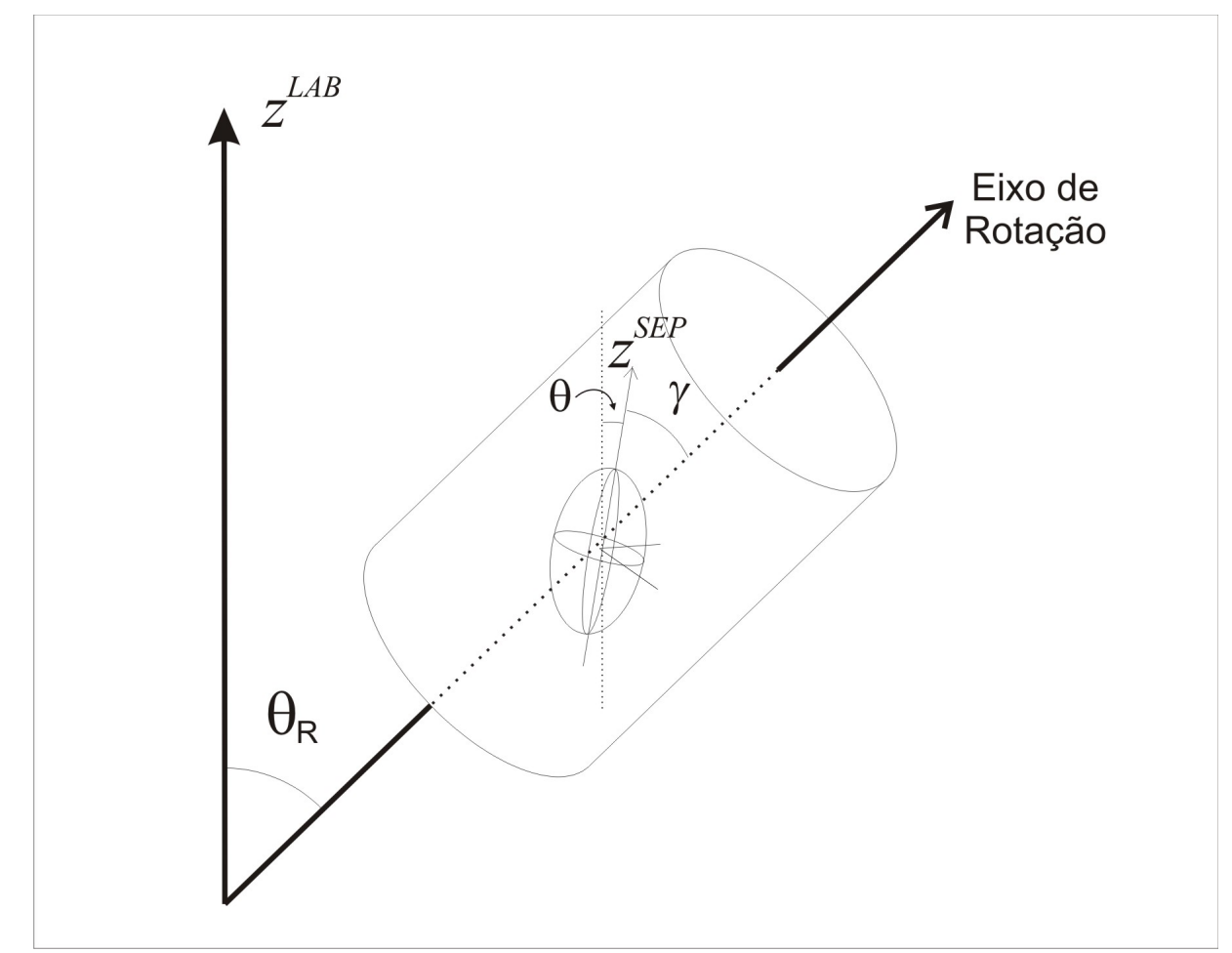

Figura 3.8-Esquema da condição de rotação do porta amostras em um experimento de MAS. O tensor de desvio químico é representado por um elipsoide, cujos eixos principais coincidem com os eixos do SEP. Fonte: OLIVEIRA JUNIOR (20)

A média da equação 3.1 .49 só é válida em regime de rotações rápidas, onde a frequência de rotação é maior do que a largura do espectro estático. Em casos onde isso não ocorre, há o surgimento de bandas laterais, separadas da linha central por frequências múltiplas da frequência de rotação.(77)

No caso de espectros de ${ }^{1} \mathrm{H}-\mathrm{RMN}$, em sistemas onde existe $\mathrm{o}$ acoplamento dipolar homonuclear entre os prótons, o splitting gerado pelo acoplamento é grande (da ordem de dezenas de $\mathrm{KHz}$ ) devido ao alto valor da constante giromagnética do ${ }^{1} \mathrm{H}\left(42.576 \mathrm{MHz}^{-T^{-1}}\right)$. Quando muitos prótons estão acoplados entre si, a técnica de MAS, com rotações da ordem de $\mathrm{KHz}$, não é suficiente para reduzir apreciavelmente o alargamento causado pelo acoplamento dipolar homonuclear sobre o espectro de ${ }^{1} \mathrm{H}-\mathrm{RMN}$.(77) 


\subsubsection{Desacoplamento por irradiação contínua de alta potência (CW)}

Esta técnica visa eliminar os efeitos da interação dipolar heteronuclear entre a espécie de observação e uma segunda espécie acoplada, obtendo-se assim espectros de alta resolução. Spins nucleares vizinhos podem se acoplar magneticamente com o núcleo observado por RMN, produzindo desdobramentos e alargamentos da linha de ressonância. O efeito é especialmente forte para o caso de núcleos de ${ }^{1} \mathrm{H}$ atuando como primeiros vizinhos (por exemplo em ligações $\mathrm{C}-\mathrm{H}$ ), pois estes núcleos possuem o maior momento de dipolo magnético de toda a tabela periódica. Nesses casos é preciso utilizar alguma técnica que atenue os efeitos da interação dipolar heteronuclear. Nos experimentos realizados neste trabalho, a técnica de desacoplamento utilizada foi a de irradiação contínua de alta potência (CW). Nesta técnica, irradia-se continuamente a amostra com um campo de rf oscilante, cuja frequência está próxima à frequência de ressonância dos núcleos ${ }^{1} \mathrm{H}$, enquanto o FID é adquirido na frequência da espécie de interesse $\mathrm{S}$. De acordo com Waugh (77), através desta técnica, a interação dipolar heteronuclear é reduzida por um fator

$$
n=\frac{\left(H_{0}-\frac{\omega_{H}}{\gamma_{H}}\right)}{\sqrt{\omega_{H}^{2}+\gamma H_{1}^{2}}}
$$

, onde $\omega_{H}$ é a frequência de oscilação do campo de desacoplamento, e $H_{1}$ é a sua intensidade.

\subsubsection{Polarização cruzada (CP)}

A técnica de polarização cruzada (CP) foi originalmente proposta para resolver a dificuldade de medida de espécies pouco abundantes, como ${ }^{13} \mathrm{C}$, através da excitação de uma espécie abundante e com constante giromagnética maior, como o caso dos núcleos ${ }^{1} \mathrm{H}$. Além do mais, a técnica permite analisar qualitativamente o acoplamento dipolar entre as espécies e auxiliar na identificação das ressonâncias observadas. Nesta técnica de ressonância dupla irradiam-se os núcleos de uma espécie I, por exemplo ${ }^{1} \mathrm{H}$, que potencialmente estão interagindo dipolarmente com vizinhos de outra espécie $S$, na tentativa de se induzir polarização na espécie $S$, e a consequente geração de um FID. O problema é que para haver transições acopladas entre os spins I e $S$, estes deveriam ter a mesma diferença de energia magnética, o que não ocorre para spins com fatores $\gamma$ diferentes. A solução para este problema começa pela observação de Hahn 
(67, 78), de que campos magnéticos externos oscilantes não têm efeito apreciável sobre um núcleo, a não ser que a frequência de oscilação esteja próxima da frequência de ressonância. Então, se forem aplicados simultaneamente dois campos oscilantes $H_{1 I}$ e $H_{1 S}$, em frequências $\omega_{I}$ e $\omega_{S}$ respectivamente, e se as frequências forem as frequências de ressonância das espécies I e $\mathrm{S}$, então o campo $H_{1 I}$ terá efeito desprezível sobre a espécie $\mathrm{S}$, e da mesma forma o campo $H_{1 S}$ terá efeito desprezível sobre a espécie I. Cada espécie pode então ser analisada em seu próprio SR. As magnetizações $M_{I}$ e $M_{S}$, em uma situação geral, precessionam em torno do respectivo campo de rf $\vec{H}_{1}$, com frequências dadas por

$$
\Omega_{I}=\gamma_{I} H_{1 I}, \quad \Omega_{S}=\gamma_{S} H_{1 S}
$$

Como os campos $H_{1}$ podem ser controlados livremente, eles podem ser escolhidos de forma a igualar a diferença entre os níveis de energia efetivos no SR de ambas as espécies. Nesta condição a separação entre os níveis de energia de ambas as espécies no SR fica

$$
\Delta E=\gamma_{I} H_{1 I}=\gamma_{S} H_{1 S}
$$

e diz-se que as espécies estão em contato. Esta condição é chamada condição de Hartmann-Hahn para os campos de rf.(78)

A sequencia de pulsos para o experimento de polarização cruzada é mostrada na figura 3.9.a. Inicialmente um pulso de $\pi / 2$ é aplicado sobre a espécie I, colocando a magnetização no plano transversal. Depois de desligado o pulso de $\pi / 2$, um campo oscilante $H_{1 I}$ na é aplicado na direção y' do SR, ficando na mesma direção da magnetização. Este pulso é chamado de pulso de spin-lock. Como este pulso é orientado na mesma direção da magnetização, os torques sobre esta são nulos no SR e a magnetização permanece com direção e sentido inalterados no SR. Simultaneamente com o pulso de spin-lock na espécie I, um outro campo oscilante na condição de Hartmann-Hahn é aplicado em ressonância com a espécie $S$, colocando as duas espécies em contato, de acordo com a equação 3.1.51. Depois do contato, é feita a aquisição do FID da espécie $S$, usando técnicas de desacoplando na espécie I durante o intervalo de aquisição. 


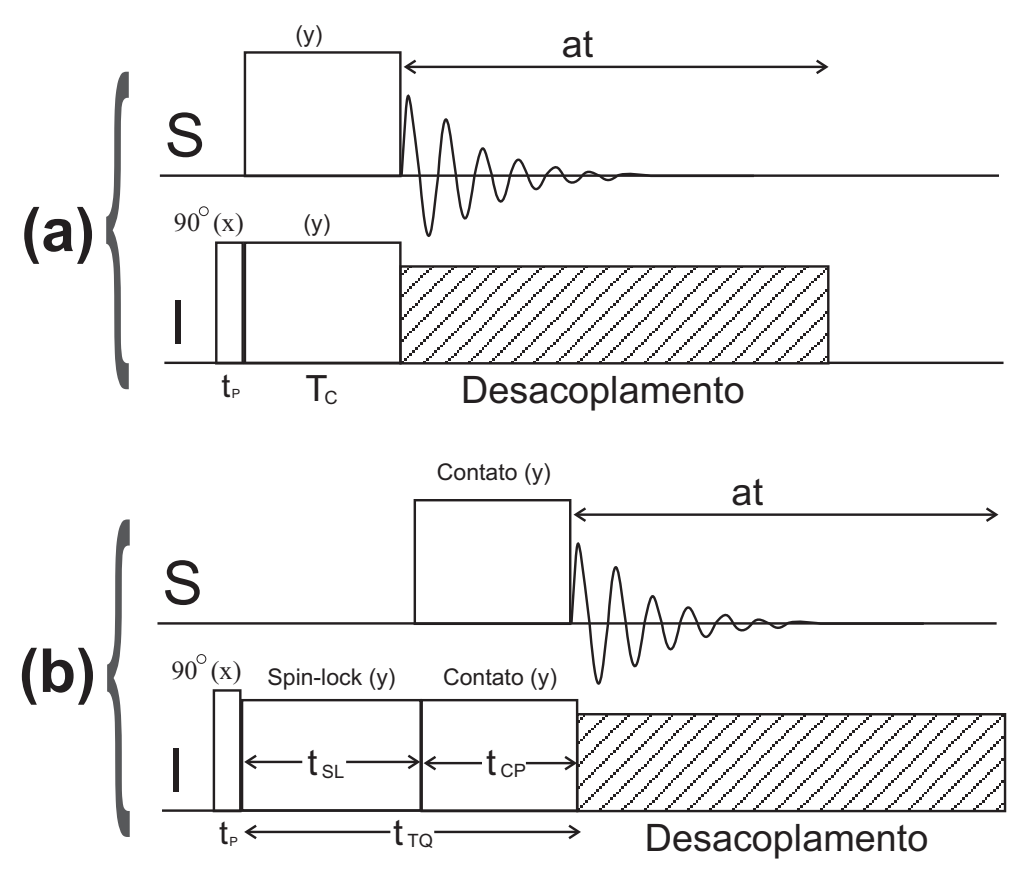

Figura 3.9-Sequencia de pulsos do experimento de RMN utilizando a técnica de polarização cruzada (a) e sequência de pulsos utilizada nos experimentos TORQUE e SLCP (b). Fonte: Elaborada pelo autor.

\subsubsection{Dinâmica de CP}

Durante o tempo de contato, dois processos contribuem para a evolução da magnetização da espécie observada, o primeiro processo é o crescimento da magnetização da espécie $S$, com tempo característico $\mathrm{T}_{I S}$. Este tempo é inversamente proporcional à intensidade do acoplamento dipolar médio, que por sua vez é proporcional ao inverso da distância internuclear $r_{I S}$, e ao número de núcleos $I$ acoplados a $S .(67,70)$ O segundo processo é o decaimento da intensidade da magnetização da espécie $I$, associado a um processo de relaxação spin-rede no sistema rotante, com tempo de relaxação característico $\mathrm{T}_{1 \rho} .(67,70)$

Uma das ferramentas utilizadas para se obter informações sobre o acoplamento dipolar heteronuclear é o experimento de CP com tempo de contato variável. Esta técnica consiste na realização de uma série de experimentos de $C P$, incrementando o tempo de contato. $A$ partir da curva da intensidade da magnetização da espécie $S$ em função da variação do tempo de contato é possível obter os parâmetros $T_{I S}$ e $T_{1 \rho}$. Para um sistema com muitos spins da espécie I fortemente acoplados, comparado com o acoplamento com a espécie $S$, de abundância menor, a resposta da magnetização da espécie $S$ em função do tempo de contato é dada pela 
equação $3.1 .52(70)$

$$
M(t)=\frac{M_{0}}{1-T_{I S} / T_{1 \rho}}\left(1-e^{-\frac{\left(1-\left(T_{I S} / T_{1 \rho}\right)\right) t}{T_{I S}}}\right) e^{-\frac{t}{T_{1 \rho}}}
$$

A Técnica de CP com tempo de contato variável é amplamente utilizada em RMN de sistemas orgânicos.(70) Entretanto, durante o pulso de spin-lock, o sistema de spins I perde magnetização devido à relaxação spin-rede no sistema rotante ao mesmo tempo em que magnetização é transferida para a espécie em contato $S$. A determinação exata dos tempos $\mathrm{T}_{I S}$ e $\mathrm{T}_{1 \rho}$ quando os dois tempos são da mesma ordem apresenta muita incerteza quando a equação 3.1 .53 é ajustada sobre os dados experimentais(70, 79). No HPW hidratado as distâncias entre ${ }^{1} \mathrm{H}$ e ${ }^{31} \mathrm{P}$, respectivamente I e $\mathrm{S}$, são longas (>6Å) (22--24), o que determina tempos de contato longos, eventualmente da ordem ou menores do que $\mathrm{T}_{1 \rho}$ de ${ }^{1} \mathrm{H}$. Por esta razão, as técnicas de $T_{1 \rho}$-quenching (TORQUE) e CP com pulso de spinlock (SLCP) $\left\{{ }^{1} \mathrm{H}_{-}{ }^{31} \mathrm{P}\right.$ foram utilizadas para obtenção dos tempos $\mathrm{T}_{I S}$ e $\mathrm{T}_{1 \rho}$, respectivamente.(79, 80)

A técnica de TORQUE permite observar a evolução da magnetização da espécie $S$ devido à transferência de polarização desde a espécie I, independentemente do efeito de relaxação spin-rede no SR para a espécie I. A sequência de pulsos para o experimento de TORQUE é mostrada na figura 3.9. b. Nesta sequência é aplicado um pulso de spin-lock na espécie I, com duração $t_{S L}$, antes do pulso de contato, com duração $t_{C P}$. A intensidade do sinal da espécie $\mathrm{S}$ é então obtida para sucessivos experimentos variando-se $\mathrm{t}_{S L}$ e $\mathrm{t}_{C P}$, de forma que o tempo total de spin-lock para a espécie $\mathrm{I}, \mathrm{t}_{T Q}=\mathrm{t}_{S L}+\mathrm{t}_{C P}$, seja mantido constante. Desta forma, a dependência do sinal com o tempo de relaxação $T_{1 \rho}$ da espécie I é eliminada, permitindo a determinação do tempo característico de contato $\mathrm{T}_{I S}$ com mais precisão, mesmo quando $\mathrm{T}_{1 \rho}<\mathrm{T}_{I S}$. (80) Os tempos $\mathrm{T}_{1 \rho}$ e $\mathrm{T}_{I S}$ podem ser obtidos à partir da análise da evolução da intensidade do sinal de CP em função da largura do pulso de contato $t_{C P}$. A expressão para a evolução da magnetização como função de $t_{C P}$ é dada por (79)

$$
M^{T O R Q U E}\left(t_{C P}\right)=M_{e q} \frac{\gamma_{H}}{\gamma_{P}} \frac{1}{\left(1-T_{I S} / T_{1 \rho}\right)}\left[e^{-\frac{t_{T Q}}{T_{1 \rho}}}-e^{-\frac{t_{T Q}-t}{T_{1 \rho} P}} e^{-\frac{t_{C P}}{T_{I S}}}\right]
$$

onde $M_{e q}$ é a magnetização no equilíbrio termodinâmico. A simples inspeção da curvatura do gráfico da função apresentada na equação 3.1.53, permite verificar se $\mathrm{T}_{I S}>\mathrm{T}_{1 \rho}$ ou não.(80) $\mathrm{A}$ figura 3.10 mostra a comparação entre os gráfico para as equações $3.1 .52 \mathrm{e} 3.1 .53$. Quando $\mathrm{T}_{I S}$ $>\mathrm{T}_{1 \rho}$ a concavidade da curva TORQUE é negativa, enquanto para $\mathrm{T}_{I S}<\mathrm{T}_{1 \rho}$ a concavidade é positiva.

Outra forma de se obter os valor para $\mathrm{T}_{1 \rho}$ é por meio da técnica de CP com pré-pulso de spin-lock (SLCP), para obtenção do tempo de relaxação $T_{1 \rho}$. A sequência de pulso para este 
experimento é a mesma utilizada no experimento de TORQUE (figura 3.9.b), mas neste caso a duração do pulso de contato $t_{C P}$ é mantida constante, enquanto se varia o tempo de spin-lock $\mathrm{t}_{S L}$. A magnetização então evolui com o tempo de acordo com a equação (80)

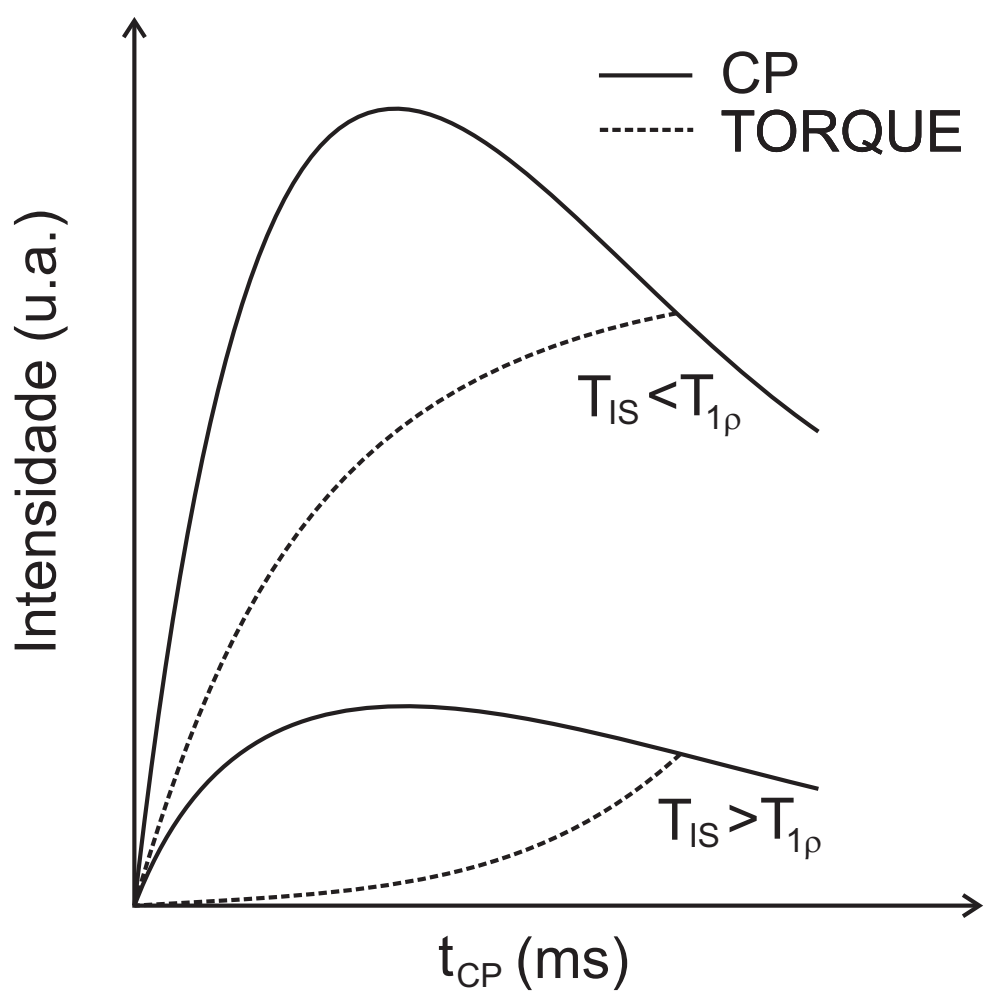

Figura 3.10-Dependência temporal da transferência de magnetização no experimento de CP convencional e no experimento de TORQUE. Fonte: Adaptada de KLUR (80)

$$
M(t)=M^{C P}\left(t_{C P}\right) e^{-\frac{t}{T_{1 \rho}}}
$$

onde $M^{C P}\left(t_{C P}\right)$ é a magnetização criada em um experimento convencional de $\mathrm{CP}$, com o tempo de contato $\mathrm{t}_{C P}$.

Os valores de $\mathrm{T}_{1 \rho}$ obtidos pela técnica de SLCP correspondem apenas aos spins I que estão acoplados com spins S. Desta forma é possível caracterizar seletivamente a dinâmica para os spins I no ambiente de coordenação de S. Para auxiliar na identificação das espécies ${ }^{1} \mathrm{H}$, o tempo $\mathrm{T}_{1 \rho}$ também pode ser medido diretamente, através de experimento de polarização direta em ${ }^{1} \mathrm{H}$, com pulso de spin-lock aplicado após o pulso de $\pi / 2$. Neste experimento não há seletividade dos ${ }^{1} \mathrm{H}$, e todos os spins I presentes na amostra contribuem para o sinal. A evolução da magnetização como função da duração $\tau$ do pulso de spin-lock é dada por (70)

$$
M(\tau)=M_{0}(t) e^{-\frac{\tau}{T_{1 \rho}}}
$$




\subsubsection{Correlação Heteronuclear (HETCOR)}

Neste experimento de dupla ressonância é utilizado o acoplamento dipolar heteronuclear para determinar a existência de correlações entre as diferentes ressonâncias de ambas as espécies, que revelem proximidade espacial.(34) A figura 3.11 mostra a sequencia de pulsos básica do experimento. Um pulso de $\pi / 2$ é aplicado sobre a espécie $I$, colocando a magnetização no plano transversal. Durante o intervalo $t_{1}$, o sistema $I$ evolui livremente, antes dos pulsos de contato, com largura $T_{C}$ fixa. Após o contato, a evolução da magnetização de $S$ é registrada durante o intervalo $t_{2}$, sob técnicas de MAS e desacoplamento heteronuclear.(77) $O$ tempo $t_{1}$ é variado em intervalos equiespaçados $\Delta t_{1}$, e para cada valor de tempo $t_{1}$ é obtido o FID na espécie $S$ durante um tempo $t_{2}$. A transformada de Fourier desse FID resulta em um espectro no espaço de frequências bidimensional. Os picos de correlação no espectro bidimensional entre as ressonâncias I e $\mathrm{S}$ indicam a existência de proximidade entre as espécies. As projeções do espectro bidimensional ao longo de $\omega_{I}$ (dimensão indireta) e $\omega_{S}$ (dimensão direta) fornecem os espectros das espécies I e S respectivamente.

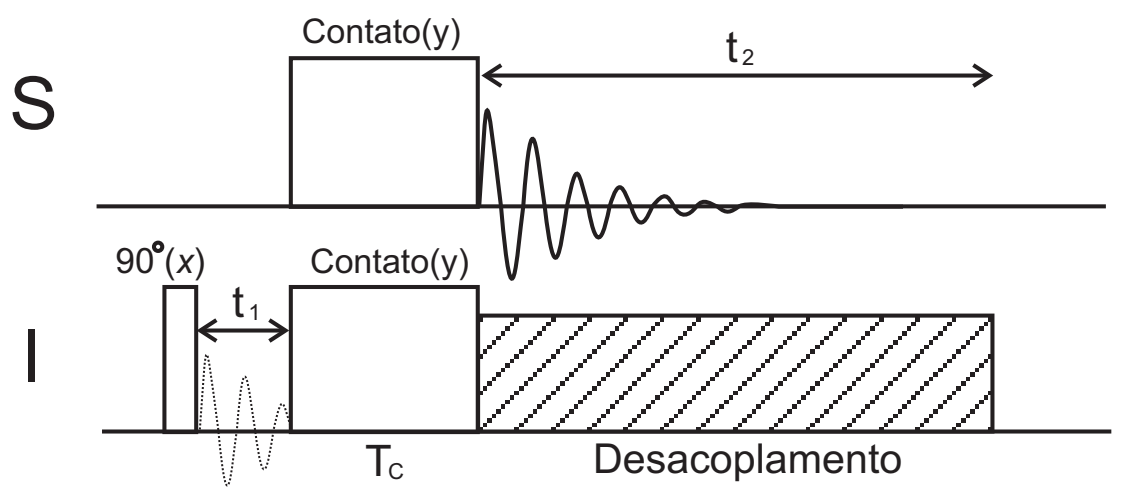

Figura 3.11-Sequencia de pulsos do experimento HETCOR. Fonte: Elaborada pelo autor.

Para obter espectros sensíveis à fase na escala indireta, o pulso de preparação de $\pi / 2$ em $I$ tem sua fase variada de $n_{i} \pi / 2$ a cada incremento $n_{i}$ da escala indireta, com $n_{i}=0,1,2, \ldots, N$, sendo $N$ o número total de pontos na dimensão indireta. Este procedimento é chamado de TPPI (do inglês Time Proporcional Phase Incrementation).(81-83) Na técnica de TPPI, os pontos são adquiridos com o dobro da taxa de digitalização, $\Delta t=\frac{1}{\left(2 \omega_{S W}\right)}$, onde $\omega_{S W}$ é a largura da janela espectral, e a fase do pulso de preparação é incrementada de $\pi / 2$ rad a cada ponto do FID. Este incremento na fase faz com que todas as frequências de modulação do FID apareçam deslocadas da metade da janela espectral. Assim, picos que apresentam frequência entre $-\frac{\omega_{S W}}{2}$ e 0 aparecem entre 0 e $+\frac{\omega_{S W}}{2}$, e picos que apresentam frequência entre 0 e $\frac{\omega_{S W}}{2}$ aparecem entre $\frac{\omega_{S W}}{2}$ e $\omega_{S W}$. Então, para picos no intervalo $\pm \frac{\omega_{S W}}{2}$ o aliasing em torno da 
frequência 0 é evitado, simulando a detecção em quadratura.(81-83)

\subsubsection{Técnicas de RMN pulsada de baixa resolução}

\subsubsection{Spin-eco de Hahn}

A técnica de spin-eco de Hahn (84) permite compensar o efeito causado pela inomogeneidade de certas interações nucleares, tais como a interação de desvio químico e o acoplamento dipolar heteronuclear, sobre a evolução da magnetização transversal.(67, 84) A sequência de pulsos para de spin-eco é composta de pulsos $\pi / 2$ e $\pi$, separados por um tempo $\tau$. A figura 3.12 mostra o diagrama vetorial da magnetização no SR. Inicialmente o pulso de $\pi / 2$ coloca a magnetização no plano transversal (figura 3.12.a). Após este pulso o sistema de spins evolui livremente durante o intervalo $\tau$. Devido aos diferentes valores nos campos locais na posição de cada conjunto de spins, existem pequenas variações na frequência de precessão, o que ocasiona uma defasagem dos spins no SR. Seja $\delta \vec{M}_{i}$ a contribuição à magnetização total associada ao conjunto de spins experimentado o mesmo campo local $\vec{H}_{i}$. O vetor $\delta \vec{M}_{i}$ precessiona no plano $\{x, y\}$ com a frequência $\omega_{i}=\omega_{0}+\delta \omega$ comum a todos os spins deste conjunto (ver figura 3.12.b) sendo $\omega_{0}$ a frequência de Larmor. Decorrido o tempo $\tau$, o ângulo de fase $\theta$ da componente $\delta \vec{M}_{i}$ com relação ao eixo $x$ do SR será:

$$
\theta(\tau)=\tau \delta \omega=\tau \gamma \delta H
$$

onde $\delta H=H_{i}-H_{0}$. Neste instante o pulso de $\pi$ é aplicado, invertendo a componente $y$ dos vetores $\delta M_{i}$ (figura 3.12.c). A diferença de frequência $\delta \omega$ não foi alterada, então $\delta \vec{M}_{i}$ continua precessionando no mesmo sentido, atingindo a direção $-y$ no instante $t=2 \tau$ (figura 3.12,d). Como o mesmo argumento pode ser aplicado a outros conjuntos de spins $\delta M_{i}$, independentemente do valor particular de $\omega_{i}$, no instante $t=2 \tau$ todos estes vetores magnetização estarão orientados ao longo da direção negativa do eixo y. Portanto, nesse instante a magnetização é completamente refocalizada, e tem o mesmo módulo inicial. Este é o sinal de spin-eco. A sequência de spin-eco de Hahn compensa, no instante $2 \tau$, o efeito de evolução dos spins associado a interações dependentes linearmente na componente $I_{z}$ do spin: interação de desvio químico, interação dipolar heteronuclear e inomogeneidade do campo 
magnético externo $H_{0} \cdot(67,84)$

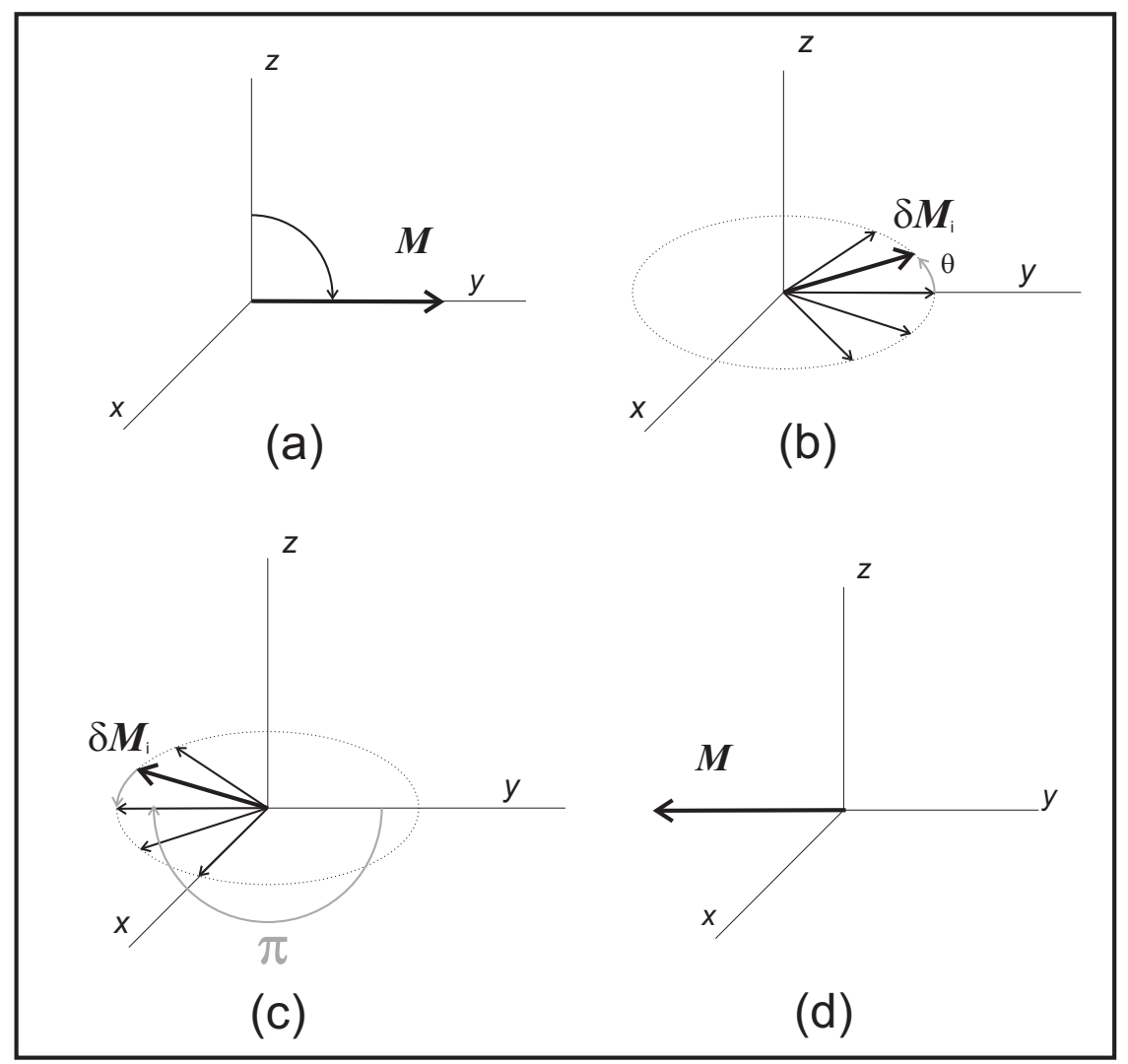

Figura 3.12-Processo de evolução da magnetização em um experimento de RMN utilizando técnica de spin-eco. (a) Magnetização após aplicação de pulso de $\pi / 2$.(b) Evolução do elemento de magnetização $\delta M_{i}$ num intervalo de tempo $\tau$. (c) Estado da magnetização imediatamente após aplicação de um pulso de $\pi$ no instante $\tau$. (d) Refocalização no instante $2 \tau$. Fonte: OLIVEIRA JUNIOR (20)

Se houver uma flutuação no valor do campo local associado a uma destas interações de spin, de maneira que a frequência de precessão de $\delta M_{i}$ seja diferente durante os períodos $\tau$ da sequência, a refocalização no instante $2 \tau$ não será completa. $O$ efeito dos diferentes campos locais originados em spins vizinhos da mesma espécie também não é compensado por esta sequência, pois o pulso de $\pi$ inverte todos os spins da mesma espécie, não havendo assim variação relativa entre a orientação do spin e o campo produzido pelo vizinho. Por estes motivos, o sinal de eco de spin apresenta uma diminuição irreversível de intensidade em função de $2 \tau$.(68, 84) Em líquidos a contribuição ao decaimento associada à dinâmica das flutuações das interações locais é frequentemente de tipo exponencial, e a constante de decaimento é o tempo de relaxação spin-spin T2.(67) Em sólidos esse decaimento é governado pelo segundo momento da interação homonuclear.(67, 68) 


\subsubsection{Ressonância dupla de eco de spin (SEDOR)}

A técnica de SEDOR permite medir o segundo momento da interação heteronuclear entre duas espécies I e S $\mathrm{M}_{2(I S)}$ (ver seção 3.1.6.2), possibilitando a realização de análises quantitativas do acoplamento heteronuclear.(67, 68) A figura 3.13. a mostra a sequência de pulsos para o experimento de SEDOR, conforme reportado por Ueda et al.(35) Dois pulsos, o primeiro de $\pi / 2$ e o segundo de $\pi$, com espaçamento $\tau_{1}$ entre ambos, são aplicados sobre a espécie $S$, criando um eco de Hahn no tempo $2 \tau_{1}$.(84) Durante a evolução inicial do sistema de spins $S$ (período $\tau_{1}$ ), um pulso $\pi$ é aplicado sobre o sistema de spins I em um instante $\tau$ durante o período de evolução. A inversão do estado de I inverte o campo magnético na posição do spin S. Desta forma, a contribuição à frequência de precessão do spin $\mathrm{S}$ devida ao campo de I será invertida, impedindo a refocalização completa da magnetização de I em $\mathrm{t}=$ $2 \tau_{1}$. Consequentemente a amplitude do eco $S(\tau)$ será atenuada, comparada com o valor obtido com a sequencia de eco de Hahn convencional So $(\tau)$. Esta atenuação depende inversamente da intensidade do acoplamento dipolar entre as duas espécies e do tempo $\tau$ entre os pulsos de $\pi / 2$ e $\pi$.(67, 84, 85) Variando-se o tempo $\tau$ entre os pulsos o sinal apresenta um decaimento $\mathrm{S}(\tau)$, devido às contribuições somadas das interações homonuclear e heteronuclear. O tempo $\tau$ é variado, e o sinal $\mathrm{S}(\tau)$ é comparado com o sinal obtido através da técnica de spin-eco de Hahn $\mathrm{S}_{0}\left(\tau_{1}\right)$. A razão $\mathrm{S}(\tau) / \mathrm{S} 0\left(\tau_{1}\right)$ é governada apenas pela interação dipolar heteronuclear, e é dada por $(85)$

$$
\frac{S(\tau)}{S_{0}\left(\tau_{1}\right)}=e^{-\frac{1}{2} M_{2(I S)}(2 \tau)^{2}}
$$

onde $M_{2(I S)}$ é o segundo momento da interação dipolar entre os spins I e S. Como mostrado na seção 3.1.6.2 o valor de $M_{2(I S)}$ pode ser obtido à partir de primeiros princípios, utilizando-se a equação 3.1 .48 (68, 75), fornecendo valiosa informação para a caracterização do acoplamento entre as espécies estudadas.

Na sequencia de $\left\{{ }^{1} \mathrm{H}\right\}-{ }^{31} \mathrm{P}$ SEDOR utilizada neste trabalho (3.13.b) a magnetização da espécie $S$ é criada através de um ciclo de CP desde ${ }^{1} \mathrm{H}$, ao invés do pulso $\pi / 2$ de preparação. A vantagem desta modificação é que o tempo de repetição fica determinado pelo tempo de relaxação spin rede $\mathrm{T}_{1}$ do ${ }^{1} \mathrm{H}$, da ordem de segundos, em lugar do $\mathrm{T}_{1}$ de ${ }^{31} \mathrm{P}$, da ordem de centenas de segundos. 
(a)

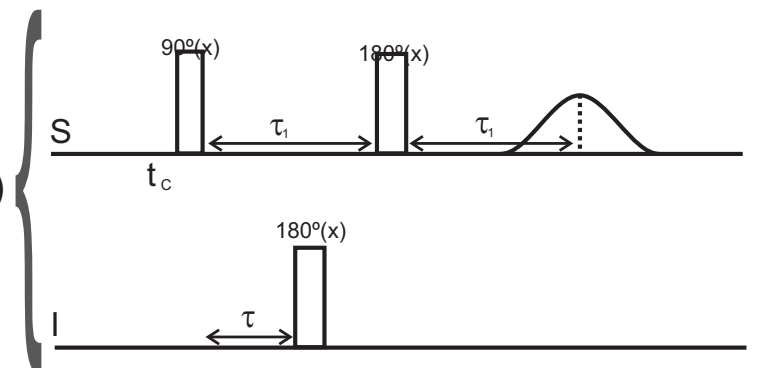

(b)

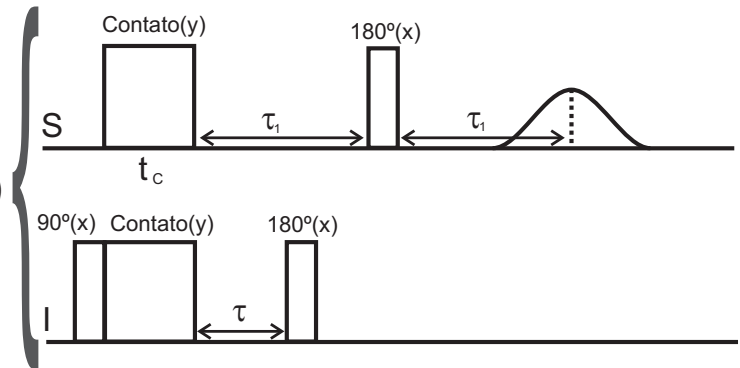

Figura 3.13-Sequência de pulsos convencional para o experimento de SEDOR (a), e sequência modificada, com um ciclo de CP substituindo o pulso de preparação (b). Fonte: Elaborada pelo autor.

\subsubsection{Aspectos básicos de um espectrômetro de ressonância magnética nuclear}

Como a frequência de Larmor reside na faixa de rf para os campos magnéticos típicos utilizados em laboratório, toda a eletrônica de RMN é construída para esta faixa de frequências. O gerador de sinal corresponde a um transmissor de rádio, e o sinal obtido da amostra é captado e amplificado por pré-amplificadores, amplificadores e detectores, similares aos de rádio receptores.(86) Nesta seção o funcionamento do espectrômetro será explicado de forma sucinta.

Na figura 3.14 é apresentado o diagrama de blocos para um espectrômetro de ressonância dupla em estado sólido. O sintetizador gera dois sinais, sendo um de alta frequência (desacoplamento) e outro de baixa frequência (observação). No transmissor 1 (desacoplamento) o sinal de alta frequência é modulado na forma de pulsos, de acordo com a sequência a ser utilizada no experimento, e amplificado por um amplificador de potência. Em seguida o sinal de alta frequência passa por um conjunto de diodos cruzados, que elimina ruídos de baixa tensão, seguindo para a sonda de RMN. O sinal de rf de baixa frequência gerado pelo sintetizador segue para um divisor de potência (PS/ $\mathrm{C}^{\circ}-0^{\circ}$ ) que divide o sinal em dois sinais em fase e sem ganho de potência. Parte do sinal será utilizada mais adiante na fase de detecção. A outra parte do sinal de baixa frequência é recebida no transmissor 2 (observação), que modula o 
sinal em forma de pulsos. O sinal é então enviado a um segundo amplificador de potência, sendo enviado em seguida para o filtro de diodos cruzados, para eliminação de ruídos de baixa tensão, e segue para um duplexador - o duplexador é responsável por isolar e separar o sinal de recepção e o sinal de transmissão - em seguida o sinal segue do duplexador para a sonda de RMN.

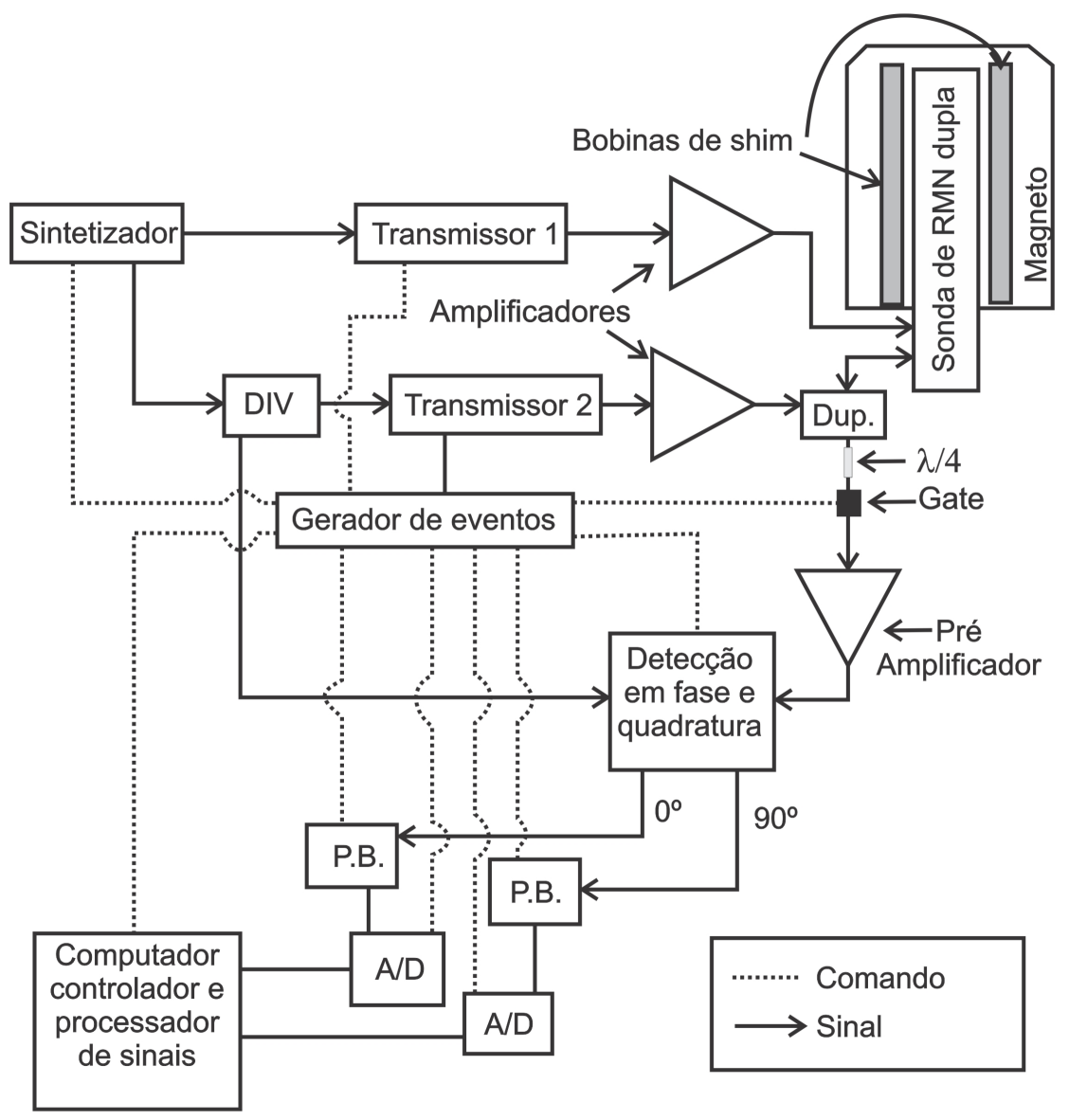

Figura 3.14-Diagrama de blocos que ilustra de forma simplificada o funcionamento do espectrômetro de RMN de dupla ressonância. Fonte: Elaborada pelo autor.

A sonda por sua vez está inserida dentro de um magneto, no caso um sistema supercondutor Oxford. O campo magnético gerado pelo ímã não tem a homogeneidade requerida para experimentos de espectroscopia de alta resolução, e deve ser corrigido por bobinas de shim, por onde circulam correntes que geram pequenas correções ao campo magnético, no caso shiming resistivo externo de 18 canais e bobinas de shiming supercondutor. A sonda, que será detalhada mais adiante, transfere a potência para a amostra. O FID induzido na bobina, da ordem de $\mu \mathrm{V}$, segue para o duplexador, que o encaminha para o pré-amplificador, onde o sinal passa a ser da ordem de V. Antes de chegar ao pré-amplificador, o sinal passa por um cabo com 1/4 do comprimento da onda de rf recebida (cabo de $\lambda / 4$ ), por um filtro de diodos cruzados e por uma chave (gate), que só é aberta no momento da detecção. A finalidade do cabo de $\lambda / 4 \mathrm{e}$ do filtro de diodos cruzados é a proteção do pré-amplificador contra possíveis ruídos residuais 
gerados pelo amplificador de potência e/ou pelo ringing do circuito RLC da sonda. Depois de passar pelo pré-amplificador o sinal é então encaminhado ao sistema de detecção em fase e quadratura, que compara o sinal com um sinal de referência, e o separa em dois sinais defasados de $90^{\circ}$ entre si, simulando as partes real e imaginária do sinal. Posteriormente os sinais são conduzidos até filtros passa baixa (P.B.), que permitirão somente a passagem de sinais da ordem de $\mathrm{KHz}$, que são os sinais resultantes da demodulação da freqüência de irradiação e que contém a informação relevante do sinal da amostra. Estes sinais são conduzidos para conversores analógicos digitais (A/D) e finalmente para um computador onde são processados. Conforme mostrado na figura 3.14 todos os processos são controlados pelo gerador de eventos, que por sua vez é controlado por um computador com interface para o usuário.

A sonda de RMN consiste basicamente de um circuito ressonante do tipo RLC. A excitação da amostra é realizada através de uma bobina solenoidal que envolve o porta amostras. Esta bobina é montada dentro de um estator que permite a rotação da amostra, assim como o ajuste de sua orientação com relação ao campo $H_{0}$. Esta bobina está disposta formando um ângulo de $54,74^{\circ}$ com o campo magnético externo no caso de experimentos de alta resolução, e $90^{\circ}$ no caso de experimentos de baixa resolução. O controle de temperatura da amostra é realizado por meio de fluxos de ar ou $\mathrm{N}_{2}$ seco. Para experimentos acima de temperatura ambiente $o$ ar é aquecido por uma resistência antes de chegar à amostra. Para experimentos de baixa temperatura, o ar é resfriado através da passagem em tubo de cobre mergulhado em nitrogênio líquido e subsequentemente aquecido até a temperatura desejada através da resistência.

\subsection{Ressonância paramagnética do elétron (RPE)}

O elétron é uma partícula elementar, que possui momento angular de spin, com $S=1 / 2$. Assim como mostrado na seção 3.1.1, ao momento de spin está associado um momento magnético $\mu_{e}$. Usualmente, em RPE a relação entre o momento magnético e o momento de spin é escrita como

$$
\hat{\vec{\mu}}_{e}=g \mu_{B} \hat{\vec{S}}
$$

onde a constante $g$ é chamada fator $g$, e $\mu_{B}$ é a unidade atômica do momento magnético, e é chamada de magneton de Bohr. $\mathrm{O}$ valor de $\mu_{B}$ é $-\frac{|e| h}{4 \pi m_{e}}$, sendo $e$ e $\mu_{e}$ a carga e a massa do elétron respectivamente. Para o elétron livre, $g=2.002319$. Assim, quando submetido a um 
campo magnético $\vec{H}_{0}=H_{0} \vec{z}$, a Hamiltoniana Zeeman do elétron fica dada por

$$
\hat{H}=-\hat{\vec{\mu}}_{e} \cdot \vec{H}_{0}=g\left|\mu_{B}\right| S \cdot H_{0}=g\left|\mu_{B}\right| H_{0} \hat{S}_{z}
$$

Os níveis de energia possíveis para o spin eletrônico são então

$$
E_{ \pm}= \pm \frac{1}{2} g\left|\mu_{B}\right| H_{0}
$$

Para que haja transição entre os níveis de energia, é necessária aplicação irradiação com ondas eletromagnéticas satisfazendo a condição de ressonância

$$
h \nu=E_{+}-E_{-}=g|\mu| H_{0},
$$

onde $\nu$ é a frequência de irradiação e, para campos típicos utilizados em RPE, reside na faixa de micro-ondas.

A equação 3.2.4 sugere duas possibilidades para a realização de um experimento de RPE em modo de onda contínua (CW). A primeira consiste em fixar $H_{0}$ e irradiar a amostra variando continuamente a frequência $\nu$ e mantendo a intensidade da radiação fixa. Quando a frequência $\nu$ atinge a condição de ressonância, a micro-onda é absorvida e a absorção é detectada por um detector de micro-ondas. Alternativamente, pode-se manter fixa a frequência $\nu$ da radiação, e variar continuamente a intensidade do campo magnético $H_{0}$. O segundo procedimento é o mais utilizado em RPE.(87)

Até aqui as equações apresentadas são válidas para o caso de elétrons livres. Considerando um elétron desemparelhado, ligado a um átomo, o momento angular do elétron terá duas contribuições. A primeira contribuição vem do spin eletrônico, e a outra vem do movimento orbital do elétron ao redor no núcleo. Assim, o momento magnético eletrônico ficará dado por:

$$
\hat{\vec{\mu}}=\mu_{B} \hat{\vec{L}}+g \mu_{B} \hat{\vec{S}}
$$

onde $\vec{L}$ é o momento orbital angular, e $|\vec{L}|=\sqrt{l(l+1)}$, onde I é um inteiro que depende da distribuição espacial da função de onda do elétron. A componente de $\vec{L}$ ao longo do eixo $z$ pode assumir apenas valores $l_{z}=-l,-l+1, \cdots, l-1, l$.

A equação 3.2 .5 ainda não está completa, uma vez que não considera a existência de interação entre o momento de spin e o momento angular orbital, chamado de acoplamento spin-órbita. A existência de acoplamento spin-órbita resulta em um deslocamento $\Delta g$ com relação ao valor de $g$ para um elétron livre. Como o valor de $\Delta g$ depende do acoplamento spin-órbita, o desvio nos valores de $g$ é um parâmetro que caracteriza o sistema molecular onde o sítio paramagnético está inserido. 
Em sólidos, a forma do espectro de RPE depende da orientação relativa dos sítios paramagnéticos com relação ao campo magnético aplicado. Por simplicidade, três casos limites serão considerados, simetria cúbica, axial e ortorrômbica. No primeiro caso, devido à simetria do sítio paramagnético, o valo de $g$ é independente da orientação da amostra. O caso axial apresenta simetria rotacional em torno de um eixo $z$. Neste caso, o espectro de RPE será anisotrópico, pois o valor de g será diferente para o caso em que $\vec{H}_{0} / / \vec{z}$ e $\vec{H}_{0} \perp \vec{z}$. Em outras palavras, diferentes valores de $g$ serão observados para as diferentes orientações do fragmento molecular com relação ao campo magnético, $g_{/ /}$e $g_{\perp}$. No terceiro caso ocorre anisotropia nas três direções, resultando em três valores distintos de $g, g_{x}, g_{y}$ e $g_{z}$. Assim, a Hamiltoniana do sistema passa a ser representada da seguinte forma (87),

$$
\hat{H}=\mu_{B} \cdot \hat{\vec{S}} \cdot \stackrel{\leftrightarrow}{g} \cdot \vec{H}_{0}
$$

onde $\stackrel{\leftrightarrow}{g}$ é um tensor, com valores principais $g_{1}, g_{2}$ e $g_{3}$. Definindo os ângulos do SEP do tensor $\overleftrightarrow{g}$ de acordo com a figura 3.4 , o campo magnético pode ser escrito como:

$$
\vec{H}_{0}^{S E P}=\left(\begin{array}{c}
H_{0 x} \\
H_{0 y} \\
H_{0 z}
\end{array}\right)_{S E P}=\left(\begin{array}{c}
H_{0} \operatorname{sen} \theta \cos \varphi \\
H_{0} \operatorname{sen} \theta \operatorname{sen} \varphi \\
H_{0} \cos \theta
\end{array}\right) .
$$

Usando a equação 3.2.7, a Hamiltoniana da equação 3.2.6 escrita no SEP fica dada por (87)

$$
\hat{H}=\mu_{B}\left(\begin{array}{c}
S_{x} \\
S_{y} \\
S_{z}
\end{array}\right) \bullet\left(\begin{array}{ccc}
g_{1} & 0 & 0 \\
0 & g_{2} & 0 \\
0 & 0 & g_{3}
\end{array}\right) \bullet\left(\begin{array}{c}
H_{0 x} \\
H_{0 y} \\
H_{0 z}
\end{array}\right)_{S E P}
$$

e

$$
\hat{H}=\mu_{B}\left(g_{1} H_{0} \hat{S}_{x} \operatorname{sen} \theta \cos \varphi+g_{2} \mathrm{H}_{0} \hat{\mathrm{S}}_{\mathrm{y}} \operatorname{sen} \theta \operatorname{sen} \varphi+\mathrm{g}_{3} \mathrm{H}_{0} \hat{\mathrm{S}}_{\mathrm{z}} \cos \theta\right)
$$

Finalmente, resolvendo a equação de autovalores para a Hamiltoniana 3.2.9, a condição de ressonância da equação 3.2 .4 fica escrita na forma (87):

$$
h \nu=E_{+}-E_{-}=g(\theta, \varphi)|\mu| B_{0},
$$

onde

$$
g(\theta, \varphi)=\sqrt{g_{1}^{2} \operatorname{sen}^{2} \theta \cos ^{2} \varphi+g_{2}^{2} \operatorname{sen}^{2} \theta \operatorname{sen}^{2} \varphi+g_{3}^{2} \cos ^{2} \theta} .
$$

A equação 3.2.11 representa o valor esperado de $g$ para um centro paramagnético em uma orientação arbitrária com relação ao campo magnético. 


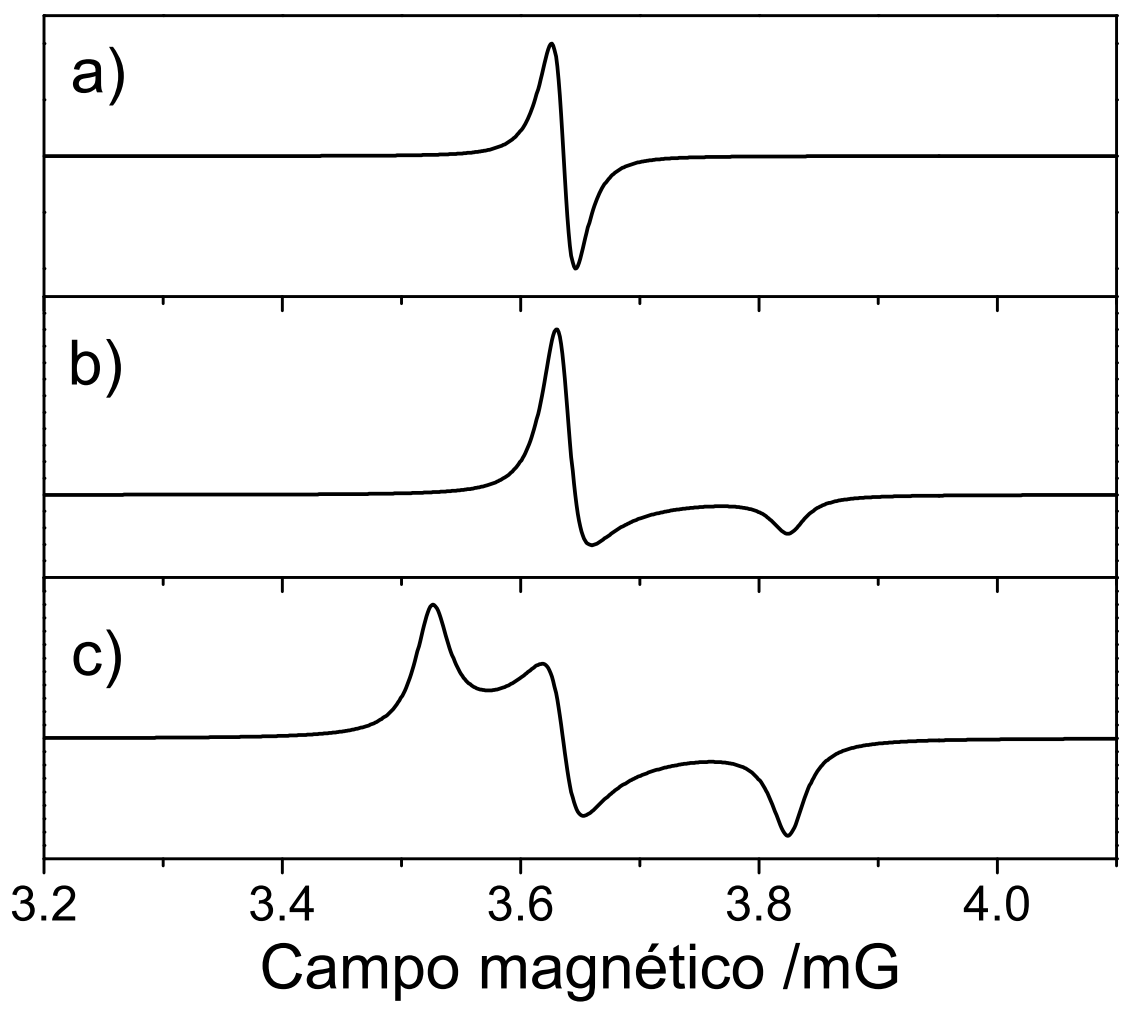

Figura 3.15-Espectros simulados RPE de uma amostra na forma de pó, para um sistema de spin $S=1 / 2$ com simetria cúbica (a), axial (b) e ortorrômbica (c). Fonte: Elaborada pelo autor.

Em um material amorfo, ou policristalino, todas as orientações dos fragmentos moleculares com relação ao campo magnético são possíveis, e o espectro de RPE apresenta um padrão de pó, como os mostrados na figura 3.15 . 
Capítulo 4

\section{Parâmetros experimentais}

Os experimentos de RMN foram realizados utilizando-se um espectrômetro Varian Unity INOVA com magneto supercondutor Oxford operando com campo magnético de $8,2 T$. Os experimentos de rotação em torno do ângulo mágico (MAS) foram realizados em rotores de nitreto de silício com $7 \mathrm{~mm}$ de diâmetro. Os espectros de ${ }^{31} \mathrm{P}$ foram obtidos via experimentos de polarização direta, com pulso de $\pi / 2$ em 3,5 $\mu$ s, frequência MAS em $6 \mathrm{KHz}$ e $5 \mathrm{KHz}$ e tempo de espera de 700 s entre aquisições. Para os espectros de ${ }^{29} \mathrm{Si}$ foi utilizado pulso de $\pi / 2$ entre 4 e $4,5 \mu s$, MAS em $5 \mathrm{KHz}$ e tempo de espera entre aquisições de 700 s. Os espectros de ${ }^{1} \mathrm{H}$ foram obtidos utilizando a sequência Depth proposta por Cory et al. para supressão do sinal de fundo (88), com pulso de $\pi / 2$ em $4 \mu \mathrm{s}$, tempo entre aquisições de $5 \mathrm{~s}$, e MAS em $6 \mathrm{KHz}$ para amostras de xerogeis e $5 \mathrm{KHz}$ para amostras de HPW hidratado. Os espectros de ${ }^{13} \mathrm{C}$ foram obtidos com técnica de polarização cruzada $\left\{{ }^{1} \mathrm{H}\right\}-{ }^{31} \mathrm{P}$ e desacoplamento heteronuclear $\mathrm{CW}$ em ${ }^{1} \mathrm{H}$, pulso de $\pi / 2$ em 3,5 $\mathrm{s}$, tempo de espera entre aquisições de $5 \mathrm{~s}$, tempo de contato de 1 ms e MAS em $5 \mathrm{KHz}$. O número típico de médias para obtenção dos espectros foram 4 para ${ }^{31} \mathrm{P}, 32$ para ${ }^{1} \mathrm{H}$, entre 100 a 200 para ${ }^{29} \mathrm{Si}$, e entre 2000 e 4000 para ${ }^{13} \mathrm{C}$.

Os experimentos de CP, TORQUE e SLCP $\left\{{ }^{1} \mathrm{H}\right\}-{ }^{31} \mathrm{P}$ foram realizados com pulso de $\pi / 2$ em $4 \mu s$, frequência de nutação $\gamma H_{1}=55 \mathrm{KHz}$ para os pulsos de spin-lock, tempo de espera entre aquisições de $5 \mathrm{~s}$ e MAS em $6 \mathrm{KHz}$ para os xerogeis e $5 \mathrm{KHz}$ para as amostras de $\mathrm{HPW} \cdot \mathrm{nH}_{2} \mathrm{O}$. Para os experimentos de SEDOR $\left\{{ }^{1} \mathrm{H}\right\}-{ }^{31} \mathrm{P}$ foi utilizado pulso de $\pi / 2$ de ${ }^{1} \mathrm{H}$ ajustados no experimento de $\mathrm{CP}$, pulsos de $\pi$ para o ${ }^{1} \mathrm{H}$ com o dobro da largura utilizada no pulso de $\pi / 2$, pulsos de $\pi$ para o ${ }^{31} \mathrm{P}$ entre $8 \mu$ s e $9 \mu$ s e intervalo entre os pulsos de $\pi$ e $\pi / 2$ variando entre 10 e $400 \mu s$.

Para os experimentos de HETCOR foram utilizados os parâmetros otimizados em CP para os diferentes núcleos. Foram medidos de 100 a 180 FID's para definir a variação temporal na dimensão indireta. Para aumento da resolução digital dos espectros foi usado preenchimento com FID's de intensidade nula para completar 1024 pontos na dimensão indireta.

Para os experimentos de ${ }^{31} \mathrm{P}$ e ${ }^{1} \mathrm{H}$ MAS RMN com variação de temperatura, a taxa de variação da temperatura foi de $2^{\circ} \mathrm{C} /$ min e a amostra foi mantida em cada temperatura durante 130 minutes para estabilização e realização das medidas. 
Os desvios químicos apresentados neste trabalho são calculados com base nas seguintes referências:

- ${ }^{31} \mathrm{P}$ : solução de ácido fosfórico $\left(\mathrm{H}_{3} \mathrm{PO}_{4} 85 \%\right)$ com desvio de fósforo em 0 ppm.

- ${ }^{29} \mathrm{Si}$ : amostra sólida de caulinita, usada como referência secundária, com desvio em -91,5ppm com relação ao tetrametilsilano (TMS).

- ${ }^{13} \mathrm{C}$ : amostra de adamantano $\left(\mathrm{C}_{10} \mathrm{H}_{16}\right)$. O espectro apresenta duas linhas, e a linha considerada como referência secundária é a de maior desvio $(\mathrm{CH})$, em 38,6ppm com relação ao TMS.

- ${ }^{1} \mathrm{H}$ : considerada como referência secundária a linha correspondente aos grupos $\mathrm{CH}_{3}$ do etanol $\left(\mathrm{CH}_{3} \mathrm{CH}_{2} \mathrm{OH}\right)$, com desvio em 1,1ppm com relação ao TMS.

A irradiação das amostras para os experimentos de UV-vis e RPE foi realizada com um sistema simulador da luz solar baseado em uma lâmpada de arco de Xe de $150 \mathrm{~W}$, diâmetro de feixe de 50mm, faixa de comprimento de onda de emissão entre 290-400nm, irradiância máxima de 750 W.m ${ }^{-2}$ (modelo 16S-150W, fabricado pela SolarLight Company, Inc., Filadélfia, EUA) equipado com sistema automático de controle de dose UVA ou UVB e radiômetros digitais acoplados a detectores de radiação UVA e UVB certificados.

Os espectros de RPE foram obtidos em temperaturas entre $10 \mathrm{~K}$ e $100 \mathrm{~K}$ em um espectrômetro Bruker Elexsys E580 operando em 9,5GHz (Banda X). A temperatura foi controlada por meio de um sistema criogênico Oxford operando com hélio líquido. Os espectros de RPE em estado sólido foram simulados utilizando a função "pepper" do pacote EasySpin ${ }^{\circledR}$ (89), implementado no programa MATLAB ${ }^{\circledR}$ (Mathworks, Inc.). Ajustes de mínimos quadrados foram realizados utilizando a função "esfit" pertencente ao mesmo pacote. Antes da realização dos experimentos as amostras, na forma de pó, foram empacotadas em tubos de quartzo e posteriormente irradiadas com luz na faixa do UV. Para garantir uniformidade a amostra foi rodada e agitada manualmente durante a irradiação do pó. A dose utilizada para radiação foi de 150 MED $\left(1 \mathrm{MED} \equiv 21 \mathrm{~mJ} . \mathrm{cm}^{-2}\right.$ para radiação UVB).

Os espectros UV-vis foram obtidos utilizando um Espectrofotômetro Jasco V-630. As placas com os filmes adsorvidos foram colocadas no local das cubetas de quartzo e os espectros adquiridos em modo de transmissão. 


\section{Preparação das amostras}

\subsection{HPW hidratado}

Conforme esclarecido na seção 2.2, o tratamento térmico do $\mathrm{HPW}$ comercial à $85^{\circ} \mathrm{C}$ por $2 \mathrm{~h}$ induz a desidratação da amostra, obtendo-se o HPW hexahidratado $\left(\mathrm{HPW} \cdot 6 \mathrm{H}_{2} \mathrm{O}\right)$. Dois tipos de tratamento térmico froram realizados sobre uma amostra de $\mathrm{HPW} \cdot \mathrm{nH}_{2} \mathrm{O}($ empresa Sigma-Aldrich, 99.995\% de pureza, excluindo até 300 ppm de Si):

- secagem em forno mufla sem controle de atmosfera - HPW-I;

- secagem em forno mufla com fluxo contínuo de $\mathrm{N}_{2}-\mathrm{HPW}-\mathrm{II}$.

Após a secagem as amostras foram transferidas para uma câmara com fluxo contínuo de $\mathrm{N}_{2}$ com umidade relativa abaixo de $20 \%$, onde foram empacotadas nos rotores utilizados para os experimentos de RMN. No capítulo 6 são mostrados dados de TGA e difração de raios-X que mostram a obtenção de estequiometrias e estruturas cristalográficas que concordam com os dados da literatura para o $\mathrm{HPW} \cdot 6 \mathrm{H}_{2} \mathrm{O}$. No entanto, como será discutido no capítulo 6, os resultados de RMN mostram diferenças quanto à estrutura local do HPW nestas amostras.

\subsection{Xerogeis fotocrômicos}

No processo de preparo das amostras fotocrômicos foram utilizados os seguintes reagentes:

- 3-aminopropiltrietóxissilano (APTS) 99\% - Sigma-Aldrich;

- Acetona 99,5\% - QHEMIS;

- Ácido 12-tungstofosfórico P.A. (HPW) - Sigma-Aldrich; 
- Tetraetilortosilicato (TEOS) 98\% - AVOCADO;

- 3-glicidoxipropiltrimetoxisilano (GLYMO) - Sigma-Aldrich;

- Butironitrilatrietóxissilano (BUT) - Sigma-Aldrich.

$\mathrm{Na}$ figura 5.1 estão representadas as estruturas dos diferentes precursores orgânicos utilizados no processo de preparação dos complexos deste trabalho.

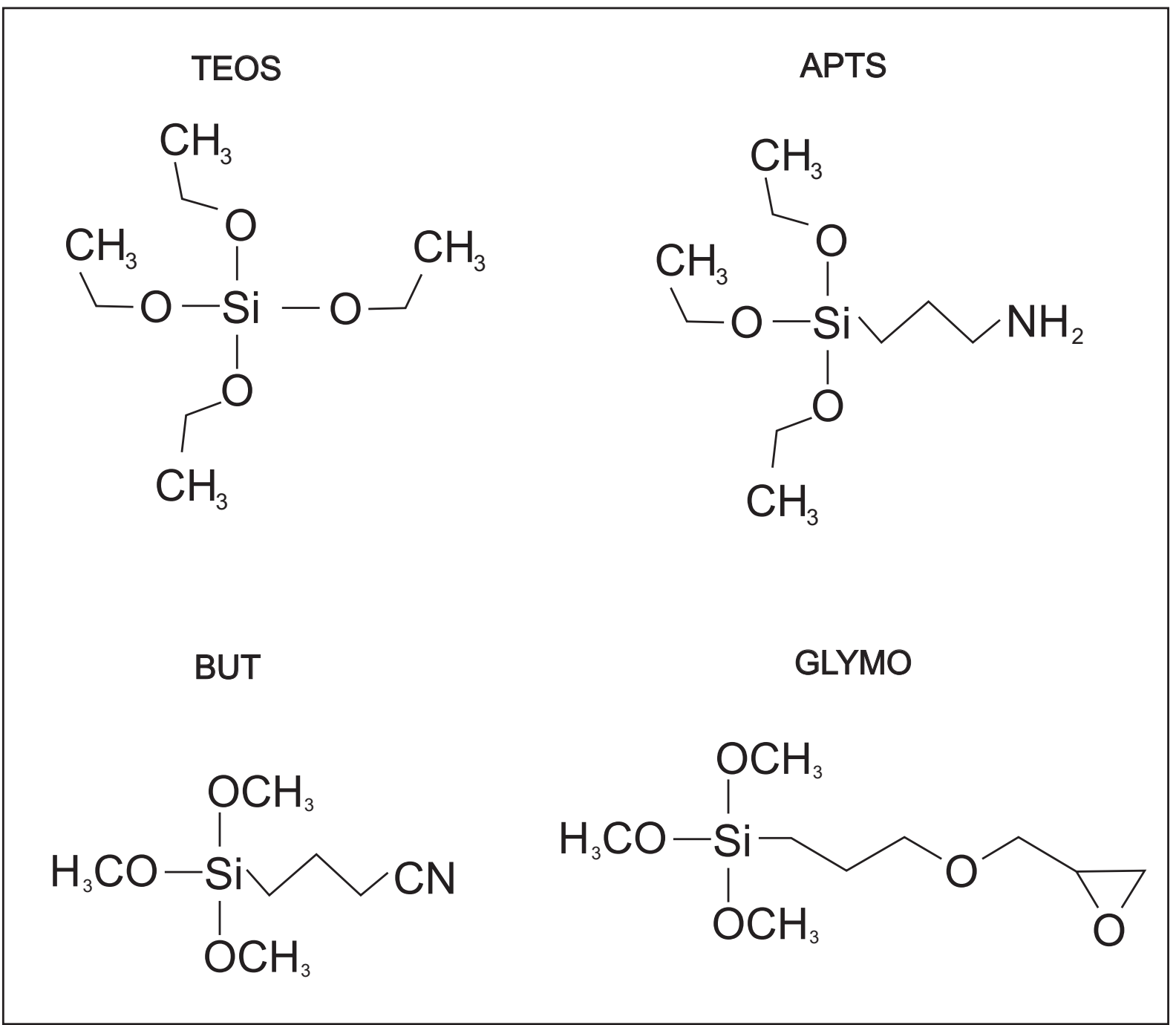

Figura 5.1-Representações estruturais dos precursores orgânicos. Fonte: Elaborada pelo autor.

As amostras foram preparadas via processo sol-gel, utilizando-se como solvente $50,0 \mathrm{ml}$ de acetona e $45 \mathrm{mmol}$ de água. Foi fixada uma quantidade padrão de $0,75 \mathrm{mmol}$ de HPW para todos os complexos. A essa quantidade HPW em solução, foram adicionados os outros reagentes, seguindo-se as porcentagens molares indicadas na tabela 5.1. Para se avaliar o efeito da umidade ambiente durante a preparação dos xerogeis, os mesmos foram preparados em três condições: 
- condições ambientes, sem controle de atmosfera, com U.R. entre 30\% e 60\% (amostras preparadas nestas condições aparecerão com o índice "amb");

- em câmara com fluxo contínuo de $\mathrm{N}_{2}$, com U.R. entre 12 e 18\% (as amostras preparadas por este método aparecerão com o índice "N2" após o nome);

- em câmara seca glove-box, com U.R. $\approx 1 \mathrm{ppm}$ (as amostras preparadas por este método aparecerão com o índice "box" após o nome)

Tabela 5.1-Porcentagens molares dos precursores envolvidos na preparação dos diferentes xerogeis.

\begin{tabular}{cccccc}
\hline \hline Amostra & $\begin{array}{c}\text { HPW } \\
\text { (\% molar) }\end{array}$ & $\begin{array}{c}\text { TEOS } \\
\text { (\% molar) }\end{array}$ & $\begin{array}{c}\text { GLYMO } \\
\text { (\% molar) }\end{array}$ & $\begin{array}{c}\text { BUT } \\
\text { (\% molar) }\end{array}$ & $\begin{array}{c}\text { APTS } \\
\text { (\% molar) }\end{array}$ \\
\hline \hline HT & 7,6 & 92,4 & - & - & - \\
HGT & 3,3 & 40,0 & 56,7 & - & - \\
HGBT & 3,1 & 37,5 & 53,1 & 6,3 & - \\
HGAT & 3,1 & 37,5 & 53,1 & - & 6,3 \\
\hline \hline
\end{tabular}

Os xerogeis foram preparados em béqueres de $80 \mathrm{ml}$ a $100 \mathrm{ml}$. Para a composição HT, inicialmente foi inserido o TEOS e $25 \mathrm{ml}$ de acetona agitando-se por $1 \mathrm{~min}$ para a dispersão do TEOS na acetona. Depois foi inserido o HPW solubilizado em $25 \mathrm{ml}$ de acetona e logo em seguida a água, deixando agitar por $10 \mathrm{~min}$ para a homogeneização total. Apesar de não possuir propriedades ópticas e mecânicas satisfatórias para aplicação em óptica, esta amostra possui a formulação mais simples possível para xerogeis contendo HPW, e será usada como amostra modelo para a confirmação de atribuições espectrais que poderão ser realizadas nos xerogeis fotocrômicos. Para a preparação da composição HGT, inicialmente foi inserido o TEOS e $25 \mathrm{ml}$ de acetona agitando-se por $1 \mathrm{~min}$ para a dispersão do TEOS na acetona. Em seguida adicionou-se o HPW solubilizado em $25 \mathrm{ml}$ de acetona e logo em seguida a água agitando-se por 3min para o início das reações de hidrólise e condensação, depois foi inserido o GLYMO, agitando-se por 10min para a homogeneização total. Estritamente, esta amostra deveria conter uma fração molar de HPW igual à das outras amostras. No entanto a preparação com maiores concentrações de TEOS leva à precipitação de particulados nos primeiros estágios do processo de preparo. Para a preparação das composições HGBT e HGAT inicialmente foi inserido o TEOS o BUT ou o APTS e $25 \mathrm{ml}$ de acetona agitando-se por $1 \mathrm{~min}$ para a dispersão dos silanos na acetona. Em seguida adicionou-se o HPW solubilizado em $25 \mathrm{ml}$ de acetona e logo em 
seguida a água agitando-se por 3min para o início das reações de hidrólise e condensação, depois foi inserido o GLYMO, agitando-se por $10 \mathrm{~min}$ para a homogeneização total. Ao final do processo de preparo os xerogeis foram deixados secar em temperatura ambiente e na mesma atmosfera de preparação. O produto final é um xerogel, que ainda mantido na mesma condição de atmosfera foi moído em almofariz e empacotado nos rotores utilizados para os experimentos de RMN.

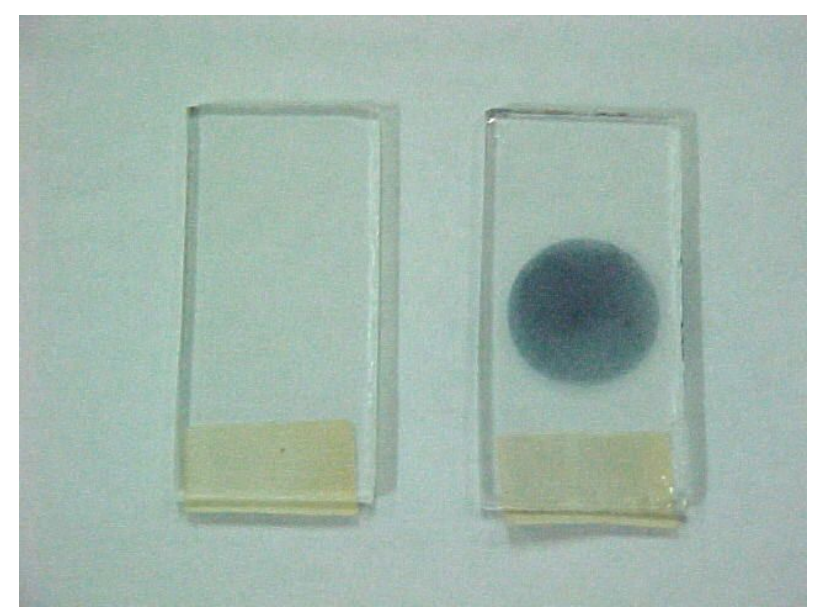

Figura 5.2-Filme obtido por método dip-coating à partir do gel de composição HGT preparado em condições ambientes. Antes (esquerda) e após (direita) irradiação com lâmpada UV. Fonte: CARVALHO (17)
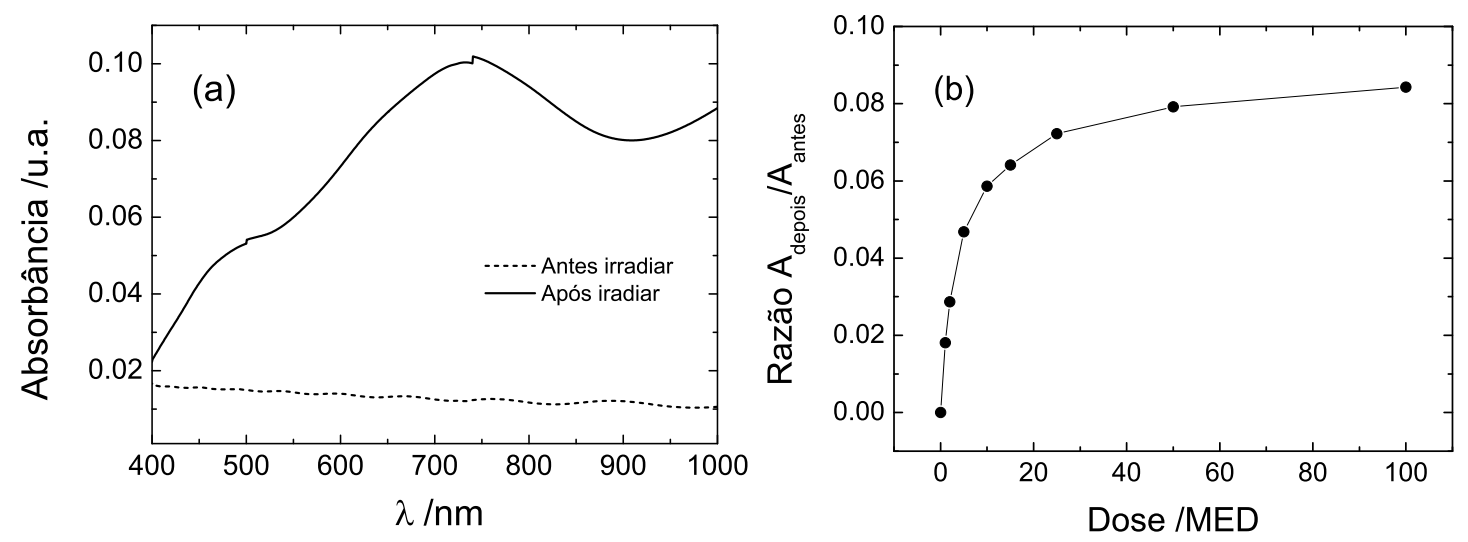

Figura 5.3-(a) Espectros de UV-vis medidos para o filme obtido a partir da amostra HGT preparada em condições ambientes, antes e após irradiação. (b) Absorbância relativa da banda em $755 \mathrm{~nm}$ em função da dose medida da razão entre a absorbância após e antes a irradiação. Fonte: Elaborada pelo autor.

A figura 5.2 mostra um exemplo de filme formado à partir da amostra HGT preparada em condições ambientes, antes e após a irradiação com lâmpada U.V. (dose de 100 MED). A coloração da amostra passa de praticamente transparente para azul. Como exemplo do tipo de resposta fotocrômica característica dos filmes, a figura 5.3 mostra dados dos espectros 
de UV-vis (figura 5.3.a) obtidos para a amostra HGT e a intensidade da banda de absorção em $755 \mathrm{~nm}$ em função da dose aplicada (figura 5.3.b). Nos espectros é possível perceber claramente o aparecimento de bandas de absorção após a irradiação, com centros em 752 nm e $487 \mathrm{~nm}$, e uma banda no final do espectro. Estas bandas podem ser atribuídas à redução do poliânion por um elétron, resultando em $\left[\mathrm{H}_{3} \mathrm{PW}_{12} \mathrm{O}_{40}\right]^{4-}$.(7, 90). Na figura 5.3.b é possível observar que a intensidade máxima da banda em $755 \mathrm{~nm}$ cresce em função da dose aplicada, e o processo começa a saturar em doses acima de 60 MED. 
Capítulo 6

\section{Resultados}

\subsection{Hidratos de HPW}

\subsubsection{HPW. $\mathrm{nH}_{2} \mathrm{O}$}

A figura 6.1 mostra espectros de ${ }^{31} \mathrm{P}$ RMN em condição estática, para a amostra de $\mathrm{HPW} \cdot \mathrm{nH}_{2} \mathrm{O}$ em diferentes temperaturas. O espectro de ${ }^{31} \mathrm{P}$ sofre um alargamento abrupto desde $440 \mathrm{~Hz}$ FWHM em $-76^{\circ} \mathrm{C}$ até $910 \mathrm{~Hz}$ em $-85^{\circ} \mathrm{C}$. Este alargamento indica que em temperaturas maiores do que $-76^{\circ} \mathrm{C}$, o poliânion encontra-se em um estado de alta mobilidade, no regime de flutuações rápidas da interação dipolar heteronuclear ${ }^{1} \mathrm{H}_{-}{ }^{31} \mathrm{P}$ (motional narrowing) (71), com alta mobilidade relativa entre o $\mathrm{P}$ e os $\mathrm{H}$ vizinhos. Esta amostra não apresenta sinal de $\mathrm{CP}$

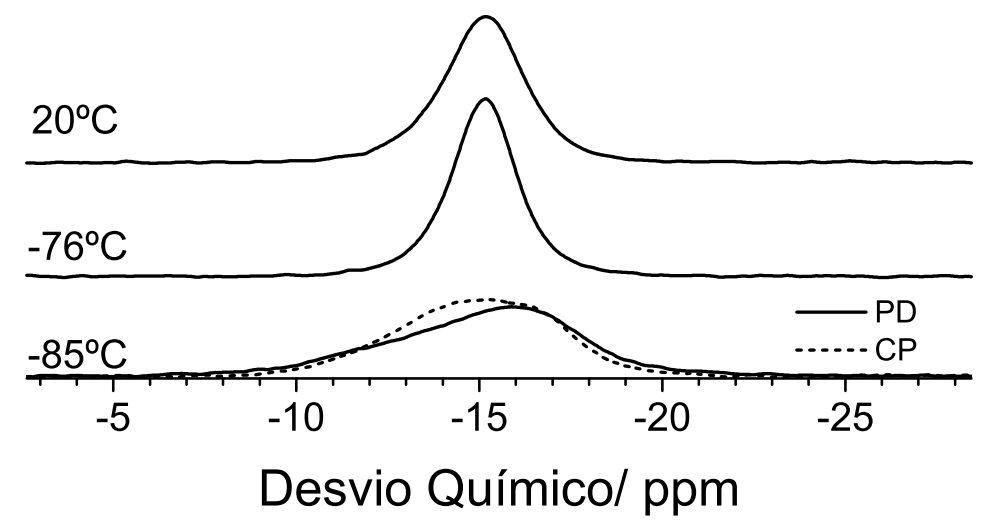

Figura 6.1-Espectros estáticos de ${ }^{31} \mathrm{P}-\mathrm{RMN}$ para o $\mathrm{HPW} \cdot \mathrm{nH}_{2} \mathrm{O}$ em diferentes temperaturas. $\mathrm{O}$ espectro tracejado foi obtido através de experimento de polarização cruzada (CP). Fonte: Elaborada pelo autor.

$\left\{{ }^{1} \mathrm{H}\right\}-{ }^{31} \mathrm{P}$ em temperatura ambiente, indicando que a interação dipolar ${ }^{1} \mathrm{H}-{ }^{31} \mathrm{P}$ média é muito baixa. Uma causa possível para este fenômeno é a existência de uma dinâmica de reorientação rápida do poliânion, comparada com a escala de tempos da $\operatorname{RMN}\left(10^{-6} \mathrm{~s}\right)$, reduzindo a interação 
dipolar efetiva entre o par de espécies. Outra possibilidade seria a ocorrência de tempos curtos de relaxação spin rede do ${ }^{1} \mathrm{H}$ no sistema rotante.(70) No entanto, esta possibilidade pode ser descartada após a realização de experimentos de spinlock ${ }^{1} \mathrm{H}$ RMN à temperatura ambiente (figura 6.2), onde foi verificado que o tempo de relaxação $T_{1 \rho}$ é da ordem de $30 \mathrm{~ms}$. Abaixo de $-85^{\circ} \mathrm{C}$ ao mesmo tempo em que ocorre o alargamento da linha espectral, o experimento de $\mathrm{CP}{ }^{1} \mathrm{H}_{-}{ }^{31} \mathrm{P}$ RMN torna-se possível (figura 6.1, traço pontilhado), indicando que o ${ }^{31} \mathrm{P}$ interage mais fortemente com os ${ }^{1} \mathrm{H}$ vizinhos.

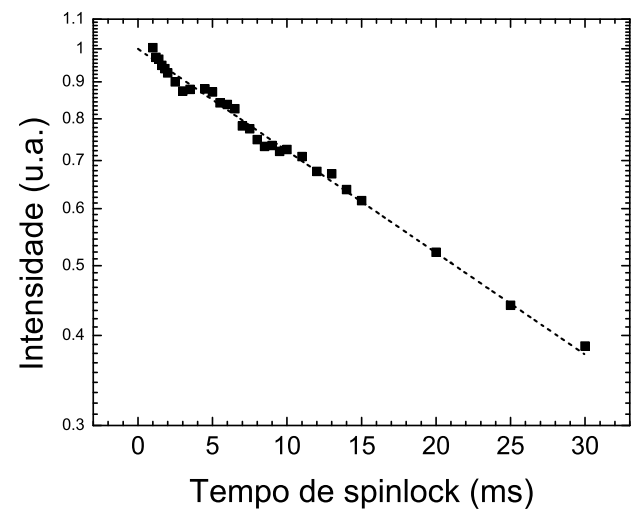

Figura 6.2-Sinal da magnetização de ${ }^{1} \mathrm{H}$ em função do tempo de spin-lock para uma amostra de $\mathrm{HPW} \cdot \mathrm{nH}_{2} \mathrm{O}$ a temperatura ambiente. Fonte: Elaborada pelo autor.

\subsubsection{Efeito de secagens sobre o $\mathrm{HPW} \cdot \mathrm{nH}_{2} \mathrm{O}$}

Como descrito na seção 5.1, diferentes condições de secagem do $\mathrm{HPW} \cdot \mathrm{nH}_{2} \mathrm{O}$ produzem amostras com estequiometria e estrutura cristalográfica média compatíveis com o HPW. $6 \mathrm{H}_{2} \mathrm{O}$, até o nível em que as técnicas de TGA e DRX em pó conseguem descriminar. No entanto, resultados de ${ }^{31} \mathrm{P}$ e ${ }^{1} \mathrm{H}$ RMN mostram diferenças na estrutura local do poliânion. Para tentar elucidar as diferenças observadas, esta seção apresenta um estudo para avaliar o efeito de diferentes secagens térmicas sobre a estrutura local do poliânion em HPW·nH $\mathrm{H}_{2} \mathrm{O}$.

A figura 6.3 a mostra a curva de análise termogravimétrica (TGA) para uma amostra de HPW comercial, desde temperatura ambiente até $350^{\circ} \mathrm{C}$. Conforme relatado na literatura, entre $175^{\circ} \mathrm{C}$ e $230^{\circ} \mathrm{C}$, toda a água é removida, e o material resultante é o $\mathrm{H}_{3} \mathrm{PW}_{12} \mathrm{O}_{40}$. (25, 26, 30, 32, 91) Assim, podemos partir do princípio de que em $300^{\circ} \mathrm{C}$ toda a água estrutural foi extraída da amostra, e tem-se HPW $\mathrm{H}_{3} \mathrm{PW}_{12} \mathrm{O}_{40}$. Tomando como referência a massa percentual no 
final da curva, podemos calcular o número médio de moléculas $\mathrm{H}_{2} \mathrm{O}$ por poliânion de HPW em temperaturas menores. O resultado obtido mostra que no estado inicial, a amostra de HPW analisada encontra-se com 23 moléculas de $\mathrm{H}_{2} \mathrm{O}$ por poliânion de HPW. O hidrato de HPW estável e com n mais próximo do valor encontrado é o HPW $21 \mathrm{H}_{2} \mathrm{O}$. A diferença no valor de $n$ pode ser devido à excesso de água na estrutura do $\mathrm{HPW} \cdot 21 \mathrm{H}_{2} \mathrm{O}$ e/ou à presença de pequenas frações de HPW $29 \mathrm{H}_{2} \mathrm{O}$. A derivada da curva de TGA é mostrada na figura 6.3. a em linha tracejada, e sua análise permite concluir a existência de três transformações (27):

- Em torno de $55^{\circ} \mathrm{C}$ a derivada apresenta uma variação, correspondente ao início da transformação de HPW·21 $\mathrm{H}_{2} \mathrm{O}$ em HPW.14 $\mathrm{H}_{2} \mathrm{O}$ (27);

- em $70^{\circ} \mathrm{C}$ a derivada apresenta um mínimo correspondente ao início da transformação de $\mathrm{HPW} \cdot 14 \mathrm{H}_{2} \mathrm{O}$ em HPW.6 $\mathrm{H}_{2} \mathrm{O}(27)$;

- um mínimo local para a derivada em $180^{\circ} \mathrm{C}$ e uma variação em $220^{\circ} \mathrm{C}$ indicam a transição de $\mathrm{HPW} \cdot 6 \mathrm{H}_{2} \mathrm{O}$ para HPW desidratado, que ocorre em dois estágios.(27)

Um patamar entre $80^{\circ} \mathrm{C}$ e $125^{\circ} \mathrm{C}$ correspondente à estequiometria para o $\mathrm{HPW} \cdot 6 \mathrm{H}_{2} \mathrm{O}$ pode ser observado na curva de TGA da figura 6.3. a. Estudos de TGA e difração de raios- $X$ da literatura mostram que o $\mathrm{HPW} \cdot 6 \mathrm{H}_{2} \mathrm{O}$ é estável na faixa de temperaturas entre $70^{\circ} \mathrm{C}$ e $170^{\circ} \mathrm{C}$ para alguns autores (23, 26, 27), ou entre $60^{\circ} \mathrm{C}$ e $130^{\circ} \mathrm{C}$ conforme relatado por Deleplanque et al..(32, 91) No entanto, para a amostra de HPW utilizada neste estudo, a curva de TGA mostra que o HPW. $6 \mathrm{H}_{2} \mathrm{O}$ é estável entre $80^{\circ} \mathrm{C}$ e $125^{\circ} \mathrm{C}$. Para comprovar a estabilidade do HPW. $6 \mathrm{H}_{2} \mathrm{O}$ nesta faixa de temperaturas, um experimento de TGA com isoterma em $105^{\circ} \mathrm{C}$ durante $5 \mathrm{~h}$ foi realizado (figura 6.4), que não mostra variação apreciável de massa neste período.

Várias amostras de $\mathrm{HPW} \cdot \mathrm{nH}_{2} \mathrm{O}$ foram submetidas a diferentes tratamentos térmicos, em forno mufla com fluxo de $\mathrm{N}_{2}$, com temperaturas escolhidas dentro da faixa de estabilidade do $\mathrm{HPW} \cdot 6 \mathrm{H}_{2} \mathrm{O}$. Para avaliar o produto final foram realizados experimentos de TGA pós-tratamento, que estão mostrados na figura 6.3.b. A tabela 6.1 exibe os valores obtidos para o número médio de moléculas de $\mathrm{H}_{2} \mathrm{O}$ por poliânion, $n$. A secagem do $\mathrm{HPW} \cdot \mathrm{nH} \mathrm{H}_{2} \mathrm{O}$ a $85^{\circ} \mathrm{C}$ por $2 \mathrm{~h}$ e a $95^{\circ} \mathrm{C}$ por 1 h leva à formação de HPW. $6 \mathrm{H}_{2} \mathrm{O}$. Embora os experimentos de TGA para o HPW.n $\mathrm{H}_{2} \mathrm{O}$ mostrem que o $\mathrm{HPW} \cdot 6 \mathrm{H}_{2} \mathrm{O}$ é estável entre $80^{\circ} \mathrm{C}$ e $125^{\circ} \mathrm{C}$, o tratamento em $95^{\circ} \mathrm{C}$ durante $2 \mathrm{~h}$ no forno leva a desidratação do HPW. $6 \mathrm{H}_{2} \mathrm{O}$, gerando uma estrutura com $n=5,6$ moléculas de $\mathrm{H}_{2} \mathrm{O}$ por poliânion. Da mesma forma, o HPW $6 \mathrm{H}_{2} \mathrm{O}$ sofre desidratação para os tratamentos em $105^{\circ} \mathrm{C}$ durante $1 \mathrm{~h}$ e $3 \mathrm{~h}$, gerando estruturas com $n=5,2$ e $2,6 \mathrm{H}_{2} \mathrm{O}$ /poliânion respectivamente. Estes dados mostram que a secagem em forno com fluxo de $\mathrm{N}_{2}$ é mais eficiente na remoção das moléculas de água na estrutura do HPW, comparado ao processo de secagem que ocorre 

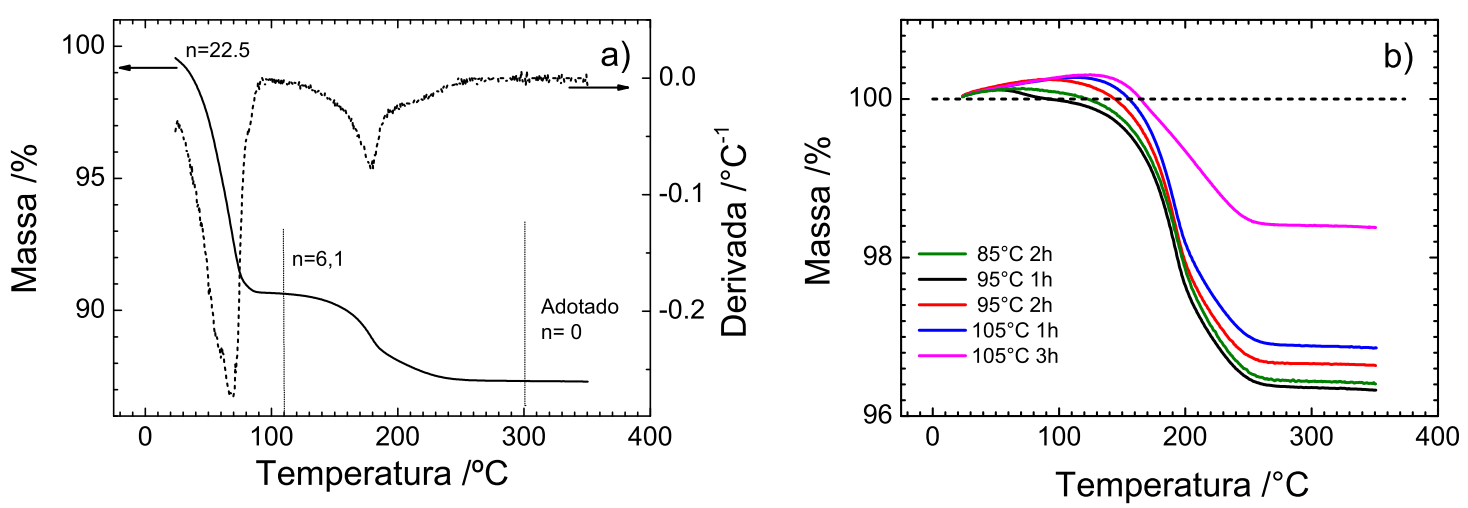

Figura 6.3-Curvas de TGA desde temperatura ambiente até $350^{\circ} \mathrm{C}$, para uma amostra de HPW comercial (a) e para a mesma amostra, após passar por diferentes tratamentos térmicos em forno com fluxo constante de $\mathrm{N}_{2}$ (b). $n$ indica a quantidade de moléculas $\mathrm{H}_{2} \mathrm{O}$ por poliânion Os experimentos foram realizados em uma microbalança térmica TG 209 $\mathrm{NETZSCH}$, variando a temperatura em passos de $10^{\circ} \mathrm{C} / \mathrm{min}$ sob fluxo de $\mathrm{N}_{2}$. Fonte: Elaborada pelo autor.

na microbalança utilizada no experimento de TGA.

Tabela 6.1-Numero médio de moléculas de água por poliânion de HPW (n) resultante de tratamentos térmicos em diferentes temperaturas e por diferentes períodos, sobre uma amostra de $\mathrm{HPW} \cdot \mathrm{nH}_{2} \mathrm{O}$ comercial. Os valores foram obtidos com base em análises de termogravimetria.

\begin{tabular}{ccc} 
Temperatura $\left({ }^{\circ} \mathbf{C}\right)$ & Tempo $(\mathbf{h})$ & $\mathbf{n}$ \\
\hline 85 & 2 & 6,0 \\
95 & 1 & 6,1 \\
95 & 2 & 5,6 \\
105 & 1 & 5,2 \\
105 & 3 & 2,6 \\
\hline \hline Fonte: Elaborada pelo autor.
\end{tabular}

A figura 6.5 mostra os espectros de ${ }^{31} \mathrm{P}$ MAS RMN e CP $\left\{{ }^{1} \mathrm{H}\right\}-{ }^{31} \mathrm{P}$ MAS RMN para as amostras de HPW em diferentes níveis de hidratação. Os valores de $n$ na figura são o número médio de moléculas de $\mathrm{H}_{2} \mathrm{O}$ por poliânion obtidos por TGA. Experimentos de HETCOR $\left\{{ }^{1} \mathrm{H}\right\}-{ }^{31} \mathrm{P}$ que serão apresentados na seção 6.1.2.1 mostram que todos os prótons contribuindo para o espectro de ${ }^{1} \mathrm{H}$ RMN pertencem ao ambiente de coordenação do poliânion de HPW para $n \leq 6$.

No estado mais hidratado, $n=22$, o espectro de ${ }^{31} \mathrm{P}$ para o HPW é bem estreito (FWHM $=5 \mathrm{~Hz}$ ), característica de uma dinâmica relativa rápida entre o poliânion de HPW e os prótons ao redor, devido tanto à alta mobilidade dos prótons, quanto à reorientação rápida do poliânion, como mostrado na seção 6.1.1. Devido a esta alta mobilidade, não foi observado sinal de CP 


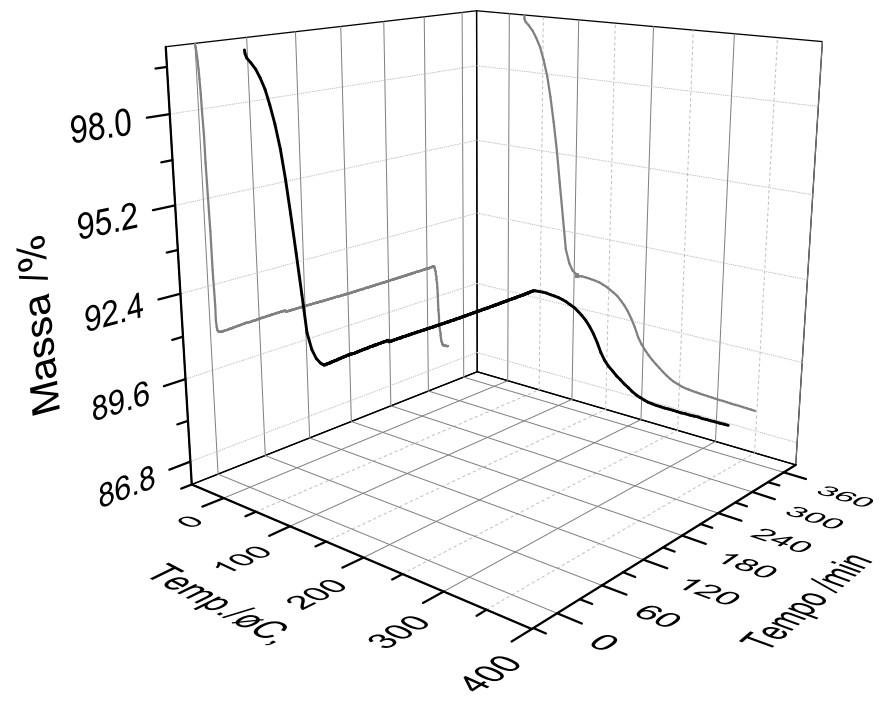

Figura 6.4-Curva de TGA para uma amostra de HPW comercial, desde temperatura ambiente até $350^{\circ} \mathrm{C}$, com isoterma em $105^{\circ} \mathrm{C}$. Experimento realizado em uma microbalança térmica TG 209 - NETZSCH, variando a temperatura em passos de $10^{\circ} \mathrm{C} / \mathrm{min}$ sob fluxo de $\mathrm{N}_{2}$. Fonte: Elaborada pelo autor.

$\left\{{ }^{1} \mathrm{H}\right\}-{ }^{31} \mathrm{P}$ para esta amostra.

Os tratamentos a $85^{\circ} \mathrm{C}$ por $2 \mathrm{~h}$ (figura 6.5.b) e $95^{\circ} \mathrm{C}$ por $1 \mathrm{~h}$ (figura 6.5.c) resultam na mesma estequiometria, $n=6$. O espectro de ${ }^{31} \mathrm{P}$ para ambas amostras (figura 6.5.b e c) é mais largo do que o espectro para a amostra de $\mathrm{HPW} \cdot 22 \mathrm{H}_{2} \mathrm{O}$, e ao contrário do que ocorre para a última, estas amostras apresentam sinal de CP $\left\{{ }^{1} \mathrm{H}\right\}-{ }^{31} \mathrm{P}$. Ambas características (largura e sinal de (P) indicam que o poliânion encontra-se em um estado de mobilidade mais restrita após a desidratação parcial. O espectro de ${ }^{31} \mathrm{P}$ RMN da figura 6.5.b apresenta uma única linha simétrica, com desvio em -15,6ppm, indicando que o ambiente de coordenação do poliânion de HPW é homogêneo na amostra. O espectro de CP $\left\{{ }^{1} \mathrm{H}\right\}-{ }^{31} \mathrm{P}$ RMN é ligeiramente mais largo do que o espectro de PD, indicando heterogeneidade para os acoplamentos dipolares ${ }^{1} \mathrm{H}-{ }^{31} \mathrm{P}$. Por outro lado, o espectro de ${ }^{31} \mathrm{P}$ da figura 6.5.c é composto por duas linhas, uma mais estreita por volta de -15,6ppm e outra alargada por volta de -14,6ppm. Além disso, a linha em -15,6ppm é mais larga do que a observada para o espectro da figura 6.5.b. A ressonância em $-14,6 \mathrm{ppm}$ pode ser atribuído a desidratação do HPW para hidratos com $n<6$ (30). Conclui-se então que embora o número médio de moléculas de água por poliânion seja $n=6$, a distribuição de ambientes locais de coordenação para os poliânions é heterogênea, ou seja, alguns ambientes são mais desidratados do que outros para o tratamento em $95^{\circ} \mathrm{C}$ por $1 \mathrm{~h}$. O espectro de $\mathrm{CP}$ $\left\{{ }^{1} \mathrm{H}\right\}{ }^{31} \mathrm{P}$ RMN para esta amostra apresenta diferenças na relação de intensidades entra as duas linhas observadas, indicando heterogeneidade para o acoplamento dipolar ${ }^{1} \mathrm{H}_{-}{ }^{31} \mathrm{P}$. 


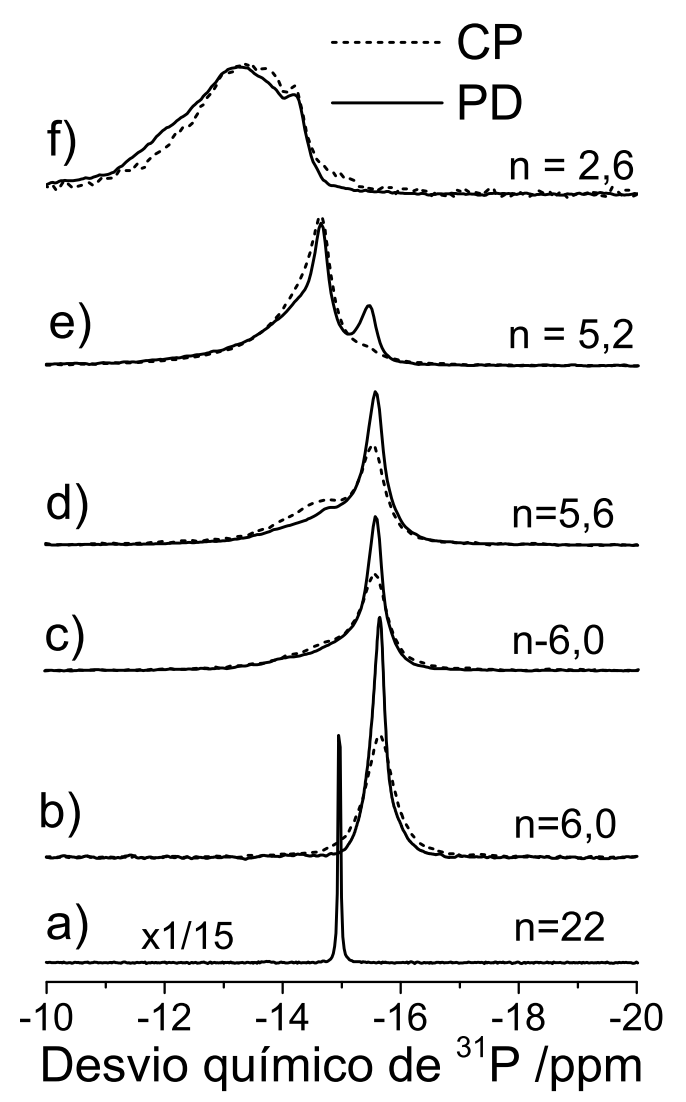

Figura 6.5-Espectros de ${ }^{31} \mathrm{P}$ MAS RMN (linha contínua) e CP $\left\{{ }^{1} \mathrm{H}\right\}{ }_{-}^{31} \mathrm{P}$ MAS RMN (linha tracejada) para amostra de $\mathrm{HPW} \cdot \mathrm{nH}_{2} \mathrm{O}$ submetidas a diferentes tratamentos térmicos em forno mufla sob fluxo de $\mathrm{N}_{2}$ : (a) sem tratamento; (b) $85^{\circ} \mathrm{C}$ por $2 \mathrm{~h}$; (c) $95{ }^{\circ} \mathrm{C}$ por $1 \mathrm{~h}$; (d) $95^{\circ} \mathrm{C}$ por $2 \mathrm{~h}$; (e) $105^{\circ} \mathrm{C}$ por $1 \mathrm{~h}$ e (f) $105^{\circ} \mathrm{C}$ por $3 \mathrm{~h}$. $n$ representa o número médio de moléculas de $\mathrm{H}_{2} \mathrm{O}$ por poliânion de HPW, obtido em experimentos de TGA (figura 6.3). Fonte: Elaborada pelo autor.

A figura 6.6 mostra os espectros de ${ }^{1} \mathrm{H}$ MAS RMN obtidos nesta série de amostras. $\mathrm{O}$ espectro de ${ }^{1} \mathrm{H}$ RMN para o tratamento em $85^{\circ} \mathrm{C}$ por $2 \mathrm{~h}$ (figura 6.6.b) está centrado em $9 \mathrm{ppm}$ e é consideravelmente mais largo do que o espectro para a amostra de $\mathrm{HPW} \cdot 22 \mathrm{H}_{2} \mathrm{O}$, mostrando que as espécies de hidratação encontram-se em um estado de mobilidade mais restrita. A técnica de MAS com rotação em $5 \mathrm{KHz}$ não é suficiente para resolver completamente as bandas laterais, indicando a existência de alto acoplamento homonuclear ${ }^{1} \mathrm{H}-{ }^{1} \mathrm{H}$ (92). $\mathrm{O}$ espectro para a amostra tratada em $95^{\circ} \mathrm{C}$ por $1 \mathrm{~h}$ (figura 6.6.c) é composto por duas ressonâncias sobrepostas, uma mais estreita e outra mais larga, similar à do espectro da figura 6.6.b, indicando sítios de prótons com alta e baixa mobilidade, respectivamente. Esta heterogeneidade é consistente com o observado para os espectros de ${ }^{31} \mathrm{P}$ RMN, indicando a existência de clusters $\mathrm{H}^{+}\left(\mathrm{H}_{2} \mathrm{O}\right)_{n}$ com diferentes valores de $n$. .

Os espectros de ${ }^{31} \mathrm{P}$ e ${ }^{1} \mathrm{H}$ RMN para o tratamento em $95^{\circ} \mathrm{C}$ por $2 \mathrm{~h}$ (figuras 6.5. $\mathrm{d}$ e 6.6. $\mathrm{d}$ respectivamente) são similares aos espectros para a amostra tratada a $95^{\circ} \mathrm{C}$ por $1 \mathrm{~h}$ (figuras 6.5.c 


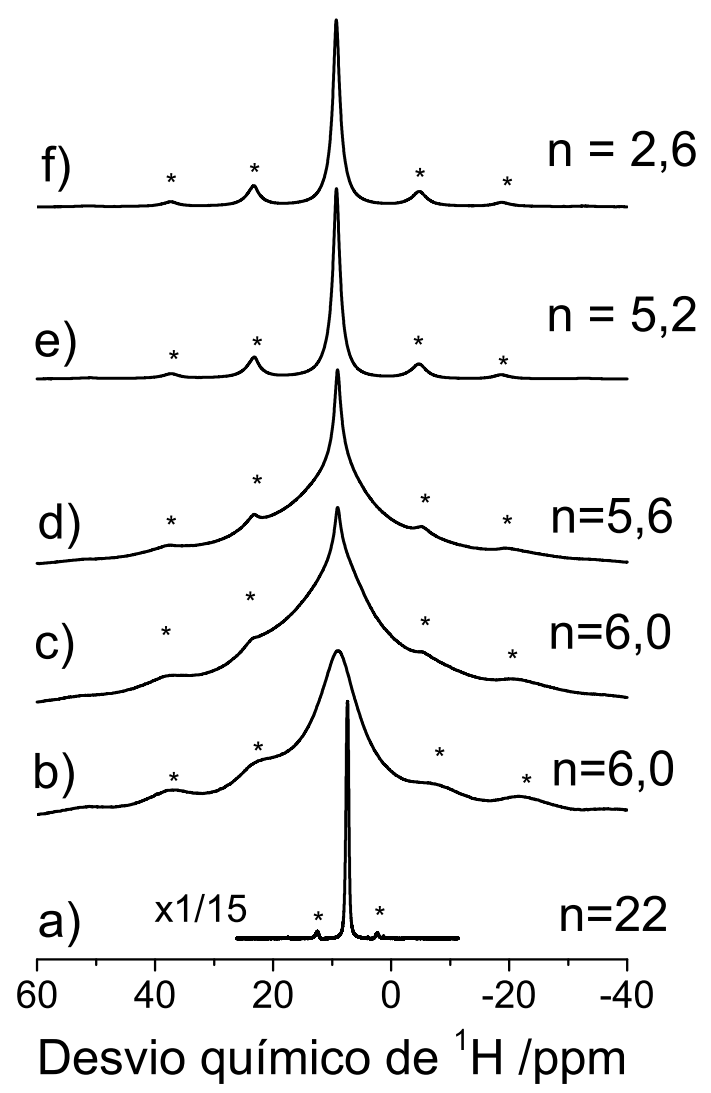

Figura 6.6-Espectros de ${ }^{1} \mathrm{H}$ MAS RMN para amostra de $\mathrm{HPW} \cdot \mathrm{nH}_{2} \mathrm{O}$ submetidas a diferentes tratamentos térmicos em forno mufla sob fluxo de $\mathrm{N}_{2}$ : (a) sem tratamento; (b) $85^{\circ} \mathrm{C}$ por $2 \mathrm{~h}$; (c) $95{ }^{\circ} \mathrm{C}$ por $1 \mathrm{~h}$; (d) $95^{\circ} \mathrm{C}$ por $2 \mathrm{~h}$; (e) $105^{\circ} \mathrm{C}$ por $1 \mathrm{~h}$ e (f) $105^{\circ} \mathrm{C}$ por $3 \mathrm{~h} . n$ representa o número médio de moléculas de $\mathrm{H}_{2} \mathrm{O}$ por poliânion de $\mathrm{HPW}$, obtido em experimentos de TGA (figura 6.3). As bandas laterais estão marcadas com asteriscos. Os espectros estão normalizados pela intensidade máxima para melhor visualização. Fonte: Elaborada pelo autor.

e 6.6.c), diferindo apenas quanto à relação de áreas entre as linhas observadas. A intensidade relativa do pico de ${ }^{31} \mathrm{P}$ em $-14,6 \mathrm{ppm}$ é maior no espectro da figura 6.5.d do que no espectro 6.5.c, indicando maior quantidade de grupos com $n<6$. Adicionalmente, a linha de ${ }^{1} \mathrm{H}$ mais estreita se torna mais intensa no espectro da figura 6.6.d, comparado ao espectro da figura 6.6.c. Portanto, esta ressonância estreita pode ser atribuída a prótons em clusters $\mathrm{H}^{+}\left(\mathrm{H}_{2} \mathrm{O}\right)_{n}$ menores, ou espécies $\mathrm{H}_{5} \mathrm{O}_{2}{ }^{+}, \mathrm{H}_{3} \mathrm{O}^{+}$e $\mathrm{H}_{2} \mathrm{O}$. Estas variações nos espectros são consistentes com os dados de TGA, de onde se tirou que o número médio de moléculas de $\mathrm{H}_{2} \mathrm{O}$ por poliânion é ligeiramente menor, $n=5,6$. Novamente, para os ambientes com menor número de prótons ao redor do poliânion, as correspondentes linhas de $\mathrm{CP}\left\{{ }^{1} \mathrm{H}\right\}-{ }^{31} \mathrm{P}$ apresentam maior intensidade, ou seja, o acoplamento ${ }^{1} \mathrm{H}_{-}{ }^{31} \mathrm{P}$ é mais intenso.

O espectro de ${ }^{31} \mathrm{P}$ RMN para esta amostra de HPW·5, $2 \mathrm{H}_{2} \mathrm{O}$ (figura 6.5.e) é constituído de três linhas principais, uma com baixa intensidade em $-15,5 \mathrm{ppm}$, e duas linhas mais intensas em 
-14,6 e -14,4ppm, mostrando um aumento na heterogeneidade de ambientes para o poliânion de HPW. Os desvios menores indicam estados de menor hidratação para o poliânion. Para o HPW $2,6 \mathrm{H}_{2} \mathrm{O}$ o espectro de ${ }^{31} \mathrm{P}$ mostra uma variedade de linhas com desvios em $-12 \mathrm{ppm}$, -13ppm e -14,2ppm. Os picos em -12ppm coincidem com o desvio reportado para o HPW desidratado (32), logo esta amostra apresenta uma mistura de ambientes com diferentes níveis de hidratação, incluindo alguns ambientes com HPW no estado desidratado. Os espectros de ${ }^{1} \mathrm{H}$ RMN para estas duas últimas amostras são mostrados na figura 6.6.e e f. Estes espectros apresentam uma linha central em $9 \mathrm{ppm}$. Os espectros são estreitos e com bandas laterais bem resolvidas, indicando baixo acoplamento dipolar homonuclear ${ }^{1} \mathrm{H}_{-}{ }^{1} \mathrm{H}$, podendo indicar prótons com alta mobilidade, prótons em moléculas de água praticamente isoladas e/ou prótons realizando ligações covalentes com os $\mathrm{O}$ do poliânion.

\subsubsection{1 $\left\{\right.$ HETCOR $\left.{ }^{1} \mathrm{H}\right\}{ }^{31} \mathrm{P}$ RMN}

Foram realizados experimentos de HETCOR $\left\{{ }^{1} \mathrm{H}\right\}-{ }^{31} \mathrm{P}$ RMN sobre as amostras de HPW. $6 \mathrm{H}_{2} \mathrm{O}$ e HPW $2,6 \mathrm{H}_{2} \mathrm{O}$ para obtenção indireta do espectro de ${ }^{1} \mathrm{H}$ para os prótons no ambiente de coordenação do poliânion de HPW. Os espectros bidimensionais estão mostrados nas figuras 6.7 e 6.8, onde no eixo vertical estão representadas as projeções sobre a frequência de ${ }^{31} \mathrm{P}$, correspondentes aos espectros de $\mathrm{CP}\left\{{ }^{1} \mathrm{H}\right\}{ }^{31} \mathrm{P}$, enquanto nos eixos horizontais estão representadas as projeções correspondentes aos espectros das espécies ${ }^{1} \mathrm{H}$ acopladas com ${ }^{31} \mathrm{P}$. Comparações entre a projeção do espectro HETCOR sobre o eixo dos ${ }^{1} \mathrm{H}$ e o espectro direto de ${ }^{1} \mathrm{H}$ MAS RMN para as diferentes amostras também são exibidas nas figuras. Para o HPW. $6 \mathrm{H}_{2} \mathrm{O}$ ○ espectro indireto de ${ }^{1} \mathrm{H}$ é ligeiramente mais alargado do que o espectro de polarização direta. Este alargamento pode ser explicado com base em uma leve heterogeneidade dinâmica para os ambientes de ${ }^{1} \mathrm{H}$, de forma que os prótons menos móveis, e consequentemente com espectro de ${ }^{1} \mathrm{H}$ mais largo devido ao maior acoplamento homonuclear ${ }^{1} \mathrm{H}-{ }^{1} \mathrm{H}$, polarizam mais eficientemente o ${ }^{31} \mathrm{P}$. A resolução do experimento de HETCOR não permite dizer se as linhas por volta de 0ppm, atribuídas a grupos $\mathrm{OH}$, como será visto nas próximas seções, fazem parte do ambiente de coordenação do HPW. Para a amostra HPW $2,6 \mathrm{H}_{2} \mathrm{O}$ os espectros de ${ }^{1} \mathrm{H}$ obtidos de forma indireta, via HETCOR, e de forma direta são muito semelhantes, indicando alto acoplamento ${ }^{1} \mathrm{H}_{-}{ }^{31} \mathrm{P}$ para os prótons compondo o espectro de ${ }^{1} \mathrm{H}$ desta amostra. Este alto acoplamento é consistente com moléculas de $\mathrm{H}_{2} \mathrm{O}$ fortemente ligadas ao poliânion e/ou prótons realizando ligação covalente com o poliânion de HPW. 

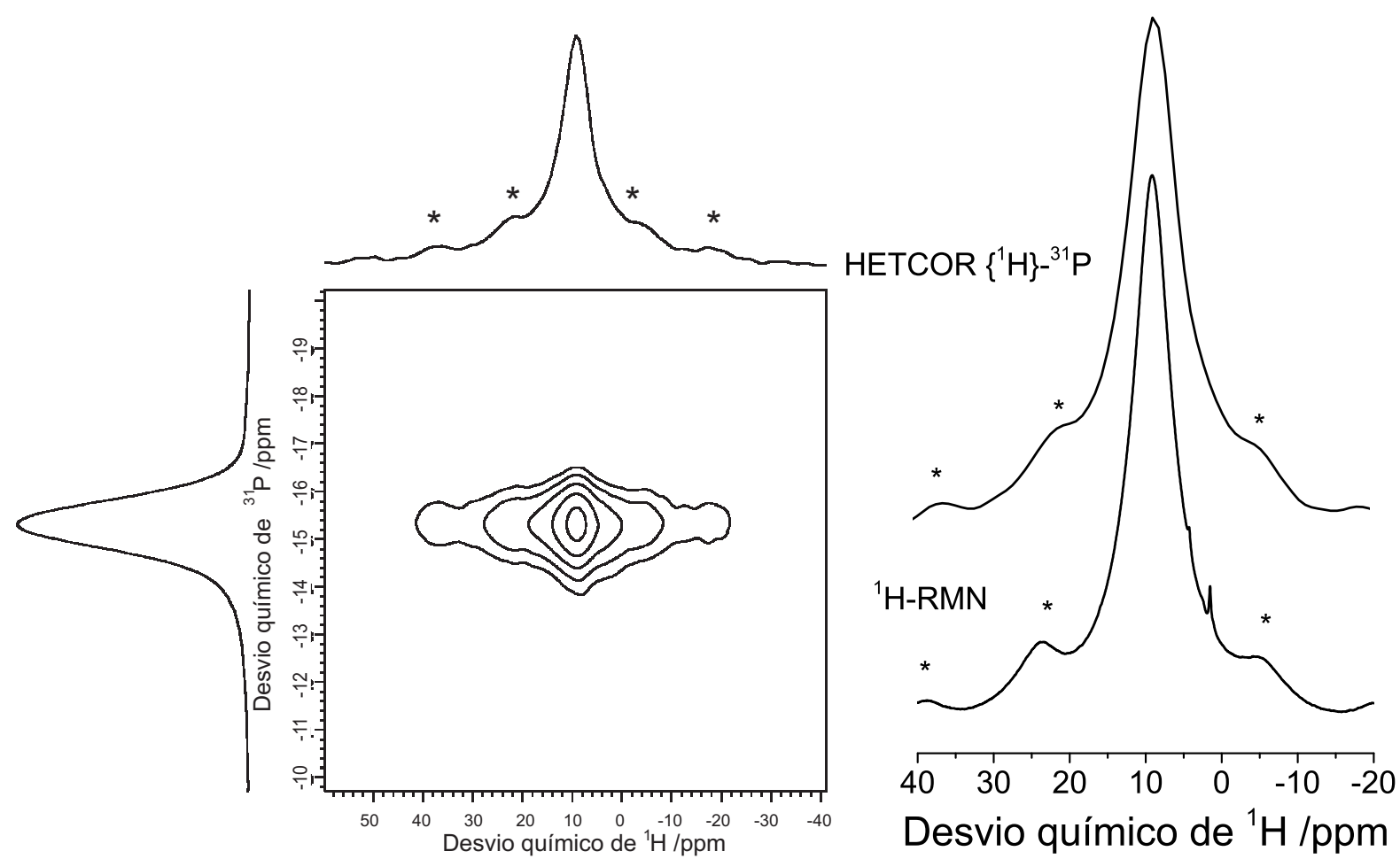

Figura 6.7-A esquerda o espectro de HETCOR $\left\{{ }^{1} \mathrm{H}\right\}-{ }^{31} \mathrm{P}$ RMN para a amostra HPW.6 $\mathrm{H}_{2} \mathrm{O}$ obtida pelo tratamento do $\mathrm{HPW} \cdot \mathrm{nH}_{2} \mathrm{O}$ à $85^{\circ} \mathrm{C}$ por $2 \mathrm{~h}$ sob fluxo de $\mathrm{N}_{2}$. A projeção vertical representa o sinal de ${ }^{31} \mathrm{P}$, enquanto a projeção horizontal representa o sinal de ${ }^{1} \mathrm{H}$ RMN. A direita a comparação entre a projeção de ${ }^{1} \mathrm{H}$ do espectro de HETCOR e o espectro de ${ }^{1} \mathrm{H}$ MAS RMN para a mesma amostra. Fonte: Elaborada pelo autor.

\subsubsection{HPW hexahidratado ( $\left.\mathrm{HPW} \cdot 6 \mathrm{H}_{2} \mathrm{O}\right)$}

$\mathrm{Na}$ literatura, diversos processos de secagens sobre $\circ \mathrm{HPW} \cdot \mathrm{nH}_{2} \mathrm{O}$ são utilizados para a obtenção do HPW.6H $\mathrm{H}_{2} \mathrm{O} .(22-24$, 27, 30, 31, 93) De acordo com a seção anterior, os tratamentos a $85^{\circ} \mathrm{C}$ por $2 \mathrm{~h}$ e $95^{\circ} \mathrm{C}$ por $1 \mathrm{~h}$ produzem amostras com a estequiometria média do HPW $6 \mathrm{H}_{2} \mathrm{O}$, embora o primeiro tratamento resulte em uma amostra mais homogênea. Portanto, o estudo mais detalhado de RMN será realizado para amostras de $\mathrm{HPW} \cdot 6 \mathrm{H}_{2} \mathrm{O}$ obtidas por tratamento térmico a $85^{\circ} \mathrm{C}$ por $2 \mathrm{~h}$. Duas condições de atmosfera foram utilizadas durante a secagem das amostras, a primeira em ar, sem controle de umidade (amostra HPWI) e a segunda com fluxo contínuo de $\mathrm{N}_{2}$ seco (amostra HPW-II). A figura 6.9 mostra a comparação entre os dados de TGA para ambas amostras. A análise das curvas de TGA mostra que independentemente da atmosfera utilizada a estequiometria final é consistente com o HPW $6 \mathrm{H}_{2} \mathrm{O}$, dentro da sensibilidade desta técnica.

Experimentos de difração de raios-X em pó foram realizados para a verificação da estrutura 


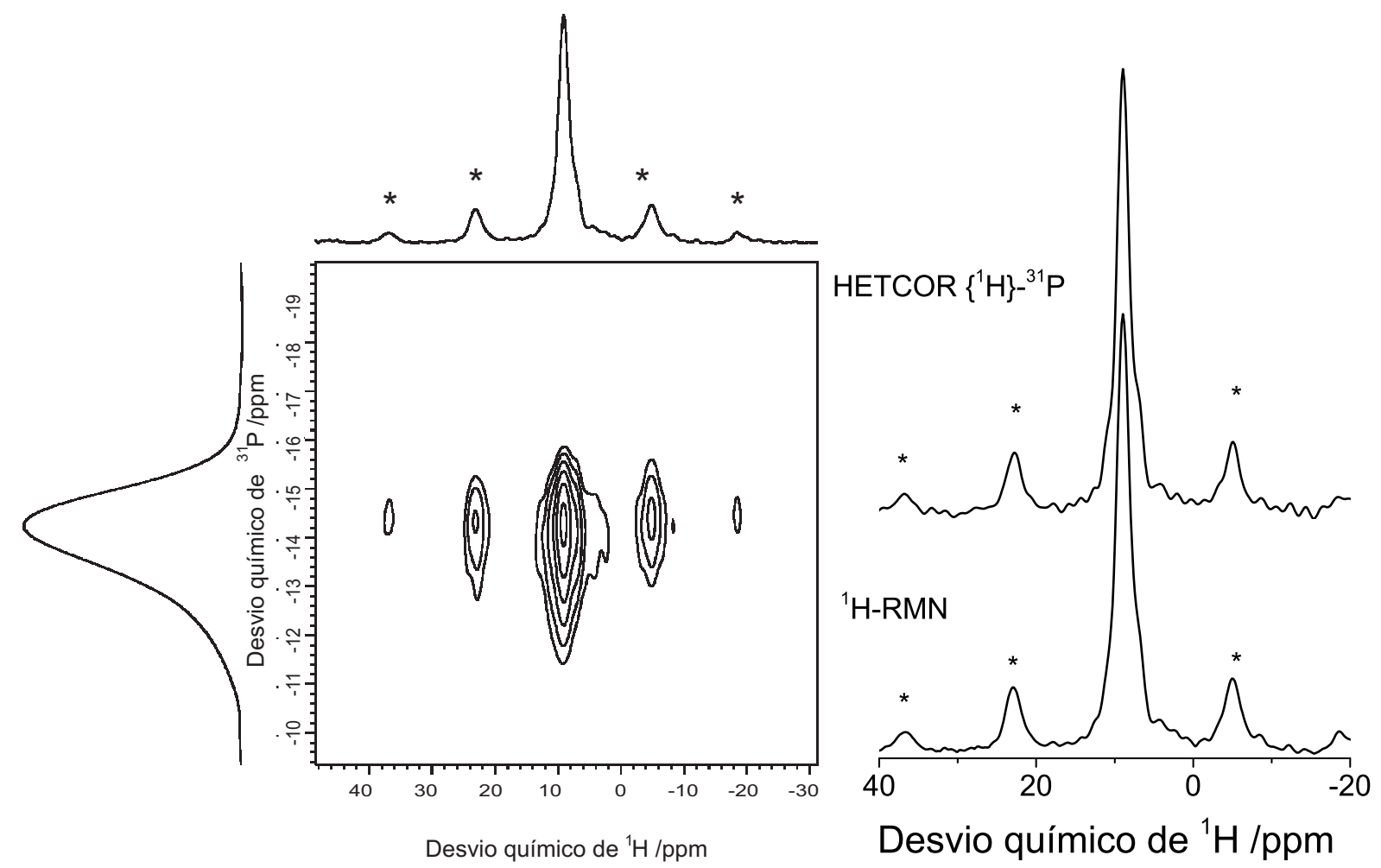

Figura 6.8-A esquerda o espectro de HETCOR $\left\{{ }^{1} \mathrm{H}\right\}-{ }^{31} \mathrm{P}$ RMN para a amostra HPW $\cdot 2,6 \mathrm{H}_{2} \mathrm{O}$ obtida pelo tratamento do $\mathrm{HPW} \cdot \mathrm{nH}_{2} \mathrm{O}$ à $105^{\circ} \mathrm{C}$ por $3 \mathrm{~h}$ sob fluxo de $\mathrm{N}_{2}$. A projeção vertical representa o sinal de ${ }^{31} \mathrm{P}$, enquanto a projeção horizontal representa o sinal de ${ }^{1} \mathrm{H}$ RMN. A direita a comparação entre a projeção de ${ }^{1} \mathrm{H}$ do espectro de HETCOR e o espectro de ${ }^{1} \mathrm{H}$ MAS RMN para a mesma amostra. Fonte: Elaborada pelo autor.

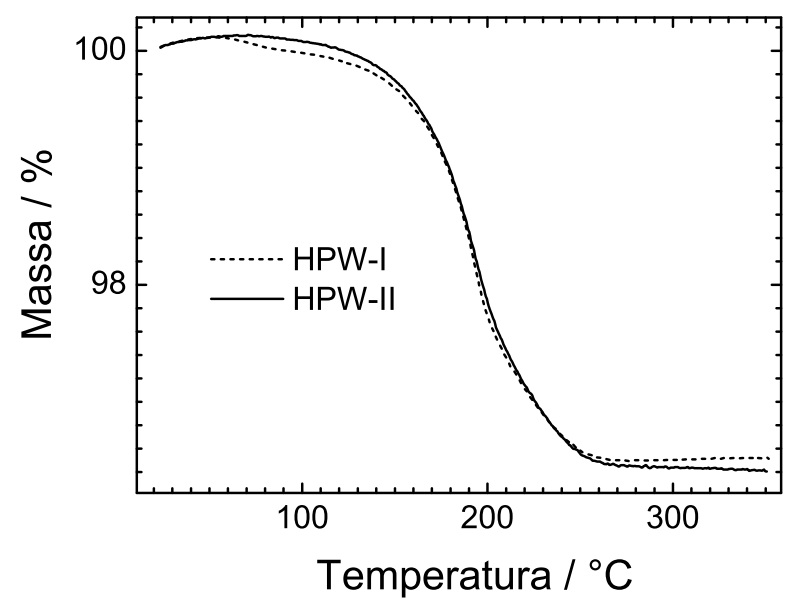

Figura 6.9-Curvas de TGA desde temperatura ambiente até $350^{\circ} \mathrm{C}$, para amostras de HPW após tratamento térmico a $85^{\circ} \mathrm{C}$ por $2 \mathrm{~h}$ em duas condições: sem controle de atmosfera (HPW-I) e com fluxo constante de $\mathrm{N}_{2}$ (HPW-II). Os experimentos foram realizados em uma microbalança térmica TG 209 - NETZSCH, variando a temperatura em passos de $10^{\circ} \mathrm{C} / \mathrm{min}$ sob fluxo de $\mathrm{N}_{2}$. Fonte: Elaborada pelo autor.

final das amostras após os tratamentos térmicos. A figura 6.10 mostra os difratogramas obtidos para as amostras de HPW-I e HPW-II comparadas ao difratograma para uma amostra 
de HPW.6 $6 \mathrm{H}_{2} \mathrm{O}$ extraído da Ref..(23) Como será discutido nas seções posteriores, durante os experimentos de RMN com variação de temperatura, alterações estruturais foram identificadas na amostra HPW-I. Por isso, a figura 6.10 mostra o difratograma de raios-X obtido para a amostra HPW-I após os experimentos de RMN com variação de temperatura.

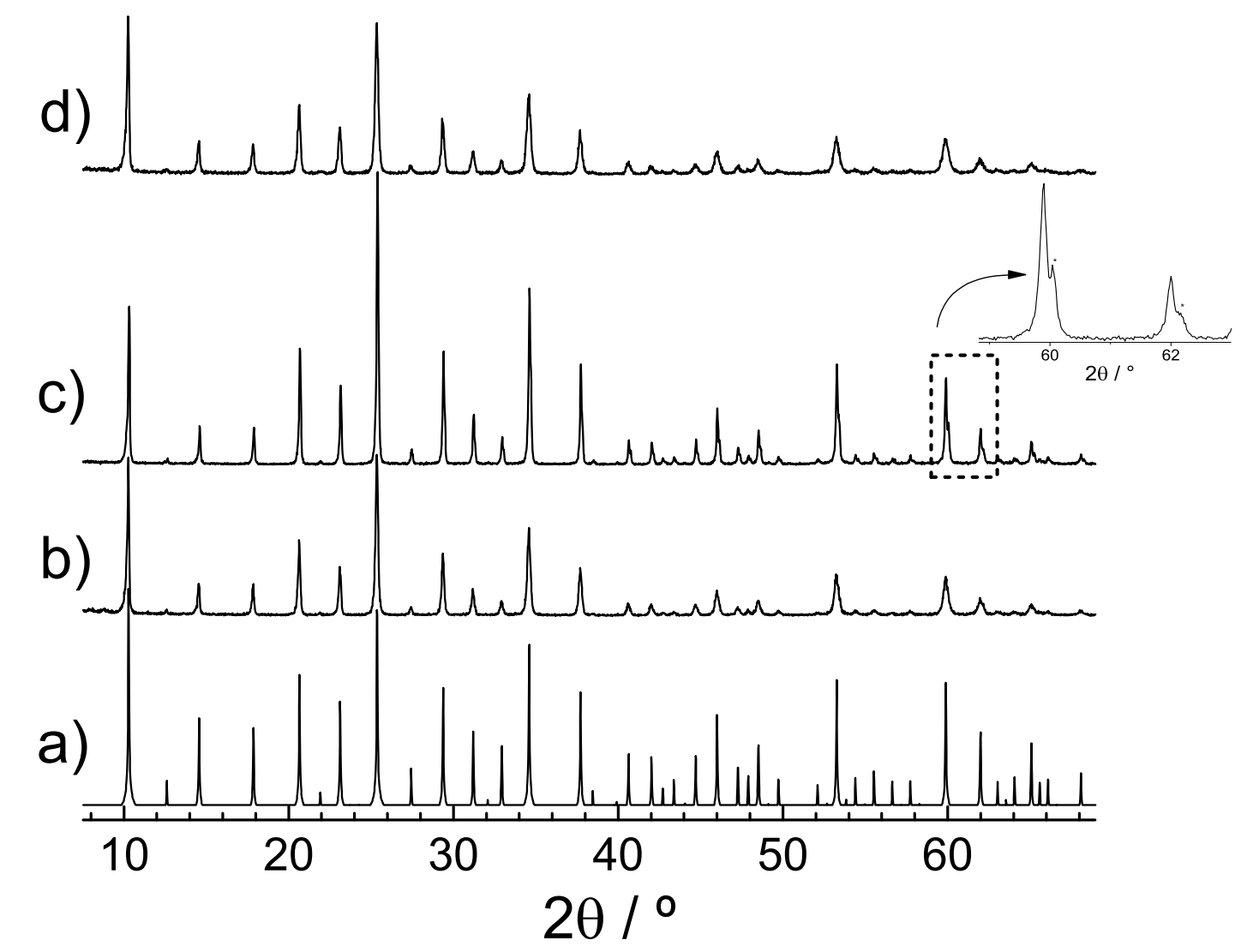

Figura 6.10-Difratogramas de raios-X para diferentes amostras em pó: $\mathrm{HPW} \cdot 6 \mathrm{H}_{2} \mathrm{O}$, difratograma calculado por refinamento utilizando o método de Rietveld - Fonte: KREMENOVIC (23) (a), HPW-I logo após secagem (b), HPW-I após ser submetido à experimentos de RMN com variação de temperatura até $85^{\circ} \mathrm{C}-0$ in set mostra em detalhe parte do difratograma (c) e HPW-II logo após secagem (d). Fonte: Elaborada pelo autor.

Os difratogramas correspondem a uma estrutura cristalina cúbica (BCC) para ambas as amostras, em acordo com os dados da literatura.(6, 23, 24, 27) Os valores do parâmetro de cela cristalina, a,obtidos para as amostras de HPW-I e HPW-II logo após as secagens são $12,158(6) \AA ̊$ e $12,159(2) \AA ̊$ respectivamente, e estão de acordo com o valor obtido por Kremenovic et al., $a=12,1516(7) \AA ̊$. Após realização dos experimentos de RMN com variação de temperatura, a estrutura cristalina da amostra HPW-I é alterada. O parâmetro $a$ sofre uma redução para $12,142(9) \AA ̊$, mostrando uma compactação da estrutura. Adicionalmente, no difratograma da figura 6.10. c é possível observar uma duplicidade nos picos acima de $50^{\circ}$, que pode ser melhor observada no in set da figura. Esta duplicidade indica a criação de defeitos locais, associados à remoção e/ou rearranjo das moléculas de $\mathrm{H}_{2} \mathrm{O}$. 


\subsubsection{1 ${ }^{31} \mathrm{P}$ RMN}

Na figura 6.11 estão mostrados os espectros de ${ }^{31} \mathrm{P}$ MAS RMN, obtidos em temperatura ambiente, para amostras de HPW submetidas a diferentes ciclagens térmicas e para uma amostra de $\mathrm{HPW} \cdot \mathrm{nH}_{2} \mathrm{O}$. Os valores de desvio químico obtidos para os diferentes espectros são exibidos na tabela 6.2. O espectro para a amostra HPW-I, submetida a tratamento térmico a $85^{\circ} \mathrm{C}$ por $2 \mathrm{~h}$ em atmosfera não controlada, é mostrado na figura 6.11.b. Este espectro apresenta um desvio na frequência de ressonância, comparado ao espectro para o $\mathrm{HPW} \cdot \mathrm{nH}_{2} \mathrm{O}$, e um aumento na largura espectral, indicando mudanças estruturais e/ou dinâmicas no ambiente químico ao redor do poliânion de HPW. O desvio químico da linha central, em -15,7ppm, é consistente com o desvio reportado na literatura para o $\mathrm{HPW} \cdot 6 \mathrm{H}_{2} \mathrm{O},-15,6 \mathrm{ppm}$.(30) $\mathrm{O}$

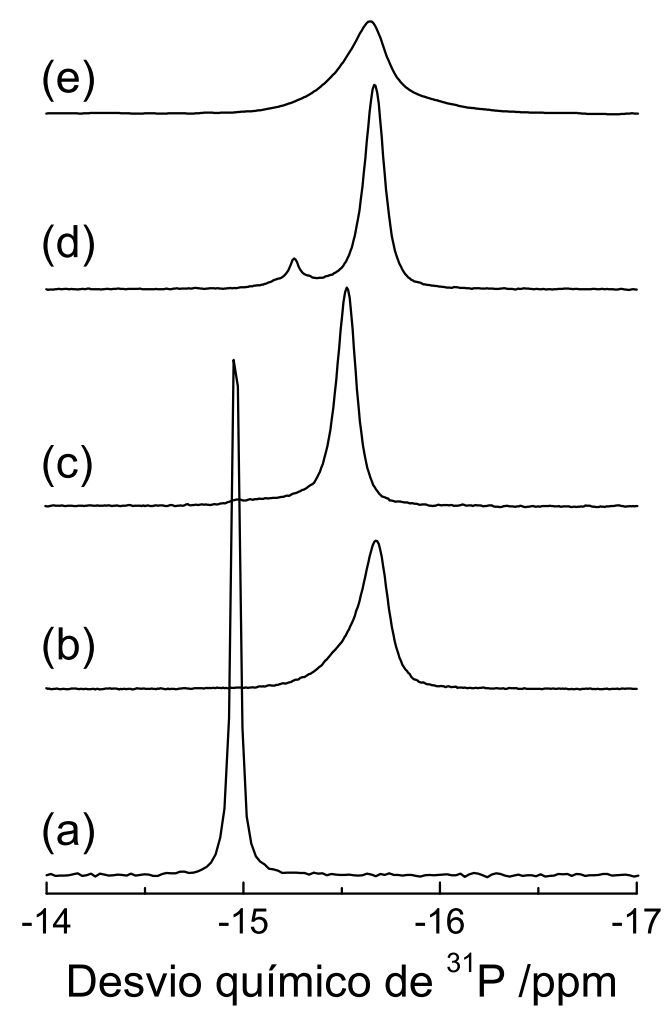

Figura 6.11-Espectros de ${ }^{31} \mathrm{P}$ MAS RMN medidos em temperatura ambiente para amostras de HPW submetidas a diferentes secagens e ciclagens térmicas. (a) Amostra comercial de $\mathrm{HPW} \cdot \mathrm{nH}_{2} \mathrm{O}$ sem tratamentos térmicos. (b) Amostra HPW-I imediatamente após secagem. (c) Amostra HPW-I após ciclagem térmica de aquecimento e resfriamento entre $20^{\circ} \mathrm{C}$ e $85^{\circ} \mathrm{C}$. (d) Amostra HPW-I seis dias após ciclagem térmica. (e) amostra HPW-II. Fonte: Elaborada pelo autor.

espectro da figura 6.11.b é assimétrico, com um ombro em -15,4ppm, indicando a existência 
de heterogeneidade estrutural ou química para as espécies no ambiente de coordenação dos poliânions de HPW. A figura 6.11.c exibe o espectro para a amostra de HPW-I após ciclo térmico de aquecimento e resfriamento entre $20^{\circ} \mathrm{C}$ e $85^{\circ} \mathrm{C}$ durante experimentos de MAS RMN com variação de temperatura (VT) mostrados mais abaixo. Este espectro apresenta uma linha mais estreita e simétrica, centrada em $-15,5 \mathrm{ppm}$, indicando a ocorrência de reorganização estrutural após os experimentos com VT, com ambientes químicos mais definidos para o HPW. Entretanto, este estado não é estável, como pode ser observado no espectro da figura 6.11.d, medido seis dias após o experimento de VT, com a amostra estocada em dessecador, selada dentro do rotor utilizado nos experimentos de RMN. A posição do pico central retorna para $-15,7 \mathrm{ppm}$, e um pico menor é observado em -15,3ppm. Este comportamento foi reproduzido para diferentes amostras, submetidas aos mesmos ciclos térmicos e secagens. Por outro lado, a figura 6.11. e exibe os espectro de ${ }^{31} \mathrm{P}$ RMN para a amostra HPW-II, que passou por secagem em atmosfera saturada com $\mathrm{N}_{2}$. O espectro exibe pico ligeiramente assimétrico, com máximo em -15,6ppm. Este espectro é invariante frente às mesmas ciclagens térmicas e períodos de estocagens aos quais a amostra de HPW-I foi submetida. Portanto, o HPW-II constitui uma amostra mais estável do que o HPW-I, e conforme será discutido neste capítulo o estado desta amostra é mais consistente com a estrutura proposta para o cristal de HPW. $6 \mathrm{H}_{2} \mathrm{O}$.

Tabela 6.2-Desvios químicos de ${ }^{31} \mathrm{P}$ e ${ }^{1} \mathrm{HRMN}$ para as amostras de HPW-I antes e após ciclagem térmica e HPW-II, obtidos dos espectros em $20^{\circ} \mathrm{C}$

\begin{tabular}{lcc} 
Amostra & ${ }^{31} \mathbf{P}-\boldsymbol{\delta}_{\text {iso }} \mathbf{( p p m )}$ & ${ }^{1} \mathbf{H}-\boldsymbol{\delta}_{\text {iso }}(\mathbf{p p m})$ \\
\hline $\mathrm{HPW} \cdot \mathrm{nH}_{2} \mathrm{O}$ & $-14,9$ & 7.4 \\
$\mathrm{HPW}-\mathrm{I}$ & $-15,7 /-15,4$ & $7,3 / 6,9$ \\
$\mathrm{HPW}-\mathrm{I}-$ aquecido & -15.5 & $7 / 6,6 / 6,2$ \\
$\mathrm{HPW}-\mathrm{I}-$ aquecido +1 dia & $-15,7 /-15,3$ & $7,6 / 6,8 / 6,4$ \\
$\mathrm{HPW}-\mathrm{I}-$ aquecido +7 dias & $-15.7 ;-15.3$ & $7,6 / 7,2 / 6,4$ \\
$\mathrm{HPW}-\mathrm{II}$ & $-15,6$ & 8,9 \\
\hline
\end{tabular}

Fonte: Elaborada pelo autor.

Foram realizados experimentos de ${ }^{31} \mathrm{P}$ MAS RMN em função da temperatura para as amostras de HPW-I e HPW-II, com aquecimento de $20^{\circ} \mathrm{C}$ a $85^{\circ} \mathrm{C}$ e subsequente resfriamento até temperatura ambiente. Os espectros de ${ }^{31} \mathrm{P}$ RMN para a amostra HPW-I durante o aquecimento e resfriamento são exibidos nas figuras 6.12. a e b respectivamente. A variação do desvio químico da linha central durante os ciclos de aquecimento e resfriamento (6.13. a) revela a existência de histerese térmica para esta amostra. Dois regimes podem ser identificados durante a evolução do sinal de ${ }^{31} \mathrm{P}$ RMN. De $20^{\circ} \mathrm{C}$ a $40^{\circ} \mathrm{C}$ o espectro é constituído de uma linha estreita, com pequena variação da largura. A partir de $40^{\circ} \mathrm{C}$, o espectro apresenta um aumento progressivo da largura, conforme mostrado no gráfico da figura 6.13. b. A temperatura de 


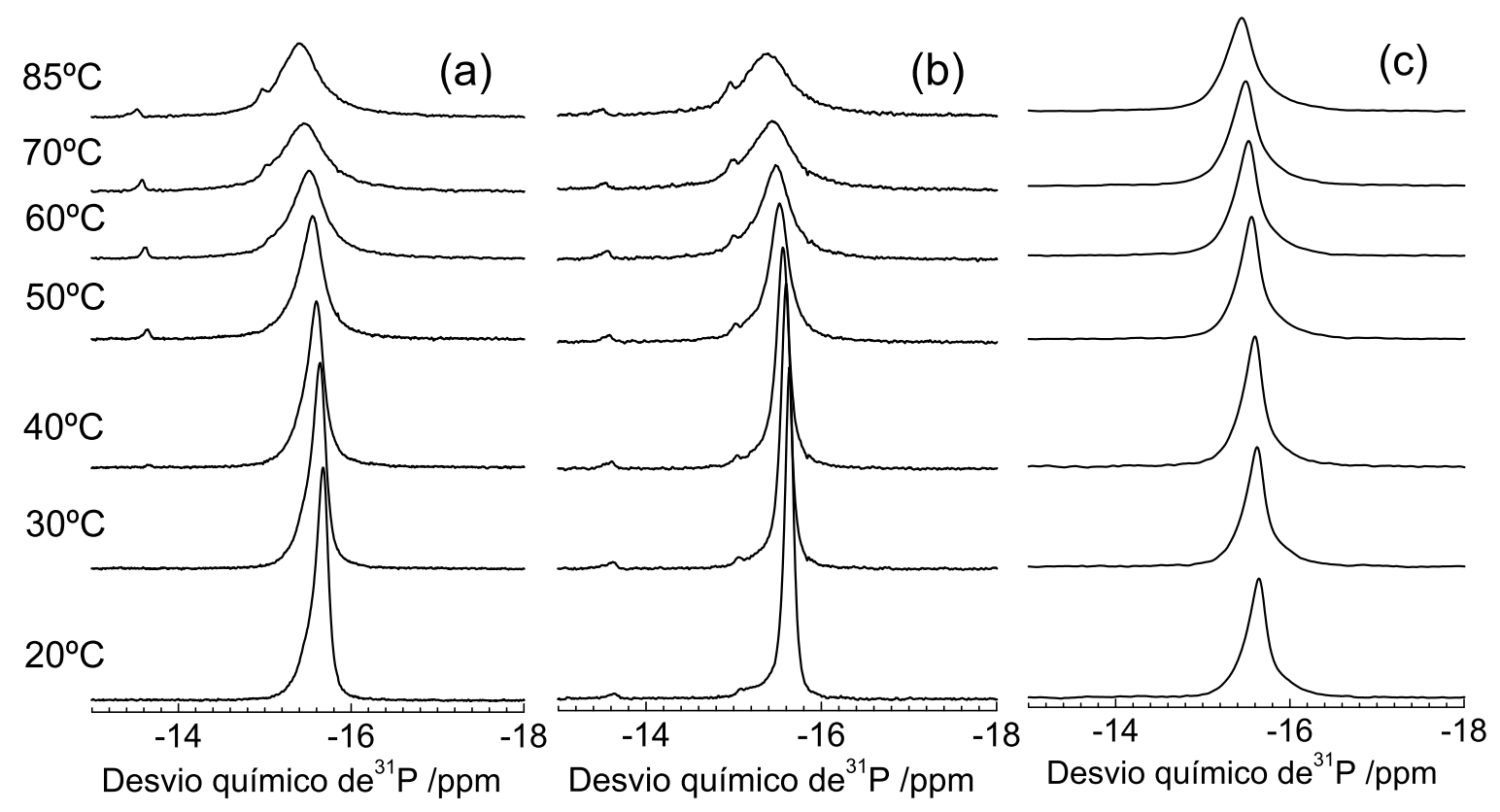

Figura 6.12-Espectros de ${ }^{31} \mathrm{P}$ MAS RMN medidos em função da temperatura durante ciclos de aquecimento (a) e resfriamento (b) sobre a amostra HPW-I, e durante o aquecimento para a amostra HPW-II (c). Fonte: Elaborada pelo autor.

transição entre estes dois regimes é consistente com a temperatura onde ocorre a transição de fase não-convergente relatada na literatura, $\mathrm{T}_{C}=47^{\circ} \mathrm{C}$, para o $\mathrm{HPW} \cdot 6 \mathrm{H}_{2} \mathrm{O} .(23$, 24) Durante o resfriamento, o alargamento espectral é revertido, no entanto é observado efeito de histerese para o desvio químico. Este efeito também pode ser observado nos espectros da figura 6.11.b e c, e é reprodutível para outras amostras de HPW-I. Durante o aquecimento, a partir de $40^{\circ} \mathrm{C}$ surge um novo sítio com sinal centrado em $\approx-13,6 \mathrm{ppm}$, e a partir de $50^{\circ} \mathrm{C}$ um pico estreito aparece em -14.9ppm. O desvio em -13,6ppm pode ser atribuído a espécies de HPW em menor estado de hidratação, conforme mostrado na seção 6.1.2 e na Ref..(30) Este sinal continua presente após o resfriamento, desaparecendo após um dia (com a amostra estocada em temperatura ambiente), correspondendo portanto à um estado metaestável. O sinal em -14,9ppm, por sua vez, também continua presente após o resfriamento da amostra, e também corresponde a um estado de metaestabilidade. Por outro lado, o sinal de ${ }^{31} \mathrm{P}$ RMN da amostra HPW-II não apresenta nenhum efeito de histerese ou metaestabilidade. Os espectros de ${ }^{31} \mathrm{P}$ RMN em função da temperatura para esta amostra são exibidos na figura 6.12. c, e são idênticos durante os ciclos de aquecimento e resfriamento. O desvio químico e a largura a meia altura para estes espectros são mostrados nas figuras 6.15, estes parâmetros variam continuamente com a temperatura, e nenhuma alteração em particular é observada por volta da temperatura de transição $\mathrm{T}_{c}$ do $\mathrm{HPW} \cdot 6 \mathrm{H}_{2} \mathrm{O}$. Como esta amostra exibe maior estabilidade, foram realizados experimentos de ${ }^{31} \mathrm{P}$ RMN abrangendo uma faixa maior de temperaturas, de $-50^{\circ} \mathrm{C}$ a $85^{\circ} \mathrm{C}$ 


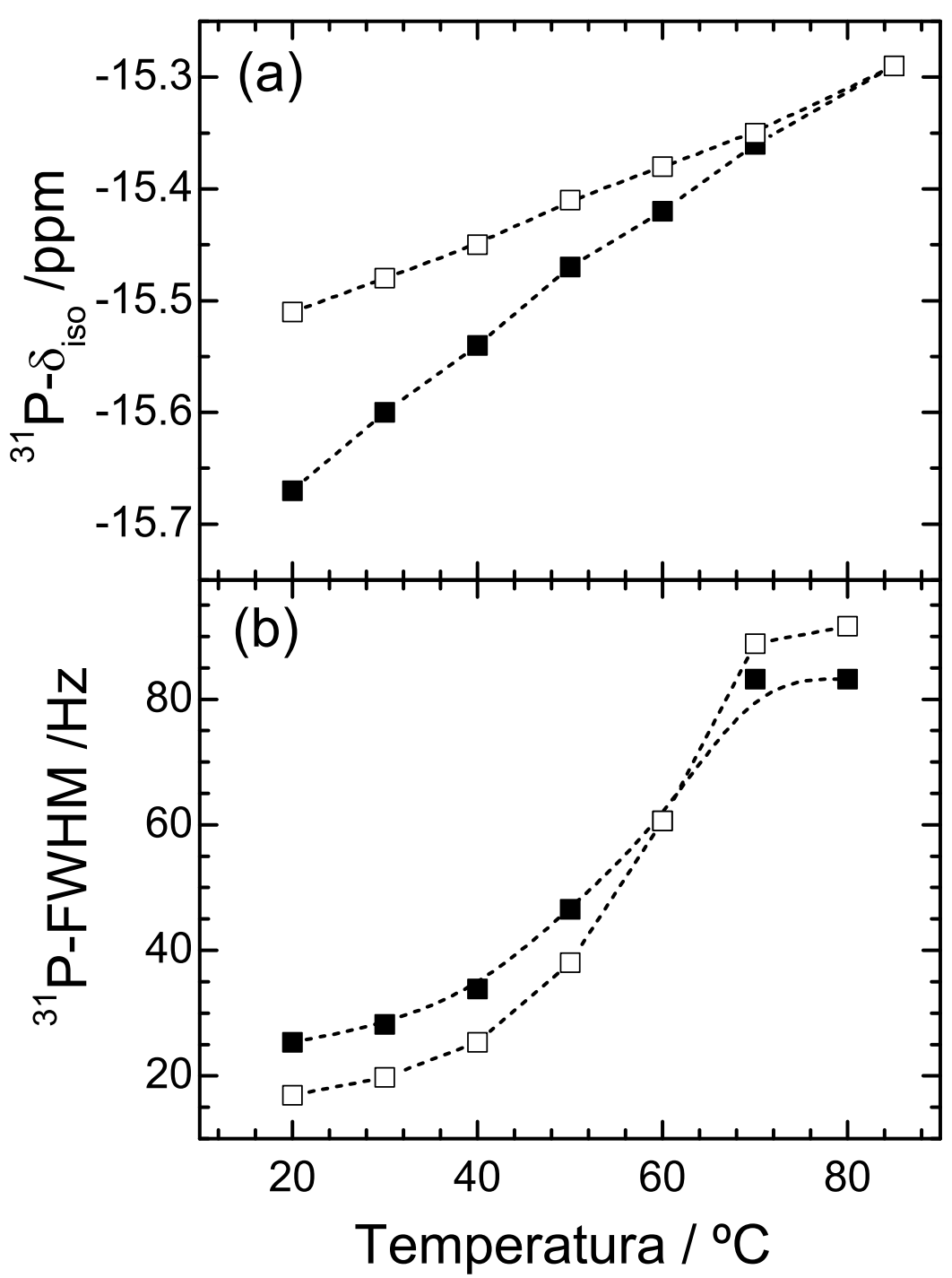

Figura 6.13-Parâmetros espectrais do experimento de ${ }^{31} \mathrm{P}$ RMN sobre a amostra HPW-I. (a) Desvio químico da linha central $\left({ }^{31} \mathrm{P}-\delta_{\text {iso }}\right)$. (b) Largura a meia altura (FWHM). Os dados foram obtidos durante o aquecimento (símbolos cheios) e o resfriamento (símbolos vazios) da amostra. Fonte: Elaborada pelo autor.

(figura 6.14). Os valores de desvio químico e largura para estes espectros, e para os espectros obtidos durante o resfriamento acima de temperatura ambiente, estão representados em função da temperatura na figura 6.15. A evolução do desvio químico de ${ }^{31} \mathrm{P}$ com a temperatura é linear (figura 6.15.a), sem nenhuma alteração que possa indicar alguma transição na estrutura local dos tetraedros $\mathrm{PO}_{4}$. A largura a meia altura (figura 6.15.b) do espectro de ${ }^{31} \mathrm{P}$ apresenta um mínimo por volta de $20^{\circ} \mathrm{C}$. Este comportamento está intimamente relacionado com alterações na estrutura e/ou dinâmica do ambiente de prótons ao redor do poliânion em função da temperatura, como será mostrado na seção 6.1.3.2. 


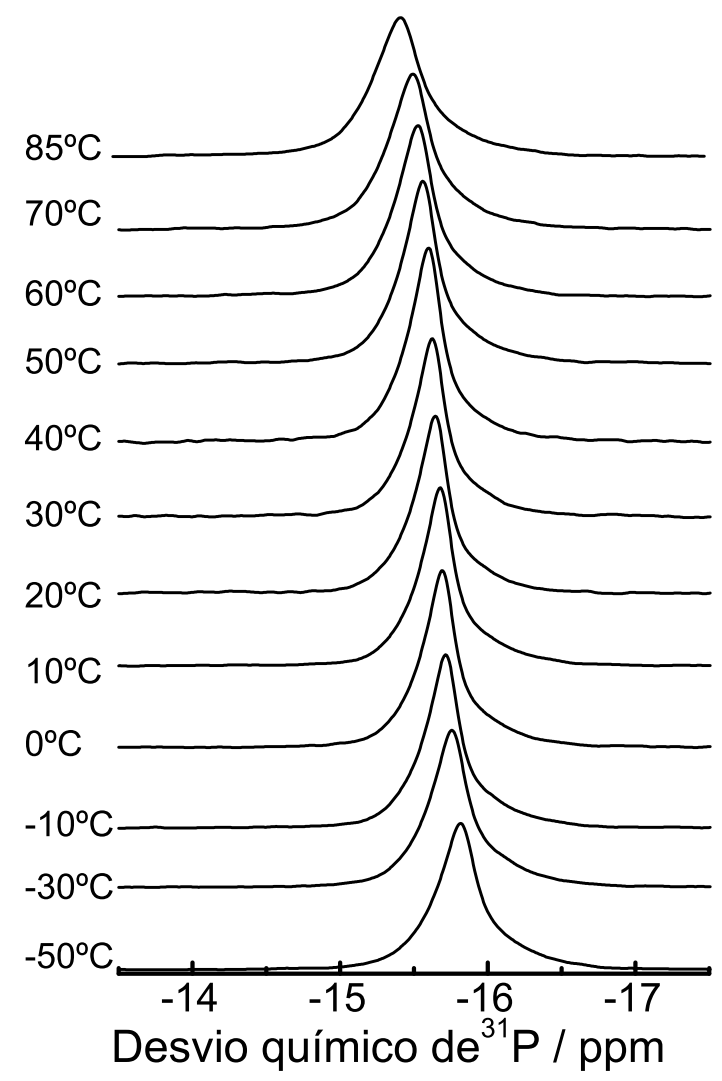

Figura 6.14-Espectros de ${ }^{31} \mathrm{P}$ RMN para a amostra HPW-II medidos em diferentes temperaturas. Fonte: Elaborada pelo autor.

\subsubsection{2 ${ }^{1} \mathrm{H}$ RMN}

Na figura 6.16 estão mostrados os espectros de ${ }^{1} \mathrm{H}$ MAS RMN, obtidos em temperatura ambiente, para amostras de HPW submetidas a diferentes ciclagens térmicas e para uma amostra de $\mathrm{HPW} \cdot \mathrm{nH}_{2} \mathrm{O}$. Os desvios químicos para os picos observados nos diferentes espectros estão compilados na tabela 6.2. $\mathrm{O}$ espectro para a amostra de $\mathrm{HPW} \cdot \mathrm{nH}_{2} \mathrm{O}$ é mostrado na figura 6.16.a, e é composto por uma linha única e estreita centrada em 7,4ppm (largura a meia altura $-F W H M=220 \mathrm{~Hz}$ ). Este valor de desvio químico pode ser atribuído a clusters do tipo $\mathrm{H}^{+}\left(\mathrm{H}_{2} \mathrm{O}\right)_{n}$.(30) $\mathrm{O}$ espectro de ${ }^{1} \mathrm{H}$ e a existência de bandas laterais bem resolvidas indica alta mobilidade para estas espécies de ${ }^{1} \mathrm{H}$ e baixo acoplamento dipolar homonuclear ${ }^{1} \mathrm{H}-{ }^{1} \mathrm{H}$.(92) Comportamento similar é observado para o espectro de ${ }^{1} \mathrm{H}$ RMN da amostra HPW-I (figura 6.16 b), medido imediatamente após a secagem da amostra. $O$ espectro apresenta linha centrada em 7,3ppm e um ombro parcialmente resolvido em 6,9ppm (FWHM total $=270 \mathrm{~Hz}$ ). Estudos anteriores revelam espectros similares de ${ }^{1} \mathrm{HRMN}$ para amostras de $\mathrm{HPW} \cdot \mathrm{nH}_{2} \mathrm{O}$ tratadas a $50^{\circ} \mathrm{C}$ e a $100^{\circ} \mathrm{C}$ (desvios químicos entre $7,0 \mathrm{ppm}$ e $7,5 \mathrm{ppm}, \mathrm{FWHM}=400 \mathrm{~Hz}$ ).(30) 


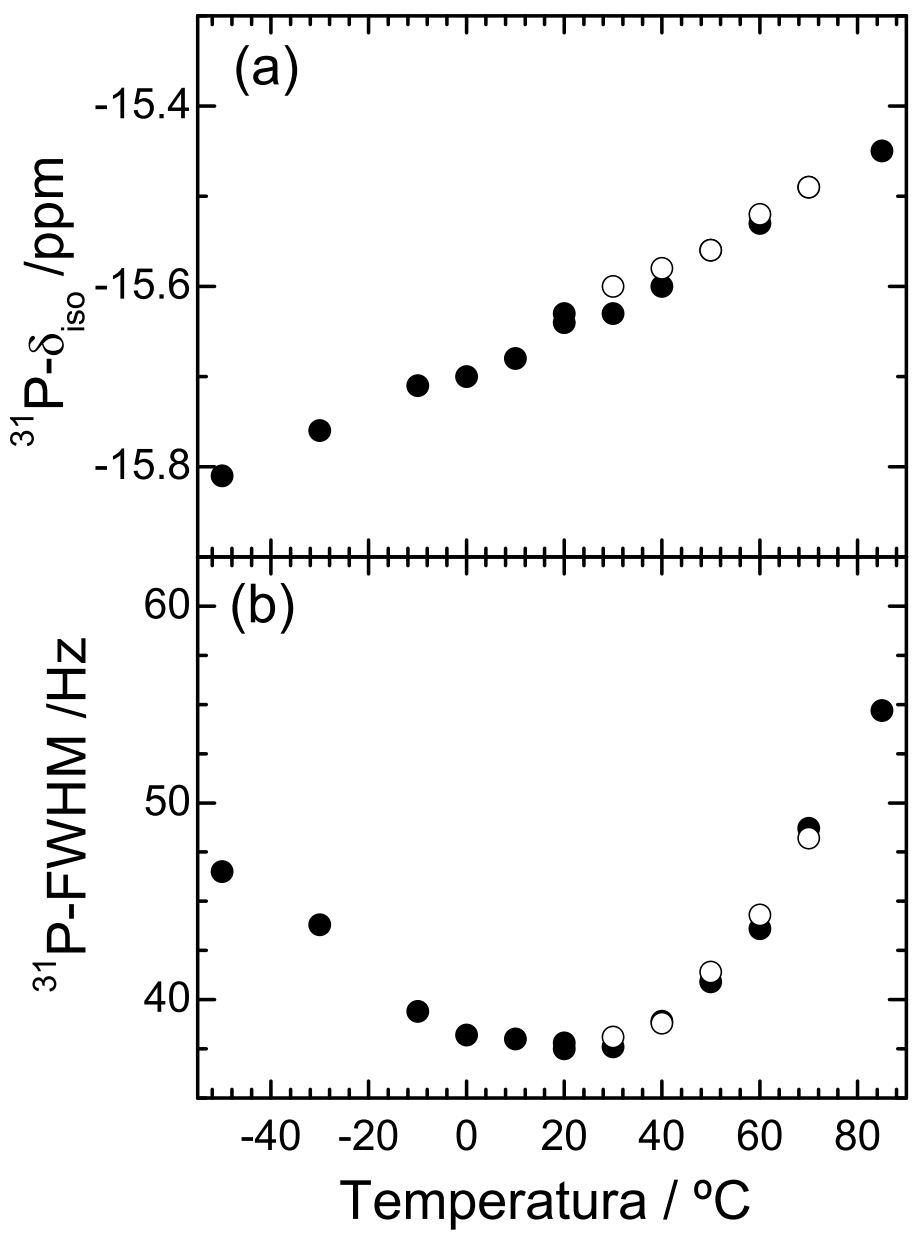

Figura 6.15-Parâmetros espectrais do experimento de ${ }^{31} \mathrm{P}$ RMN sobre a amostra HPW-II. (a) Desvio químico da linha central $\left({ }^{31} \mathrm{P}-\delta_{\text {iso }}\right)$. (b) Largura a meia altura (FWHM). Os dados foram obtidos durante o aquecimento (símbolos cheios) e o resfriamento (símbolos vazios) da amostra. Fonte: Elaborada pelo autor.

Após um ciclo de aquecimento e resfriamento entre $20^{\circ} \mathrm{C}$ e $85^{\circ} \mathrm{C}$ durante a realização de experimentos de MAS RMN, a amostra HPW-I exibe um espectro de ${ }^{1} \mathrm{H}$ RMN mais complexo em temperatura ambiente (figura 6.16.c), com dois picos em 6,6ppm e 6,2ppm e um ombro largo por volta de $7 \mathrm{ppm}$. Medidas subsequentes nesta amostra resultam em espectros com alterações, indicando que o espectro mostrado na figura 6.16.c corresponde a prótons em um estado metaestável. Seis dias após o ciclo térmico a amostra encontra-se em um estado mais estável, e o espectro de ${ }^{1} \mathrm{H}(6.16 \mathrm{~d})$ apresenta linhas centradas em 7,6ppm, 7,2ppm e 6,4ppm. O mesmo conjunto de linhas e tempos de evolução é observado para um segundo ciclo térmico para esta mesma amostra, com diferenças apenas na relação de intensidades entre os picos. As linhas em 6,6ppm e 6,2ppm podem ser atribuídas a moléculas de $\mathrm{H}_{2} \mathrm{O}$ com alta mobilidade em clusters grandes, enquanto as linhas em 7,6ppm e 7,2ppm podem ser atribuídas a clusters 
menores, como $\mathrm{H}^{+}\left(\mathrm{H}_{2} \mathrm{O}\right)_{n}$ e íons $\mathrm{H}_{5} \mathrm{O}_{2}{ }^{+} .(30,94)$
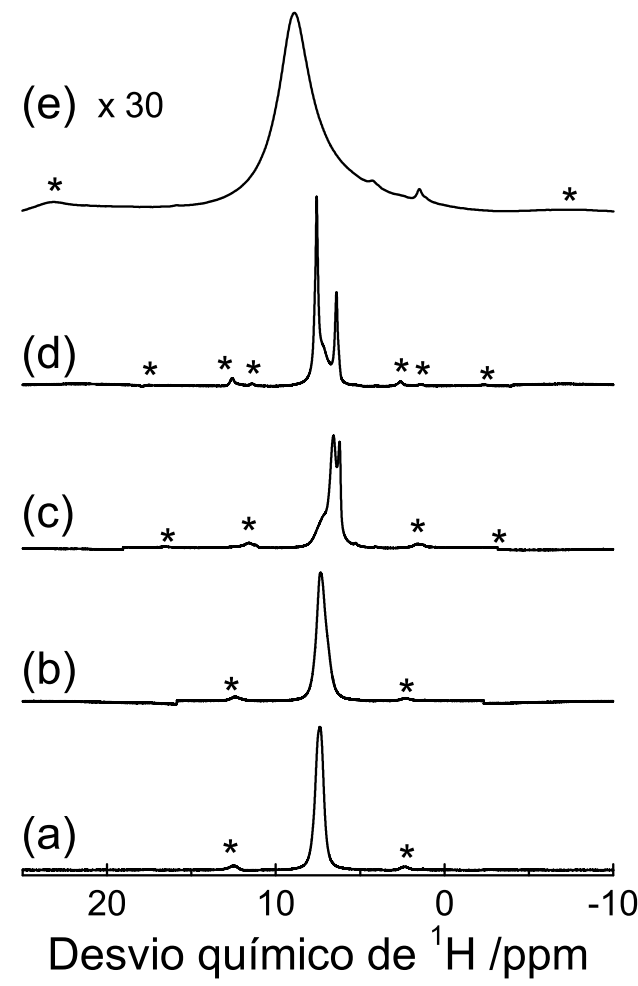

Figura 6.16-Espectros de ${ }^{1} \mathrm{H}$ MAS RMN medidos em temperatura ambiente para amostras de HPW submetidas a diferentes secagens e ciclagens térmicas. (a) Amostra comercial de $\mathrm{HPW} \cdot \mathrm{nH}_{2} \mathrm{O}$ sem tratamentos térmicos. (b) Amostra HPW-I imediatamente após secagem. (c) Amostra HPW-I após ciclagem térmica de aquecimento e resfriamento entre $20^{\circ} \mathrm{C}$ e $85^{\circ} \mathrm{C}$. (d) Amostra HPW-I seis dias após ciclagem térmica. (e) amostra HPW-II. Fonte: Elaborada pelo autor.

Por outro lado, o espectro de ${ }^{1} \mathrm{H}$ para a amostra de HPW-II (figura 6.16.e) apresenta uma linha larga $(F W H M=1 \mathrm{KHz})$ e centrada em $8.9 \mathrm{ppm}$. O desvio da linha para valores maiores do que os observados para o HPW-I indica que esta ressonância corresponde a prótons mais ácidos. Este resultado é consistente com resultados reportados anteriormente, onde uma ressonância em 8,5ppm, observada para uma amostra de $\mathrm{HPW}$ tratada a $100^{\circ} \mathrm{C}$, foi atribuída a íons $\mathrm{H}_{3} \mathrm{O}^{+}$ realizando ligações de hidrogênio com moléculas $\mathrm{H}_{2} \mathrm{O}$.(30) A linha espectral observada na figura 6.16. e apresenta uma leve assimetria na direção de desvios menores, indicando a presença de espécies $\mathrm{H}^{+}\left(\mathrm{H}_{2} \mathrm{O}\right)_{n}$ e/ou $\mathrm{H}_{5} \mathrm{O}_{2}{ }^{+}$. Para resolver parcialmente as bandas laterais do espectro de ${ }^{1} \mathrm{H}$ para o HPW-II, é preciso rodar a amostra a velocidades maiores $(5 \mathrm{KHz})$ do que as utilizadas para o HPW-I $(2 \mathrm{KHz})$, indicando a existência de forte acoplamento dipolar homonuclear para as espécies ${ }^{1} \mathrm{H}$, e consequentemente mobilidade reduzida para estes prótons, comparando-se com as outras amostras.

Na figura 6.17 são mostrados espectros de ${ }^{1} \mathrm{H}$ MAS RMN em função da temperatura para 
as amostras de HPW-I, durante aquecimento de $20^{\circ} \mathrm{C}$ a $85^{\circ} \mathrm{C}$ (figura 6.17. a) e subsequente resfriamento até temperatura ambiente (figura 6.17.b), e de HPW-II durante aquecimento (figura 6.17.c). Conforme mostrado acima, antes do aquecimento, o espectro de ${ }^{1} \mathrm{H}$ RMN para a amostra HPW-I é constituído de uma única linha centrada em 7,3ppm. Com o aumento da temperatura, o espectro de ${ }^{1} \mathrm{H}$ passa por mudanças substanciais por volta de $40^{\circ} \mathrm{C}$, onde o espectro é alargado e uma nova ressonância começa a surgir por volta de 6,5ppm. Para temperaturas mais altas a linha em $7,6 \mathrm{ppm}$ desaparece e o espectro em $85^{\circ} \mathrm{C}$ fica constituído por uma única linha, centrada em 6ppm. Durante o resfriamento, mudanças contínuas ocorrem no espectro de ${ }^{1} \mathrm{H}$ RMN, sem nenhuma temperatura específica de transição (figura 6.17.b). Abaixo de $40^{\circ} \mathrm{C}$ algumas linhas passam a ser resolvidas no espectro, e em temperatura ambiente o espectro resultante é complexo, e composto de diversas linha sobrepostas. Este espectro corresponde a um estado metaestável para as espécies de ${ }^{1} \mathrm{H}$, como mostrado pela evolução temporal em temperatura ambiente (figuras 6.16.c e d). As diferentes espécies observadas podem constituir moléculas de água intersticial e/ou clusters do tipo $\mathrm{H}^{+}\left(\mathrm{H}_{2} \mathrm{O}\right)_{n}$, com diferentes valores de $n$.

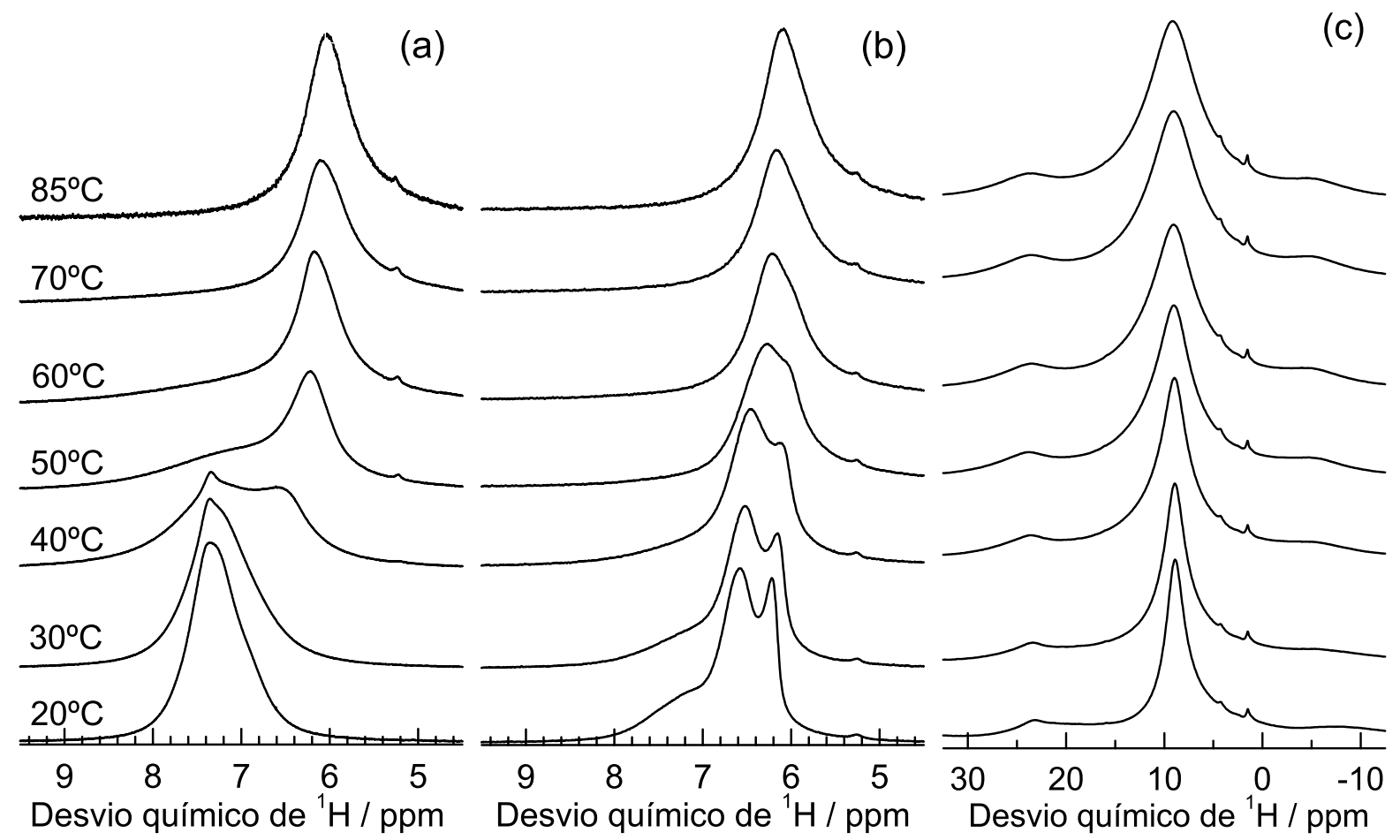

Figura 6.17-Espectros de ${ }^{1} \mathrm{H}$ MAS RMN medidos em função da temperatura durante ciclos de aquecimento (a) e resfriamento (b) sobre a amostra HPW-I, e durante o aquecimento para a amostra HPW-II (c). Fonte: Elaborada pelo autor.

Para a amostra HPW-II nenhuma destas transformações complexas é observada em função da temperatura nos espectros de ${ }^{1} \mathrm{H}$ RMN (figura 6.17.c). A ausência de histerese térmica no intervalo de temperaturas analisado indica que nesta amostra os prótons encontram-se em 
um estado mais estável. O espectro de ${ }^{1} \mathrm{H}$ é constituído de uma única linha, cuja largura (FWHM) aumenta com a temperatura. As bandas laterais não são completamente resolvidas nos espectros, indicando alto acoplamento dipolar homonuclear para as espécies ${ }^{1} \mathrm{H}$, mesmo em altas temperaturas. Duas linhas estreitas e de menor intensidade são visíveis em 4,3ppm e $1,5 \mathrm{ppm}$, que podem estar associadas a prótons com alta mobilidade, como por exemplo prótons de grupos $\mathrm{OH}$, difundindo entre sítios $\mathrm{O}$. $\mathrm{O}$ aumento de largura da linha central poderia ter duas explicações. A primeira seria uma dinâmica rápida para os ${ }^{1} \mathrm{H}$, diminuindo o valor do tempo de relaxação longitudinal $\left(T_{1}\right)$ até a ordem do tempo de relaxação transversal $\left(T_{2}\right)$. Uma segunda explicação poderia ser o aumento no acoplamento dipolar ${ }^{1} \mathrm{H}-{ }^{1} \mathrm{H}$ devido à alterações estruturais no ambiente de prótons. Para verificar a primeira alternativa, foi medido o tempo de relaxação spin-rede, utilizando-se a técnica de inversão e recuperação.(71) Estes resultados são mostrados na figura 6.18. Os tempos de relaxação obtidos foram de $0,37 \pm 0,05 \mathrm{~s}$ e $0,46 \pm 0,05 \mathrm{~s}$, para os experimentos realizados a $20^{\circ} \mathrm{C}$ e $85^{\circ} \mathrm{C}$ respectivamente. Estes valores semelhantes de $T_{1}$ indicam que o alargamento observado em altas temperaturas não pode ser causado por uma dinâmica rápida.

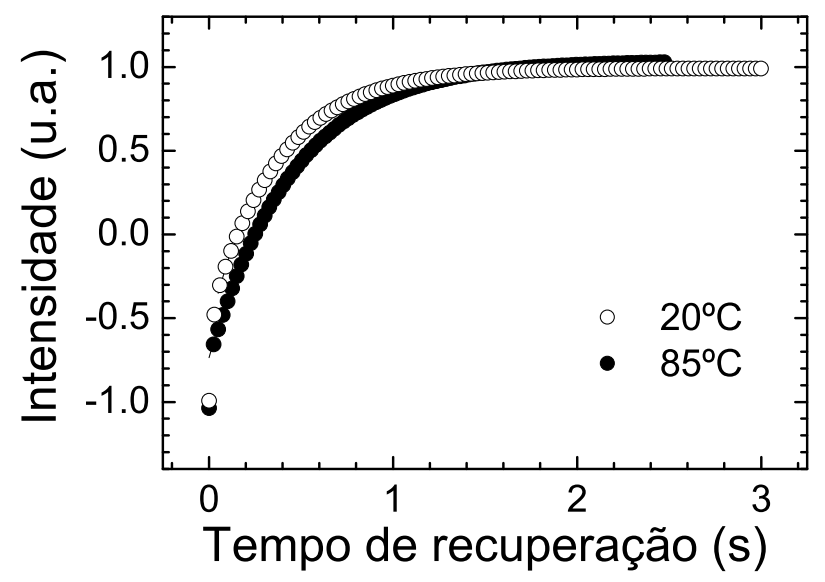

Figura 6.18-Experimentos de inversão e recuperação ${ }^{1} \mathrm{H}$ RMN realizados em $20^{\circ} \mathrm{C}$ e $85^{\circ} \mathrm{C}$, sobre a amostra HPW-II. Fonte: Elaborada pelo autor.

Para avançar na identificação das espécies de ${ }^{1} \mathrm{H}$ que constituem o espectro para a amostra HPW-II, foram realizados experimentos de ${ }^{1} \mathrm{H}$ RMN em baixa temperatura, e os espectros obtidos desde $-50^{\circ} \mathrm{C}$ até $85^{\circ} \mathrm{C}$ estão mostrados na figura 6.19. a. Observando os espectros de ${ }^{1} \mathrm{H}$ RMN duas mudanças principais podem ser observadas em função do decréscimo na temperatura. Primeiramente a linha central apresenta um alargamento substancial, ao mesmo tempo em que a intensidade e a extensão em frequência do conjunto de bandas laterais aumentam. Estas alterações indicam que há um aumento do acoplamento dipolar homonuclear ${ }^{1} \mathrm{H}-{ }^{1} \mathrm{H}$ devido à redução da mobilidade dos prótons em baixas temperaturas. Adicionalmente, para temperaturas 

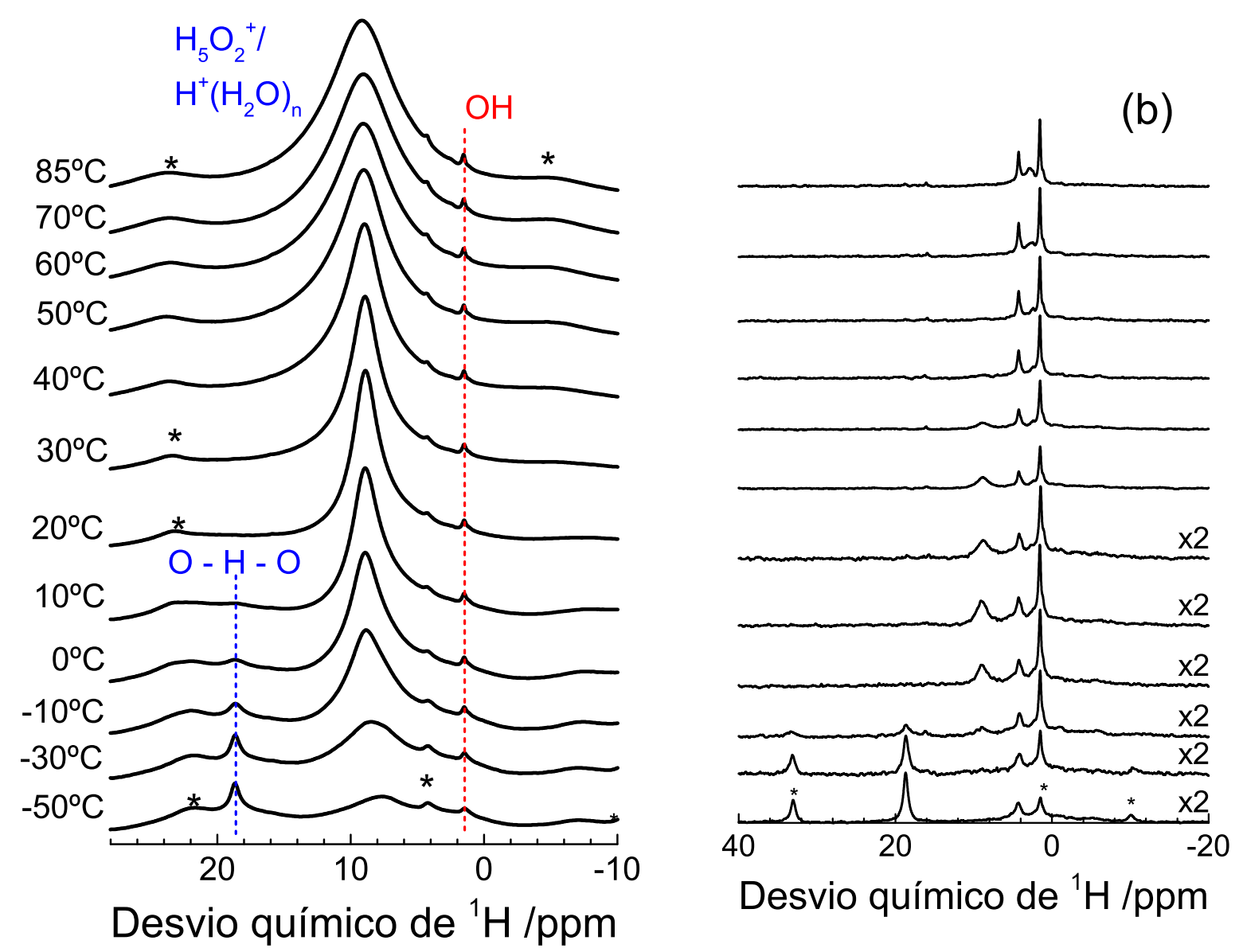

Figura 6.19-Espectros de ${ }^{1} \mathrm{H}$ MAS RMN medidos em função da temperatura para a amostra HPW-II utilizando duas técnicas: (a) técnica de polarização direta; (b) técnica de spin-eco de Hahn.(84) Os asteriscos indicam as bandas laterais. Fonte: Elaborada pelo autor.

mais baixas uma ressonância estreita $(F W H M=290 \mathrm{~Hz})$ e centrada em 18,7ppm se torna visível, e sua intensidade cresce com o decréscimo na temperatura. Este desvio químico é característico de prótons estabelecendo pontes de hidrogênio fortes, provavelmente devido à interação mais forte do próton central do dioxônio com uma das moléculas $\mathrm{H}_{2} \mathrm{O}$.(94) A figura 6.20 mostra o desvio químico e a largura a meia altura da linha central do espectro de ${ }^{1} \mathrm{H}$ RMN em função da temperatura. Na figura 6.20. a é possível observar uma alteração na inclinação da evolução dos desvios químicos por volta de $-10^{\circ} \mathrm{C}$, mostrando que o ambiente de prótons sofre mudanças substanciais na primeira região de temperaturas. Para temperaturas acima de $0^{\circ} \mathrm{C}$ o desvio químico não sofre grande alteração, variando de $8.9 \mathrm{ppm}$ em $0^{\circ} \mathrm{C}$ para $9.2 \mathrm{ppm}$ em $85^{\circ} \mathrm{C}$. A evolução da largura de linha (figura 6.20.b) apresenta um mínimo em temperatura ambiente, assim como observado para a largura das linhas de ${ }^{31} \mathrm{P}$ na seção anterior. Esta coincidência indica que as alterações no ambiente de prótons estão intimamente relacionadas com as alterações observadas nos espectros de ${ }^{31} \mathrm{P}$.

Como explicado na seção 3.1.8.1, em um experimento de spin-eco a intensidade do sinal 


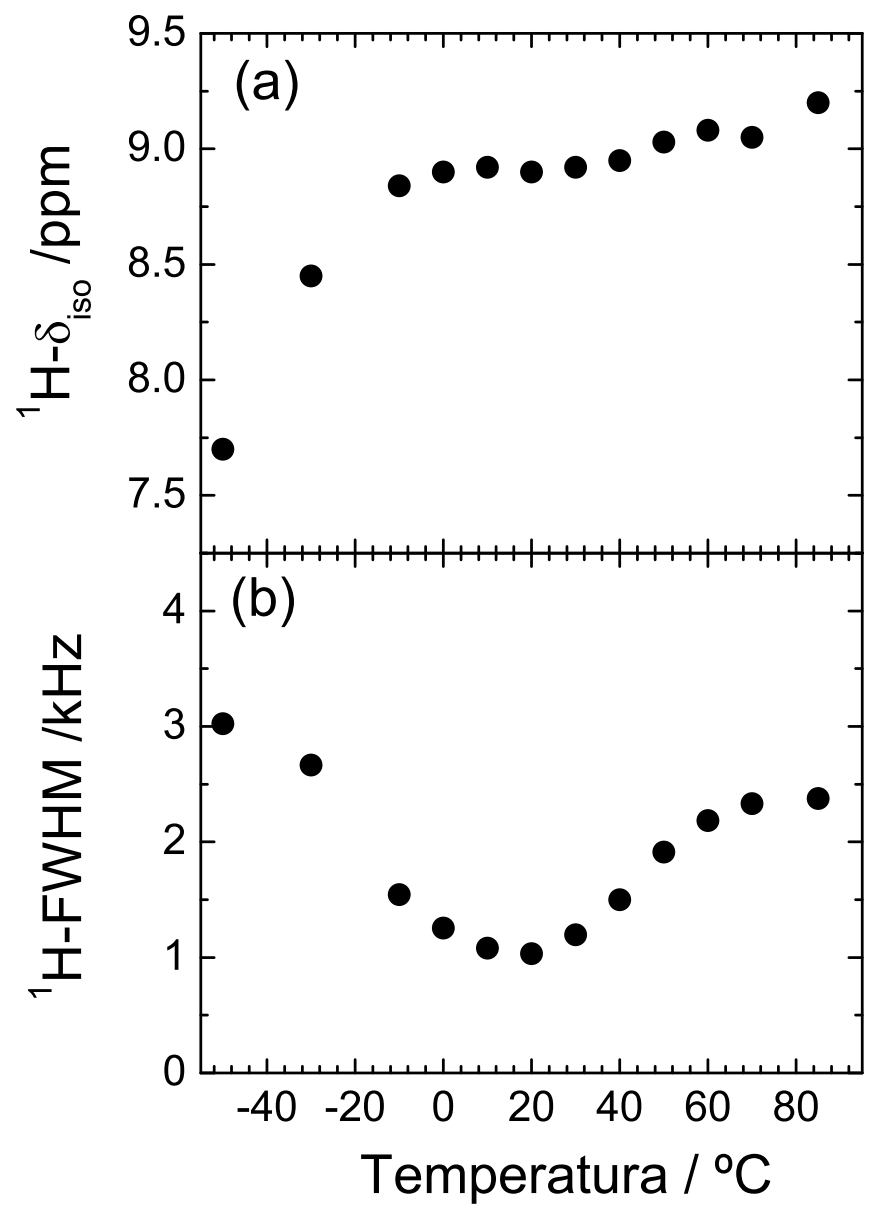

Figura 6.20-Parâmetros espectrais do experimento de ${ }^{1} \mathrm{H}$ RMN sobre a amostra HPW-II. (a) Desvio químico da linha central $\left({ }^{31} \mathrm{P}-\delta_{\text {iso }}\right)$. (b) Largura a meia altura (FWHM). Fonte: Elaborada pelo autor.

decai em função do tempo de separação $\tau$ entre os pulsos de $\pi / 2$ e $\pi$. Em RMN de ${ }^{1} \mathrm{H}$ em sólidos este decaimento é governado pelo segundo momento da interação dipolar homonuclear ${ }^{1} \mathrm{H}-{ }^{1} \mathrm{H}$. Portanto esta técnica pode ser utilizada para separar ressonâncias correspondentes a espécies experimentando diferentes intensidades de acoplamento dipolar homonuclear, uma vez que para valores de $\tau$ longos o sinal das espécies mais acopladas é atenuado. Os espectros de spin-eco ${ }^{1} \mathrm{H}$ RMN para a amostra HPW-II (com $\tau=1 \mathrm{~ms}$ ), medidos em diferentes temperaturas estão exibidos na figura 6.19.b. A linha central, em 9ppm, aparece fortemente atenuada nos espectros de spin-eco, revelando que este conjunto de prótons possui um alto acoplamento dipolar homonuclear, consistentemente com o esperado para espécies $\mathrm{H}_{5} \mathrm{O}_{2}{ }^{+}$em ligações moderadas de $\mathrm{H}$ com os $\mathrm{O}$ do poliânion.(24) As linhas mais intensas observadas nos espectros da figura 6.19.b correspondem a prótons móveis, e com baixo acoplamento dipolar homonuclear, como os prótons em pontes de hidrogênio ressoando em -18,7ppm (para temperaturas abaixo de $-10^{\circ} \mathrm{C}$ ) e prótons difundindo entre grupos $\mathrm{OH}$, ressoando em 1,5ppm e 4,2ppm. A intensidade 
das linhas em 1,5ppm e 4,2ppm aumenta com a temperatura, indicando um aumento na população destes prótons. Acima de $30^{\circ} \mathrm{C}$ é possível observar uma nova linha em $2,8 \mathrm{ppm}$, indicando acessibilidade a mais sítios para a difusão dos prótons nas temperaturas mais altas.

\subsubsection{Polarização cruzada $\left\{{ }^{1} \mathbf{H}\right\}-{ }^{31} \mathrm{P}$ RMN e analise de tempos de relaxação}

Foram realizados experimentos de $\left\{{ }^{1} \mathrm{H}\right\}{ }^{31} \mathrm{P}$ RMN a temperatura ambiente, para verificação qualitativa do acoplamento dipolar efetivo entre os núcleos ${ }^{31} \mathrm{P}$ e os ${ }^{1} \mathrm{H}$ no ambiente químico ao redor do poliânion de HPW. Trabalhos anteriores reportam a impossibilidade de obtenção de sinal de polarização cruzada $\left\{{ }^{1} \mathrm{H}\right\}{ }^{31} \mathrm{P}$ em HPW $\cdot \mathrm{nH}_{2} \mathrm{O} .(18,30)$ Como mostram os resultados de ${ }^{31} \mathrm{P}$ RMN em condição estática (figura 6.1 da seção 6.1.1), este comportamento se deve à alta mobilidade relativa entre o poliânion de HPW e as espécies protônicas, causando a redução do acoplamento dipolar entre ${ }^{1} \mathrm{H}$ e ${ }^{31} \mathrm{P}$. Por outro lado, as amostras HPW-I e HPW-II de HPW apresentam sinal de CP, como mostra a figura 6.21, demonstrando a existência de acoplamento dipolar apreciável entre ${ }^{1} \mathrm{H}$ e ${ }^{31} \mathrm{P}$, o que revela que o poliânion se encontra em um estado de mobilidade restrita, comparado ao $\mathrm{HPW} \cdot \mathrm{nH}_{2} \mathrm{O}$. Como comparação, o espectro de polarização direta também é mostrado na figura 6.21. Os espectros em polarização direta e cruzada em $20^{\circ} \mathrm{C}$ são quase idênticos para o HPW-I (figura 6.21.a). Em alta temperatura a amostra HPW-I também apresenta sinal de CP (figura 6.21.b), mostrando que a mobilidade relativa entre o poliânion e os prótons ao redor não é alta a ponto de promediar a interação dipolar ${ }^{1} \mathrm{H}-{ }^{31} \mathrm{P}$. No entanto, as linhas menores, centradas em -13,5ppm e -14,8ppm (figuras 6.12. a e b) não apresentam sinal de CP em nenhuma das temperaturas analisadas, indicando que os prótons ao redor destas espécies de ${ }^{31} \mathrm{P}$ apresentam dinâmica rápida. As figuras 6.21.c e 6.21.d mostram os espectros de polarização direta e cruzada para a amostra $\mathrm{HPW}$-II, em $20^{\circ} \mathrm{C} \mathrm{e} 85^{\circ} \mathrm{C}$. Em temperatura ambiente os espectros de polarização direta e cruzada são diferentes, o espectro de polarização cruzada é mais largo, indicando a existência de uma distribuição heterogênea de acoplamentos dipolares ${ }^{1} \mathrm{H}_{-}{ }^{31} \mathrm{P}$. Esta heterogeneidade é menos pronunciada em $85^{\circ} \mathrm{C}$.

A possibilidade de realização de experimentos de polarização cruzada, permite a análise seletiva dos tempos de contato e do tempo de relaxação spin-rede no sistema rotante $T_{1 \rho}$ para as espécies ${ }^{1} \mathrm{H}$ pertencentes ao ambiente químico do poliânion. As curvas obtidas para as amostras HPW-I e HPW-II, utilizando-se a técnica de TORQUE $\left\{{ }^{1} \mathrm{H}\right\}{ }^{31} \mathrm{P}$, são apresentadas na figura 6.22. A convexidade das curvas de TORQUE demonstra que $\mathrm{T}_{H P}>\mathrm{T}_{1 \rho}$.(80) Desta forma, o experimento convencional de CP com tempo de contato variável não foi realizado, 


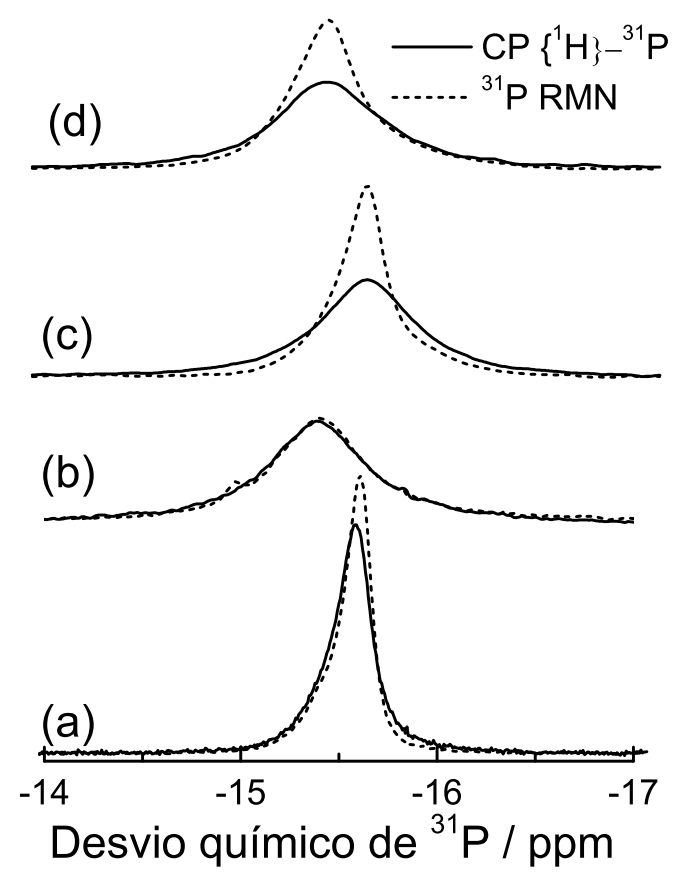

Figura 6.21-Espectros de ${ }^{31} \mathrm{P}$ RMN em polarização direta (linhas tracejadas) e $\mathrm{CP}\left\{{ }^{1} \mathrm{H}\right\}{ }^{31} \mathrm{P}$ (linhas contínuas) para as amostras HPW-I em $20^{\circ} \mathrm{C}$ (a) e $85^{\circ} \mathrm{C}$ (b) e HPW-II em $20^{\circ} \mathrm{C}$ (c) e $85^{\circ} \mathrm{C}$ (d). Fonte: Elaborada pelo autor.

visto que a determinação dos tempos característicos não seria confiável, conforme discutido na seção 3.1.7.4. Devido à complexidade da equação 3.1.53, a determinação dos tempos $\mathrm{T}_{H P}$ e $\mathrm{T}_{1 \rho}$ apresenta grandes incertezas. Por este motivo os valores de $\mathrm{T}_{1 \rho}$ obtidos pela técnica de SLCP foram utilizados como parâmetros iniciais para o ajuste de mínimos quadrados das curvas TORQUE. Os tempos THP obtidos dos ajustes são mostrados na tabela 6.3. O tempo de contato obtido para a amostra HPW-I é ligeiramente maior do que o obtido para o HPW-II, mostrando um acoplamento dipolar menos intenso entre ${ }^{1} \mathrm{H}$ e ${ }^{31} \mathrm{P}$. Esta diferença nos tempos de contato característicos pode indicar que na amostra HPW-I o poliânion encontra-se em um estado de mais alta mobilidade, ou em um ambiente com menos prótons ou prótons mais móveis.

Para obter informação qualitativa a respeito da dinâmica dos diferentes ambientes de prótons, o tempo de relaxação $T_{1 \rho}$ foi medido de forma direta por meio de experimentos de spin-lock de ${ }^{1} \mathrm{H}$. Também foram realizados experimentos de SLCP $\left\{{ }^{1} \mathrm{H}\right\}-{ }^{31} \mathrm{P}$ para a obtenção indireta dos tempos $\mathrm{T}_{1 \rho}$ para os prótons acoplados com ${ }^{31} \mathrm{P}$, que podem ser certamente atribuídos aos prótons no ambiente de coordenação do poliânion de HPW. 


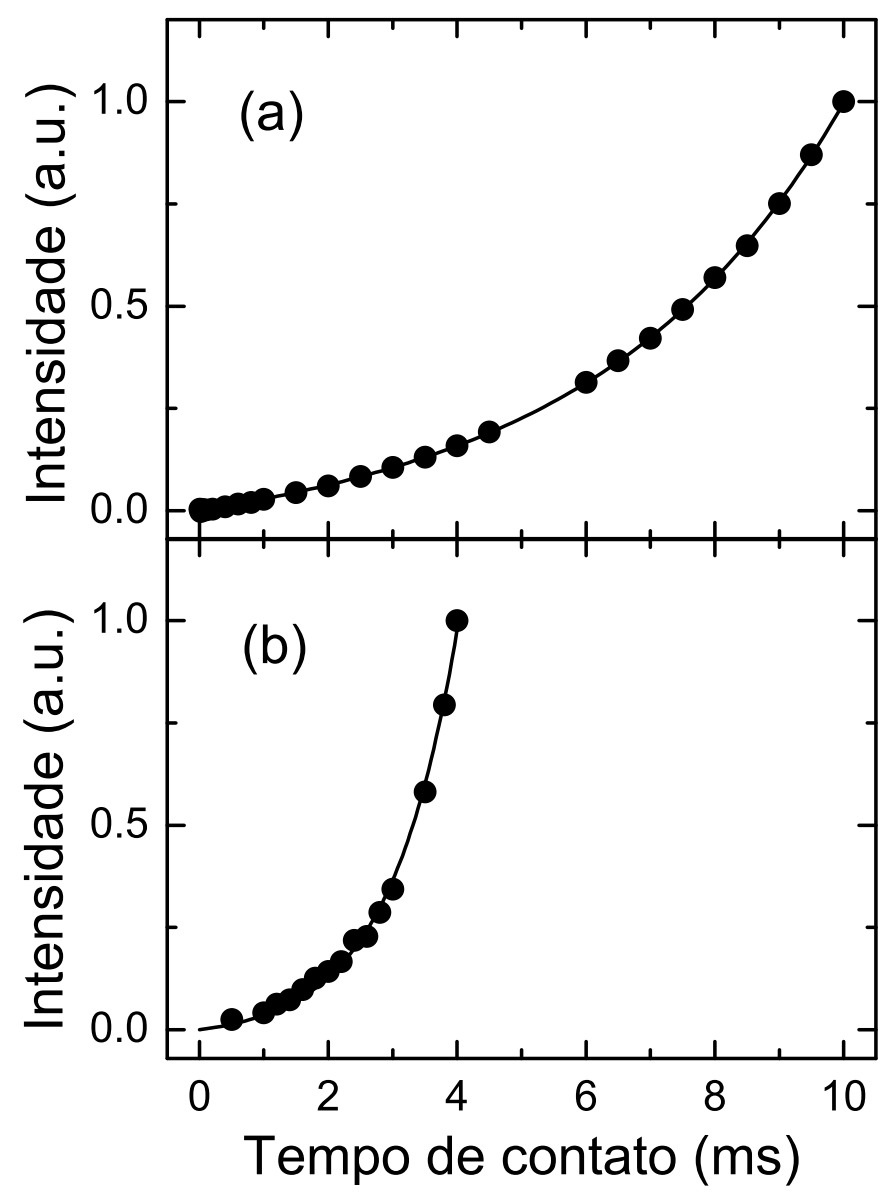

Figura 6.22-Sinal de ${ }^{31} \mathrm{P}$ obtido em função do tempo de contato na técnica de TORQUE $\left\{{ }^{1} \mathrm{H}\right\}$ ${ }^{31}$ Ppara as amostras HPW-I (a) HPW-II (b). As linhas contínuas são ajustes de mínimos quadrados utilizando a equação 3.1.53. Fonte: Elaborada pelo autor.

Tabela 6.3-Valores para o tempo de relaxação spin-rede no sistema rotante $\left(T_{1 \rho}\right)$ medidos nos experimentos de spin-loch ${ }^{1} \mathrm{H}$ e SLCP $\left\{{ }^{1} \mathrm{H}\right\}-{ }^{31} \mathrm{P}$; e valores para o tempo característico $\mathrm{T}_{H P}$ determinados nos experimentos de TORQUE $\left\{{ }^{1} \mathrm{H}\right\}{ }^{31} \mathrm{P}$.

\begin{tabular}{|c|c|c|c|c|c|}
\hline Amostra & Temperatura & & Spin-lock ${ }^{1} H^{T_{1 \rho}}$ & $\operatorname{SLCP}\left\{{ }^{1} \mathbf{H}\right\}-{ }^{31} \mathbf{P}$ & $\begin{array}{c}\mathbf{T}_{H P} \\
\text { TORQUE }\left\{{ }^{1} \mathbf{H}\right\}-{ }^{31} \mathbf{P}\end{array}$ \\
\hline \multirow[t]{2}{*}{ HPW-I } & $20^{\circ} \mathrm{C}$ & & $5,3 \pm 0,1$ & $2,5 \pm 0,1$ & $9 \pm 1$ \\
\hline & $-50^{\circ} \mathrm{C}$ & $\begin{array}{r}8 p p m \\
18 p p m\end{array}$ & $\begin{array}{l}0,3 \pm 0,1 / 1,4 \pm 0,1 \\
0,5 \pm 0,1 / 3,6 \pm 0,8\end{array}$ & $1,1 \pm 0,1$ & - \\
\hline \multirow[t]{2}{*}{ HPW-II } & $20^{\circ} \mathrm{C}$ & & $0,4 \pm 0,1 / 1,1 \pm 0,1$ & $0,5 \pm 0,1 / 1,4 \pm 0,1$ & $6 \pm 1$ \\
\hline & $85^{\circ} \mathrm{C}$ & & $0,4 \pm 0,1 / 1,2 \pm 0,1$ & $0,7 \pm 0,1 / 1,5 \pm 0,1$ & - \\
\hline
\end{tabular}




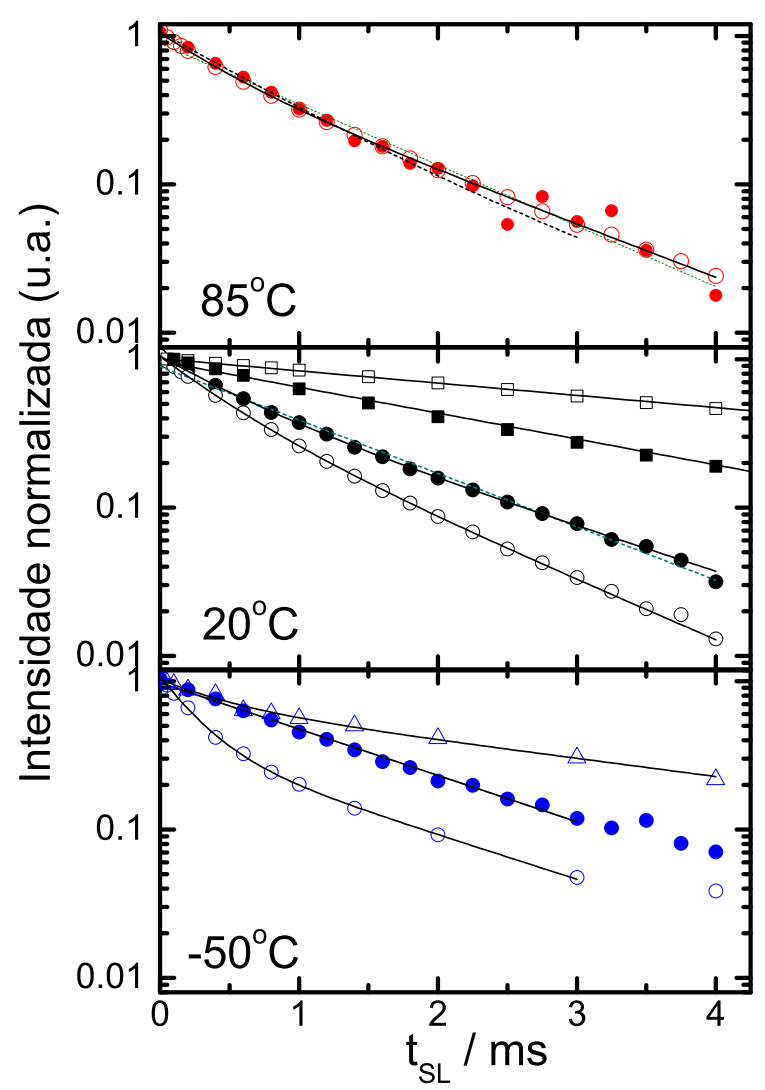

Figura 6.23-Curvas de relaxação spin-rede no sistema rotante para ${ }^{1} \mathrm{H}$ medidas em temperatura ambiente para HPW-I (quadrados) e em diferentes temperaturas para HPW-II (círculos/triângulos). Símbolos abertos: medida direta via experimento de spin-lock ${ }^{1} \mathrm{H}$ para as ressonâncias em $9 \mathrm{ppm}$ (círculos) e -18ppm (triângulos). Símbolos cheios: medida indireta via experimentos de SLCP $\left\{{ }^{1} \mathrm{H}\right\}{ }^{31} \mathrm{P}$. As linhas são ajustes de mínimos quadrados mono- e bi-exponenciais dos dados experimentais. Fonte: Elaborada pelo autor.

A figura 6.23 exibe as curvas de relaxação medidas para a amostra HPW-I pelas técnicas de spin-lock ${ }^{1} \mathrm{H}$ (quadrados abertos) e SLCP $\left\{{ }^{1} \mathrm{H}\right\}-{ }^{31} \mathrm{P}$ (quadrados fechados). As curvas são do tipo exponencial para ambas as técnicas, e os valores de $\mathrm{T}_{1 \rho}$ obtidos de forma direta e indireta são respectivamente 5,3 $\pm 0,1 \mathrm{~ms}$ e $2,5 \pm 0,1 \mathrm{~ms}$. A diferença nestes valores de $T_{1 \rho}$ indica que há mais prótons contribuindo para o espectro de ${ }^{1} \mathrm{H}$ RMN do que aqueles participando do ambiente de coordenação do poliânion.

Na figura 6.23 também estão exibidas as curvas de relaxação medidas para a amostra HPW-Il pelas técnicas de spin-lock ${ }^{1} \mathrm{H}$ (círculos abertos) e SLCP $\left\{{ }^{1} \mathrm{H}\right\}-{ }^{31} \mathrm{P}$ (círculos fechados) para diferentes temperaturas. No gráfico em escala semi-logarítmica as curvas de spin-lock ${ }^{1} \mathrm{H}$ não são lineares, indicando que a relaxação não pode ser caracterizada por um único valor de $\mathrm{T}_{1 \rho}$. No entanto, curvas bi-exponenciais puderam ser satisfatoriamente ajustadas aos dados experimentais por método de mínimos quadrados, resultando em dois valores de $T_{1 \rho}$. Este método de ajuste é uma aproximação, o sistema pode ser mais complexo, apresentando, por 
exemplo, uma distribuição de tempos de relaxação. Os valores encontrados estão mostrados na tabela 6.3. O comportamento não exponencial para estes decaimentos indica heterogeneidade estrutural, isto é, duas espécies distintas de ${ }^{1} \mathrm{H}$, e/ou dinâmica, isto é, movimentos moleculares envolvendo duas escalas de tempo característico. Por outro lado, as curvas de $\operatorname{SLCP}\left\{{ }^{1} \mathrm{H}\right\}-{ }^{31} \mathrm{P}$ apresentam comportamento mais próximo de mono-exponencial. Os valores de $\mathrm{T}_{1 \rho}$ obtidos dos ajustes mono- e bi-exponencial são exibidos na tabela 6.3. Comparando estes resultados com aqueles obtidos para o HPW-I, os valores de $\mathrm{T}_{1 \rho}$ para os prótons acoplados a ${ }^{31} \mathrm{P}$ são distintos, indicando a existência de diferenças na dinâmica dos ambientes de hidratação do poliânion nas duas amostras. A relaxação observada pode ser essencialmente descrita pelos valores de $\mathrm{T}_{1 \rho}$ longos, variando entre $1,1 \mathrm{~ms}$ e $1,5 \mathrm{~ms}$, que são muito próximos aos maiores valores obtidos de forma direta nos experimentos de spin-lock ${ }^{1} \mathrm{H}$ para a linha em torno de $9 \mathrm{ppm}$ (valores entre $1,1 \mathrm{~ms}$ e $1,4 \mathrm{~ms})$. Este resultado demonstra que a maioria dos prótons observados no espectro de ${ }^{1} \mathrm{H}$ RMN se encontram no ambiente de coordenação do HPW, interagindo dipolarmente com ${ }^{31} \mathrm{P}$. Por outro lado, os valores de $\mathrm{T}_{1 \rho}$ encontrados para os prótons em ligações de hidrogênio resolvidos em baixa temperatura $(0.5 \pm 0.2 \mathrm{~ms}$ e $3.6 \pm 0.8 \mathrm{~ms})$ são claramente diferentes dos valores medidos para os prótons acoplados a ${ }^{31} \mathrm{P}(1,1 \pm \mathrm{ms})$. Portanto, pode-se concluir que os ${ }^{1} \mathrm{H}$ em ligações de $\mathrm{H}$ não estão polarizando ${ }^{31} \mathrm{P}$. Isto indica que o acoplamento dipolar ${ }^{1} \mathrm{H}_{-}{ }^{31} \mathrm{P}$ é desprezível para estas espécies. Como estas espécies ${ }^{1} \mathrm{H}$ possuem alta mobilidade, de acordo com os experimentos de spin-eco de ${ }^{1} \mathrm{H}$, não é possível afirmar univocamente que sejam prótons remotos ao poliânion.

\subsubsection{SEDOR $\left\{{ }^{1} H\right\}^{-31} \mathrm{P}$ RMN}

Na figura 6.24 são mostrados os decaimentos dos sinais SEDOR $\left\{{ }^{1} \mathrm{H}\right\}-{ }^{31} \mathrm{P}$, obtidos do quociente $S(\tau) / S_{0}$, em função do tempo de defasagem $\tau$. Os experimentos foram realizados a baixa temperatura $\left(-95^{\circ} \mathrm{C}\right)$ a fim de se garantir que o sistema esteja no regime de rede rígida, não havendo mudança de orientação do vetor internuclear com relação ao campo externo. Nesse caso o comportamento tipicamente esperado para o decaimento do sinal SEDOR é gaussiano, de acordo com a equação 3.1.57, cuja largura está associada ao segundo momento da interação dipolar ${ }^{1} \mathrm{H}_{-}{ }^{31} \mathrm{P}\left(\mathrm{M}_{2 H P}\right)$.(68) Os resultados para a amostra HPW-I apresentam uma quebra na inclinação do gráfico linearizado, o que indica heterogeneidade para os ambientes de coordenação do ${ }^{31} \mathrm{P}$, com diferentes valores de $\mathrm{M}_{2 H P}$, e/ou que o limite de rede rígida não foi atingido para alguns ${ }^{1} \mathrm{H}$. Considerando-se que o limite de rede rígida tenha sido atingido para a 
maioria dos prótons, é possível estimar um valor para $\mathrm{M}_{2 H P}$ considerando-se apenas a maior faixa de tempos com comportamento linear para o decaimento no gráfico linearizado $\left((2 \tau)^{2}>\right.$ $\left.0,16 \mathrm{~ms}^{2}\right)$. O valor de $\mathrm{M}_{2 H P}$ resultante deste procedimento é $(6,9 \pm 0,3) \times 10^{6} \operatorname{rad}^{2} \mathrm{~s}^{-2}$. Após os experimentos com variação de temperatura, mostrados nas seções anteriores, o experimento de SEDOR foi repetido, resultando em um valor único de $\mathrm{M}_{2 H P}$ igual a $(6,2 \pm 0,1) \times 10^{6} \mathrm{rad}^{2} \mathrm{~s}^{-2}$, indicando uma reorganização estrutural para os ambientes de ${ }^{1} \mathrm{H}$ ao redor do poliânion. Para a amostra HPW-II o decaimento SEDOR no gráfico linearizado também apresenta uma pequena variação na inclinação por volta de $(2 \tau)^{2}=0,1 \mathrm{~ms}^{2}$. Como observado nos experimentos de ${ }^{1} \mathrm{H}$ RMN na seção 6.1.3.2, em temperaturas mais baixas são observados prótons realizando ligações de hidrogênio. Estes prótons apresentam dinâmica rápida, mesmo em $-50^{\circ} \mathrm{C}$ (temperatura mais baixa em que foram realizados experimentos de alta resolução). Este fato pode indicar que o desvio dos resultados de SEDOR de um comportamento gaussiano pode ser devido a mobilidade destes prótons, mesmo em $-95^{\circ} \mathrm{C}$. Desta forma, pode-se supor que o regime de rede rígida é atingido para a maioria dos prótons, ou seja, para os prótons em grupos $\mathrm{H}_{5} \mathrm{O}_{2}{ }^{+}$. Considerando a inclinação do gráfico linearizado apenas na região com $(2 \tau)^{2}>0,1 \mathrm{~ms}^{2}$,o valor de $\mathrm{M}_{2 H P}$ resultante é $(8,5 \pm 0,5) \times 10^{6} \mathrm{rad}^{2} \mathrm{~s}^{-2}$. Este valor deve ser considerado como a melhor aproximação para o valor de $\mathrm{M}_{2 H P}$ compatível com a condição de rede rígida.

Considerando a expressão de Van Vleck (75) para o segundo momento heteronuclear (Equação 3.1.48), e medindo-se as distâncias H-P a partir de dados cristalográficos do $\mathrm{HPW} \cdot 6 \mathrm{H}_{2} \mathrm{O}$ a $-190^{\circ} \mathrm{C}$, obtidos da literatura (22--24), o valor de $\mathrm{M}_{2 H P}$ pôde ser calculado, resultando em $12,1 \times 10^{6} \mathrm{rad}^{2} \mathrm{~s}^{-2}$. Este valor é substancialmente maior do que o valor observado para as amostras de HPW-I e HPW-II. No entanto, considerando o cenário em que os prótons em ligações de hidrogênio não estejam acoplados com ${ }^{31} \mathrm{P}$, devido à mobilidade rápida, o cálculo do valor de $M_{2 H P}$ pela equação de $V a n$ Vleck resulta em $9,4 \times 10^{6} \operatorname{rad}^{2} \mathrm{~s}^{-2}$, que é próximo ao valor observado para a amostra HPW-II. 


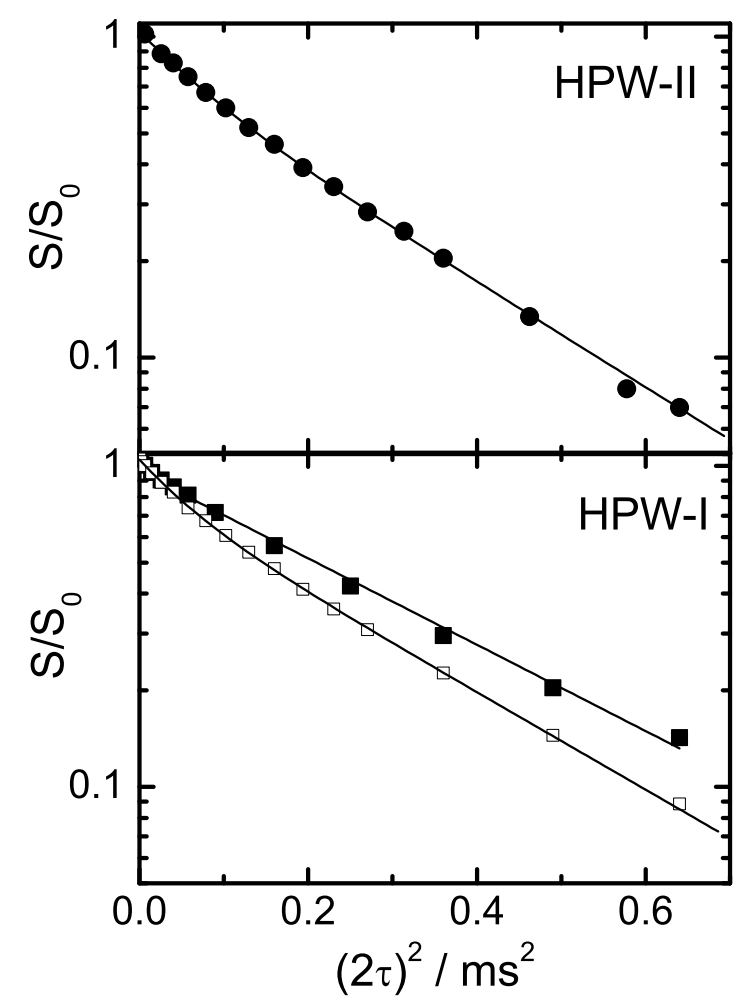

Figura 6.24-Gráfico linearizado da razão $S(\tau) / S_{0}$ como função de $(2 \tau)^{2}$, para o experimento de SEDOR $\left\{{ }^{1} \mathrm{H}\right\}{ }^{31}$ PRMN, para as amostras HPW-I antes (quadrados vazios) e após (quadrados cheios) ciclo de aquecimento e resfriamento durante experimentos de RMN e para a amostra HPW-II (círculos cheios). As linhas são ajustes de mínimos quadrados. Fonte: Elaborada pelo autor. 


\subsection{Xerogeis}

\subsection{1 ${ }^{13}$ C RMN}

O objetivo destes experimentos é verificar a estabilidade das cadeias orgânicas presentes na matriz ormosil, frente aos diferentes tratamentos térmicos realizados para secagem dos xerogeis. Como a sensibilidade da RMN de ${ }^{13} \mathrm{C}$ em PD é baixa, o estudo das espécies orgânicas presentes nos xerogéis foi realizado através de experimentos de $\mathrm{CP}\left\{{ }^{1} \mathrm{H}\right\}{ }^{13} \mathrm{C}$ MAS RMN. As atribuições para as espécies de ${ }^{13} \mathrm{C}$ no espectro estão descritas na Ref..(20) A figura 6.25 mostra a comparação entre os espectros para a amostra HGT-N2 sem tratamento térmico (figura 6.25.a), com tratamento térmico a $85^{\circ} \mathrm{C}$ (figura 6.25. b) e com tratamento térmico a $150^{\circ} \mathrm{C}$ (figura 6.25.c). Para facilitar a atribuição das espécies de ${ }^{13} \mathrm{C}$ presentes na amostra, a figura 6.25. d mostra também o espectro de ${ }^{13} \mathrm{C}$ MAS RMN para uma amostra de GLYMO pura. Os picos correspondentes às diferentes espécies de ${ }^{13} \mathrm{C}$ estão identificados com os números correspondentes aos carbonos da molécula de GLYMO exibida na figura. Comparando o espectro do GLYMO com os outros espectros da figura 6.25, observa-se o desaparecimento das linhas referentes aos carbonos 5 e 6, correspondentes ao grupo funcional epóxi do GLYMO, mostrando que uma das ligações com oxigênio é desfeita no processo de gelatinização do sol. Trabalhos anteriores mostram que o anel epóxi reage com água, resultando em um grupo diol (20, 95), gerando o pico em 65ppm (indicado como I na figura 6.25) atribuído a grupos $\mathrm{RCOH} .(20,95)$ Nos espectros a e $\mathrm{b}$ da figura 6.25, também aparece um pico estreito e centrado em 15ppm, identificado com uma seta. De acordo com a Ref. (20), este pico é atribuído a grupos alcoóis resultantes do processo de preparação dos xerogeis.

O espectro para a amostra tratada a $85^{\circ} \mathrm{C}$ é muito próximo ao espectro para a amostra sem tratamento, mostrando que o tratamento nesta temperatura não altera o estado das estruturas orgânicas da matriz ormosil. Por outro lado, após o tratamento a $150^{\circ} \mathrm{C}$ por $2 \mathrm{~h}$, o espectro de ${ }^{13} \mathrm{C}$ é visivelmente alterado, exibindo uma distribuição larga de linhas nas regiões entre 10 e 50 ppm atribuída a grupos $\mathrm{CH}_{2}$ e $\mathrm{CH}_{3}$, e entre 70 e 120 ppm atribuída a ligações de carbono com oxigênio e alcanos. Conclui-se então que o tratamento a $150^{\circ} \mathrm{C}$ fragmenta as cadeias orgânicas. Portanto, o tratamento em $85^{\circ} \mathrm{C}$ será escolhido como padrão para a secagem dos xerogéis em geral. 


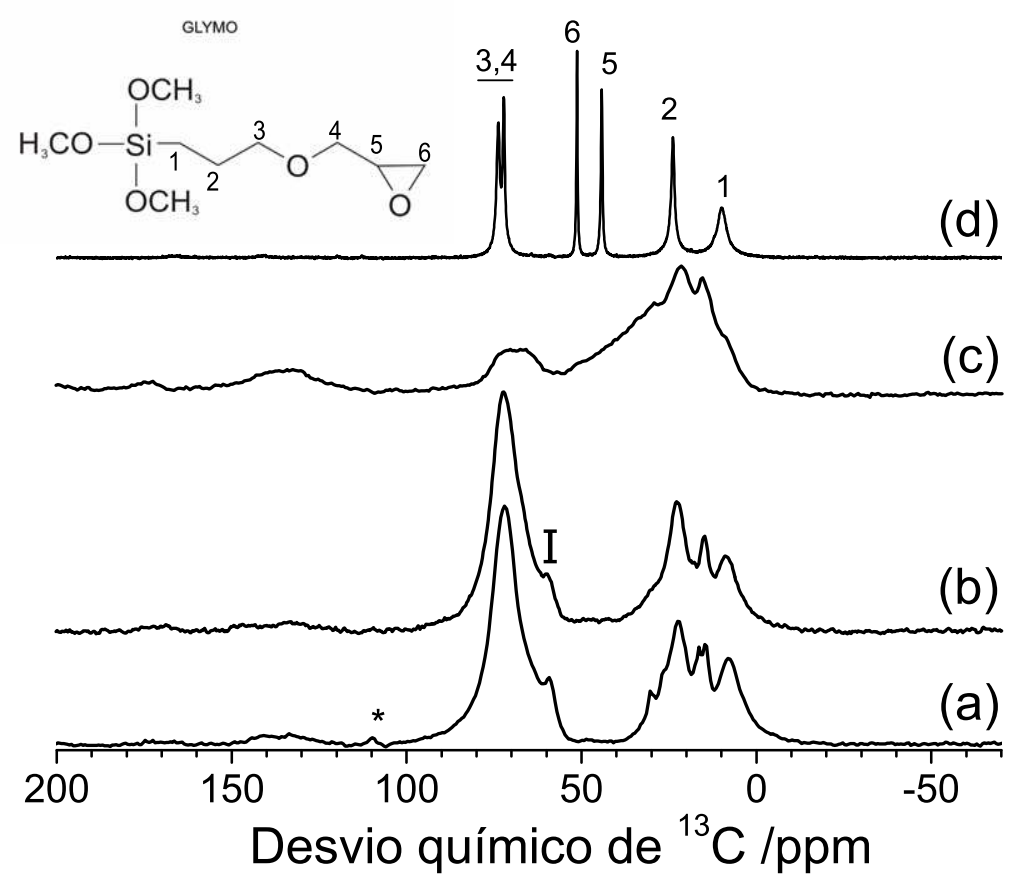

Figura 6.25-Espectros de $\mathrm{CP}\left\{{ }^{1} \mathrm{H}\right\}-{ }^{13} \mathrm{C}$ MAS RMN obtidos para a amostra HGT-N2 sem tratamento térmico $(\mathrm{a})$, com tratamento em $85^{\circ} \mathrm{C}(\mathrm{b})$ e com tratamento em $150^{\circ} \mathrm{C}(\mathrm{c})$, comparados a um espectro de ${ }^{13} \mathrm{C}$ MAS RMN para uma amostra de GLYMO puro (d). As bandas laterais são indicadas por asteriscos. Fonte: Elaborada pelo autor.

\subsection{2 ${ }^{29} \mathrm{Si} \mathrm{RMN}$}

Estudos detalhados de ${ }^{29} \mathrm{Si}$ RMN nos xerogéis deste trabalho já foram realizados em trabaIhos anteriores (20), conforme mencionado na seção 2.5. Portanto, nesta seção serão somente discutidas as possíveis alterações estruturais na matriz ormosil em função dos tratamentos térmicos e da atmosfera de preparo dos xerogeis.

Os experimentos de ${ }^{29} \mathrm{Si}$ MAS RMN foram realizados sobre as amostras HGT-Amb, HGTN2 e HT-N2. Os espectros obtidos são mostrados na figura 6.26. A tabela 6.4 mostra as espécies de silicatos identificados, e suas respectivas populações, obtidas à partir do ajuste de funções gaussianas pelo método de mínimos quadrados aos dados da figura 6.26. Para ambas as amostras, foram identificadas espécies de silicatos tetraédricos $\mathrm{Q}_{n}$, formando $n$ pontes $\mathrm{Si}$-O-Si por tetraedro, com $n=1$ ( $\approx-80 \mathrm{ppm}), n=2(\approx-91 \mathrm{ppm}), n=3(\approx-101 \mathrm{ppm})$ e $n=4(\approx$ -110ppm).(96) Para a amostra HGT-N2, além destes grupos $Q_{n}$, também são identificadas espécies de silicatos $\mathrm{T}_{n}$, onde o Si realiza uma ligação covalente com um átomo de carbono e $n$ pontes do tipo Si-O-Si, com $n=3(\approx-65 \mathrm{ppm})$ e $n=1(\approx-44 \mathrm{ppm}) .(73,06)$

Para a amostra HT-N2, após o tratamento a $150^{\circ} \mathrm{C}$, há uma redução da população de 

(a)
(b)
(c)
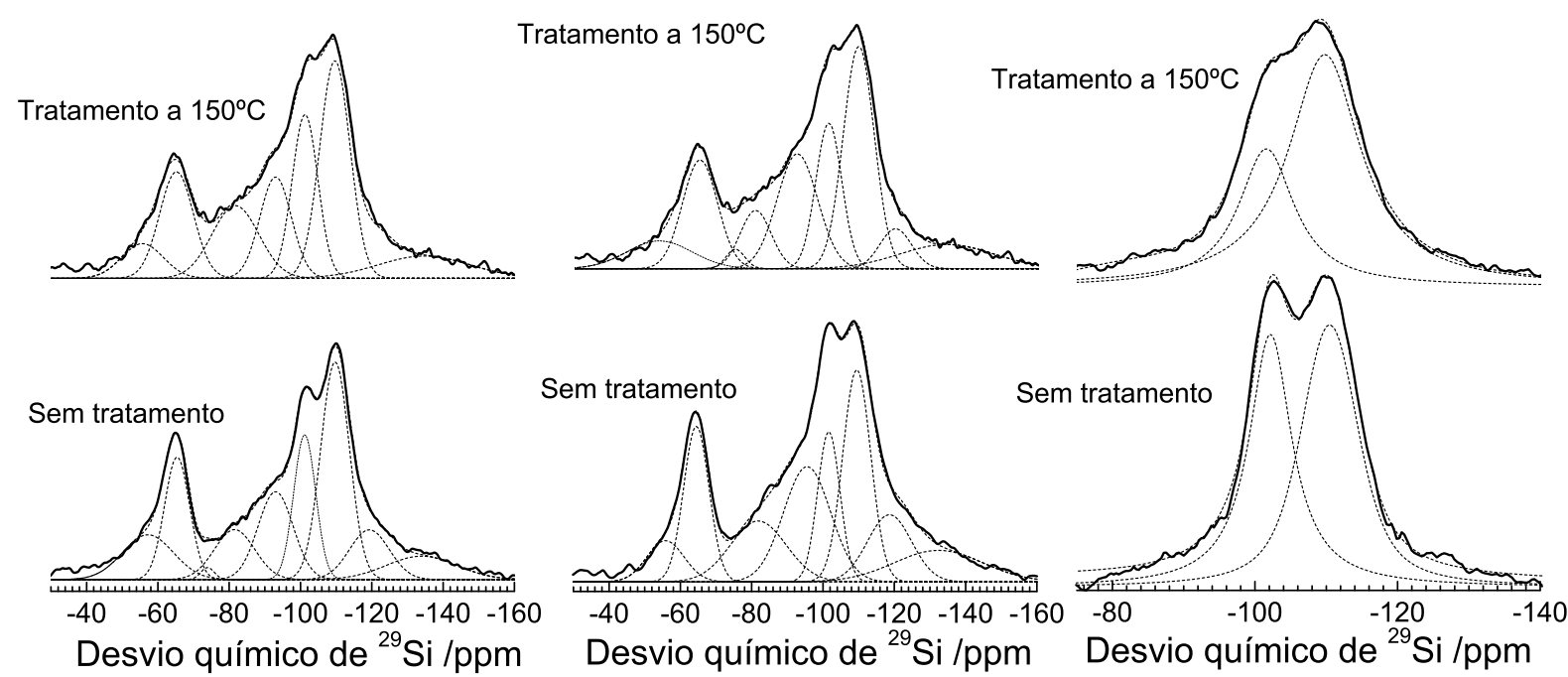

Figura 6.26-Espectros de ${ }^{29} \mathrm{Si}$ MAS RMN para as amostras HGT-Amb (a), HGT-N2 (b) e HT-N2, antes e após tratamento térmico a $150^{\circ} \mathrm{C}$ por $2 \mathrm{~h}$, sob fluxo contínuo de $\mathrm{N}_{2}$. As linhas pontilhadas representam ajustes de mínimos quadrados, utilizando-se funções gaussianas. Fonte: Elaborada pelo autor.

Tabela 6.4-Distribuição dos grupos silicato em diferentes xerogeis. Porcentagens baseadas na área relativa das curvas gaussianas ajustadas por método de mínimos quadrados aos espectros de ${ }^{29} \mathrm{Si}$ MAS RMN das figuras 6.26 e 6.27. As amostras indicadas com secas foram submetidas a tratamento em forno mufla a $150^{\circ} \mathrm{C}$ por $2 \mathrm{~h}$ sob fluxo de $\mathrm{N}_{2}$.

\begin{tabular}{|c|c|c|c|c|c|c|c|c|c|}
\hline $\begin{array}{c}\text { Condição } \\
\text { de } \\
\text { Preparo }\end{array}$ & Amostra & $\mathrm{Q}_{4}(\%)$ & $\mathrm{Q}_{3}(\%)$ & $\mathrm{Q}_{2}(\%)$ & $Q_{1}(\%)$ & $\mathrm{T}_{3}(\%)$ & $\mathrm{T}_{2}(\%)$ & $\mathrm{T}_{1}(\%)$ & $\overline{B O}$ \\
\hline \multirow{2}{*}{ Ambiente } & $\overline{\text { HGT }}$ & 38 & 28 & $\overline{14}$ & $\overline{10}$ & $\overline{11}$ & $\overline{14}$ & $\overline{11}$ & 3,4 \\
\hline & HGT(seca) & 34 & 17 & 13 & 14 & - & 15 & 7 & 3,0 \\
\hline \multirow{4}{*}{ Fluxo de $\mathrm{N}_{2}$} & HT & 54 & 46 & - & - & - & - & - & 3,5 \\
\hline & HT(seca) & 67 & 31 & - & 2 & - & - & - & 3,6 \\
\hline & HGT & 32 & 12 & 21 & 13 & - & 15 & 5 & 2,8 \\
\hline & HGT(seca) & 34 & 15 & 18 & 8 & 1 & 15 & 8 & 2,9 \\
\hline Glove-box & HGT & 38 & 13 & 18 & 6 & 4 & 13 & 9 & 2,9 \\
\hline
\end{tabular}

Fonte: Elaborada pelo autor.

espécies $Q_{3}$ (46\% para 31\%), e um aumento na população de espécies $Q_{4}$ (54\% para 67\%) e $\mathrm{Q}_{1}(0 \%$ para $2 \%)$. Por outro lado, a distribuição de espécies de silicato na amostra HGT-N2 se mantém praticamente inalterada. Para a avaliação da conectividade média da matriz de silicatos em ambas as amostras, a tabela 6.4 apresenta o cálculo do número médio de pontes Si-O-Si $(\overline{B O})$ por átomo de Si. Em ambas as amostras a conectividade média se mantém praticamente inalterada após o tratamento térmico, mostrando que não há variação significativa 
na estrutura da matriz de silicatos.

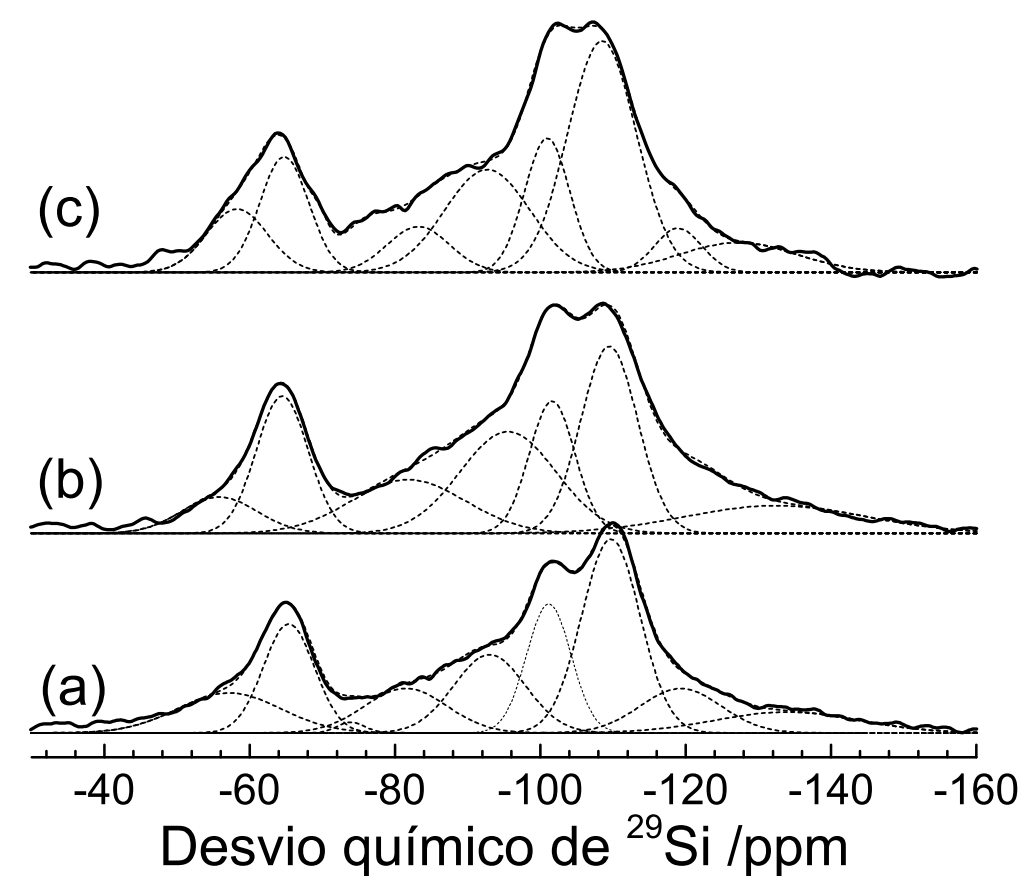

Figura 6.27-Espectros de ${ }^{29} \mathrm{Si}$ MAS RMN para a amostra HGT preparada em diferentes condições de atmosfera: sem controle de atmosfera (a), em câmara com fluxo de $\mathrm{N}_{2}$ e U.R. < $20 \%$ (b) e em glove-box, com U.R. $\approx 0.1 \mathrm{ppm}$ (c). As linhas pontilhadas representam ajustes de mínimos quadrados, utilizando-se funções gaussianas. Fonte: Elaborada pelo autor.

A figura 6.27 mostra os espectros de ${ }^{29} \mathrm{Si}$ RMN obtido para as amostras HGT-Amb, HGT-N2 e HGT-Box. A composição das amostras é a mesma, dada pela tabela 5.1, mas as três foram preparadas em diferentes condições de atmosfera: sem controle de atmosfera (HGT-Amb - figura 6.27.a); em atmosfera saturada com $\mathrm{N}_{2}$ (HGT-N2 - figura 6.27.b); e em câmara seca glove-box (HGT-Box - figura 6.27.c). Os dados obtidos por ajustes de mínimos quadrados sobre espectros estão apresentados na tabela 6.4. Os espectros para as três amostras são constituídos de grupos de silicatos $Q_{4}, Q_{3}, Q_{2}$ e $Q_{1}$, e grupos de organosilicatos $T_{3}$ e $T_{2}$. As frações entre os diferentes grupos de ${ }^{29} \mathrm{Si}$ são similares, para as amostras HGT-N2 e HGT-Box, mostrando que a diferença de umidade na atmosfera durante o preparo destas amostras não é suficiente para influenciar na formação da matriz ormosil. Por outro lado, a amostra HGT-Amb, preparada em condições mais úmidas, apresenta maior condensação do que as outras amostras, o número médio de pontes Si-O-Si para esta amostra é $\overline{B O}=3,4$, enquanto para as amostras HGT-N2 e HGT-Box $\overline{B O}=2,8$ e 2, 9 respectivamente. 


\subsection{3 ${ }^{31} \mathrm{P}$ RMN}

Na figura 6.28 são apresentados os espectros de ${ }^{31} \mathrm{P}$ MAS RMN para os diferentes xerogeis, preparados em condições ambientes (figura 6.28. a), sob fluxo de $\mathrm{N}_{2}$ (figura 6.28.b) e em glove-box (figura 6.28.c). Para efeitos de comparação, os espectros para as amostras de $\mathrm{HPW} \cdot \mathrm{nH}_{2} \mathrm{O}$ e HPW-II, obtido conforme descrito na seção 6.1.3, estão inseridos na figura 6.28. Conforme será explicado na seção 6.2.4 as amostras preparadas em condições ambiente e sob fluxo de $\mathrm{N}_{2}$ apresentam um excesso de hidratação, que dificulta a atribuição das espécies de ${ }^{1} \mathrm{H}$. Por este motivo, as amostras foram submetidas a secagem a $85^{\circ} \mathrm{C}$ por $2 \mathrm{~h}$ em forno com fluxo de $\mathrm{N}_{2}$. Os espectros obtidos após as secagens térmicas estão mostrados em linhas tracejadas na figura 6.28 .

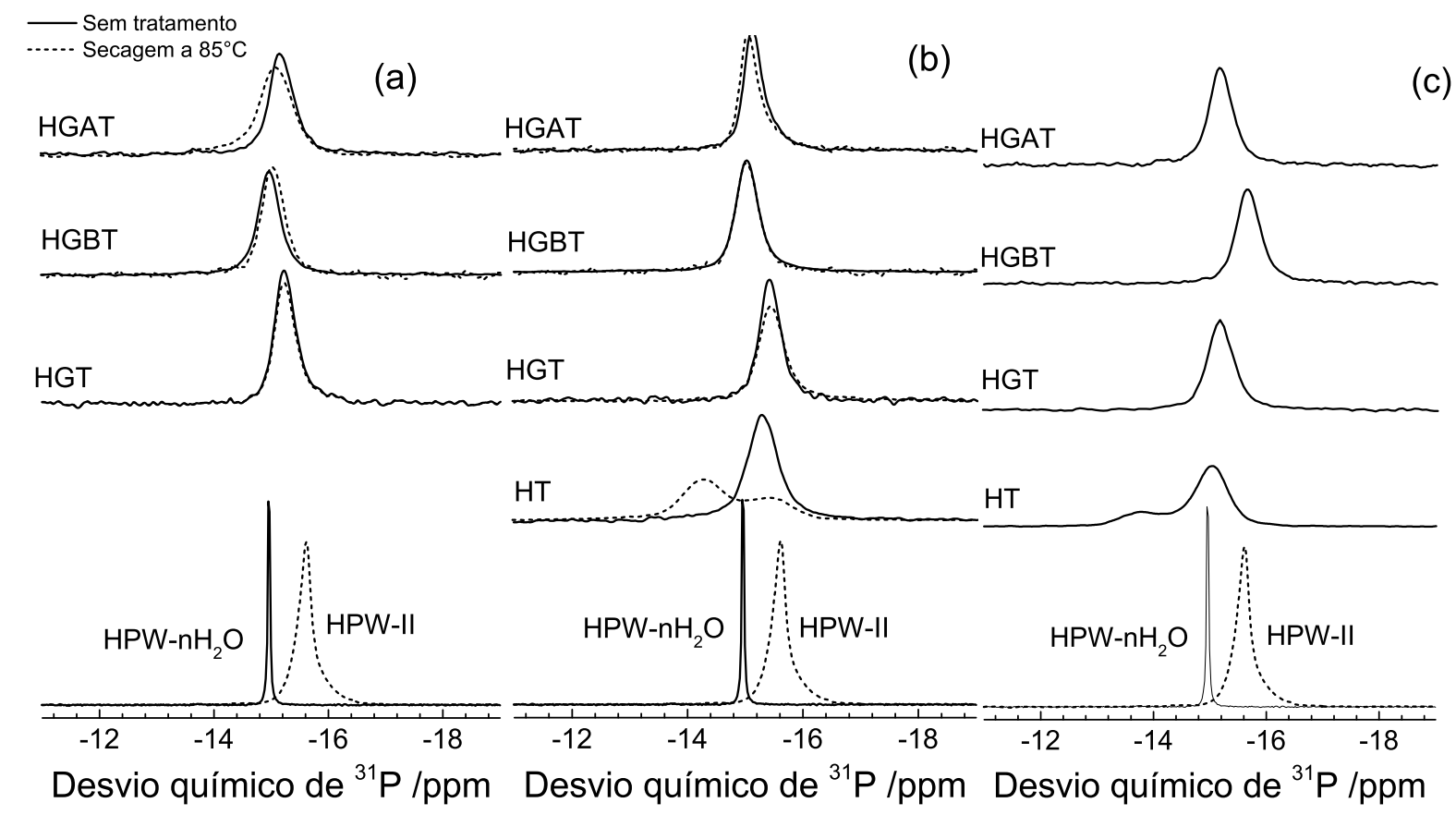

Figura 6.28-Espectros de ${ }^{31} \mathrm{P}$ MAS RMN para as amostras de xerogeis preparadas em diferentes condições de atmosfera: sem controle de atmosfera (a); atmosfera saturada com $\mathrm{N}_{2}$ (b); e em atmosfera seca dentro de uma glove-box (c). Linhas contínuas representam experimentos em amostras sem tratamento térmico, e linhas tracejadas correspondem a experimentos em amostras submetidas a secagens sob fluxo de $\mathrm{N}_{2}$ em $85^{\circ} \mathrm{C}$. Os espectros para amostras de $\mathrm{HPW} \cdot \mathrm{nH}_{2} \mathrm{O}$ (linha contínua) e HPW-II (linha tracejada) estão representados para efeitos de comparação. Fonte: Elaborada pelo autor.

A tabela 6.5 mostra os desvios químicos isotrópicos e larguras de linha a meia altura (FWHM) para os espectros da figura 6.28. Com exceção das amostras HT, os espectros para todas as amostras são constituídos de uma única linha, com centro variando entre -15,0ppm e -15,7ppm, próximo ao observado para o HPW-II (-15,6ppm), e larguras variando entre $50 \mathrm{~Hz}$ e 
$72 \mathrm{~Hz}$, da ordem do dobro da largura observada para o HPW-II (FWHM $=39 \mathrm{~Hz})$. Não são observadas linhas que indiquem a decomposição do HPW, como por exemplo espécies lacunares $\left[\mathrm{PW}_{11} \mathrm{O}_{39}\right]^{7-}$ formadas à partir da perda de um átomo de tungstênio, que apresentariam desvio químico em torno de de 10ppm.(97) Os valores de desvio químico indicam que o ambiente de coordenação para o poliânion de HPW apresenta estrutura semelhante ao observado para HPWII, ou seja, o poliânion está interagindo com espécies de hidratação, como as discutidas na seção 6.1.3. A diferença de largura com relação ao HPW-Il pode indicar que existe uma distribuição maior de ambientes de coordenação possíveis para o poliânion nos xerogéis (diferentes níveis de hidratação). Outra possibilidade seria o alargamento da linha devido à acoplamento dipolar heteronuclear ${ }^{1} \mathrm{H}_{-}{ }^{31} \mathrm{P}$ residual, mas experimentos de ${ }^{31} \mathrm{P}$ MAS RMN com e sem desacoplamento $\mathrm{CW}$ dos ${ }^{1} \mathrm{H}$ resultam em larguras de linha semelhantes, indicando que a técnica de MAS é suficiente para promediar a interação dipolar. As únicas composições que apresentam alterações nos parâmetros espectrais em função das condições de preparo dos xerogéis são as amostras HGBT e HT. Para a primeira, uma variação do desvio da linha central é observada para a preparação em glove-box com relação às outras condições de preparo. Abaixo serão discutidas as mudanças observadas para as amostras HT.

Tabela 6.5-Desvios químicos isotrópicos para os espectros da figura 6.28, referentes aos xerogeis sem tratamento térmico.

\begin{tabular}{|c|c|c|c|c|c|c|c|c|}
\hline \multirow{2}{*}{$\begin{array}{l}\text { Condições } \\
\text { de preparo }\end{array}$} & \multirow[b]{2}{*}{ HT } & \multicolumn{2}{|c|}{${ }^{31} \mathrm{P}-\delta_{i s o}(\mathrm{ppm})$} & \multirow[b]{2}{*}{ HGAT } & \multirow[b]{2}{*}{ HT } & \multicolumn{2}{|c|}{ FWHM (Hz) } & \multirow[b]{2}{*}{ HGAT } \\
\hline & & HGT & HGBT & & & HGT & HGBT & \\
\hline Ambiente & - & $-15,2$ & $-15,0$ & $-15,1$ & - & 50 & 64 & 72 \\
\hline Fluxo de $\mathrm{N}_{2}$ & $-15,3$ & $-15,4$ & $-15,0$ & $-15,1$ & 88 & 52 & 66 & 53 \\
\hline Glove-box & $\begin{array}{l}-15,0 / \\
-13,8\end{array}$ & $-15,2$ & $-15,7$ & $-15,2$ & - & 64 & 72 & 67 \\
\hline
\end{tabular}

Fonte: Elaborada pelo autor.

Para o conjunto de amostras HT os espectros apresentam variações de acordo com as condições de preparo. Para a amostra HT-N2, o espectro é constituído de uma única linha centrada em -15,3ppm e com $88 \mathrm{~Hz}$ de largura, consistente com a coordenação do HPW com espécies de hidratação, como ocorre para os demais xerogeis. A amostra preparada em glove-box (HT-Box) apresenta uma espectro mais complexo, com duas linhas centradas em -15.0ppm e -13,8ppm. Conforme resultados da seção 6.1.2, o pico em -13,8ppm corresponde a poliânions de HPW inseridos em ambientes de coordenação com hidratação reduzida $(n<3)$, possivelmente realizando ligação covalente com um ou dois prótons. Portanto, para a amostra HT, a atmosfera de preparo influencia fortemente o nível de hidratação do ambiente de coordenação do HPW. Esta diferença com relação às outras amostras pode ser justificada pelas diferenças estruturais 
entre os dois tipos de xerogeis, uma vez que a amostra HT não possui grupos orgânicos em sua composição.

Como pode ser observado nos espectros da figura 6.28, apenas o espectro para a amostra HT-N2 mostra alterações após a secagem térmica, tornando-se similar ao espectro para a amostra HT-Box, salvo diferenças nas relações de intensidade, mostrando que para esta amostra a secagem remove moléculas de $\mathrm{H}_{2} \mathrm{O}$ no ambiente de coordenação do HPW, criando ambientes de coordenação semelhantes aos encontrados para a amostra HT-N2. Para as outras amostras a secagem não acarreta alterações significativas para os espectros de ${ }^{31} \mathrm{P} R M N$, indicando que em primeira aproximação o ambiente de coordenação do HPW é mais estável termicamente.

\subsection{4 ${ }^{1} \mathrm{H}$ RMN}

Na figura 6.29 são apresentados os espectros de ${ }^{1} \mathrm{H}$ MAS RMN para os xerogeis, preparados em condições ambientes (figura 6.29.a), sob fluxo de $\mathrm{N}_{2}$ (figura 6.29.b) e em glove-box (figura 6.29.c). Como será mostrado na seção 6.2.6, a largura dos picos no espectro de ${ }^{1} \mathrm{H}$ dos xerogeis apresenta uma redução com o aumento da temperatura, reduzindo a sobreposição entre as diferentes linhas espectrais. Assim, para obter maior resolução das espécies de ${ }^{1} \mathrm{H}$, os espectros apresentados na figura 6.29 foram medidos a $85^{\circ} \mathrm{C}$, que é a maior temperatura a que foram processadas estas amostras. Para efeitos de comparação, os espectros para as amostras de HPW·nH $\mathrm{H}_{2} \mathrm{O}$ e HPW-II também estão mostrados na figura. A tabela 6.6 sumariza os desvios químicos observados para os diferentes espectros de ${ }^{1} \mathrm{H}$ e as atribuições que serão discutidas nas próximas seções. Uma linha estreita e centrada entre 6,8ppm e 5,5ppm pode ser observada nos espectros para as amostras preparadas sem controle de umidade, na figura 6.29. Após secagem das amostras a $85^{\circ} \mathrm{C}$ por $2 \mathrm{~h}$ sob fluxo de $\mathrm{N}_{2}$ (espectros em linhas tracejadas na figura 6.29.a), esta linha estreita não é observada. O desvio químico destas espécies é consistente com aglomerados de moléculas de $\mathrm{H}_{2} \mathrm{O}$, e o estreitamento da ressonância indica alta mobilidade em $85^{\circ} \mathrm{C}$ para estes prótons. Resultados de HETCOR $\left\{{ }^{1} \mathrm{H}\right\}-{ }^{31} \mathrm{P}$ RMN sobre a amostra HGAT-Amb mostrados na seção 6.2.8, indicam que estas espécies de prótons não estão acoplados dipolarmente com ${ }^{31} \mathrm{P}$. A ausência de acoplamento com ${ }^{31} \mathrm{P}$ pode ser devido à alta mobilidade destas espécies, ou tratam-se de aglomerados de moléculas de água que não participam do ambiente de coordenação do HPW. Os espectros para as amostras preparadas em atmosfera saturada com $\mathrm{N}_{2}$ também apresentam picos correspondentes à prótons de hidratação, 
Tabela 6.6-Desvios químicos para os picos observados nos espectros de ${ }^{1} \mathrm{H}$ RMN (figura 6.29) para os diversos xerogeis. Os desvios marcados com asterisco são tomados dos espectros medidos para amostras submetidas a secagem em $85^{\circ} \mathrm{C}$ por $2 \mathrm{~h}$ sob fluxo de $\mathrm{N}_{2}$. A sigla N.R. representa linhas que podem estar presentes, mas não estão resolvidas no espectro.

\begin{tabular}{|c|c|c|c|c|c|c|}
\hline $\begin{array}{l}\text { Condição } \\
\text { de preparo }\end{array}$ & Amostra & $\begin{array}{c}\mathrm{H}_{2} \mathrm{O} \\
\text { móveis } \\
(\mathrm{ppm})\end{array}$ & $\begin{array}{c}\mathrm{H}_{2} \mathrm{O} \text { e/ou } \\
\mathrm{H}^{+}\left(\mathrm{H}_{2} \mathrm{O}\right)_{n} \\
(\mathrm{ppm})\end{array}$ & $\begin{array}{c}\mathrm{OH} \mathrm{e/ou} \\
\mathrm{H}_{2} \mathrm{O}(\mathrm{ppm})\end{array}$ & SiOH (ppm) & $\begin{array}{c}\mathrm{OH} \\
(\mathbf{p p m})\end{array}$ \\
\hline \multirow{3}{*}{ Ambiente } & HGT & 6,8 & $7,4^{*}$ & 3,7 & 2,3 & 1,4 \\
\hline & HGBT & 6,4 & $6,0 *$ & 3,9 & N.R. & 1,4 \\
\hline & HGAT & 5,4 & $5,8^{*}$ & 4,0 & 2,6 & 1,6 \\
\hline \multirow{4}{*}{ Fluxo $\mathrm{N}_{2}$} & $\mathrm{HT}$ & 7,5 & $\approx 7^{*}$ (ombro) & 3,9 & 2,4 (ombro) & 1,5 \\
\hline & HGT & 6,9 & $6,6 *$ (ombro) & 3,9 & 2,2 & 1,3 \\
\hline & HGBT & 5,9 & $6,0^{*}$ & 3,7 & 2,1 (ombro) & 1,5 \\
\hline & HGAT & - & $6,0 *$ (ombro) & 3,8 & 2,4 & 1,4 \\
\hline \multirow{4}{*}{ Glove-box } & $\mathrm{HT}$ & - & 7,4 & N.R. & N.R. & 1,6 \\
\hline & HGT & - & 6,6 & 3,7 & 2,2 (ombro) & 1,2 \\
\hline & HGBT & - & 6,1 & 3,8 & N.R. & 1,3 \\
\hline & HGAT & - & 6,3 & 3,9 & 2,5 & 1,6 \\
\hline
\end{tabular}

Fonte: Elaborada pelo autor.

por volta de 6,8ppm, mas a área relativa destes picos é menor - ou não é observado, no caso da amostra HGAT-N2 - comparando com os espectros da figura 6.29. a. Adicionalmente, esta linha é mais alargada. Portanto, o preparo em atmosfera mais seca resulta em xerogéis menos hidratados, e o alargamento da linha indica menor mobilidade para estes prótons. Finalmente, para os xerogeis preparados em glove-box, os espectros da figura 6.29. c não apresentam linhas correspondentes a estas espécies de $\mathrm{H}_{2} \mathrm{O}$ móveis, indicando que a preparação dos xerogeis nestas condições evita o acúmulo destas espécies nas amostras.

As amostras HT apresentam composições mais simples, e portanto serão úteis na atribuição das linhas espectrais de ${ }^{1} \mathrm{H}$. Os espectros da amostra HT-N2, após o tratamento em $85^{\circ} \mathrm{C}$, e da amostra HT-Box apresentam linhas em 1,4ppm e 2,5ppm. Estudos de ${ }^{1} \mathrm{H}$ MAS RMN em HPW suportado em sílica, para materiais calcinados a $200^{\circ} \mathrm{C}$, revelam um espectro muito semelhante ao destas amostras, com o pico principal centrado em 1.8 ppm atribuído a grupos $\mathrm{OH}$ na superfície da sílica.(98) Como as amostras HT não apresentam grupos orgânicos em sua composição, os picos observados provavelmente correspondem a grupos $\mathrm{OH}$ da matriz de $\mathrm{Si}$. A ressonância em 1,4ppm, a mais estreita, corresponde a prótons mais móveis e/ou isolados de outros prótons. Estas espécies $\mathrm{OH}$ também podem ocorrer no ambiente de coordenação do HPW, como observado para a amostra HPW-II. Além destas ressonâncias associadas à grupos $\mathrm{OH}$, o espectro da amostra HT-Box apresenta uma linha larga e centrada em 7ppm, similar à observada para as amostras de $\mathrm{HPW} \cdot 6 \mathrm{H}_{2} \mathrm{O}$, que pode ser atribuída a prótons em aglomerados de moléculas $\mathrm{H}_{2} \mathrm{O}$ com mobilidade restrita. Tanto os $\mathrm{OH}$ móveis, quanto os aglomerados de moléculas de $\mathrm{H}_{2} \mathrm{O}$ são observados para as amostras de $\mathrm{HPW} \cdot 6 \mathrm{H}_{2} \mathrm{O}$. 


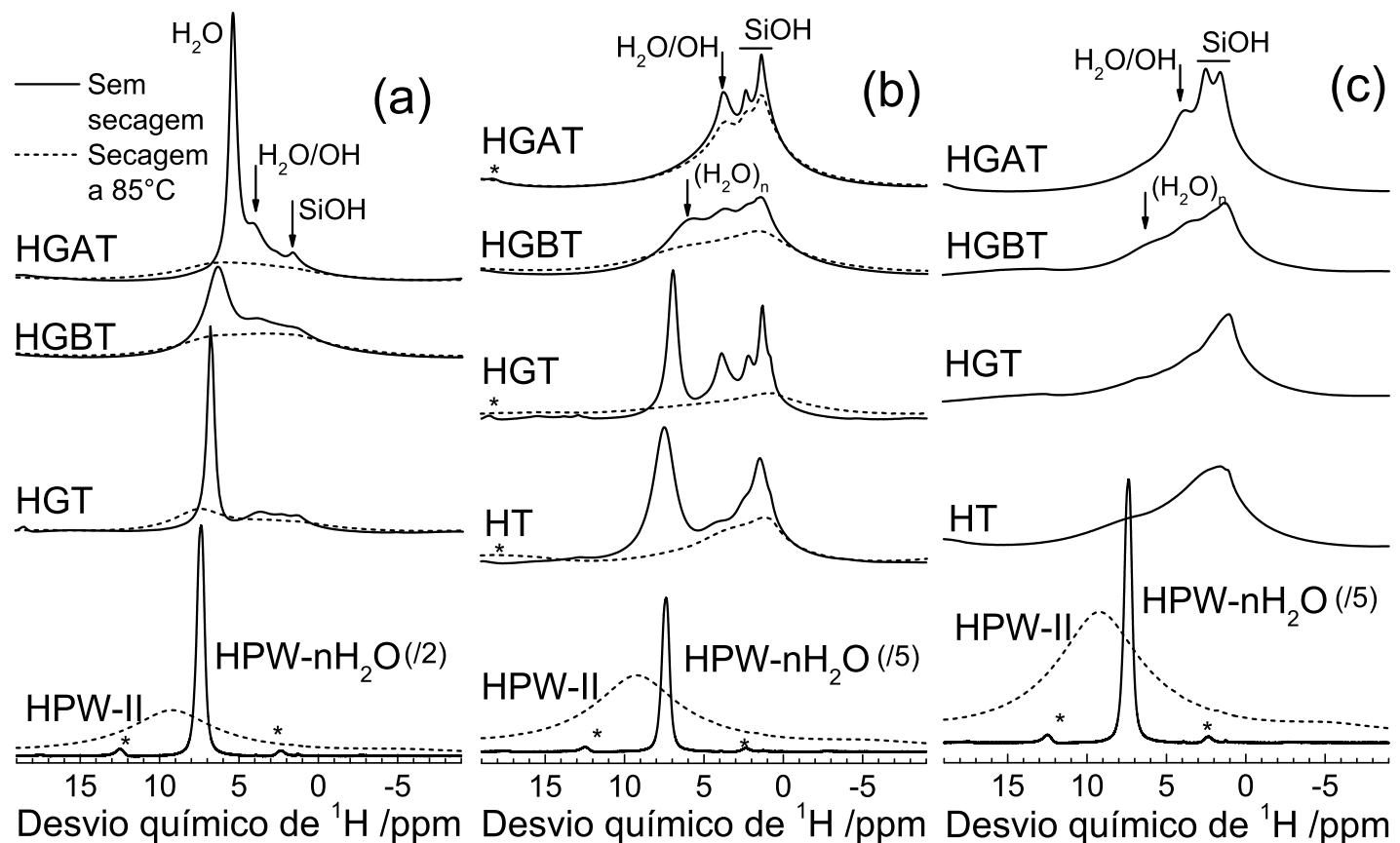

Figura 6.29-Espectros de ${ }^{1} \mathrm{H}$ MAS RMN medidos em $85^{\circ} \mathrm{C}$ para as amostras de xerogeis preparadas em diferentes condições de atmosfera: sem controle de atmosfera (a); atmosfera saturada com $\mathrm{N}_{2}$ (b); e em atmosfera seca dentro de uma glove-box (c). Linhas contínuas representam experimentos em amostras sem tratamento térmico, e linhas tracejadas correspondem a experimentos em amostras submetidas a secagens sob fluxo de $\mathrm{N}_{2}$ em $85^{\circ} \mathrm{C}$. Os espectros para amostras de HPW. $\mathrm{nH}_{2} \mathrm{O}$ (em temperatura ambiente) e HPW-II (em $\left.85^{\circ} \mathrm{C}\right)$ estão representados para efeitos de comparação. Fonte: Elaborada pelo autor.

A ressonância em torno de 4ppm está presente nos espectros de todos os xerogeis, e pode ser atribuídos à grupos $\mathrm{OH}$ e/ou moléculas de $\mathrm{H}_{2} \mathrm{O}$. Após o tratamento a $85^{\circ} \mathrm{C}$, esta linha sofre um alargamento, que pode indicar que após a secagem apenas grupos com interação mais forte com o ambiente permanecem na amostra.

Em resumo, as principais espécies de prótons identificadas, com base nos espectros de ${ }^{1} \mathrm{H}$ RMN são:

- Grupos $\mathrm{OH}$ - conectados à matriz de silicatos e/ou participando do ambiente de coordenação do HPW;

- espécies de hidratação - como aglomerados de $\mathrm{H}_{2} \mathrm{O}$ intersticial inseridas na estrutura da matriz ormosil ou espécies de hidratação no ambiente de coordenação do poliânion, podendo ser clusters $\mathrm{H}^{+}\left(\mathrm{H}_{2} \mathrm{O}\right)_{n}$ ou até íons $\mathrm{H}_{5} \mathrm{O}_{2}{ }^{+}$e $\mathrm{H}_{3} \mathrm{O}^{+}$ou moléculas de $\mathrm{H}_{2} \mathrm{O}$. 


\subsubsection{Experimentos de CP $\left\{{ }^{1} H_{-}{ }^{31} \mathrm{P}\right.$ MAS RMN}

Assim como para as amostras de HPW hidratado, foram realizados experimentos de CP $\left\{{ }^{1} \mathrm{H}\right\}-{ }^{31} \mathrm{P}$ RMN a temperatura ambiente nos xerogeis para análise qualitativa do acoplamento dipolar efetivo entre os núcleos ${ }^{31} \mathrm{P}$ e os ${ }^{1} \mathrm{H}$ no ambiente químico do poliânion. Para todas as amostras de xerogeis, o acoplamento dipolar heteronuclear entre ${ }^{1} \mathrm{H}$ e ${ }^{31} \mathrm{P}$ é suficientemente intenso para gerar sinal de CP. Os espectros de CP e PD para os diferentes xerogeis (sem tratamento térmico) são exibidos na figura 6.30. $\mathrm{O}$ espectro de $\mathrm{CP}$ para os xerogeis em geral é ligeiramente mais largo, indicando heterogeneidade do acoplamento dipolar ${ }^{1} \mathrm{H}_{-}{ }^{31} \mathrm{P}$. A diferença entre a relação de intensidades para os espectros de CP e PD para a amostra HT-Box (figura 6.30.c) indica acoplamento dipolar ${ }^{1} \mathrm{H}_{-}{ }^{31} \mathrm{P}$ mais intenso para as espécies ressoando em $-13,8 \mathrm{ppm}$.

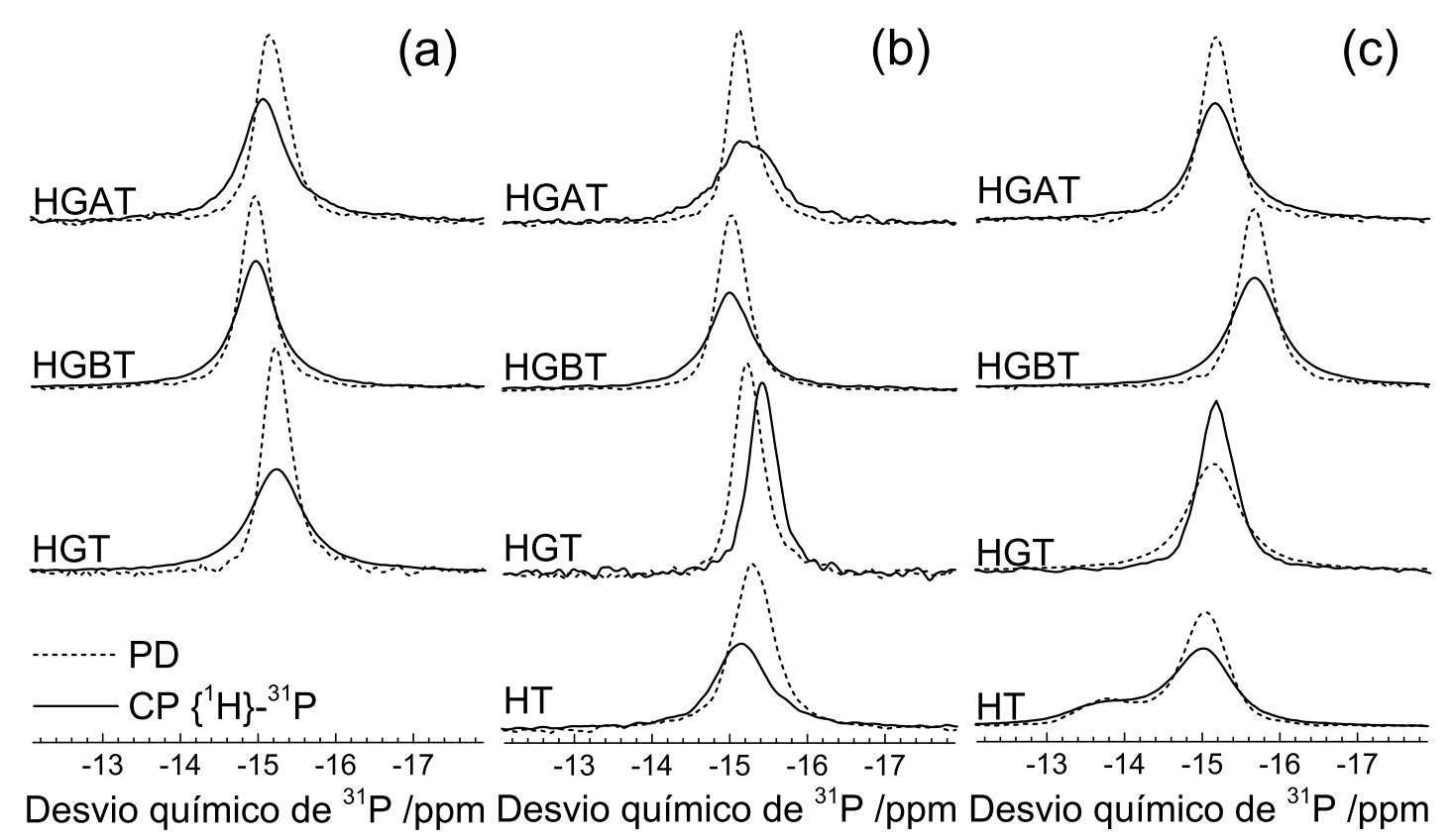

Figura 6.30-Espectros de $\mathrm{CP}\left\{{ }^{1} \mathrm{H}\right\}{ }^{31} \mathrm{P}$ e ${ }^{31} \mathrm{P}$ MAS RMN para as amostras de xerogeis preparadas em diferentes condições de atmosfera: sem controle de atmosfera (a); atmosfera saturada com $\mathrm{N}_{2}$ (b); e em atmosfera seca dentro de uma glove-box (c). As amostras não passaram por nenhum processo de secagem. Linhas contínuas representam experimentos de polarização cruzada, e linhas tracejadas correspondem a experimentos de polarização direta. Fonte: Elaborada pelo autor.

Os espectros de CP $\left\{{ }^{1} \mathrm{H}\right\}-{ }^{31} \mathrm{P}$ RMN para os xerogéis após os tratamentos térmicos (não mostrados) foram comparáveis aos espectros da figura 6.30, com exceção do espectro para a amostra HT-N2, mostrado na figura 6.31. Este espectro de CP apresenta três linhas, centradas 
em -12,8ppm, -13,9 e -14,9ppm, enquanto o espectro de PD para a mesma amostra apresenta picos em -14,2ppm e-15,4ppm. A ausência do sinal em -12,8ppm no espectro de PD indica que esta linha corresponde a espécies com baixa população e acoplamento dipolar ${ }^{1} \mathrm{H}_{-}{ }^{31} \mathrm{P}$ intenso. De acordo com Ganapathy et al., este desvio químico corresponde a HPW desidratado, e o poliânion realiza ligação covalente com três hidrogênios.(32) Esta atribuição é consistente com o alto acoplamento dipolar heteronuclear observado. A variedade de linhas observada no espectro de CP para a amostra HT-N2 seca e as diferenças no acoplamento dipolar ${ }^{1} \mathrm{H}-{ }^{1} \mathrm{H}$ mostram que esta amostra é altamente heterogênea, com uma distribuição de níveis de hidratação para os ambientes de coordenação do HPW.

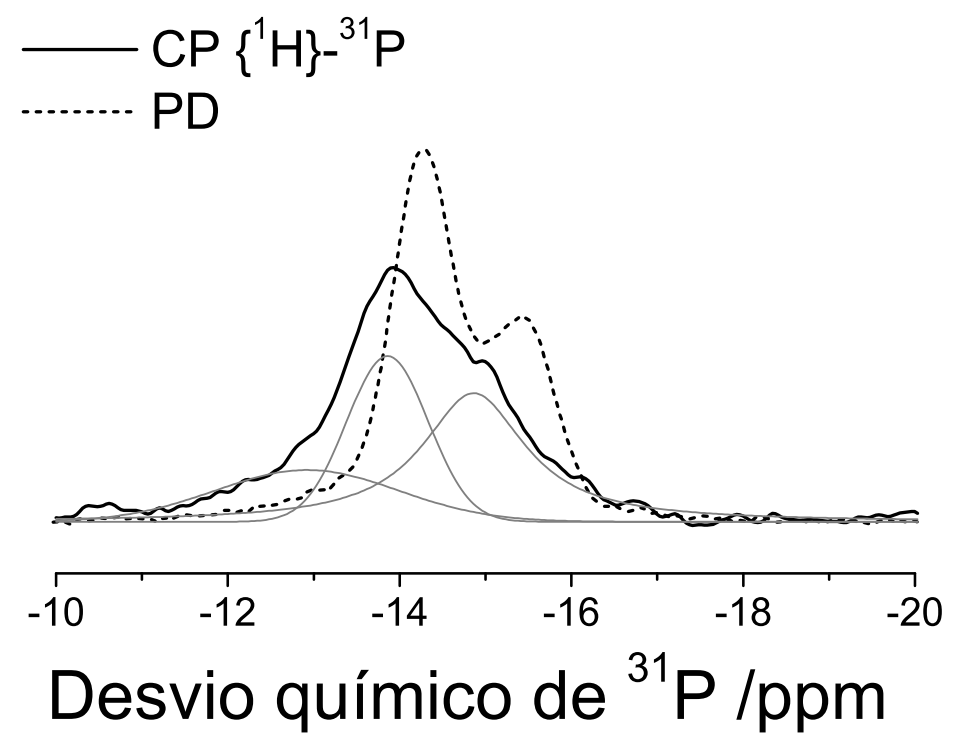

Figura 6.31-Espectros de $\mathrm{CP}\left\{{ }^{1} \mathrm{H}\right\}{ }^{31} \mathrm{P}$ (linhas contínuas) e ${ }^{31} \mathrm{P}$ MAS RMN (linhas tracejadas) para a amostra HT-N2 submetida a tratamento térmico em $85^{\circ} \mathrm{C}$ por $2 \mathrm{~h}$ sob fluxo de $\mathrm{N}_{2}$. As linhas em cinza representam ajustes de mínimos quadrados com funções gaussianas aos dados do espectro de CP. Fonte: Elaborada pelo autor.

Como no caso das amostras de HPW hidratado, a dinâmica de transferência de polarização ${ }^{1} \mathrm{H} \rightarrow{ }^{31} \mathrm{P}$ foi analisada através de experimentos de TORQUE $\left\{{ }^{1} \mathrm{H}\right\}-{ }^{31} \mathrm{P}$ RMN, para a obtenção dos tempos característicos $\mathrm{T}_{H P}$ e $\mathrm{T}_{1 \rho}$. As curvas obtidas para os vários xerogeis são apresentadas na figura 6.32. Vale ressaltar que o tempo máximo de contato nestes experimentos não pode ultrapassar o tempo total $t_{T Q}$ da equação 3.1.53. Desta forma, os experimentos foram otimizados de forma a maximizar o tempo $t_{T Q}$ sem comprometer a relação sinal/ruído, devido a efeitos de $\mathrm{T}_{1 \rho}$. Portanto, as curvas de TORQUE foram normalizadas pela constante $M_{e q} \frac{\gamma_{H}}{\gamma_{P}}$ ajustada. Devido a complexidade maior para os espectros de ${ }^{31} \mathrm{P}$ da amostra HT-Box, não foi possível obter valores confiáveis para o tempo $\mathrm{T}_{H P}$, e portanto o mesmo não foi computado. 
A convexidade das curvas de TORQUE demonstra que a condição $\mathrm{T}_{H P}<\mathrm{T}_{1 \rho}$ ocorre apenas para a amostra HGT-Box. Para as outras amostras, em alguns casos as curvas se aproximam de uma reta, indicando $\mathrm{T}_{H P} \approx \mathrm{T}_{1 \rho}$ e em outros apresentam concavidade positiva, mostrando que $\mathrm{T}_{H P}>\mathrm{T}_{1 \rho}$.(80) De forma geral, os valores de $\mathrm{T}_{H P}$ são sempre da ordem de $\mathrm{T}_{1 \rho}$, justificando a escolha da técnica de TORQUE para determinação de $\mathrm{T}_{H P}$. Experimentos de SLCP $\left\{{ }^{1} \mathrm{H}\right\}{ }^{31} \mathrm{P}$ também foram realizados para os xerogeis, para determinação mais precisa de $\mathrm{T}_{1 \rho}$ (figura 6.33). Os tempos $\mathrm{T}_{H P}$ e $\mathrm{T}_{1 \rho}$, obtidos por ambas as técnicas são mostrados na tabela 6.7 .

(a)

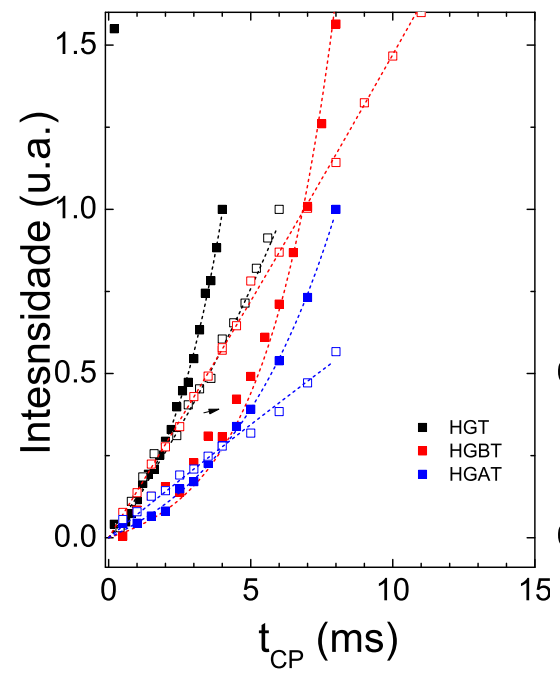

(b)

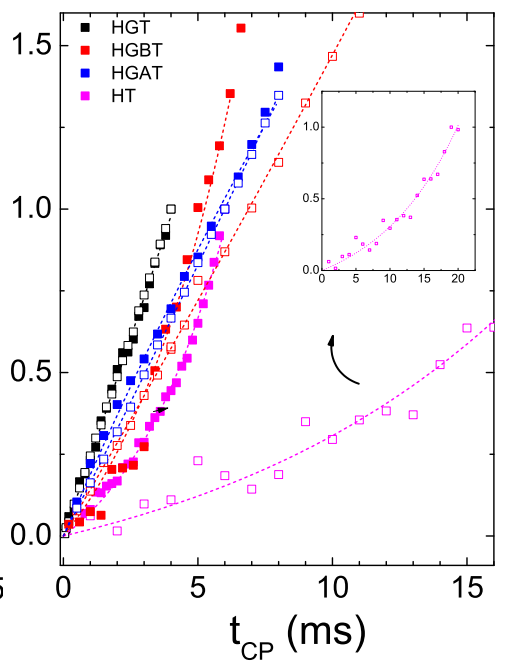

(c)

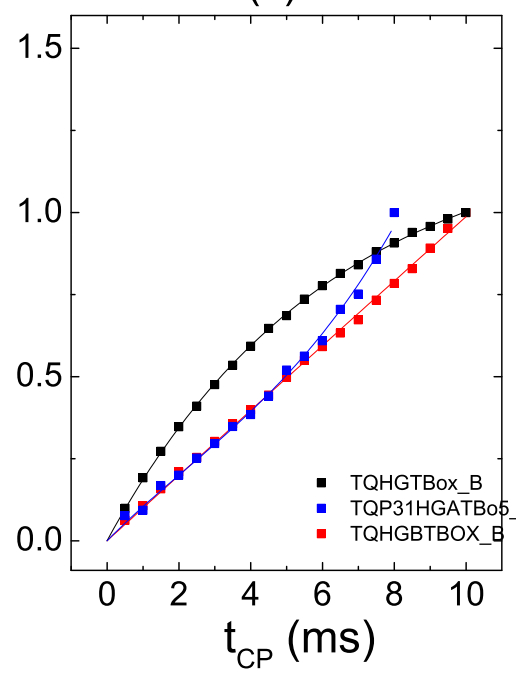

Figura 6.32-Curvas TORQUE $\left\{{ }^{1} \mathrm{H}\right\}-{ }^{31} \mathrm{P}$ RMN para os xerogeis preparados em diferentes condições de atmosfera: sem controle de atmosfera (a); atmosfera saturada com $\mathrm{N}_{2}$ (b); e em atmosfera seca dentro de uma glove-box (c). Simbolos cheios representam experimentos sobre as amostras sem nenhum tratamento, enquanto símbolos vazios representam experimentos em amostras submetidas a secagem a $85^{\circ} \mathrm{C}$ por $2 \mathrm{~h}$ sob fluxo de $\mathrm{N}_{2}$. As linhas tracejadas são ajustes de mínimos quadrados utilizando a equação 3.1 .53 . A normalização das curvas foi realizada considerando-se o valor obtido para $M_{0}$ nos ajustes. $\mathrm{O}$ in set mostra o conjunto completo de dados experimentais para a amostra HT-N2. Fonte: Elaborada pelo autor.

Dentre as amostras preparadas em condições ambientes, a amostra HGBT-Amb é a que apresenta maior variação no tempo $\mathrm{T}_{H P}$ antes e após a secagem térmica, indicando que além da remoção das moléculas de água, houve alteração nas espécies de prótons ao redor do poliânion, aumentando o acoplamento dipolar ${ }^{1} \mathrm{H}^{31} \mathrm{P}$ médio. Esta alteração pode ser de ordem dinâmica e/ou estrutural. Para as outras amostras preparadas em condição ambiente não foram observadas alterações significativas nos tempos após as secagens.

Considerando as amostras preparadas em câmara com fluxo de $\mathrm{N}_{2}$, os valores de $\mathrm{T}_{H P}$ não variam consideravelmente após a secagem dos xerogéis HGT, HGBT e HGAT, portanto 
(a)

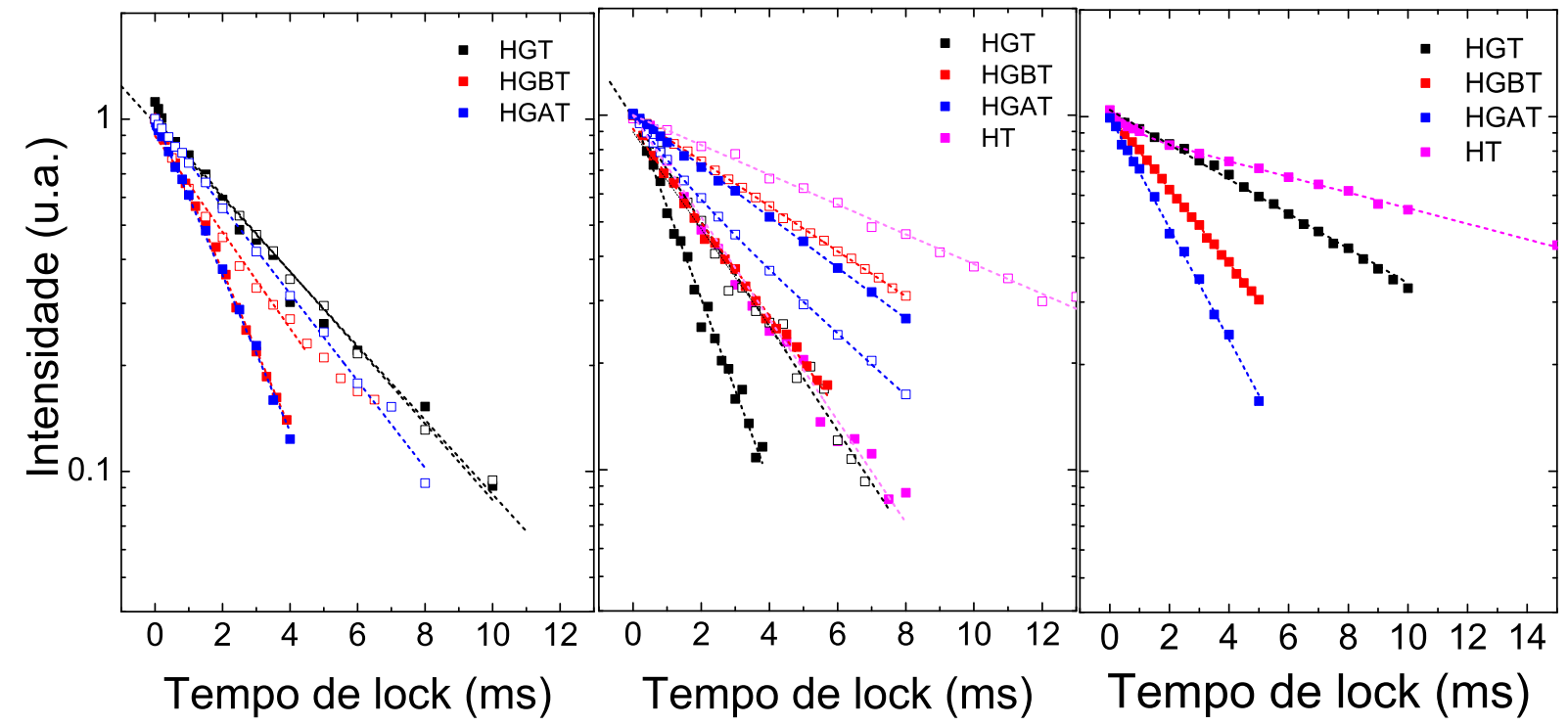

Figura 6.33-Curvas SLCP $\left\{{ }^{1} \mathrm{H}\right\}{ }^{31} \mathrm{P}$ RMN para os xerogeis preparados em diferentes condições de atmosfera: sem controle de atmosfera (a); atmosfera saturada com $\mathrm{N}_{2}$ (b); e em atmosfera seca dentro de uma glove-box (c). Simbolos cheios representam experimentos sobre as amostras sem nenhum tratamento, enquanto símbolos vazios representam experimentos em amostras submetidas a secagem a $85^{\circ} \mathrm{C}$ por $2 \mathrm{~h}$ sob fluxo de $\mathrm{N}_{2}$. As linhas tracejadas são ajustes de mínimos quadrados utilizando a equação 3.1 .54 . Fonte: Elaborada pelo autor.

não há grandes alterações no acoplamento dipolar médio ${ }^{1} \mathrm{H}-{ }^{31} \mathrm{P}$ nestes xerogeis. Por outro lado, para a amostra HT-N2 é observado um grande decréscimo do tempo $\mathrm{T}_{H P}$ - redução no acoplamento ${ }^{1} \mathrm{H}_{-}{ }^{31} \mathrm{P}$ - e um acréscimo em $\mathrm{T}_{1 \rho}$ - alteração na dinâmica dos prótons e/ou redução na intensidade do acoplamento dipolar homonuclear ${ }^{1} \mathrm{H}-{ }^{1} \mathrm{H}$ (99), mostrando que há alterações estruturais significativas para os prótons no ambiente de coordenação do poliânion, como já havia sido observado nos experimentos de ${ }^{31} \mathrm{P}$ RMN. De fato, na amostra HT-N2 não há grupos orgânicos na matriz $\mathrm{SiO}$, tornando a matriz menos hidrofílica, o que facilita a remoção das moléculas $\mathrm{H}_{2} \mathrm{O}$ via tratamento térmico. $\mathrm{O}$ valor de $\mathrm{T}_{1 \rho}$ apresenta pequena variação para as amostras HGBT e HGAT, mostrando alteração na dinâmica e/ou acoplamento homonuclear dos prótons no ambiente de coordenação do HPW.(99) Para a amostra HGAT-N2 um decaimento bi-exponencial é observado (figura 6.33. b), indicando heterogeneidade para os ambientes de coordenação do poliânion, ou diferentes processos de relaxação ocorrendo simultaneamente.

Os tempos $\mathrm{T}_{H P}$ para as amostras preparadas em glove-box são todos da mesma ordem, mostrando que o acoplamento médio ${ }^{1} \mathrm{H}_{-}{ }^{31} \mathrm{P}$ é semelhante. Apenas alterações na dinâmica dos prótons são observadas, por meio da diferença nos valores de $\mathrm{T}_{1 \rho}$. 
Tabela 6.7-Tempos de contato $\left(\mathrm{T}_{H P}\right)$ e de relaxação spin-rede no sistema rotante $\left(\mathrm{T}_{1 \rho}\right)$ obtidos respectivamente pelas técnicas de TORQUE e SLCP $\left\{{ }^{1} \mathrm{H}\right\}{ }^{31} \mathrm{P}$ RMN, antes e após tratamento térmico a $85^{\circ} \mathrm{C}$ por $2 \mathrm{~h}$ sob fluxo contínuo de $\mathrm{N}_{2}$. Valores de $\mathrm{M}_{2 H P}$ obtidos dos experimentos de SEDOR em $-95^{\circ} \mathrm{C}$ (seção 6.2.7).

\begin{tabular}{|c|c|c|c|c|c|c|c|}
\hline \multirow{2}{*}{$\begin{array}{l}\text { Condição } \\
\text { de } \\
\text { preparo }\end{array}$} & \multirow[b]{2}{*}{ Amostra } & \multicolumn{3}{|c|}{ Sem secagem } & \multicolumn{3}{|c|}{ Secagem em $85^{\circ} \mathrm{C}$} \\
\hline & & $\begin{array}{c}\mathbf{T}_{\boldsymbol{H P}} \\
( \pm 1 \mathrm{~ms})\end{array}$ & $\begin{array}{c}\mathbf{T}_{1 \rho} \\
( \pm 0,1 \mathrm{~ms})\end{array}$ & $\begin{array}{c}\mathbf{M}_{2 H P} \\
\left(\times 10^{6} \mathrm{rad}^{2} \mathrm{~s}^{-2}\right)\end{array}$ & $\begin{array}{c}\mathbf{T}_{\boldsymbol{H} \boldsymbol{P}} \\
( \pm 1 \mathrm{~ms})\end{array}$ & $\begin{array}{c}\mathbf{T}_{1 \rho} \\
( \pm 0,1 \mathrm{~ms})\end{array}$ & $\begin{array}{c}\mathrm{M}_{2 H P} \\
\left(\times 10^{6} \mathrm{rad}^{2} \mathrm{~s}^{-2}\right)\end{array}$ \\
\hline \multirow[t]{2}{*}{-} & HPW & - & - & - & 9 & 2,5 & $8,5 \pm 0,5$ \\
\hline & HGT & 5 & 3,1 & $12,4 \pm 0,8$ & 2 & 3,0 & $19,2 \pm 0,2$ \\
\hline \multirow{2}{*}{ Ambiente } & HGBT & 10 & 2,0 & $17,1 \pm 0,1$ & 3 & 3,2 & $15,5 \pm 0,3$ \\
\hline & HGAT & 4 & 2,0 & $14,8 \pm 0,2$ & 3 & 3,5 & $13,0 \pm 0,2$ \\
\hline \multirow{4}{*}{ Fluxo $\mathrm{N}_{2}$} & HT & 2 & 3,0 & $13,4 \pm 0,1$ & 21 & 10,3 & $11,8 \pm 0,1$ \\
\hline & HGT & 5 & 4,0 & $22,0 \pm 0,2$ & 5 & 4,1 & $24,4 \pm 0,4$ \\
\hline & HGBT & 5 & 3,3 & $17,8 \pm 0,3$ & 6 & 6,8 & $27,3 \pm 0,6$ \\
\hline & HGAT & 5 & 6,1 & $15,7 \pm 0,1$ & 7 & $5,0 / 1,4$ & $14,9 \pm 0,2$ \\
\hline \multirow{4}{*}{ Glove-Box } & HT & - & 19,9 & $13,0 \pm 0,1$ & - & - & - \\
\hline & HGT & 4 & 8,9 & $15,6 \pm 0,2$ & - & - & - \\
\hline & HGBT & 5 & 4,7 & $15,5 \pm 0,2$ & - & - & - \\
\hline & HGAT & 4 & 2,8 & $10,5 \pm 0,3$ & - & - & - \\
\hline
\end{tabular}

Fonte: Elaborada pelo autor.

\subsubsection{Experimentos RMN com variação de temperatura}

\subsubsection{1 ${ }^{31} \mathrm{P}$ RMN}

Os espectros de ${ }^{31} \mathrm{P}$ MAS RMN para todos os xerogeis estudados neste trabalho não apresentam grandes alterações em função da temperatura, acima da temperatura ambiente, exibindo apenas um aumento linear nos valores de desvio químico, como acontece para o HPW-II. Portanto, não serão mostrados os espectros em função da temperatura para todas as amostras, uma vez que os espectros para as amostras HGAT na figura 6.34 e os respectivos parâmetros (desvio químico e FWHM) na figura 6.35) representam as variações observadas nos outros xerogeis estudados.

Os espectros de ${ }^{31} \mathrm{P}$ MAS RMN em função da temperatura para a amostra HGAT preparada em câmara com fluxo de $\mathrm{N}_{2}$ são exibidos na figura 6.34.a. Pequenas variações dos parâmetros espectrais podem ser observadas para estes espectros, como um estreitamento das linhas espectrais com o aumento da temperatura, conforme pode ser observado na figura 6.35.b, indicando aumento da mobilidade relativa entre o poliânion de HPW e seu ambiente de coordenação e/ou redução na heterogeneidade da amostra. Pequenas variações em função da 
temperatura são observadas para o desvio químico (figura 6.35. a), mais evidentes em $-30^{\circ} \mathrm{C} \mathrm{e}$ $-50^{\circ} \mathrm{C}$, indicando que o poliânion e a estrutura de seu ambiente de coordenação não sofrem alterações significativas com a temperatura. Por outro lado, para a amostra HGAT preparada em glove-box, cujos espectros de ${ }^{31} \mathrm{P}$ estão mostrados na figura 6.34. b, o comportamento acima de temperatura ambiente é similar ao observado para os espectros da amostra HGAT-N2, como mostram os parâmetros espectrais na figura 6.35, no entanto entre $20^{\circ} \mathrm{C}$ e $0^{\circ} \mathrm{C}$ há uma variação abrupta no desvio químico (figura 6.35. a), que se mantém até $-50^{\circ} \mathrm{C}$ (temperatura mais baixa estudada). Esta é a primeira observação de variações de desvio químico tão significativas em função da temperatura para os espectros de ${ }^{31} \mathrm{P}$ dos compostos estudados neste trabalho (incluindo as amostras de HPW hidratado discutidas na seção 6.1.3). Este comportamento indica variações estruturais e/ou dinâmicas de ordem maior para o ambiente de prótons ao redor do poliânion. De fato, os experimentos de spin-eco ${ }^{1} \mathrm{H}$ RMN, mostrados mais abaixo mostram um aumento significativo no acoplamento dipolar homonuclear ${ }^{1} \mathrm{H}-{ }^{1} \mathrm{H}$ para esta amostra.
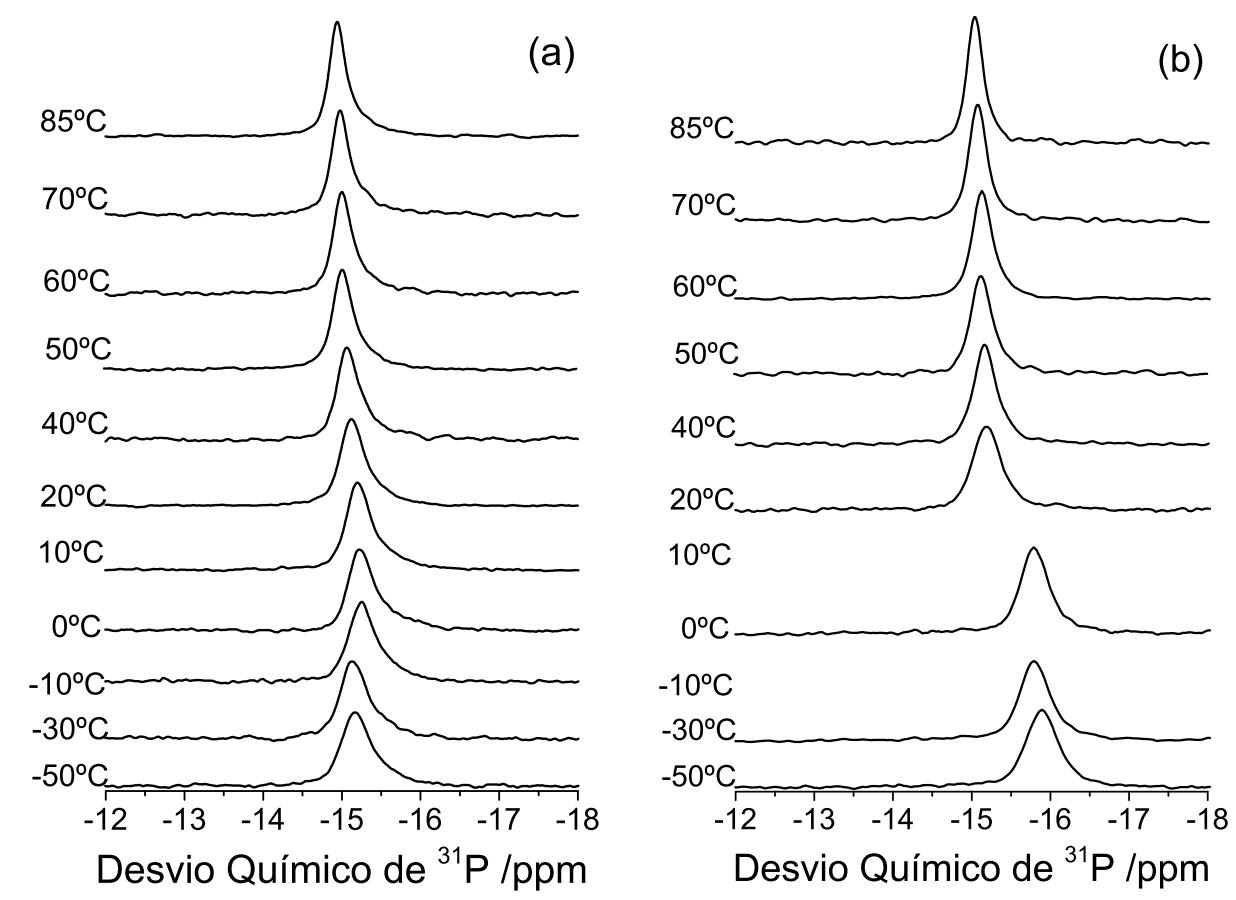

Figura 6.34-Espectros de polarização direta ${ }^{31} \mathrm{P}$ MAS RMN em função da temperatura, para amostras HGAT preparadas em câmara com fluxo de $\mathrm{N}_{2}$ (a) e em glove-box (b). Fonte: Elaborada pelo autor. 


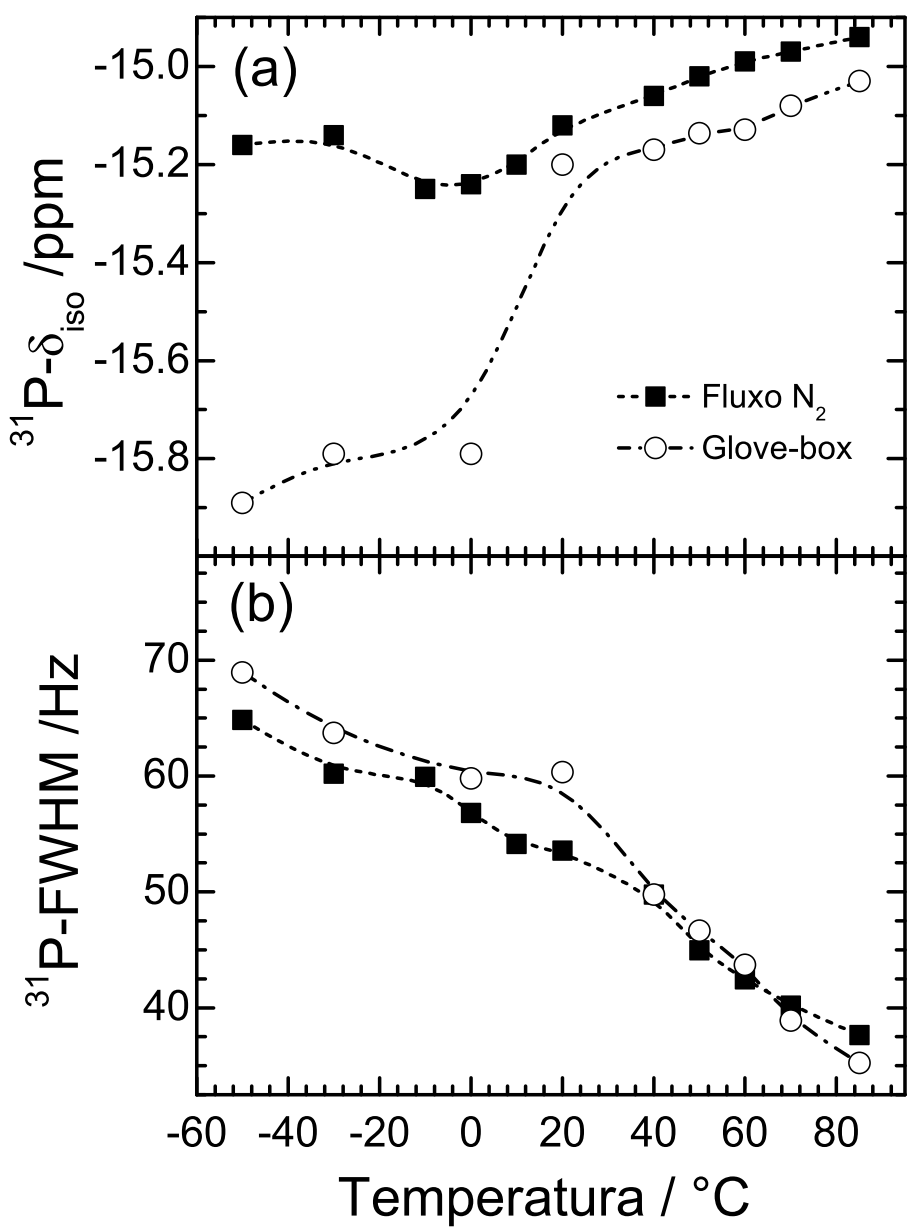

Figura 6.35-Parâmetros espectrais do experimento de ${ }^{31} \mathrm{P}$ RMN sobre amostras HGAT preparadas em câmara com fluxo de $\mathrm{N}_{2}$ (quadrados cheios) e em glove-box (círculos vazios). (a) Desvio químico da linha central $\left({ }^{31} \mathrm{P}-\delta_{\text {iso }}\right)$. (b) Largura a meia altura $(\mathrm{FWHM})$. As linhas tracejadas são guias para os olhos. Fonte: Elaborada pelo autor.

\subsubsection{2 ${ }^{1} \mathrm{H}$ RMN}

Os espectros de ${ }^{1} \mathrm{H}$ MAS RMN apresentam estreitamento das linhas espectrais com o aumento da temperatura para todas as amostras. Este estreitamento indica que há redução no acoplamento dipolar homonuclear entre os ${ }^{1} \mathrm{H}$, consistente com um aumento na dinâmica destas espécies. Para a amostra HGBT o estreitamento das linhas espectrais é menos acentuado, indicando que nesta amostra são necessárias temperaturas maiores para a ativação dos movimentos observados para as outras amostras.

As amostras preparadas com fluxo de $\mathrm{N}_{2}$ possuem menor quantidade de $\mathrm{H}_{2} \mathrm{O}$ móveis (ressonância estreita em 7ppm), o que permite analisar com maior detalhe o comportamento 
das outras linhas espectrais, cujos desvios são mostrados na tabela 6.6. Por isto, estas amostras foram escolhidas para analisar o comportamento das espécies de ${ }^{1} \mathrm{H}$ em função da temperatura. Os espectros de ${ }^{1} \mathrm{H}$ RMN para estas amostras estão mostrados na figura 6.36. Como observado na seção 6.2.4, as amostras HGBT e HGAT possuem baixo nível de hidratação. Quando a temperatura é incrementada entre $20^{\circ} \mathrm{C}$ e $85^{\circ} \mathrm{C}$, é possível observar um estreitamento apreciável para a linha em $\approx 7 \mathrm{ppm}$, mostrando que os $\mathrm{H}$ em espécies de hidratação ganham mobilidade. Como discutido na seção 6.2.4, foram identificadas ao menos dois tipos de espécies ressoando em $\approx 3,8 \mathrm{ppm}$, prótons com mobilidade mais alta $\left(\mathrm{em} 85^{\circ} \mathrm{C}\right)$, que são eliminados pela secagem térmica, e prótons com mobilidade mais restrita, que não são susceptíveis aos tratamentos térmicos. A linha estreita está presente nas amostras HGT e HGAT em alta temperatura, e apresenta aumento na largura com o decréscimo da temperatura, mostrando que estes prótons apresentam mobilidade mais restrita em temperatura ambiente. Para as amostras HT e HGBT a linha em 3,8ppm é mais alargada, mesmo em altas temperaturas, indicando espécies de prótons com mobilidade mais restrita. Como será discutido na seção 7.2 esta ressonância pode ser atribuída a moléculas de $\mathrm{H}_{2} \mathrm{O}$ adsorvida na superfície da matriz $\mathrm{SiO}$.

Os picos entre 2,5ppm e $0 \mathrm{ppm}$ podem ser atribuídos a grupos $\mathrm{OH}$ no ambiente de coordenação do HPW, ou grupos pertencentes à matriz ormosil, como grupos $\mathrm{CH}_{2}, \mathrm{COH}$ e $\mathrm{SiOH}$, com base nos argumentos da seção 6.2.4 e nos experimentos de HETCOR na seção 6.2.8. Estas linhas também apresentam estreitamento com a temperatura, indicando acoplamentos ${ }^{1} \mathrm{H}_{-}{ }^{1} \mathrm{H}$ mais altos em baixa temperatura. Mais uma vez, o estreitamento é mais evidente para as amostras HGT e HGAT.

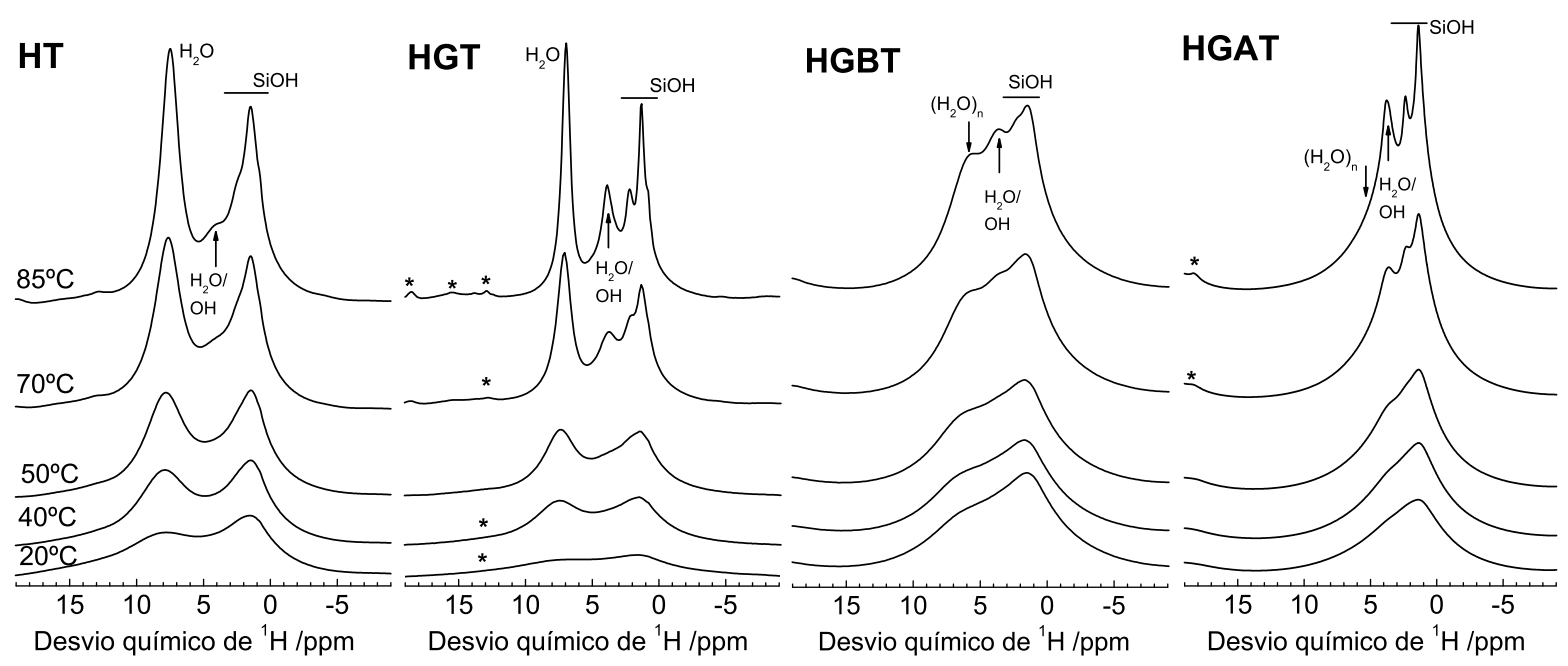

Figura 6.36-Espectros de ${ }^{1} \mathrm{H}$ RMN em função da temperatura para os xerogeis preparados em atmosfera saturada com $\mathrm{N}_{2}$. Fonte: Elaborada pelo autor.

Para aprofundar nas atribuições aos picos de ${ }^{1} \mathrm{H}$, experimentos similares aos realizados para HPW-II, desde $-50^{\circ} \mathrm{C}$ até $85^{\circ} \mathrm{C}$, foram realizados para as amostras HGAT-N2 e HGAT- 
Box. Estas amostras foram escolhidas por serem menos hidratadas, mesmo sem passar por secagens térmicas, e possuírem espectros com linhas bem resolvidas, facilitando a separação das diferentes espécies de ${ }^{1} \mathrm{H}$. A figura 6.37. a mostra os espectros de ${ }^{1} \mathrm{H}$ MAS RMN em função da temperatura para a amostra HGAT preparada em glove-box. No espectro de mais alta temperatura é possível identificar quatro grupos de linhas, em 6,5ppm, 3,8ppm, 2,5ppm e 1,5ppm. Como relatado anteriormente, os espectros apresentam um alargamento com a redução da temperatura, devido à redução na mobilidade das espécies de ${ }^{1} \mathrm{H}$ e o consequente aumento do acoplamento dipolar homonuclear ${ }^{1} \mathrm{H}-{ }^{1} \mathrm{H}$.

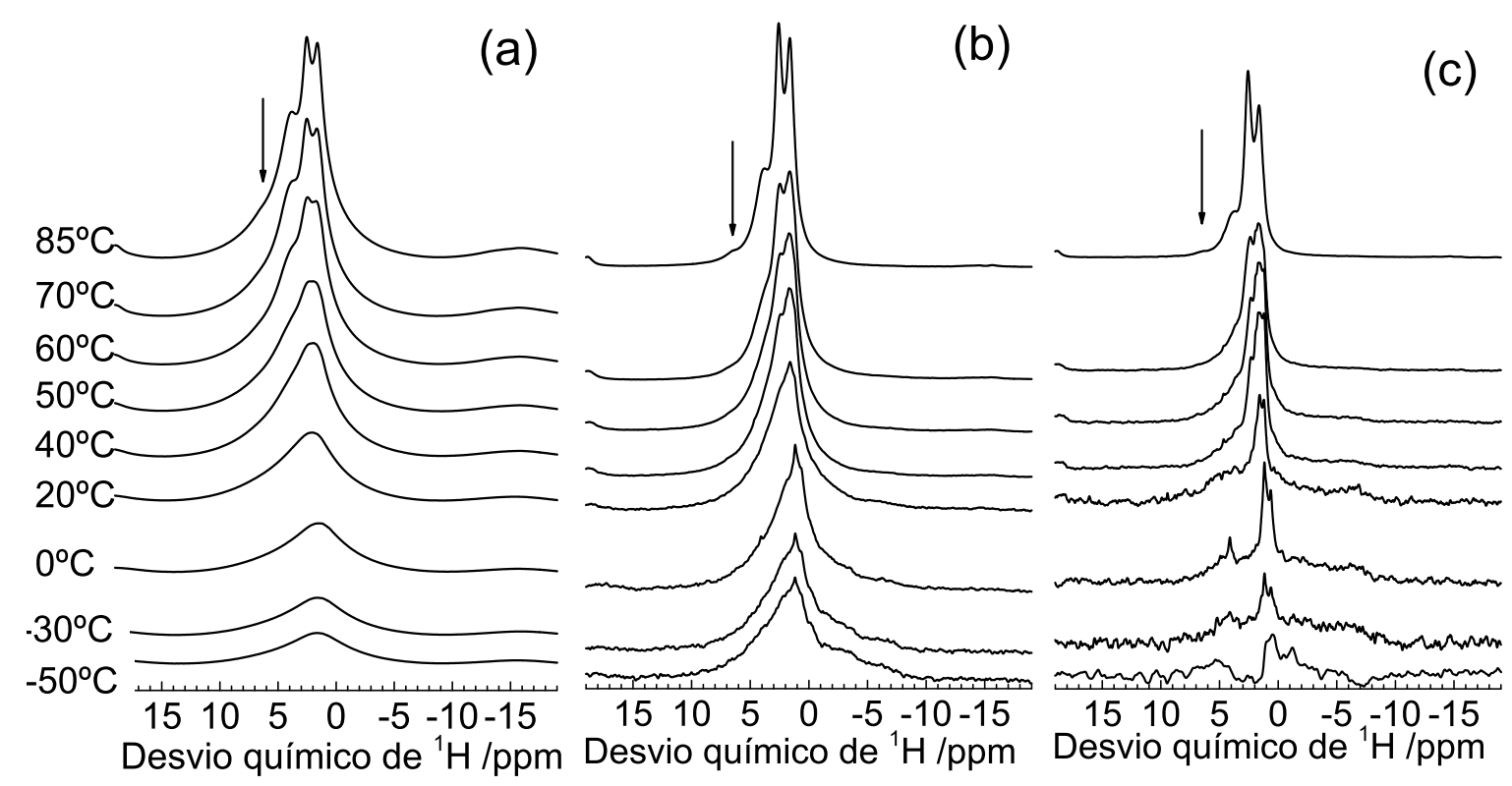

Figura 6.37-Espectros de ${ }^{1} \mathrm{H}$ RMN em função da temperatura, para a amostra HGAT preparada em glove-box, obtidos por polarização direta (a) e técnica de spin-eco de Hahn com tempo $\tau$ de separação entre os pulsos de $\pi / 2$ e $\pi$ em $332 \mu s$ (b) e $996 \mu s$ (c). As setas indicam o desvio em $6,5 \mathrm{ppm}$, que corresponde à posição esperada para a ressonância de espécies $\mathrm{H}^{+}\left(\mathrm{H}_{2} \mathrm{O}\right)_{n}$. Fonte: Elaborada pelo autor.

Assim como para as amostras de HPW hidratado, foram realizados experimentos de ${ }^{1} \mathrm{H}$ spin-eco sobre a amostra HGAT-Box para a analise qualitativa dos acoplamentos dipolares ${ }^{1} \mathrm{H}-{ }^{1} \mathrm{H}$ para as diferentes espécies de ${ }^{1} \mathrm{H}$. Foram medidos espectros em função da temperatura com tempos de separação $\tau$ entre os pulsos de $\pi$ e $\pi / 2$ de $332 \mu$ s e $996 \mu \mathrm{s}$, mostrados nas figuras 6.37. b e 6.37.c respectivamente. O primeiro aspecto interessante na comparação entre os espectros de ${ }^{1} \mathrm{H}$ em PD e spin-eco em $85^{\circ} \mathrm{C}$ é a forte atenuação da ressonância em $6,5 \mathrm{ppm}$ (esta posição está indicada com uma seta na figura 6.37), indicando forte acoplamento dipolar para as espécies ressoando nesta frequência. O segundo aspecto é a atenuação do pico em 3,8ppm em função de $\tau$, indicando acoplamento dipolar homonuclear moderado para estas espécies. Os picos em 2,5 e 1,5 apresentam redução mais lenta de intensidade em função de 
$\tau$, e correspondem a espécies com acoplamento dipolar homonuclear baixo. Observando os espectros das figuras 6.37.b e 6.37.c em função da temperatura, é possível perceber que as linhas em $3,8 \mathrm{ppm}$ e $2,5 \mathrm{ppm}$ deixam de ser resolvidas abaixo de $40^{\circ} \mathrm{C}$, indicando que a redução na mobilidade destas espécies aumenta o acoplamento dipolar médio ${ }^{1} \mathrm{H}-{ }^{1} \mathrm{H}$. Por outro lado, o sinal em 1,5ppm continua visível e relativamente estreito até mais baixas temperaturas, indicando menor energia de ativação para a dinâmica destas espécies, consistentemente com prótons difundindo entre grupos $\mathrm{OH}$, como observado para o HPW-II. Outra alternativa seria a atribuição desta ressonância a grupos $\mathrm{SiOH}$ isolados, justificando o baixo acoplamento dipolar observado, mesmo em temperaturas mais baixas. Para o experimento de spin-eco ${ }^{1} \mathrm{H}$ na figura 6.37.c, realizado com $\tau$ mais longo, é possível perceber um decaimento considerável da intensidade das linhas espectrais abaixo de temperatura ambiente, indicando um aumento no acoplamento dipolar ${ }^{1} \mathrm{H}_{-}{ }^{1} \mathrm{H}$ para estas temperaturas. Este aumento é devido à redução na mobilidade das espécies de ${ }^{1} \mathrm{H}$, como pode ser observados nos espectros diretos. No entanto, mais abaixo será mostrado que para a amostra HGAT-N2 o aumento do acoplamento dipolar não é tão intenso a ponto de suprimir o sinal de spin-eco em baixas temperaturas. Esta observação confirma a atribuição realizada anteriormente à alteração nos desvios de ${ }^{31} \mathrm{P} R M N$, que refletem alterações significativas na estrutura/dinâmica do ambiente de prótons ao redor do poliânion.

Na figura 6.38 são mostrados os espectros de ${ }^{1} \mathrm{H}$ obtidos via experimentos de polarização direta e spin-eco em função da temperatura para a amostra HGAT preparada em câmara saturada com $\mathrm{N}_{2}$. Em temperatura ambiente, os espectros de ${ }^{1} \mathrm{H}$ são similares aos observados para a amostra preparada em glove-box. Por outro lado, nas temperaturas mais altas, o espectro exibe linhas mais estreitas para a amostra HGAT-N2, indicando maior ganho de mobilidade com a temperatura para algumas espécies. Salvas as diferenças quanto à dinâmica, a amostra HGAT-N2 contem as mesmas espécies observadas para a amostra HGAT-Box. Nos espectros da figura 6.38. c, é possível observar que a atenuação na intensidade do sinal de spin-eco não é tão significativa como para a amostra HGAT-Box. Como havia sido mencionado anteriormente, o aumento no acoplamento dipolar ${ }^{1} \mathrm{H}^{-1} \mathrm{H}$ devido à alterações estruturais/dinâmicas nesta amostra não é tão significativo quanto para a amostra HGAT-Box. Este resultado é consistente com o observado nos experimentos de ${ }^{31} \mathrm{P}$ RMN na seção anterior, que mostram que para a amostra HGAT-Box o ambiente de coordenação do HPW sofre alterações estruturais e/ou dinâmicas abaixo de $0^{\circ} \mathrm{C}$, provocando alterações no desvio químico de ${ }^{31} \mathrm{P}$. O mesmo não foi observado para a amostra HGAT-N2. 


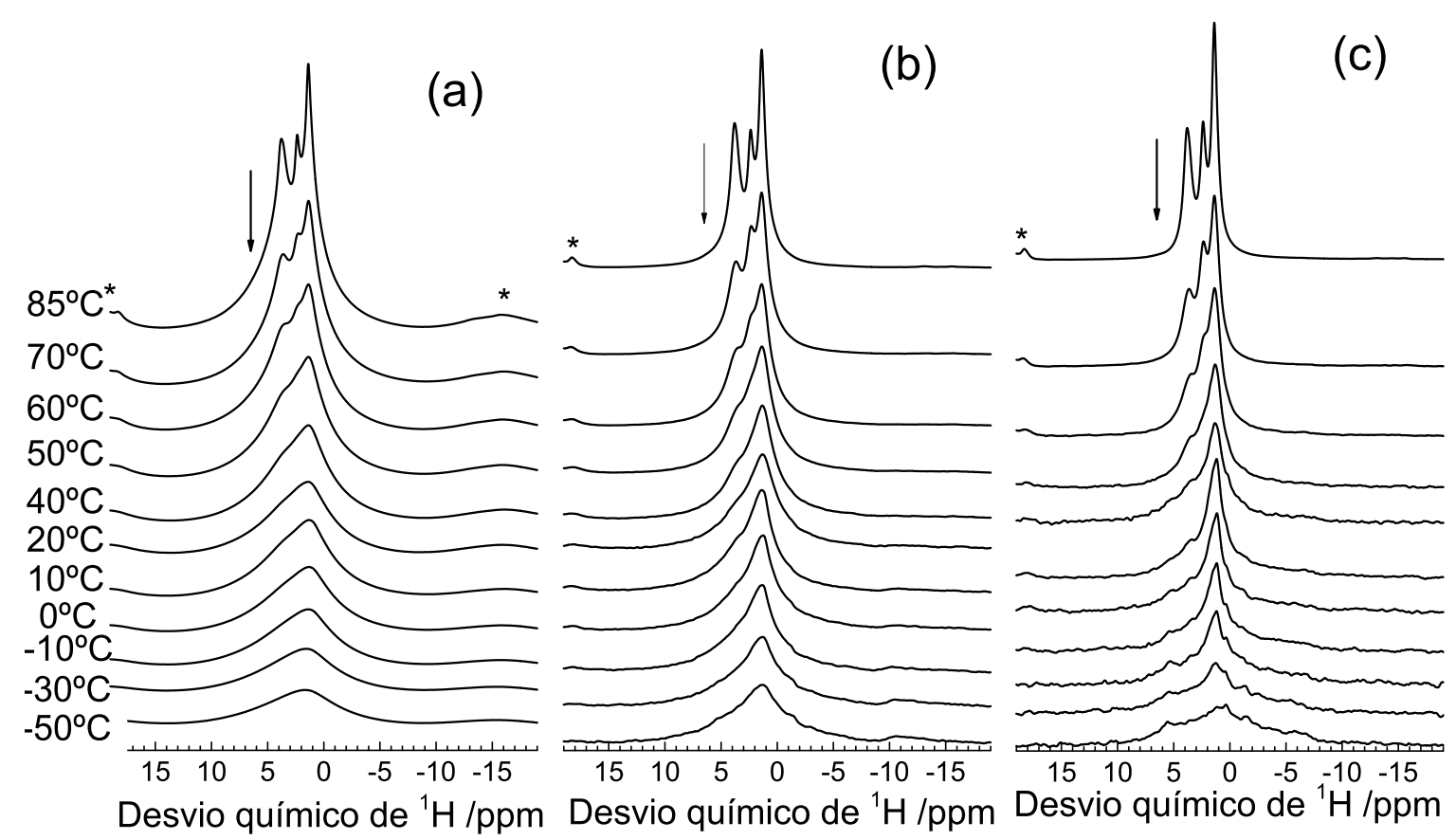

Figura 6.38-Espectros de ${ }^{1} \mathrm{H}$ RMN em função da temperatura, para a amostra HGAT preparadas em câmara com fluxo de $\mathrm{N}_{2}$, obtidos por polarização direta (a) e técnica de spin-eco de Hahn com tempo $\tau$ de separação entre os pulsos de $\pi / 2$ e $\pi$ em $332 \mu \mathrm{s}$ (b) e $996 \mu \mathrm{s}$ (c). As setas indicam o desvio em $6,5 \mathrm{ppm}$, que corresponde à posição esperada para a ressonância de espécies $\mathrm{H}^{+}\left(\mathrm{H}_{2} \mathrm{O}\right)_{n}$. Fonte: Elaborada pelo autor.

\subsubsection{Tempo de relaxação spin-rede no sistema rotante $-\mathbf{T}_{1 \rho}$}

Sobre as amostras HGAT preparada em câmara com fluxo de $\mathrm{N}_{2}$ e em glove-box, foram realizados experimentos de SLCP $\left\{{ }^{1} \mathrm{H}\right\}-{ }^{31} \mathrm{P}$ para diferentes temperaturas, com o intuito de obter informação qualitativa a respeito da dinâmica das espécies de prótons no ambiente de coordenação do poliânion de HPW. Adicionalmente foram realizados experimentos de spin-lock ${ }^{1} \mathrm{H}$ RMN para obter informação global a respeito da dinâmica das espécies de ${ }^{1} \mathrm{H}$ presentes na amostra. As curvas de relaxação obtidas são mostradas na figura 6.39. A maioria das curvas obtidas são do tipo bi-exponenciais, como acontece para o HPW-II, mostrando que a relaxação das espécies segue um comportamento complexo, que pode ser descrito por dois valores de $\mathrm{T}_{1 \rho}$. Para ambas as amostras, em alta temperatura, foi possível acompanhar o decaimento de três diferentes picos no espectro de ${ }^{1} \mathrm{H}$ RMN, centrados em 1,5ppm, 2,5ppm e 3,8ppm. No entanto, em temperatura ambiente a falta de definição dos picos de ressonância inviabiliza a separação das espécies, e o decaimento do sinal total foi contabilizado para analise da relaxação. Os valores de $\mathrm{T}_{1 \rho}$ obtidos estão mostrados na tabela 6.8. Em $-50^{\circ} \mathrm{C}$ os tempos $\mathrm{T}_{1 \rho}$ obtidos pelo experimento direto de spin-lock ${ }^{1} \mathrm{H}$ e pelo experimento de SLCP $\left\{{ }^{1} \mathrm{H}\right\}-{ }^{31} \mathrm{P}$ são diferentes, 

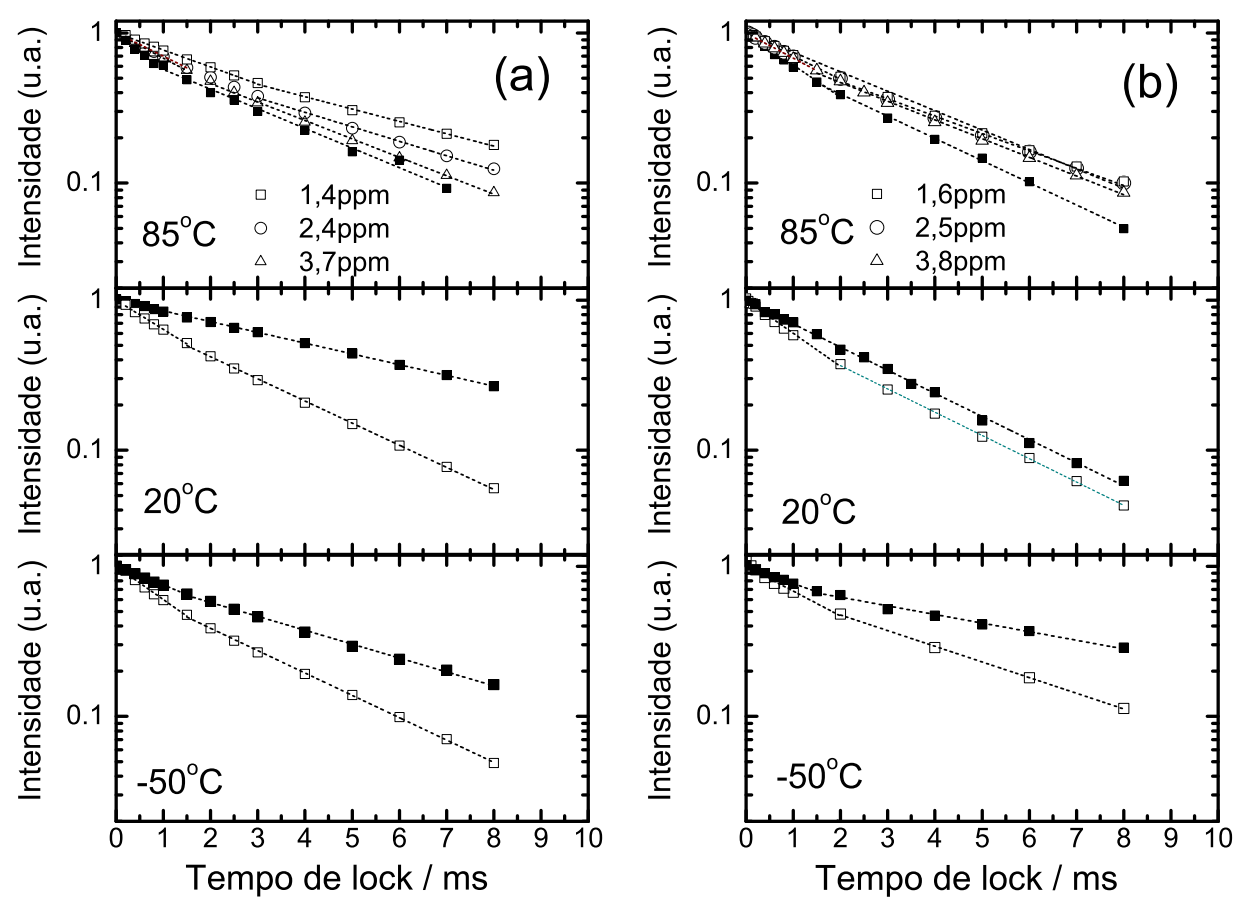

Figura 6.39-Curvas de decaimento da magnetização em função do tempo de spin-lock para diferentes temperaturas nos experimentos de SLCP $\left\{{ }^{1} \mathrm{H}\right\}{ }^{31} \mathrm{P}$ (símbolos cheios) e spin-lock ${ }^{1} \mathrm{H}$ RMN (símbolos vazios), para as amostras HGAT preparadas em câmara com fluxo de $\mathrm{N}_{2}$ (a) e em glove-box (b). Fonte: Elaborada pelo autor.

Tabela 6.8-Valores de tempo de relaxação spin-rede no sistema rotante $\left(T_{1 \rho}\right)$ para amostras de HGAT preparadas em câmara com fluxo de $\mathrm{N}_{2}$ (HGAT-N2) e em glove-box (HGAT-Box). Os tempos foram obtidos de experimentos de spin-lock ${ }^{1} \mathrm{H}$ RMN e SLCP $\left\{{ }^{1} \mathrm{H}\right\}-{ }^{31} \mathrm{P}$.

$$
\text { Amostra Temperatura }\left({ }^{\circ} \mathrm{C}\right) \quad \begin{gathered}
\mathrm{T}_{1 \rho}( \pm 0,1 \mathrm{~ms}) \\
\text { Spin-lock }{ }^{1} \mathrm{H} \quad \mathrm{CP}\left\{{ }^{1} \mathrm{H}_{\}}-{ }^{31} \mathrm{P}\right.
\end{gathered}
$$

\begin{tabular}{|c|c|c|c|c|}
\hline \multirow{5}{*}{ HGAT-N2 } & & 1,4ppm: & $3,8 / 5,3$ & \multirow{3}{*}{$3,3 / 4,8$} \\
\hline & 85 & 2,4ppm: & $2,8 / 4,5$ & \\
\hline & & 3,8ppm: & $2,6 / 3,6$ & \\
\hline & 20 & & 2,9 & 6,1 \\
\hline & -50 & & $2,0 / 2,9$ & $3,5 / 4,7$ \\
\hline \multirow{5}{*}{ HGAT-Box } & & 1,6ppm: & 3,4 & \multirow{3}{*}{$2,0 / 2,9$} \\
\hline & 85 & 2,5ppm: & $3,8 / 4,6$ & \\
\hline & & 3,8ppm: & $2,6 / 3,5$ & \\
\hline & 20 & & $2,0 / 2,8$ & 2,8 \\
\hline & -50 & & $2,6 / 4,2$ & $3,8 / 7,6$ \\
\hline
\end{tabular}

Fonte: Elaborada pelo autor. 
mostrando a existência de prótons na amostra que não estão acoplados dipolarmente com ${ }^{31} \mathrm{P}$, e provavelmente não estão localizados no ambiente de coordenação do HPW. Este cenário é consistente com a baixa concentração de HPW nestes xerogeis (3,1\% em mol - vide tabela 5.1). Com o aumento da temperatura até temperatura ambiente, os valores de $T_{1 \rho}$ não apresentam grande variação para a amostra HGAT-N2. Por outro lado, para a amostra HGAT-Box, os valores de $\mathrm{T}_{1 \rho}$ obtidos de forma direta e indireta variam respectivamente de 4,2ms e 7,6ms para o mesmo valor em $20^{\circ} \mathrm{C}, 2,8 \mathrm{~ms}$. Este resultado mostra que a dinâmica das espécies de prótons é mais susceptível à variação de temperatura para a amostra HGAT-Box. A variação abrupta no desvio químico de ${ }^{31} \mathrm{P}$ por volta de $0^{\circ} \mathrm{C}$ nesta amostra reforça este resultado, indicando alterações estruturais para o ambiente de coordenação do poliânion. Em mais altas temperaturas, em ambas amostras os valores de $T_{1 \rho}$ sofrem alterações, indicando diferenças na dinâmica. Os dados de ${ }^{1} \mathrm{H}$ RMN mostrados nas figuras 6.37 e 6.38 confirmam este resultado, mostrando um aumento na mobilidade das espécies de prótons com a temperatura. Em alta temperatura foi possível resolver o valor de $T_{1 \rho}$ independentemente para cada linha espectral, e o mesmo resulta da mesma ordem para todas as espécies de prótons.

\subsubsection{SEDOR $\left\{{ }^{1} \mathbf{H}\right\}-{ }^{31} \mathrm{P}$ RMN}

Os decaimentos dos sinais SEDOR $\left\{{ }^{1} \mathrm{H}\right\}-{ }^{31} \mathrm{P}$ para as diferentes amostras e condições de preparo, antes e depois da secagem térmica, são mostrados na figura 6.40. As curvas foram obtidas em baixa temperatura $\left(-95^{\circ} \mathrm{C}\right)$, para excluir efeitos da dinâmica sobre o acoplamento heteronuclear ${ }^{1} \mathrm{H}_{-}{ }^{31} \mathrm{P}$ medido. $\mathrm{O}$ decaimento é do tipo gaussiano para todas as amostras, indicando que o sistema se encontra no regime de rede rígida, não havendo mudança de orientação dos vetores internucleares ${ }^{1} \mathrm{H}_{-}{ }^{31} \mathrm{P}$ com relação ao campo externo. Os valores de $\mathrm{M}_{2 H P}$, obtidos por método de mínimos quadrado usando a equação 3.1.57, são mostrados na tabela 6.7. A variação dos valores de $\mathrm{M}_{2 H P}$ medidos nas diferentes amostras reflete a complexidade do ambiente de prótons ao redor do poliânion nestes xerogeis. Para as amostras HGT-Amb e HGBT-N2 o valor de $\mathrm{M}_{2 H P}$ aumenta após as secagens térmicas. Este comportamento é o oposto do que seria esperado, uma vez que as secagens térmicas removem espécies de hidratação na amostra. Um cenário possível é considerar que após a secagem a mobilidade relativa entre o poliânion e os prótons é menor, assim como ocorre para as amostras de HPW hidratado. Para as amostras HGAT(-Amb e -N2), HT(-Amb e -N2), HGTN2 e HGBT-Amb o valor de $M_{2 H P}$ não se altera significativamente após a secagem térmica, 
mostrando que nestas amostras o ambiente de coordenação do poliânion não é afetado pela secagem térmica. $\mathrm{O}$ valor de $\mathrm{M}_{2 H P}$ entre as amostras preparadas em glove-box é praticamente da mesma ordem, conforme pode ser observado pelas curvas na figura 6.40 e pelos valores na tabela 6.7, com valores entre $10,5 \times 10^{6} \mathrm{rad}^{2} \mathrm{~s}^{-2}$ e $15,6 \times 10^{6} \mathrm{rad}^{2} \mathrm{~s}^{-2}$, que são próximos ao valor calculado para o cristal de HPW. $6 \mathrm{H}_{2} \mathrm{O}, 12,1 \times 10^{6} \mathrm{rad}^{2} \mathrm{~s}^{-2}$.

Como mostrado na equação 3.1 .48 , os valores de $\mathrm{M}_{2 H P}$ estão diretamente vinculados ao número de prótons interagindo dipolarmente com o ${ }^{31} \mathrm{P}$ e inversamente à distância $\mathrm{r}_{H P}$. De forma geral o valor de $\mathrm{M}_{2 H P}$ para os xerogeis é sempre maior ou da ordem do valor encontrado para o HPW $6 \mathrm{H}_{2} \mathrm{O}$. Como o $\mathrm{P}$ está no centro do poliânion, as distâncias entre o $\mathrm{P}$ e os $\mathrm{H}$ no ambiente de coordenação do HPW estão limitadas pelas distâncias intramoleculares $\mathrm{P}_{-} \mathrm{O}_{t}$ no poliânion. Portanto, pode-se concluir que nos xerogeis o ambiente de coordenação do poliânion é constituído por um numero maior de espécies protonadas do que no HPW.6 $6 \mathrm{H}_{2} \mathrm{O}$.
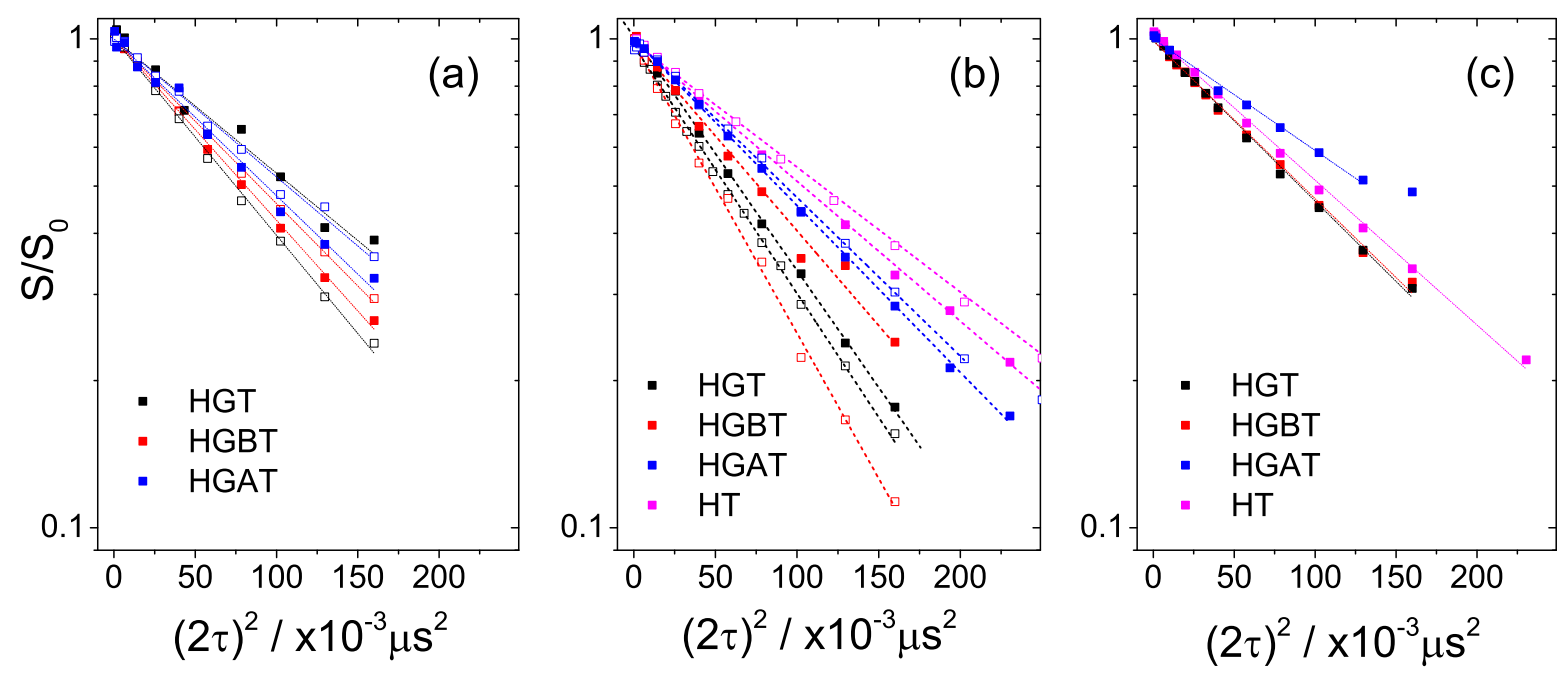

Figura 6.40-Curvas linearizadas para o decaimento da razão $\frac{S(2 \tau)}{S_{0}}$ como função do tempo $(2 \tau)$ no experimento de SEDOR $\left\{{ }^{1} \mathrm{H}\right\}-{ }^{31} \mathrm{P}$ RMN, para os xerogeis preparados em diferentes condições de atmosfera: sem controle de atmosfera (a); atmosfera saturada com $\mathrm{N}_{2}$ (b); e em atmosfera seca dentro de uma glove-box (c). Simbolos cheios representam experimentos sobre as amostras sem nenhum tratamento, enquanto símbolos vazios representam experimentos em amostras submetidas a secagem a $85^{\circ} \mathrm{C}$ por $2 \mathrm{~h}$ sob fluxo de $\mathrm{N}_{2}$. As linhas tracejadas são ajustes de mínimos quadrados utilizando a equação 3.1.57. Fonte: Elaborada pelo autor. 
Tabela 6.9-Valores de desvio químico para as linhas observadas nas projeções de ${ }^{1} \mathrm{H}$ dos espectros HETCOR para diferentes amostras e experimentos.

\begin{tabular}{|c|c|c|c|c|c|c|c|c|c|}
\hline \multirow[t]{2}{*}{ Amostra } & \multicolumn{4}{|c|}{ HETCOR $\left\{{ }^{1} \mathbf{H}\right\}-{ }^{13} \mathbf{C}$} & \multicolumn{2}{|c|}{ HETCOR $\left\{{ }^{1} \mathbf{H}\right\}-{ }^{29} \mathrm{Si}$} & \multicolumn{3}{|c|}{ HETCOR $\left\{{ }^{1} \mathbf{H}\right\}-{ }^{31} \mathbf{P}$} \\
\hline & $\mathrm{OCH}_{2}$ & $\mathrm{COH}$ & $\mathrm{CH}_{2}$ & $\mathrm{SiCH}_{2}$ & $\mathrm{SiOH}$ & $\mathrm{SiOH}$ & $\mathrm{H}_{2} \mathrm{O}$ & $\mathrm{OH}$ & pm) \\
\hline HT-N2 & - & - & - & - & 2,5 & 0,8 & $\begin{array}{c}6 / 4,5 \\
\text { (ombros) }\end{array}$ & 3,4 & 1,3 \\
\hline $\begin{array}{c}\text { HGAT- } \\
\text { Amb }\end{array}$ & 3,5 & 3,5 & 1 & 1 & - & - & 4,9 & N.R. & N.R. \\
\hline $\begin{array}{l}\text { HGAT- } \\
\text { N2 }\end{array}$ & - & - & - & - & - & - & $\begin{array}{c}5 \\
\text { (ombro) }\end{array}$ & 3,2 & 1,2 \\
\hline $\begin{array}{l}\text { HGAT- } \\
\text { Box }\end{array}$ & - & - & - & - & - & - & $\begin{array}{c}6 \\
\text { (ombro) }\end{array}$ & 3,3 & 1,4 \\
\hline
\end{tabular}

Fonte: Elaborada pelo autor.

\subsubsection{Experimentos de correlação heteronuclear (HETCOR) $\left\{{ }^{1} \mathbf{H}\right\}$ - ${ }^{31} \mathbf{P},\left\{{ }^{1} \mathbf{H}\right\}-{ }^{13} \mathrm{C}$ e $\left\{{ }^{1} \mathbf{H}\right\}-{ }^{29} \mathrm{Si} \mathrm{RMN}$}

Com vista em clarificar as atribuições para os ambientes químicos de ${ }^{1} \mathrm{H}$, foram realizados experimentos bidimensionais de correlação heteronuclear (HETCOR), transferindo polarização de ${ }^{1} \mathrm{H}$ para os núcleos ${ }^{29} \mathrm{Si},{ }^{13} \mathrm{C}$ e ${ }^{31} \mathrm{P}$. Estes experimentos permitem obter de forma indireta $\mathrm{O}$ espectro de ${ }^{1} \mathrm{H}$ para os prótons acoplados dipolarmente com cada núcleo. A tabela 6.9 resume os valores de desvio químico observados para os espectros indiretos de ${ }^{1} \mathrm{H}$ obtidos dos diferentes experimentos de HETCOR.

Para identificar as espécies de ${ }^{1} \mathrm{H}$ acopladas dipolarmente a ${ }^{29} \mathrm{Si}$ foram realizados experimentos de HETCOR $\left\{{ }^{1} \mathrm{H}\right\}-{ }^{29} \mathrm{Si}$ sobre a amostra HT preparada em câmara com fluxo de $\mathrm{N}_{2}$, após secagem térmica em $85^{\circ} \mathrm{C}$. Esta amostra foi escolhida para reduzir possíveis ambiguidades nas atribuições das espécies de ${ }^{1} \mathrm{H}$, pois não possui grupos orgânicos na estrutura, e a secagem reduz a quantidade de espécies de hidratação da amostra. O espectro obtido encontra-se na figura 6.41. No eixo vertical está representada a projeção sobre a frequência de ${ }^{29} \mathrm{Si}$, correspondente ao espectro $\mathrm{CP}\left\{{ }^{1} \mathrm{H}\right\}{ }^{29} \mathrm{Si}$, enquanto no eixo horizontal está representada a projeção correspondente ao espectro das espécies ${ }^{1} \mathrm{H}$ acopladas com ${ }^{29} \mathrm{Si}$. A projeção vertical apresenta majoritariamente espécies $Q_{3}(-101 \mathrm{ppm})$, visto que em espécies $\mathrm{Q}_{4}$ os ${ }^{29} \mathrm{Si}$ estão mais distantes dos ${ }^{1} \mathrm{H}$, reduzindo o sinal de CP. Na figura 6.41 o espectro de ${ }^{1} \mathrm{H}$ obtido a partir 
da projeção do espectro HETCOR é comparado ao espectro direto de ${ }^{1} \mathrm{H}$ RMN. A semelhança entre os dois espectros reforça a atribuição deste sinal de ${ }^{1} \mathrm{H}$ com grupos $\mathrm{OH}$ pertencentes à matriz de silicatos. Os prótons ressoando em $0,8 \mathrm{ppm}$ apresentam menor intensidade no espectro HETCOR, indicando menor acoplamento dipolar médio ${ }^{1} \mathrm{H}-{ }^{29} \mathrm{Si}$.
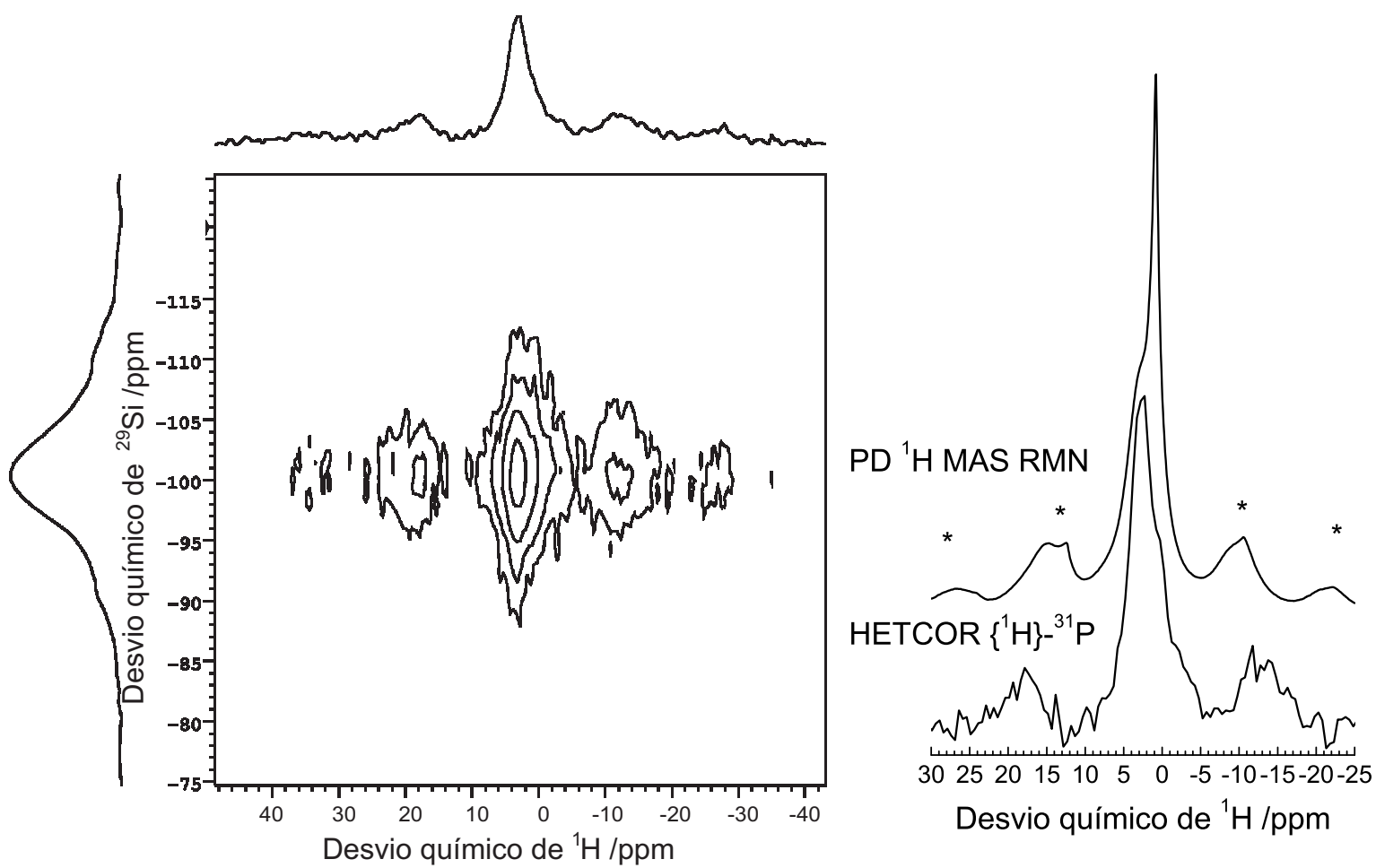

Figura 6.41-A esquerda o espectro de HETCOR $\left\{{ }^{1} \mathrm{H}\right\}-{ }^{29} \mathrm{Si}$ RMN para a amostra HT-N2 tratada a $85^{\circ} \mathrm{C}$. A projeção vertical representa o sinal de ${ }^{29} \mathrm{Si}$, enquanto a projeção horizontal representa o sinal de ${ }^{1} \mathrm{H}$ RMN. A direita a comparação entre a projeção de ${ }^{1} \mathrm{H}$ do espectro de HETCOR e o espectro de ${ }^{1} \mathrm{H}$ MAS RMN para a mesma amostra. Fonte: Elaborada pelo autor.

Para identificação das espécies de prótons pertencentes aos grupos orgânicos da matriz ormosil, foi realizado o experimento de HETCOR $\left\{{ }^{1} \mathrm{H}\right\}-{ }^{13} \mathrm{C}$ RMN sobre a amostra HGAT preparada em glove-box. Os espectros bidimensionais estão mostrados na figura 6.42, onde no eixo vertical estão representadas as projeções sobre a frequência de ${ }^{13} \mathrm{C}$, correspondentes aos espectros de CP $\left\{{ }^{1} \mathrm{H}\right\}-{ }^{13} \mathrm{C}$, enquanto nos eixos horizontais estão representadas as projeções correspondentes aos espectros das espécies ${ }^{1} \mathrm{H}$ acopladas com ${ }^{13} \mathrm{C}$. Este experimento também foi realizado em $85^{\circ} \mathrm{C}$, para redução do acoplamento dipolar ${ }^{1} \mathrm{H}-{ }^{1} \mathrm{H}$. À direita na figura 6.42 estão representadas as projeções horizontais correspondentes às ressonâncias de ${ }^{13} \mathrm{C}$ observadas. Estes espectros correspondem aos prótons próximos a cada sítio de ${ }^{13} \mathrm{C}$. As posições verticais correspondentes a cada projeção horizontal estão indicadas na figura 6.42 . O pico de ${ }^{13} \mathrm{C}$ em 72ppm corresponde a grupos $\mathrm{OCH}_{2}$ na cadeia orgânica do GLYMO, e a projeção no eixo dos ${ }^{1} \mathrm{H}$ mostra um espectro com um pico centrado em $3 \mathrm{ppm}$. O pico de ${ }^{13} \mathrm{C}$ em $60 \mathrm{ppm}$ 
corresponde a grupos $\mathrm{C}-\mathrm{OH}$ resultantes da abertura do anel epóxi do GLYMO, e o espectro de ${ }^{1} \mathrm{H}$ correspondente a estes grupos apresenta um pico mais estreito do que o observado para os grupos $\mathrm{OCH}_{2}$, e também centrado em 3ppm. Os picos em 22ppm e 8ppm correspondem a grupos $\mathrm{CH}_{2}$ e $\mathrm{SiCH}_{2}$ respectivamente, e o espectro dos ${ }^{1} \mathrm{H}$ acoplados a estas espécies apresenta um pico largo, centrado em 1ppm.
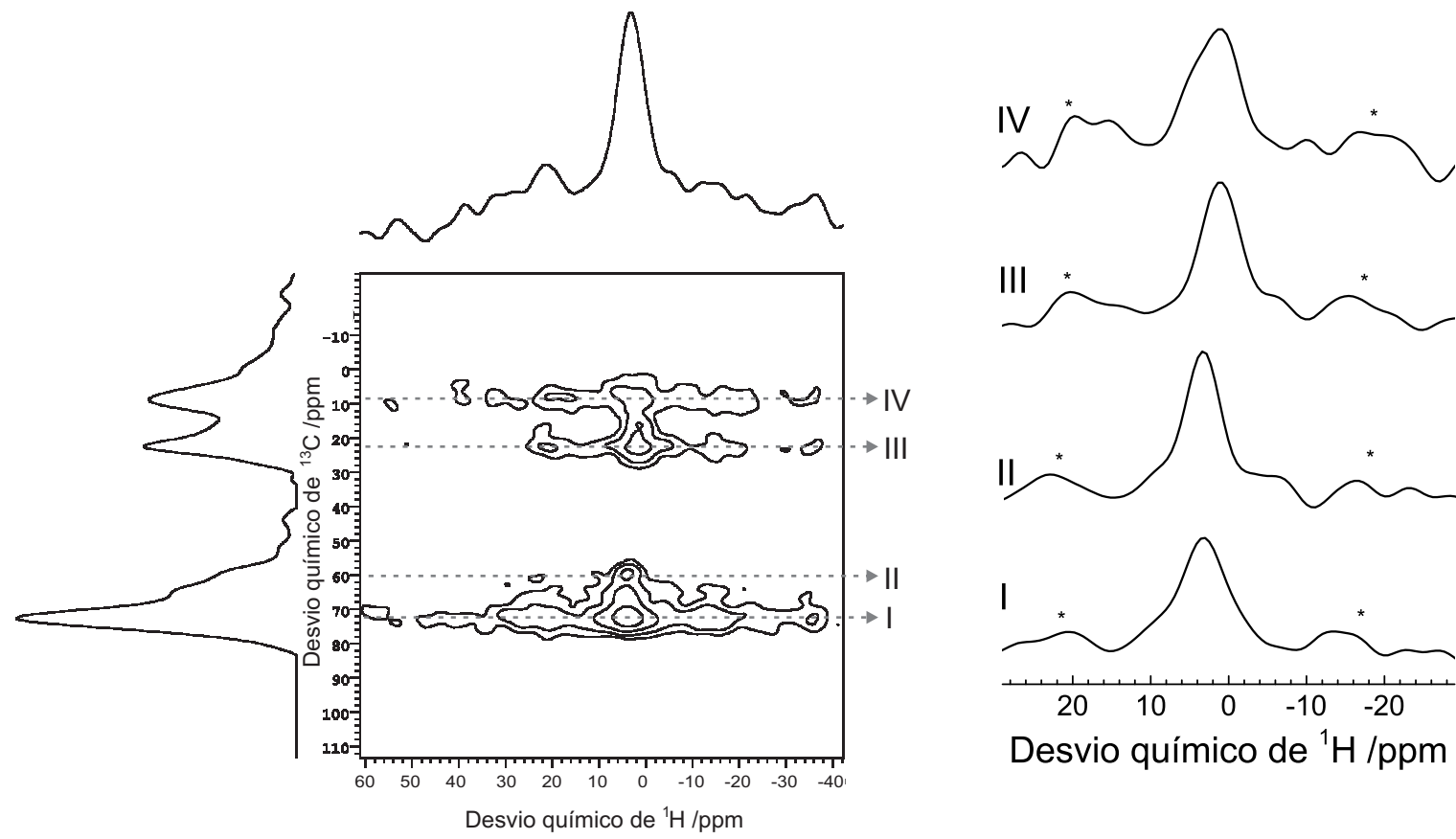

Figura 6.42-A esquerda o espectro de HETCOR $\left\{{ }^{1} \mathrm{H}\right\}{ }^{13} \mathrm{C}$ RMN medido em $85^{\circ} \mathrm{C}$, para a amostra HGAT preparada em glove-box. A projeção vertical representa o sinal de ${ }^{13} \mathrm{C}$, enquanto a projeção horizontal representa o sinal de ${ }^{1} \mathrm{H}$ RMN. A direita a comparação entre a projeção as frequências de ${ }^{13} \mathrm{C}$ do espectro de HETCOR e o espectro de ${ }^{1} \mathrm{H}$ MAS RMN para a mesma amostra. Fonte: Elaborada pelo autor.

Foram realizados experimentos de HETCOR $\left\{{ }^{1} \mathrm{H}\right\}-{ }^{31} \mathrm{P}$ RMN sobre as amostras HGAT preparadas nas três condições de atmosfera (sem secagem), e para a amostra HT-N2 (após secagem), para identificação das espécies de ${ }^{1} \mathrm{H}$ no ambiente de coordenação do poliânion de HPW. Os espectros bidimensionais estão mostrados nas figuras 6.43, 6.45, 6.46 e 6.47, onde no eixo vertical estão representadas as projeções sobre a frequência de ${ }^{31} \mathrm{P}$, correspondentes aos espectros de $\mathrm{CP}\left\{{ }^{1} \mathrm{H}\right\}-{ }^{31} \mathrm{P}$, enquanto nos eixos horizontais estão representadas as projeções correspondentes aos espectros das espécies ${ }^{1} \mathrm{H}$ acopladas com ${ }^{31} \mathrm{P}$. Estes experimentos foram realizados em $85^{\circ} \mathrm{C}$, para redução do acoplamento dipolar ${ }^{1} \mathrm{H}-{ }^{1} \mathrm{H}$, obtendo assim estreitamento das linhas espectrais, facilitando a identificação das diferentes espécies de ${ }^{1} \mathrm{H}$. Comparações entre a projeção do espectro HETCOR sobre o eixo dos ${ }^{1} \mathrm{H}$ e o espectro direto de ${ }^{1} \mathrm{H}$ MAS RMN para as diferentes amostras são exibidas na figura 6.44 .

Na figura 6.43 é exibido o espectro HETCOR para a amostra HGAT-Amb sem qualquer 
tratamento térmico. A projeção sobre o eixo dos ${ }^{1} \mathrm{H}$ do espectro não exibe o pico estreito por volta de $7 \mathrm{ppm}$, observado no espectro direto de ${ }^{1} \mathrm{H}$ para a mesma amostra (figura 6.44.a - linha contínua), mostrando que de fato este pico corresponde à moléculas de $\mathrm{H}_{2} \mathrm{O}$ cujos prótons não estão acoplados dipolarmente com o ${ }^{31} \mathrm{P}$ do poliânion. Por outro lado, o espectro indireto de ${ }^{1} \mathrm{H}$ obtido do experimento HETCOR apresenta características similares ao espectro de polarização direta ${ }^{1} \mathrm{H}$ RMN para a amostra HGAT-Amb após tratamento térmico, como mostra a comparação entre os dois espectros na figura 6.44. a (linha tracejada para o espectro de PD). A largura das linhas espectrais em ambos os espectros, e o nível de ruído da projeção HETCOR, inviabiliza um maior aprofundamento na comparação entre os espectros. No entanto, a semelhança entre os espectros de HETCOR da amostra sem tratamento, e o espectro direto de ${ }^{1} \mathrm{H}$ RMN para a amostra tratada, mostra que o ambiente de coordenação do poliânion de HPW não é afetado pelos tratamentos térmicos, consistentemente com a invariabilidade do segundo momento $\mathrm{M}_{2 H P}$ (tabela 6.7).

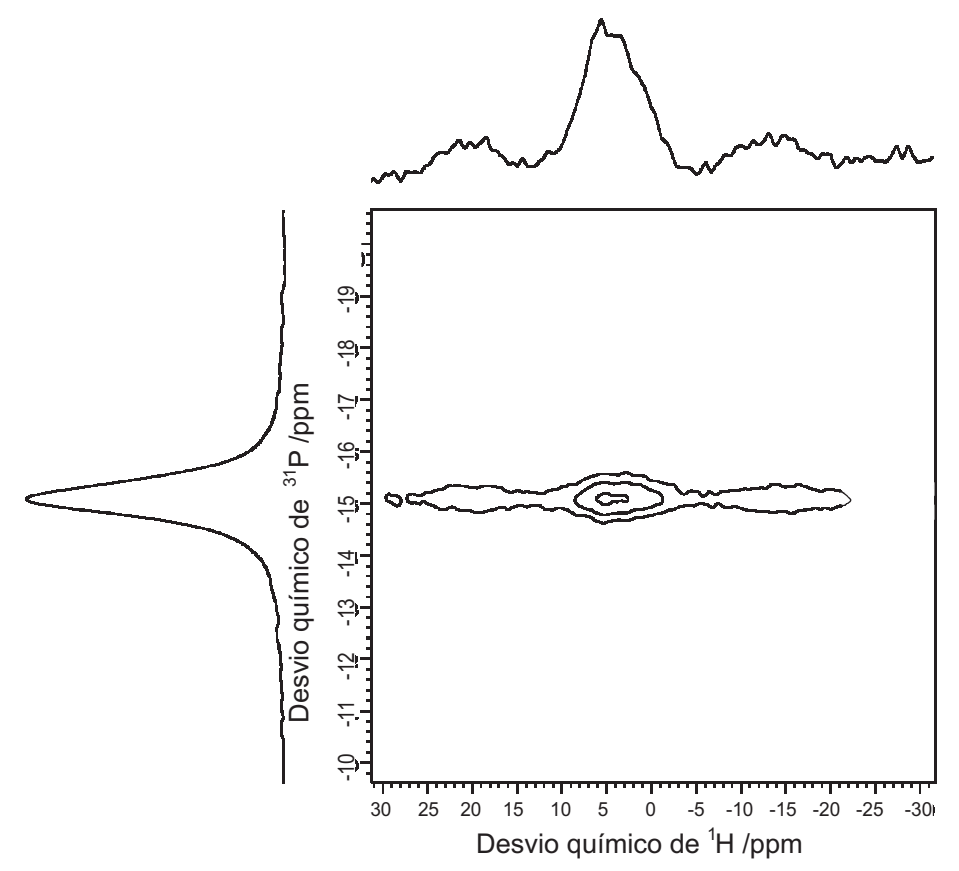

Figura 6.43-Espectro de HETCOR $\left\{{ }^{1} \mathrm{H}\right\}{ }^{31} \mathrm{P}$ RMN medido em $85^{\circ} \mathrm{C}$, para a amostra HGAT preparada em condições ambientes. A projeção vertical representa o sinal de ${ }^{31} \mathrm{P}$, enquanto a projeção horizontal representa o sinal de ${ }^{1} \mathrm{H}$ RMN. Fonte: Elaborada pelo autor.

Na figura 6.45 é exibido o espectro HETCOR para a amostra HGAT-N2 sem qualquer tratamento térmico. A projeção sobre o eixo dos ${ }^{1} \mathrm{H}$ do espectro HETCOR exibe um espectro com três linhas principais, um ombro parcialmente resolvido em 5,5ppm e duas mais estreitas em 3,3ppm e 1,4ppm. O ombro em 5,5ppm é observado no espectro direto de ${ }^{1} \mathrm{H}$ RMN, e havia anteriormente sido atribuída a espécies de hidratação com alto acoplamento dipolar ${ }^{1} \mathrm{H}-{ }^{1} \mathrm{H}$. Sua presença no espectro HETCOR mostra que estas espécies se encontram no ambiente de coordenação do poliânion de HPW, e é consistente afirmar que se tratam de grupos similares aos 


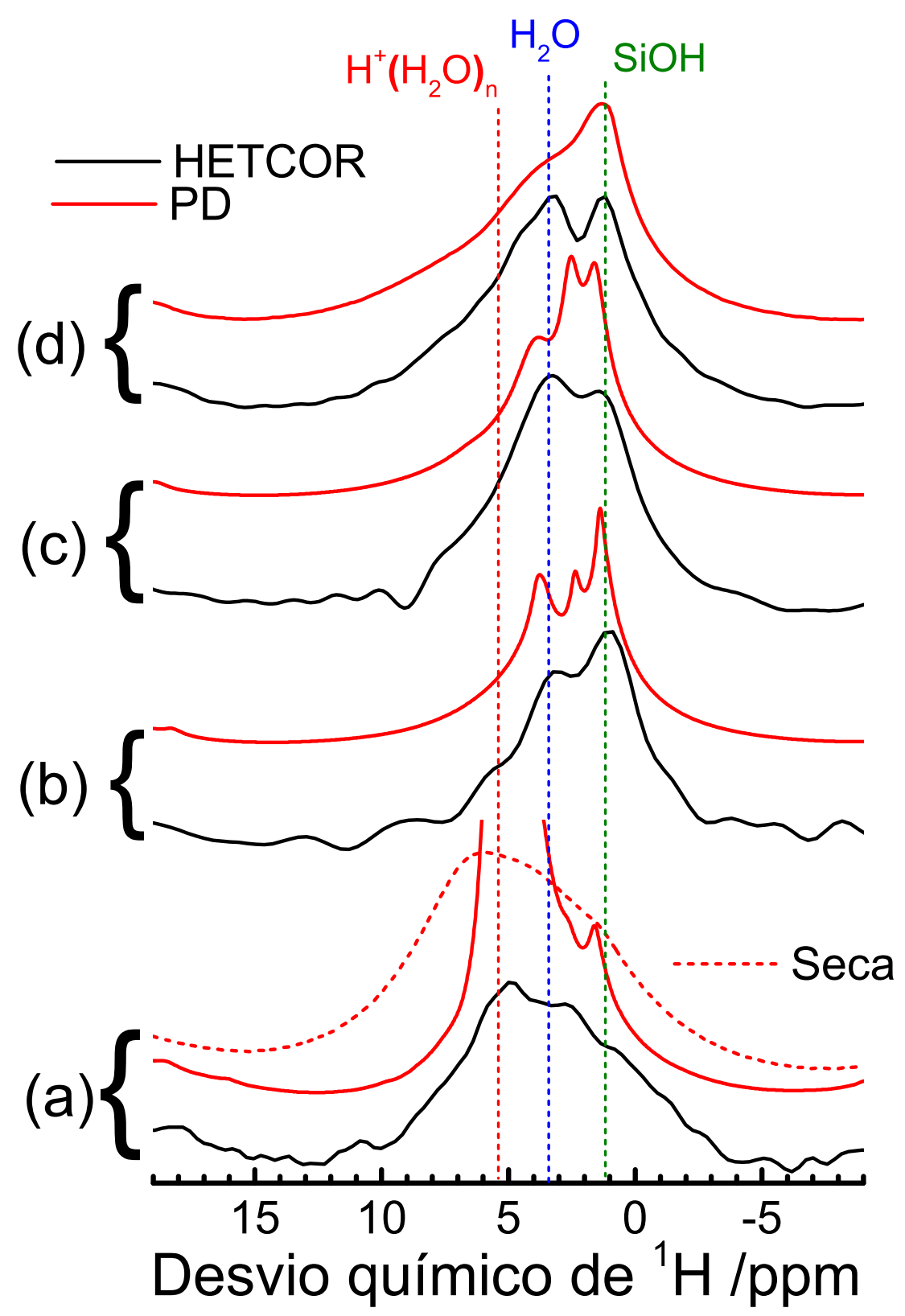

Figura 6.44-Comparações entre a projeção de ${ }^{1} \mathrm{H}$ do espectro de HETCOR $\left\{{ }^{1} \mathrm{H}\right\}{ }^{31} \mathrm{P}$ (preto) e o espectro de PD ${ }^{1} \mathrm{H}$ MAS RMN (vermelho) para as amostras HGAT-Amb (a - projeção extraída do espectro da figura 6.43), HGAT-N2 (b - projeção extraída do espectro da figura 6.45) e HGAT-Box (c - projeção extraída do espectro da figura 6.46) sem secagens, e HT-N2 submetida à secagem ( $d$ - projeção extraída do espectro da figura 6.47). Fonte: Elaborada pelo autor.

encontrados para as amostras de $\mathrm{HPW} \cdot 6 \mathrm{H}_{2} \mathrm{O}$, como moléculas de $\mathrm{H}_{2} \mathrm{O}$ e clusters $\mathrm{H}^{+}\left(\mathrm{H}_{2} \mathrm{O}\right)_{n}$. $\mathrm{O}$ desvio menor do que o observado para os clusters em $\mathrm{HPW} \cdot 6 \mathrm{H}_{2} \mathrm{O}$ indica valores de $n$ maiores do que os encontrados para a última.(30) Os valores de $\mathrm{M}_{2 H P}$ encontrados para esta amostra $\left(\mathrm{M}_{2 H P}=15,7 \times 10^{6} \mathrm{rad}^{2} \mathrm{~s}^{-2}\right.$, conforme seção 6.2.7) também reflete o número maior de moléculas de $\mathrm{H}_{2} \mathrm{O}$ ao redor do poliânion do que nas amostras de $\mathrm{HPW} \cdot 6 \mathrm{H}_{2} \mathrm{O}$. O pico em $1,4 \mathrm{ppm}$ foi anteriormente atribuído à prótons em grupos $\mathrm{OH}$ fracamente acoplados via 


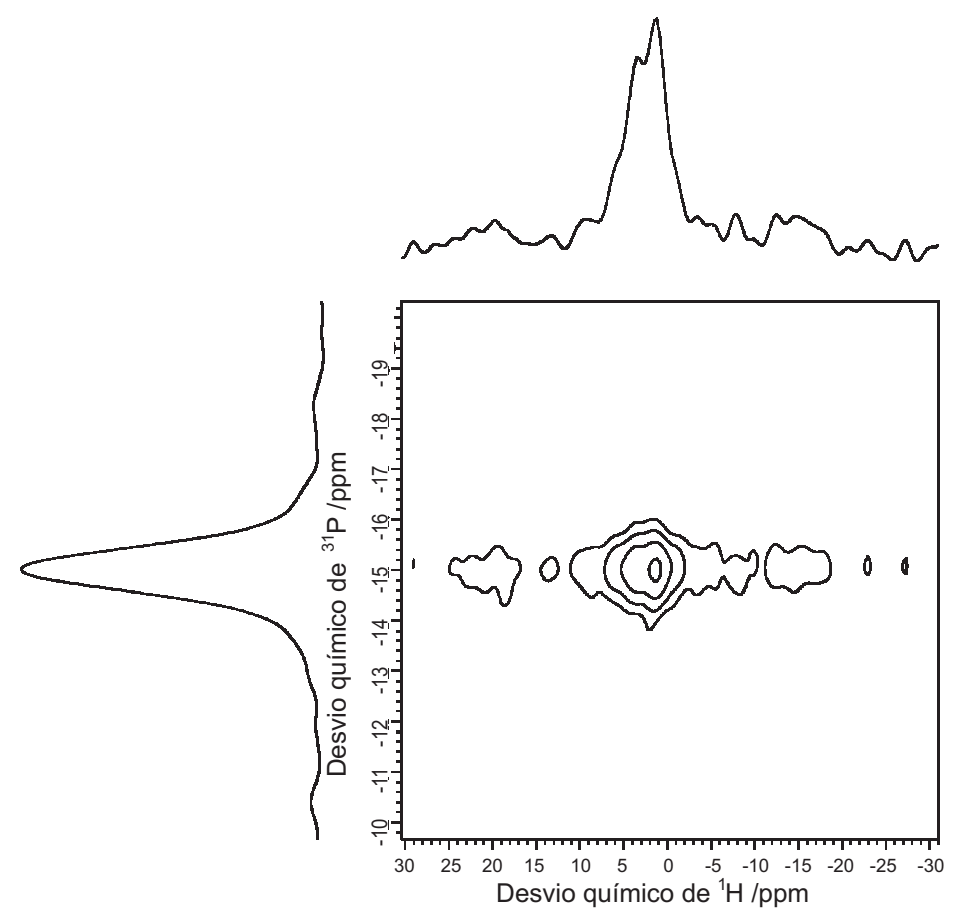

Figura 6.45-Espectro de HETCOR $\left\{{ }^{1} \mathrm{H}\right\}{ }^{31} \mathrm{P}$ RMN medido em $85^{\circ} \mathrm{C}$, para a amostra HGAT preparada em câmara com fluxo de $\mathrm{N}_{2}$. A projeção vertical representa o sinal de ${ }^{31} \mathrm{P}$, enquanto a projeção horizontal representa o sinal de ${ }^{1} \mathrm{H}$ RMN. Fonte: Elaborada pelo autor.

interação dipolar com outros prótons. A presença deste pico no espectro indireto de HETCOR $\left\{{ }^{1} \mathrm{H}\right\}-{ }^{31} \mathrm{P}$ torna possível a atribuição deste pico a grupos $\mathrm{OH}$ no ambiente de coordenação do poliânion, podendo ser $\mathrm{H}$ difundindo entre sítios $\mathrm{O}$ e/ou $\mathrm{SiOH}$. O pico em 3,4ppm, por sua vez, corresponde à prótons com mobilidade mais restrita do que aqueles ressonando em 1,4ppm, podendo ser outras espécies $\mathrm{OH}$, ou moléculas de $\mathrm{H}_{2} \mathrm{O}$, como será discutido na seção 7.2 . Na figura 6.46 é exibido o espectro HETCOR para a amostra HGAT-Box. A projeção horizontal do espectro HETCOR é mostrada na figura 6.44.c. O espectro para esta amostra é semelhante ao observado para a amostra HGAT-N2. O ombro em 6,5ppm pode ser atribuído a clusters $\mathrm{H}^{+}\left(\mathrm{H}_{2} \mathrm{O}\right)_{n}$ com $n$ menor do que o encontrado para a primeira, considerando o desvio químico maior.(30) Esta atribuição é consistente com o valor de $\mathrm{M}_{2 H P}=10,5 \times 10^{6} \mathrm{rad}^{2} \mathrm{~s}^{-2}$, que é o menor dentre os valores encontrados para os xerogeis estudados. Adicionalmente, a projeção HETCOR exibe os picos em 3,4ppm e 1,4ppm observados para a amostra HGAT-N2, mas com relação de intensidades diferente.

De acordo com os resultados de HETCOR $\left\{{ }^{1} \mathrm{H}\right\}-{ }^{13} \mathrm{C}$, grupos $\mathrm{C}-\mathrm{OH}$ resultantes da abertura do anel epóxi da molécula de GLYMO apresentam ressonância em torno de 3ppm, e o pico observado em torno deste desvio nos espectros de $\operatorname{HETCOR}\left\{{ }^{1} \mathrm{H}\right\}-{ }^{31} \mathrm{P}$ poderia indicar interação entre os grupos orgânicos e o poliânion de HPW. No entanto, a projeção de ${ }^{1} \mathrm{H}$ para o espectro de HETCOR $\left\{{ }^{1} \mathrm{H}\right\}-{ }^{31} \mathrm{P}$ para a amostra HT-N2 seca (espectro hetcor na figura 6.47 e projeção 


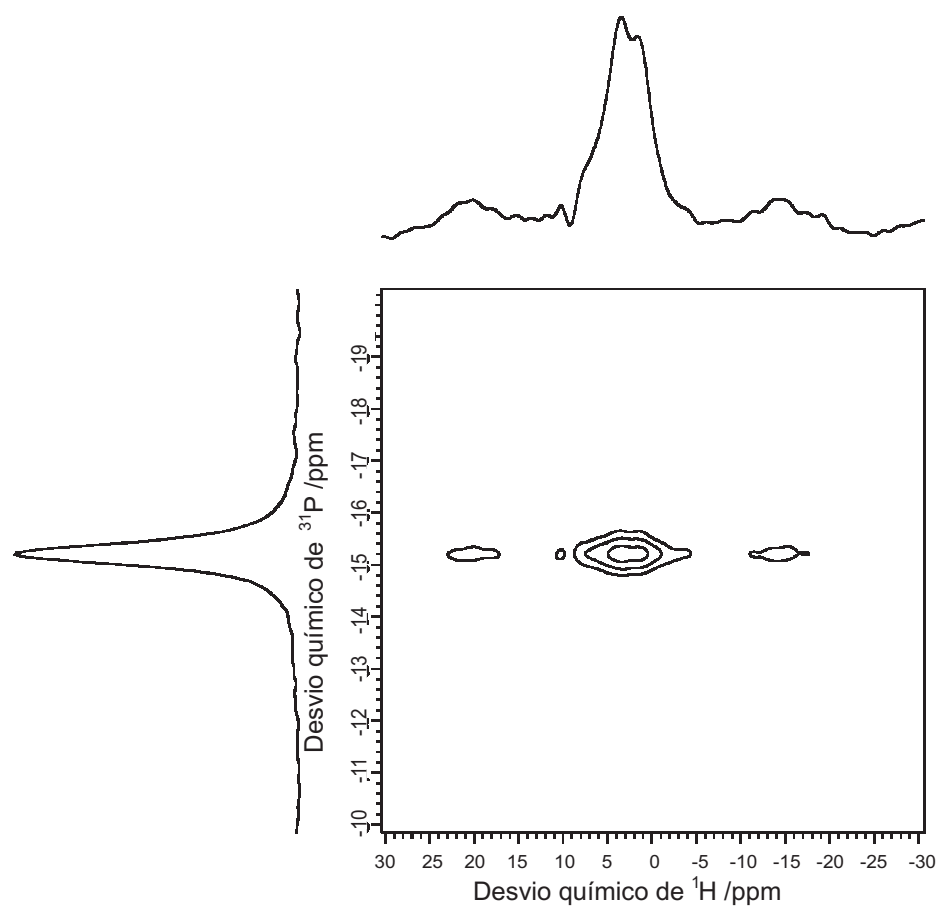

Figura 6.46-Espectro de HETCOR $\left\{{ }^{1} \mathrm{H}\right\}{ }^{31} \mathrm{P}$ RMN medido em $85^{\circ} \mathrm{C}$, para a amostra HGAT preparada em glove-box. A projeção vertical representa o sinal de ${ }^{31} \mathrm{P}$, enquanto a projeção horizontal representa o sinal de ${ }^{1} \mathrm{H}$ RMN. Fonte: Elaborada pelo autor.

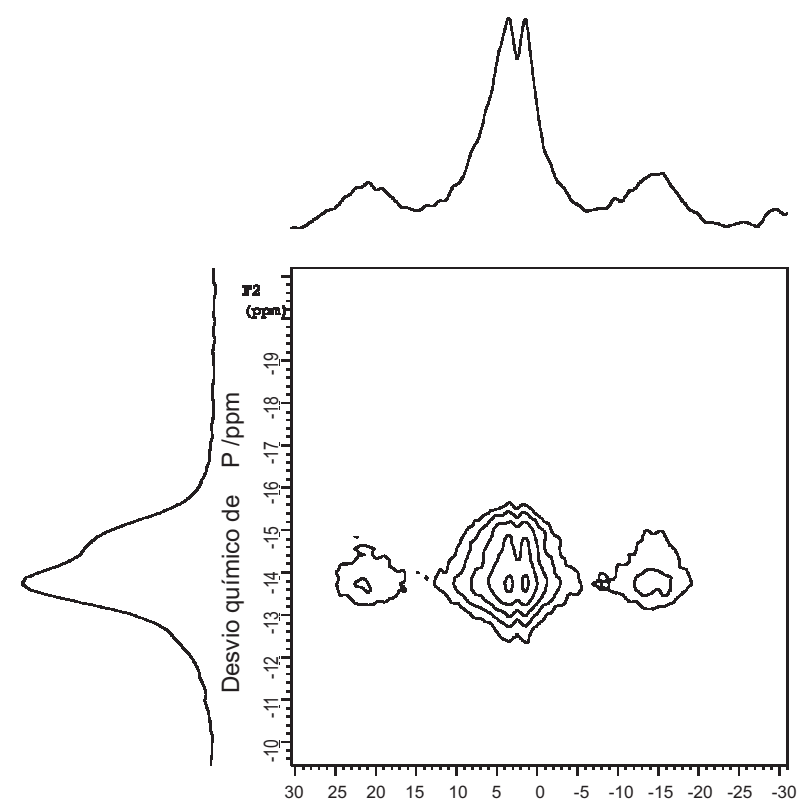

Figura 6.47-Espectro de HETCOR $\left\{{ }^{1} \mathrm{H}\right\}-{ }^{31} \mathrm{P}$ RMN medido em $20^{\circ} \mathrm{C}$, para a amostra HT preparada em câmara com fluxo de $\mathrm{N}_{2}$. A projeção vertical representa o sinal de ${ }^{31} \mathrm{P}$, enquanto a projeção horizontal representa o sinal de ${ }^{1} \mathrm{H}$ RMN. Fonte: Elaborada pelo autor.

na figura 6.44.d), que não possui grupos orgânicos em sua composição, é muito parecido ao da amostra HGAT-N2. Portanto não há evidência experimental para a presença de grupos funcionais orgânicos se coordenando com o poliânion. 


\subsubsection{Experimentos de ressonância paramagnética eletrônica (RPE)}

Como explicado na seção 2.6, quando os xerogéis híbridos são irradiados com luz ultra violeta, a molécula de HPW sofre redução, e a configuração eletrônica do tungstênio passa de $d^{0}$ para $d^{1}$. Neste estado o $W$ apresenta um elétron desemparelhado, e as amostras passam a responder em experimentos de RPE. Por este motivo, a técnica de RPE em modo de onda contínua $(\mathrm{CW})$ foi utilizada para obter informação a respeito do estado reduzido em amostras irradiadas. Em temperatura ambiente o sinal de RPE não é mensurável, pois nesta temperatura o elétron excitado realiza saltos rápidos entre os diferentes sítios W na molécula de tungstênio (transições $d$-d). Portanto os experimentos foram realizados em temperaturas entre $20 \mathrm{~K}$ e 100K. A figura 6.48 exibe o espectro de RPE obtido após a irradiação da amostra HGT-Box. Este espectro exibe as características típicas dos espectros obtidos para todo o conjunto de amostras deste trabalho. É possível observar sinal em três regiões espectrais. O sinal por volta de $g=1,93$ apresenta simetria axial e é tipicamente atribuído a impurezas de molibdênio (100, 101) proveniente do precursor $\mathrm{HPW} \cdot \mathrm{nH}_{2} \mathrm{O}$. Este sinal é o único observável no espectro de RPE para as amostras não irradiadas. O sinal em torno de $g=2,00$ é isotrópico e aparece apenas em amostras irradiadas. Este sinal não é observado para as amostras preparadas em condições ambientes, e apresenta intensidade considerável para as amostras preparadas em glove-box. A atribuição deste sinal ainda está em discussão. Finalmente, o sinal por volta de $g=1,85$ corresponde à centros paramagnéticos $\mathrm{WO}_{6}$ em poliânions de HPW.(15, 33, 100) Este último sinal é o de maior interesse deste trabalho, e será estudado em detalhe abaixo.

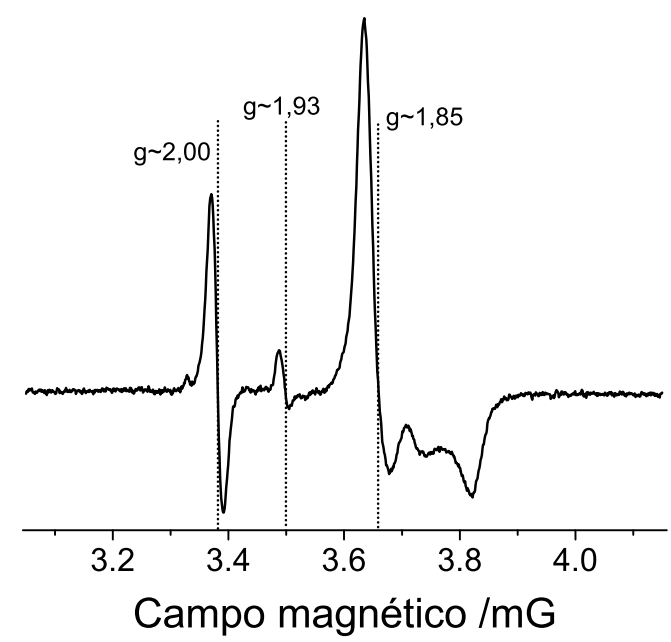

Figura 6.48-Espectro de RPE para a amostra HGT preparada em glove-box. O espectro foi medido em 20K, após a irradiação da amostra. Fonte: Elaborada pelo autor. 


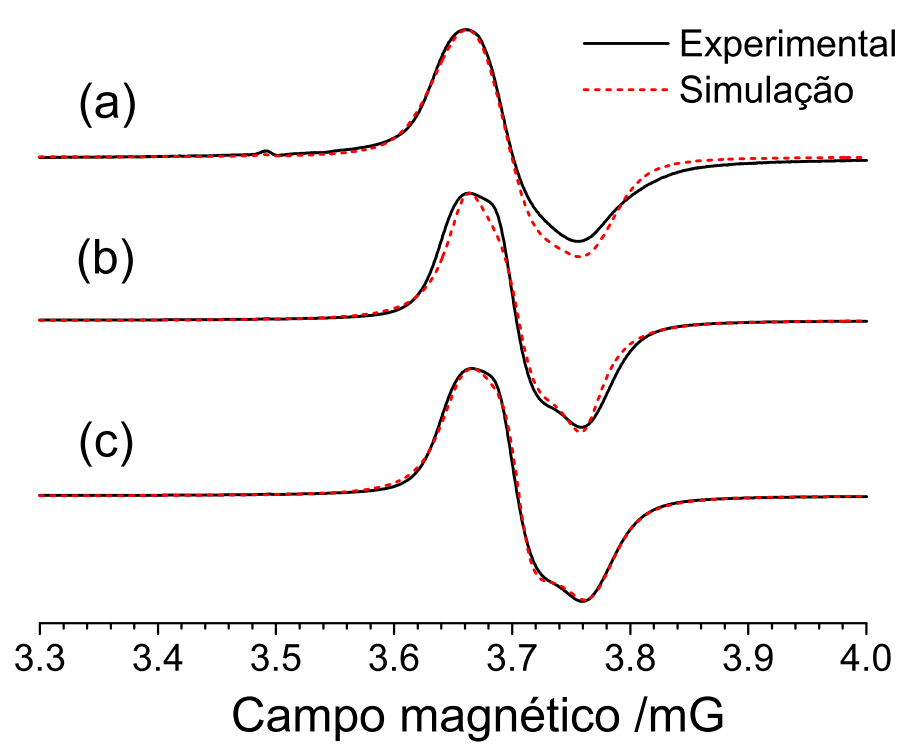

Figura 6.49-Espectros de RPE para as amostras HGAT (a), HGBT (b) e HGT (c), preparadas em condição ambiente e irradiadas com lâmpada de xenônio (dose = 150MED U.V.). As linhas tracejadas são simulações utilizando o programa EasySpin ${ }^{\circledR}$.(89) Fonte: Elaborada pelo autor.

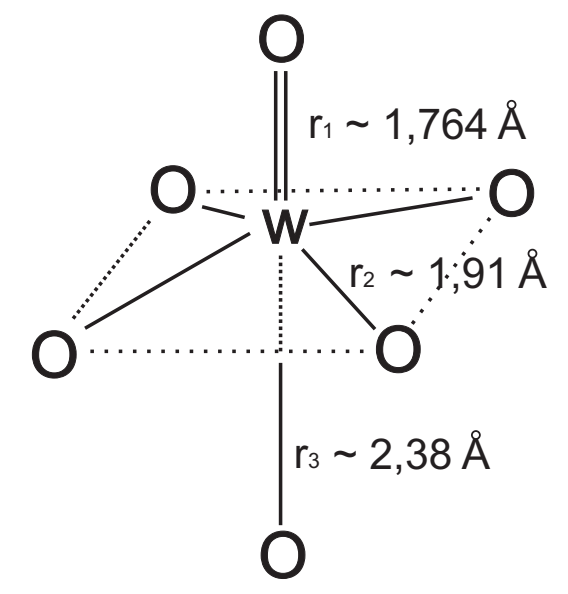

Figura 6.50-Ambiente local de um átomo de tungstênio em um poliânion de HPW. Octaedro com simetria $\mathrm{C}_{4 v}$. Distâncias estimadas com base em dados de difração de raios-X.(23) Fonte: Elaborada pelo autor.

As figuras 6.49, 6.52 e 6.53 exibem os espectros de RPE (linhas contínuas) medidos em $30 \mathrm{~K}$ respectivamente para os conjuntos de amostras preparadas em condições ambientes, em câmara com fluxo de $\mathrm{N}_{2}$ e em glove box, após irradiação com na faixa do U.V (dose de 150MED). Foram realizadas simulações com o programa EasySpin ${ }^{\circledR}$ (89), utilizando a hamiltoniana da equação 3.2 .6 (linhas tracejadas). Os valores principais do tensor $\stackrel{\leftrightarrow}{g}$ obtidos das simulações estão exibidos na tabela 6.10. O único isótopo de tungstênio com spin $I \neq 0$ 
é o ${ }^{183} \mathrm{~W}$, com $I=1 / 2$ e abundância natural de $13,26 \%$. Em trabalhos com poliânions de Lindqvist $\left(\mathrm{W}_{6} \mathrm{O}_{19}\right)^{3-}$ foi observado o acoplamento hiperfino ${ }^{183} \mathrm{~W}$ em espectros de RPE*.(100) No entanto nos espectros obtidos neste trabalho o acoplamento hiperfino não é observado, devido à grande largura de linha, e portanto não foi considerado nas simulações.

Os espectros de RPE para as amostras preparadas em condições ambientes são semelhantes para os três tipos de xerogeis estudados (figura 6.49), com características típicas de um íon $\mathrm{W}^{5+}$ em um campo ligante ortorrômbico, com valores de $g_{x x}, g_{y y}$ e $g_{z z}$ variando pouco entre as amostras. No poliânion de HPW, o tungstênio se coordena com seis oxigênios em uma estrutura octaédrica distorcida, como mostrado na figura 6.50. Como é de praxe na literatura de campos ligantes octaédricos distorcidos, como observado para $\mathrm{WO}_{6}$ em HPW, as componentes $g_{i i}$ foram definidas de forma que $g_{x x}>g_{y y}>g_{z z}$, e o eixo $z$ do SEP do tensor $\stackrel{\leftrightarrow}{g}$ é paralelo ao eixo de distorção tetragonal (direção da ligação $W=0$ na figura 6.50).(102-106) Os valores de $g$ obtidos são consistentes com resultados anteriores obtidos para diferentes hidratos de polioxometalatos com um elétron excitado.(90, 100)

Após a secagem do conjunto de amostras preparadas em condições ambientes, os espectros de RPE medidos são heterogêneos (figura 6.51), apresentando mais de uma linha sobrepostas. É razoável supor que com a secagem das amostras surjam diferenças nos níveis de hidratação para diferentes poliânions de HPW. Com base nesta suposição, as simulações foram realizadas tomando como ponto de partida a soma entre o espectro simulado com um sítio ortorrômbico idêntico ao das amostras sem secagem (ressonância 1 - correspondente a sítios em ambientes mais hidratados) e um segundo espectro com simetria ortorrômbica (ressonância 2). Estas duas ressonâncias foram suficientes para simular o espectro de RPE. Os resultados destas simulações estão mostrados na figura 6.51 e os valores de $g$ obtidos para as diferentes amostras estão representados na tabela 6.10. Os parâmetros para a ressonância 1 são muito próximos aos parâmetros de RPE para amostras mais hidratadas, indicando que esta corresponde a um centro paramagnético idêntico ao encontrado para as amostras mais hidratadas. A ressonância 2 apresenta valores de $g_{x x}, g_{y y}$ e $g_{z z}$ em torno de 1,86, 1,85 e 1,77 para as três amostras tratadas, e tem simetria mais próxima de axial. A fração em área das duas ressonâncias $\left(I_{1} / I_{2}\right.$ na tabela 6.10) não varia muito entre estas amostras.

Para comparar as duas ressonâncias encontradas, foram calculados parâmetros que caracterizam a simetria do tensor $\stackrel{\leftrightarrow}{g}$ : o parâmetro de assimetria $\eta$, que indica o quanto a simetria se desvia do caso axial, e o parâmetro de anisotropia $\Delta$, que é uma medida de quanto os valores do tensor se desviam do valor isotrópico (média dos valores principais $g_{i s o}$ ). Os parâmetros

* Os experimentos do trabalho citado foram realizados em amostras diluídas em solução de anidrido acético e dimetilformaldeído,(100) enquanto os experimentos do presente estudo foram realizados em amostras sólidas. 
Tabela 6.10-Valores para os valores principais do tensor $\stackrel{\leftrightarrow}{g}$ obtidos por meio de simulação dos espectros de RPE medidos para o conjunto de xerogeis preparados em diferentes condições de controle de atmosfera. Dados para amostras preparadas em condição ambiente, e submetidas a secagem em $85^{\circ} \mathrm{C}$ por $2 \mathrm{~h}$ sob fluxo de $\mathrm{N}_{2}$ também são exibidos. I representa a fração em área de cada ressonância utilizada para simular os espectros

\begin{tabular}{|c|c|c|c|c|c|c|c|c|}
\hline \multirow{2}{*}{$\begin{array}{c}\text { Condição } \\
\text { de } \\
\text { preparo }\end{array}$} & \multirow[b]{2}{*}{ Amostra } & \multicolumn{3}{|c|}{ Ressonância 1} & \multicolumn{3}{|c|}{ Ressonância 2} & \multirow{2}{*}{$\begin{array}{l}\text { Fração } \\
I_{1} / I_{2}\end{array}$} \\
\hline & & $g_{x x}$ & $g_{y y}$ & $g_{z z}$ & $g_{x x}$ & $g_{y y}$ & $g_{z z}$ & \\
\hline \multirow{3}{*}{ Ambiente } & HGT & 1,850 & 1,827 & 1,797 & - & - & - & $\overline{1}$ \\
\hline & HGBT & 1,849 & 1,827 & 1,800 & - & - & - & 1 \\
\hline & HGAT & 1,853 & 1,832 & 1,798 & - & - & - & 1 \\
\hline \multirow{3}{*}{ Fluxo de $\mathrm{N}_{2}$} & HGT & 1,848 & 1,827 & 1,796 & 1,859 & 1,856 & 1,774 & 0,70 \\
\hline & HGBT & 1,849 & 1,821 & 1,793 & 1,862 & 1,849 & 1,772 & 0,43 \\
\hline & HGAT & 1,839 & 1,822 & 1,800 & 1,861 & 1,846 & 1,775 & 0,50 \\
\hline \multirow{3}{*}{ Glove-box } & HGT & 1,846 & 1,820 & 1,783 & 1,860 & 1,855 & 1,770 & 0,40 \\
\hline & HGBT & 1,839 & 1,820 & 1,780 & 1,862 & 1,849 & 1,770 & 0,20 \\
\hline & HGAT & 1,838 & 1,825 & 1,798 & 1,863 & 1,848 & 1,771 & 0,28 \\
\hline \multirow{3}{*}{$\begin{array}{l}\text { Ambiente } \\
+ \text { secagem }\end{array}$} & HGT & 1,869 & 1,817 & 1,790 & 1,862 & 1,852 & 1,772 & 0,40 \\
\hline & HGBT & 1,858 & 1,822 & 1,789 & 1,864 & 1,851 & 1,772 & 0,40 \\
\hline & HGAT & 1,840 & 1,831 & 1,798 & 1,862 & 1,852 & 1,773 & 0,47 \\
\hline
\end{tabular}

Fonte: Elaborada pelo autor.

são dados por:

$$
\begin{aligned}
g_{i s o} & =\frac{g_{x x}+g_{y y}+g_{z z}}{3} \\
\Delta & =g_{z z}-\frac{g_{x x}+g_{y y}}{2} \\
\eta & =\frac{g_{x x}-g_{y y}}{g_{z z}} .
\end{aligned}
$$

Para o caso axial $\eta=0$, já para o caso onde o tensor de blindagem é isotrópico $\Delta=0$. $\mathrm{O}$ sinal de $\Delta$ indica qual valor principal do tensor se desvia mais do caso isotrópico, se $\Delta>0$, $g_{x x}$ e $g_{y y}$ se desviam mais do valor isotrópico, e se $\Delta>0, g_{z z}$ é que se desvia mais. Na tabela 6.11 são mostrados os valores calculados para cada ressonância.

Comparando as duas ressonâncias 1 e 2, os valores da tabela 6.10 mostram que a o valor $g_{i s o}$ não tem uma alteração apreciável, que justifique a atribuição das duas ressonâncias à centros de natureza distinta. Os valores de $\eta$ para as ressonâncias 1 e 2 são da mesma ordem para algumas amostras, mostrando simetria semelhante, e maior para a ressonância 2 em outras amostras, mostrando uma simetria menos axial para esta ressonância. No entanto, os 
valores de $\Delta$ mostram uma diferença sistemática entre os sítios 1 e 2 em todas as amostras. Os valores de $\Delta$ são negativos para ambos os centros, mostrando que o valor de $g_{z z}$ é o que mais se afasta do valor isotrópico. Para a ressonância 2 o módulo de $\Delta$ é da ordem do dobro do valor observado para a ressonância 1 , mostrando há uma variação substancial da componente $g_{z z}$ entre as duas ressonâncias.

Estudos utilizando teoria de funcional densidade (DFT) em conjunto com experimentos de RPE em $\mathrm{VO}^{2+}$ adsorvido em zeólitas correlacionam a distância da ligação dupla $\mathrm{V}=\mathrm{O}$ com o valor de $g_{z z}$.(102) Os estudos foram realizados para campos ligantes com diferentes simetrias, como $\mathrm{C}_{2 v}, \mathrm{C}_{4 v}$ e $\mathrm{C}_{s}$. Estes estudos mostram um aumento no valor de $g_{z z}$ proporcionalmente ao aumento na distância da ligação $\mathrm{V}=\mathrm{O}$.(102) $\mathrm{O} \mathrm{V}^{I V}$ apresenta configuração eletrônica $\mathrm{d}^{1}$, assim como $\circ \mathrm{W}^{5+}$. Estudos mais detalhados precisam ser realizados para determinar se os $\mathrm{W}^{5+}$ em campos ligantes octaédricos no poliânion se encontram no mesmo estado eletrônico fundamental dos $\mathrm{V}^{I V}$ nos estudos citados. Mas em uma primeira tentativa, será suposto que a correlação entre a componente $g_{z z}$ e a distância da ligação $\mathrm{W}=\mathrm{O}$ seja a mesma para os dois sistemas.

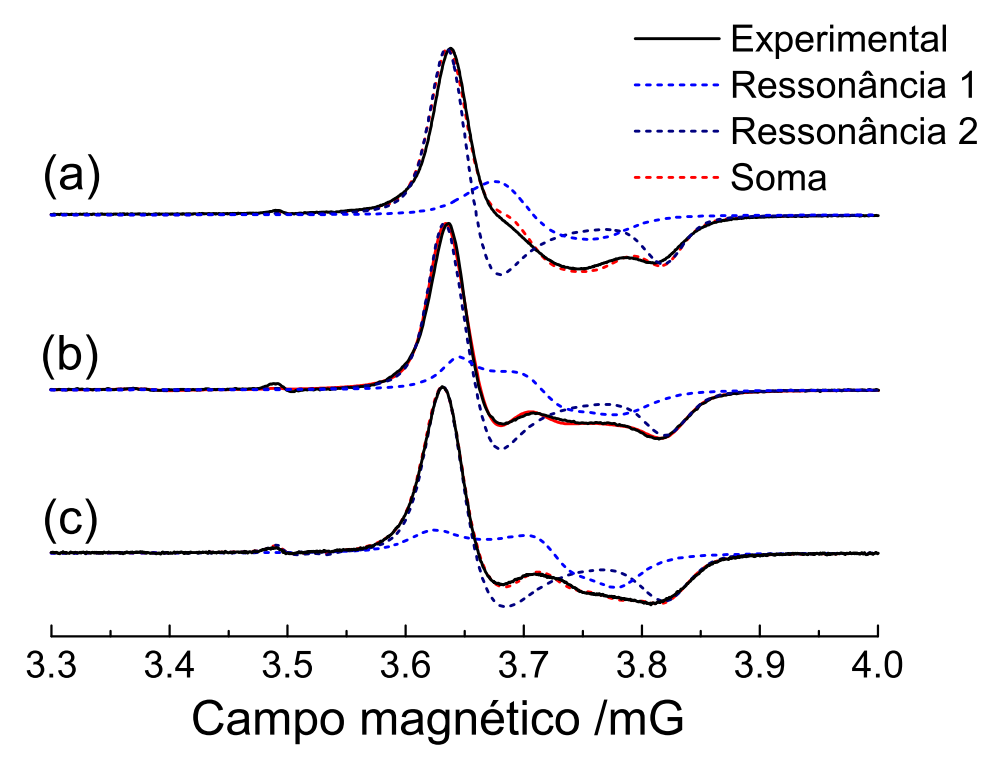

Figura 6.51-Espectros de RPE para as amostras HGAT (a), HGBT (b) e HGT (c), preparadas em condição ambiente, submetidas à secagem em $85^{\circ} \mathrm{C}$ por $2 \mathrm{~h}$ sob fluxo de $\mathrm{N}_{2}$ e irradiadas com lâmpada de xenônio (dose $=150 \mathrm{MED}$ U.V.). As linhas tracejadas são simulações utilizando o programa EasySpin ${ }^{\circledR}$.(89) Fonte: Elaborada pelo autor.

A figura 6.50 mostra a geometria para os octaedros $\mathrm{WO}_{6}$ na ausência de interação com outras moléculas. Supondo que haja interação entre o poliânion e íons $\mathrm{H}_{3} \mathrm{O}^{+}$ou moléculas de $\mathrm{H}_{2} \mathrm{O}$, conforme o esquema da figura 2.5.(62) a transferência de um próton desde as moléculas de $\mathrm{H}_{2} \mathrm{O}$ até o poliânion determinaria um enfraquecimento para a ligação $\mathrm{W}=\mathrm{O}$, alongando a distância $r_{1}$ na figura 6.50 , e determinando uma simetria diferente para o campo ligante 
do centro paramagnético. O que se observa nos resultados observados para os xerogeis, é que a secagem destes leva à uma heterogeneidade para os centros paramagnéticos $\mathrm{WO}_{6}$. A nova ressonância observada em amostras secas apresenta um deslocamento considerável de $g_{z z}$ para valores menores, consistentemente com a contração do octaedro $\mathrm{WO}_{6}$. Assim, de acordo com a correlação observada nos estudos citados $\left(g_{z z} \propto r_{1}\right)$, pode-se supor que a ressonância 1 corresponda a centros $\mathrm{WO}_{6}$ realizando ligações fortes com espécies protônicas (elongação do eixo axial), enquanto a ressonância 2 corresponde a centros $\mathrm{WO}_{6}$ realizando ligações mais fracas com prótons no ambiente de coordenação do HPW.

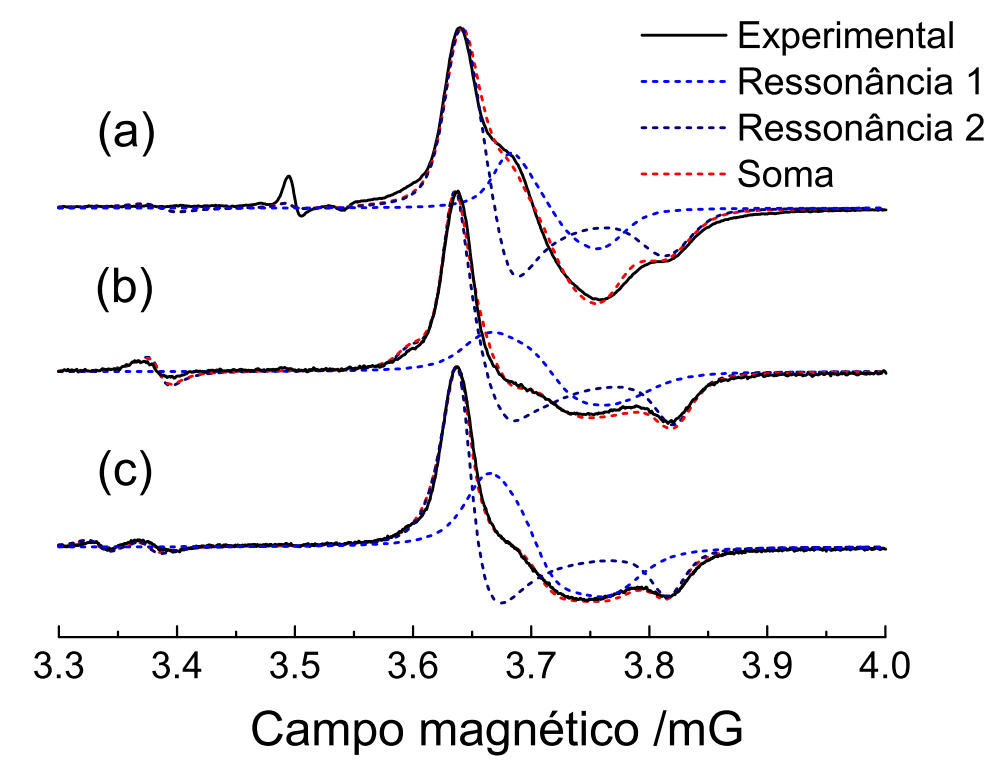

Figura 6.52-Espectros de RPE para as amostras HGAT (a), HGBT (b) e HGT (c), preparadas em câmara com fluxo de $\mathrm{N}_{2}$ e irradiadas com lâmpada de xenônio (dose $=150 \mathrm{MED}$ U.V.). As linhas tracejadas são simulações utilizando o programa EasySpin ${ }^{\circledR} .(89)$ Fonte: Elaborada pelo autor.

Para as amostras preparadas em câmara com fluxo de $\mathrm{N}_{2}$, os espectros de RPE obtidos (figura 6.52) são similares aos espectros da figura 6.51, apresentando duas ressonâncias sobrepostas. Esta similaridade torna consistente a atribuição da ressonância 1 a sítios paramagnéticos em estruturas similares à mostrada na figura 2.5. Os valores de $g$ obtidos para a ressonância 2 nos espectros da figura 6.52 são muito próximos dos obtidos para as amostras submetidas a secagem.

Para as amostras preparadas em glove-box o sinal correspondente aos centros paramagnéticos em HPW (figura 6.53) apresentam as mesmas características dos espectros para as amostras preparadas em câmara com fluxo de $\mathrm{N}_{2}$, diferindo-se apenas quanto à relação de intensidades entre as duas ressonâncias observadas. Para estas amostras a fração da ressonância 1 é a menor dentre as amostras estudadas, resultado consistente com os menores níveis de hidratação para estas amostras. Por outro lado, para estas amostras a ressonância em $g=2,00$ 


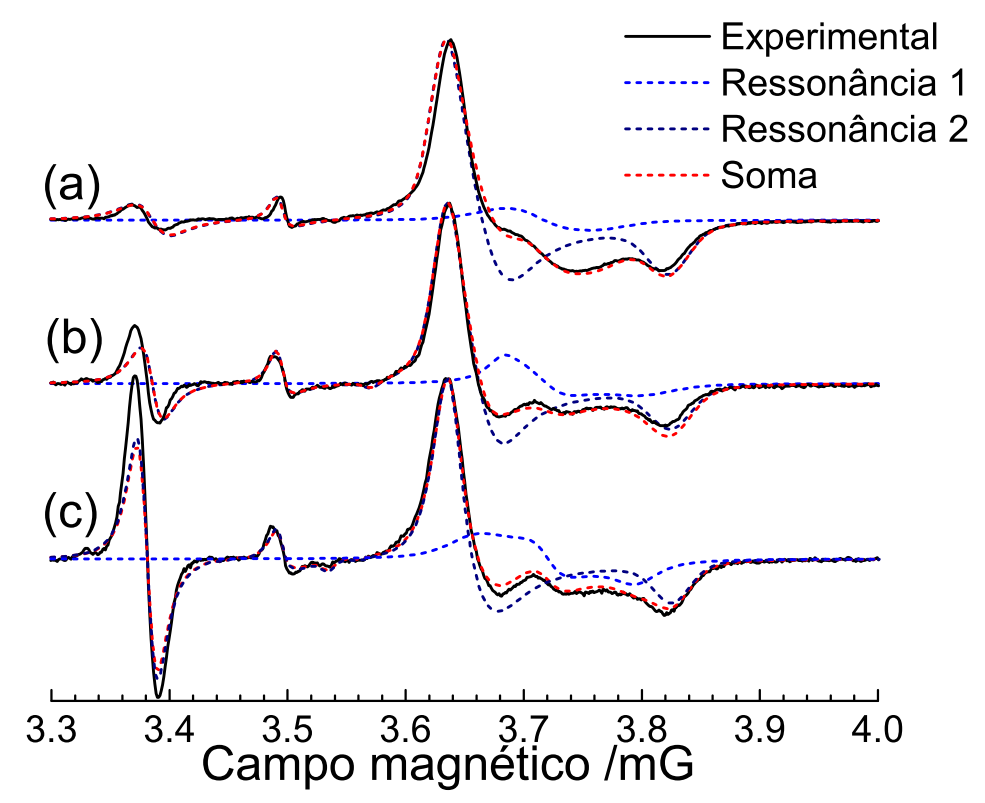

Figura 6.53-Espectros de RPE para as amostras HGAT (a), HGBT (b) e HGT (c), preparadas em glove-box e irradiadas com lâmpada de xenônio (dose = 150 MED U.V.). As linhas tracejadas são simulações utilizando o programa EasySpin ${ }^{\circledR}$.(89) Fonte: Elaborada pelo autor.

apresenta intensidade consideravelmente maior do que a observada para os xerogeis preparados em em câmara com fluxo de $\mathrm{N}_{2}$.

A figura 6.54 exibe os espectros de RPE em função da temperatura para a amostra HGT preparada em diferentes atmosferas. Os espectros obtidos para a amostra HGT-Amb (figura 6.54.a) apresentam uma única linha, como discutido anteriormente, e sua largura aumenta com a temperatura. Este comportamento pode ser explicado em termos da dinâmica do elétron desemparelhado. Em sua forma reduzida, o HPW é um composto polivalente, contendo espécies $\mathrm{W}^{6+}$ e $\mathrm{W}^{5+}$. Estas espécies apresentam bandas de transferência de carga intervalente, por meio de transições d-d.(101) Em baixas temperaturas $(T<40 \mathrm{~K})$ estudos de RPE mostram que o elétron desemparelhado encontra-se localizado em um único sítio $\mathrm{WO}_{6}$.(90, 100) Com o aumento da temperatura o processo de saltos entre diferentes sítios $\mathrm{WO}_{6}$ na molécula é termicamente ativado pelas vibrações moleculares do HPW. Sanchez et al. correlacionaram o aumento na largura de linha pico-a-pico $\left(\Delta H_{p p}\right)$ dos espectros de RPE com o processo de saltos do elétron desemparelhado.(101) Em seu estudo eles consideraram dois termos para a largura de linha:

$$
\Delta H_{p p}(T)=\Delta H_{p p}(0)+\delta H_{p p}(T)
$$

O termo $\Delta H_{p p}(0)$ é basicamente a largura de linha em $T=0 \mathrm{~K}$, devido à contribuições da interação dipolar entre íons paramagnéticos, acoplamentos hiperfinos não resolvidos e heterogeneidade para os campos ligantes dos íons paramagnéticos. O termo $\delta H_{p p}(T)$ é 
Tabela 6.11-Valores para os parâmetros do tensor $\stackrel{\leftrightarrow}{g}$ obtidos por meio de simulação dos espectros de RPE medidos para o conjunto de xerogeis preparados em diferentes condições de controle de atmosfera. Dados para amostras preparadas em condição ambiente, e submetidas a secagem em $85^{\circ} \mathrm{C}$ por $2 \mathrm{~h}$ sob fluxo de $\mathrm{N}_{2}$ também são exibidos. $g_{\text {iso }}$ é o valor isotrópico do tensor, $\Delta$ é o parâmetro de anisotropia e $\eta$ é o parâmetro de assimetria, conforme definidos na equação 6.2.1.

\begin{tabular}{|c|c|c|c|c|c|c|c|}
\hline \multirow{2}{*}{$\begin{array}{c}\text { Condição } \\
\text { de } \\
\text { preparo }\end{array}$} & \multirow[b]{2}{*}{ Amostra } & \multicolumn{3}{|c|}{ Ressonância 1} & \multicolumn{3}{|c|}{ Ressonância 2} \\
\hline & & $g_{\text {iso }}$ & $\Delta$ & $\eta$ & $g_{\text {iso }}$ & $\Delta$ & $\eta$ \\
\hline \multirow{3}{*}{ Ambiente } & HGT & 1,825 & $-0,042$ & 0,013 & - & - & - \\
\hline & HGBT & 1,825 & $-0,038$ & 0,027 & - & - & - \\
\hline & HGAT & 1,827 & $-0,044$ & 0,030 & - & - & - \\
\hline \multirow{3}{*}{ Fluxo de $\mathrm{N}_{2}$} & HGT & 1,824 & $-0,042$ & 0,029 & 1,830 & $-0,083$ & 0,0020 \\
\hline & HGBT & 1,821 & $-0,042$ & 0,031 & 1,828 & $-0,084$ & 0,0072 \\
\hline & HGAT & 1,820 & $-0,031$ & 0,021 & 1,827 & $-0,078$ & 0,0082 \\
\hline \multirow{3}{*}{ Glove-box } & HGT & 1,816 & $-0,050$ & 0,035 & 1,829 & $-0,088$ & 0,0027 \\
\hline & HGBT & 1,813 & $-0,049$ & 0,032 & 1,827 & $-0,086$ & 0,0073 \\
\hline & HGAT & 1,820 & $-0,034$ & 0,022 & 1,827 & $-0,084$ & 0,0085 \\
\hline \multirow{3}{*}{$\begin{array}{r}\text { Ambiente } \\
+ \text { secagem }\end{array}$} & HGT & 1,826 & $-0,053$ & 0,043 & 1,829 & $-0,085$ & 0,0055 \\
\hline & HGBT & 1,823 & $-0,051$ & 0,038 & 1,829 & $-0,085$ & 0,0076 \\
\hline & HGAT & 1,823 & $-0,038$ & 0,0044 & 1,829 & $-0,084$ & 0,0056 \\
\hline
\end{tabular}

Fonte: Elaborada pelo autor.

o termo da largura dependente da temperatura, e é devido ao alargamento causado pelos processos de relaxação induzidos pelo movimento de saltos. Para temperaturas muito baixas, o tempo de relaxação spin-rede $\left(T_{1}\right)$ é muito longo, e a largura de linha é dominada pela relaxação transversal ou relaxação spin-spin (com tempo característico $T_{2}$ ). Com o aumento da temperatura, $T_{1}$ decresce, até ficar menor do que $T_{2}$, e a largura de linha passa a depender do tempo $T_{1}$, e consequentemente varia com a temperatura. Portanto, para temperaturas altas a largura $\delta H_{p p}(T)$ depende do tempo de vida $\tau_{s}$ do estado de spin excitado. Cálculos mostram que o tempo de vida $\tau_{s}$ é proporcional ao tempo de correlação $\tau_{h}$ do movimento do elétron desemparelhado.(107) Desta forma,

$$
\delta H_{p p}(T)=C \nu_{h}
$$

onde $\nu_{h}$ é a frequência com que ocorrem os saltos do elétron desemparelhado. A equação 6.2.3 correlaciona a largura de linha do espectro de RPE com a frequência dos saltos, e em estudos detalhados da largura de linha em função da temperatura para complexos de Keggin, Sanchez et al. estimaram a energia de ativação $E_{a}$ para o processo de deslocalização do elétron 
desemparelhado, obtendo $E_{a} \approx 0,035 \mathrm{eV}$ para $\mathrm{SiW}_{12} \mathrm{O}_{40}{ }^{5-} .(100)$

Em 20K os espectros das amostras HGT preparadas condições ambientes (figura 6.54.a) correspondem a sítios ortorrômbicos em todos os casos, indicando que o elétron se encontra localizado em um único sítio $\mathrm{WO}_{6}$. Com o aumento da temperatura, os espectros sofrem um alargamento devido ao processo de salto do elétron desemparelhado entre sítios $\mathrm{WO}_{6}$. $\mathrm{O}$ espectro de RPE pode ser simulado com uma única componente ortorrômbica até $60 \mathrm{~K}$. Acima desta temperatura, a simulação com apenas uma ressonância não é satisfatória, mostrando que o sistema de spins é heterogêneo, provavelmente devido a diferenças no processo de deslocalização do elétron ocorrendo em diferentes poliânions. Acima de $60 \mathrm{~K}$ os espectros de RPE seguem alargando, mostrando um aumento na deslocalização do elétron paramagnético. Os espectros obtidos para a amostra HGT-N2 (figura 6.54.b) são heterogêneos em 20K, contendo sítios $\mathrm{WO}_{6}$ interagindo de forma diferente com as espécies no ambiente de coordenação do HPW, conforme discutido anteriormente. Os parâmetros espectrais não apresentam grandes mudanças com a temperatura até $60 \mathrm{~K}$. A partir desta temperatura o processo de saltos para o elétron começa a ser ativado e o sistema de spins passa por transformações semelhantes às que ocorrem para a amostra HGT-Amb. As mesmas características podem ser observadas para os espectros de RPE da amostra HGT-Box (figura 6.54.c). O sistema é composto basicamente por dois sítios paramagnéticos em baixas temperaturas, e é mais complexo e alargado em temperaturas acima de 60K. Para esta última amostra, é observada um maior alargamento da linha central com o aumento da temperatura, e o sinal correspondente aos centros $\mathrm{WO}_{6}$ fica com intensidade da ordem ou menor do que o sinal correspondente às impurezas de Mo em 100K, o que sugere que a energia de ativação para o processo de saltos nesta amostra é menor. Estas alterações observadas com a temperatura são todas termicamente reversíveis.

A figura 6.55 exibe os espectros de RPE em função da temperatura para a amostra HGBT preparada em diferentes atmosferas. Os espectros obtidos para a amostra HGBT-Amb (figura 6.55. a) em mais baixas temperaturas são similares aos obtidos para a amostra HGT-Amb. O mesmo alargamento com a temperatura também é observado para esta amostra. Diferente do que ocorre para a amostra HGT-Amb, os espectros para a amostra HGBT-Amb se tornam isotrópicos a partir de $70 \mathrm{~K}$, indicando que nesta a energia de ativação para os processo de saltos é menor. Os espectros obtidos para as amostras HGBT-N2 e HGBT-Box (figuras 6.55, b e 6.55.c) são muito similares aos obtidos para as amostras HGT correspondentes, apresentando duas componentes em baixa temperatura, e um espectro mais alargado e complexo em temperaturas acima de 70K. Assim como ocorre para o conjunto de amostras HGT, os espectros para estas amostras sofrem um aumento substancial na largura, e uma redução de intensidade com a temperatura. Estes efeitos são mais evidentes quanto mais secas são as amostras. 

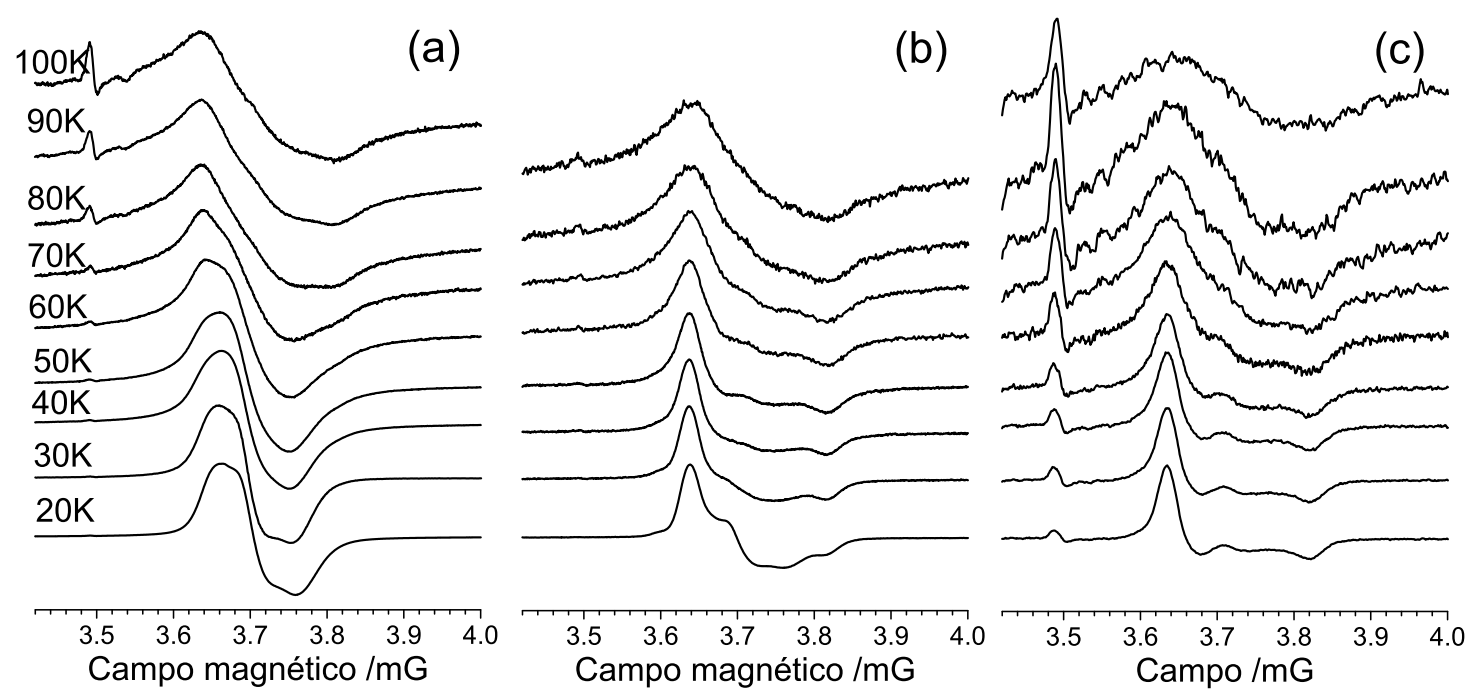

Figura 6.54-Espectros de RPE em função da temperatura para as amostras HGT preparadas em diferentes condições: (a) Sem controle de atmosfera; (b) em câmara com fluxo de N2 e (c) em glove-box. Os espectros estão normalizados pela intensidade máxima. Fonte: Elaborada pelo autor.
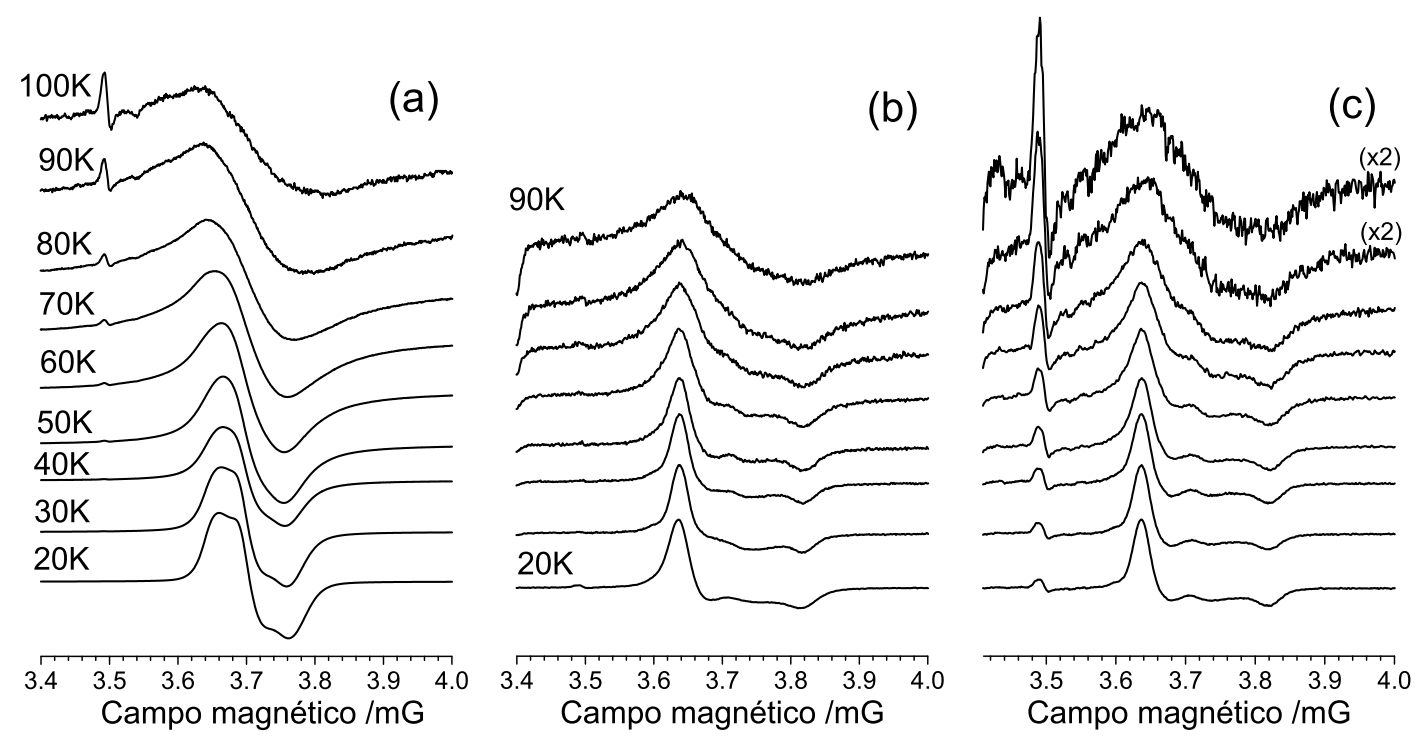

Figura 6.55-Espectros de RPE em função da temperatura para as amostras HGBT preparadas em diferentes condições: (a) Sem controle de atmosfera; (b) em câmara com fluxo de N2 e (c) em glove-box. Os espectros estão normalizados pela intensidade máxima. Fonte: Elaborada pelo autor.

A figura 6.56 exibe os espectros de RPE em função da temperatura para a amostra HGAT preparada em diferentes atmosferas. Os espectros obtidos para a amostra HGAT-Amb (figura 6.56. a) apresentam o mesmo comportamento observado para a amostra HGT-Amb, apresentam 
uma única linha ortorrômbica em temperatura ambiente, passando por transformações em torno de $60 \mathrm{~K}$, e se tornando alargados e heterogêneos em mais altas temperaturas. Para a amostra HGAT-Amb a redução na intensidade do sinal de RPE com a temperatura é mais significativa. Os espectros de RPE para a amostra HGAT-N2 (figura 6.56.b) são os mais atípicos dentre os resultados obtidos para os xerogeis estudados neste trabalho. Em $20 \mathrm{~K}$ o espectro é praticamente composto pela ressonância 1, idêntica às observadas nas amostras mais hidratadas. Em $30 \mathrm{~K}$ o espectro se torna heterogêneo, similar ao das outras amostras preparadas nas mesmas condições, com uma relação de intensidades de 0.3:1 entre as ressonâncias 1 e 2 . Acima $30 \mathrm{~K}$ os espectros apresentam comportamento similar ao observado para as amostras HGT-N2 e HGBT-N2. Os espectros para a amostra HGAT-Box (figura 6.56.c) apresentam o mesmo comportamento observado para as amostras HGT-Box e HGBT-Box.

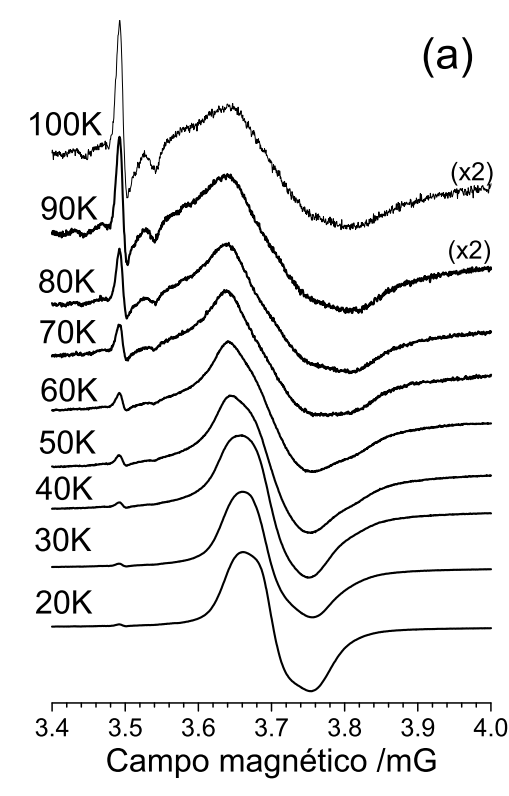

(a)

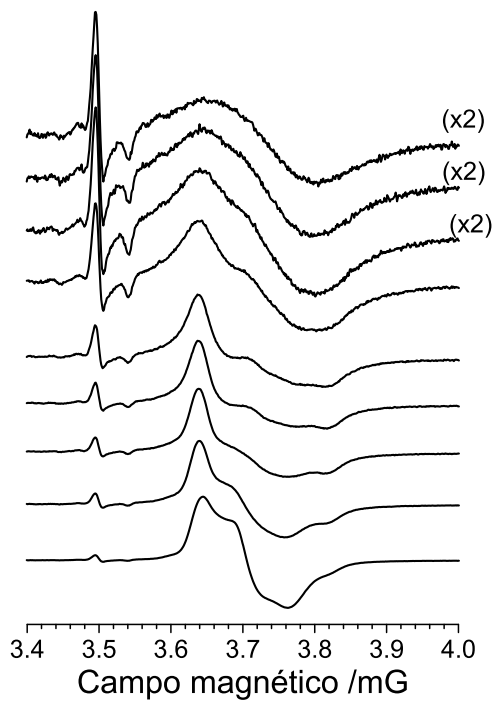

(b)

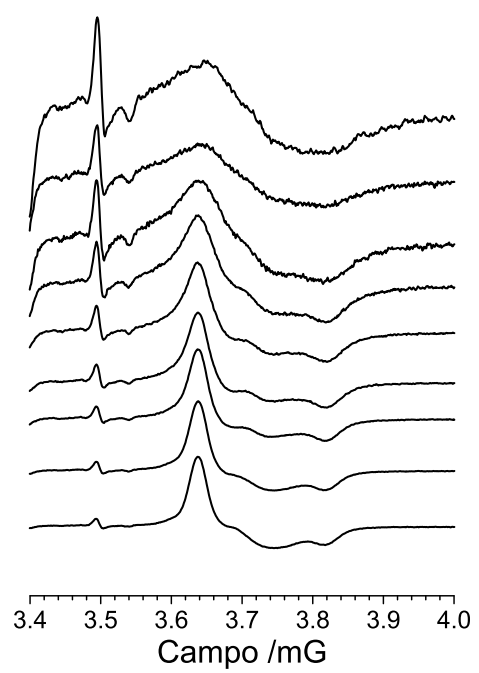

Figura 6.56-Espectros de RPE em função da temperatura para as amostras HGAT preparadas em diferentes condições: (a) Sem controle de atmosfera; (b) em câmara com fluxo de N2 e (c) em glove-box. Os espectros estão normalizados pela intensidade máxima. Fonte: Elaborada pelo autor.

Comparando cada conjunto de amostras analisado (ambiente, câmara de $\mathrm{N}_{2}$ ) e glove-box, não são observadas diferenças sistemáticas, em função da composição da amostra, indicando que a natureza dos grupos orgânicos presentes na amostra não influencia diretamente o campo ligante do íon $\mathrm{W}^{5+}$.

O sinal com $g=2,00$ corresponde a um radical formado após a irradiação, e é observado apenas para as amostras HGBT-N2, HGT-N2 e para todas as amostras preparadas em glove-box. Este sinal apresenta diferentes intensidades entre as amostras, e sua intensidade (relativa à linha de impurezas de Mo) aumenta com a temperatura, como mostra a figura 6.57. Nenhuma 
correlação entre o sinal para o centro $\mathrm{WO}_{6}$ em HPW e este radical ressoando em $g=2,00$ pôde ser observada nos experimentos de RPE, e portanto supõe-se que estas espécies são geradas em outra região da amostra, não tendo relação direta com o poliânion de HPW. Uma alternativa seria a formação de defeitos na matriz de silicato devido à vacâncias geradas na posição dos $\mathrm{H}$ em $\mathrm{SiOH}$, dando origem a um radical SiO•.(108, 109) No entanto, mais estudos precisam ser conduzidos para confirmar a identificação deste sinal.
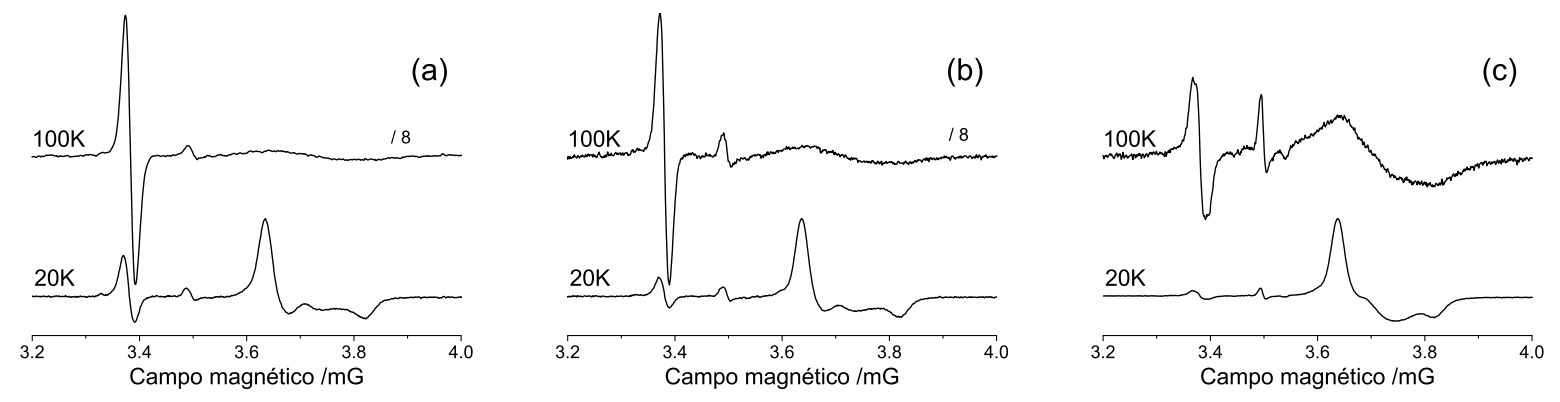

Figura 6.57-Espectros de RPE medidos em $20 \mathrm{~K}$ e $100 \mathrm{~K}$ para as amostras HGT (a), HGBT (b) e HGAT (c) preparadas em glove-box. Fonte: Elaborada pelo autor.

\subsubsection{0 ${ }^{31} \mathrm{P}$ e ${ }^{1} \mathrm{H}$ MAS RMN em amostras irradiadas}

Conforme demonstrado em trabalhos anteriores, a técnica de ${ }^{31} \mathrm{P}$ RMN é sensível ao estado irradiado de xerogeis contendo grupos amina, e a reversibilidade do processo fotocrômico foi demonstrada.(18, 20) Da mesma forma, no presente trabalho foram realizados experimentos de ${ }^{31} \mathrm{P}$ RMN nas amostras HGAT-Amb e HGAT-N2 antes e após irradiação do pó com radiação UV durante 30min (dose aproximada de 150MED). Os espectros para ambas amostras são similares, e seguem o mesmo comportamento, portanto na figura 6.58 são mostrados apenas os espectros para a amostra HGAT-N2. Logo após a irradiação o espectro de ${ }^{31} \mathrm{P}$ RMN apresenta um novo sítio em -11,3 ppm (figura 6.58.b). O surgimento deste novo ambiente de coordenação para ${ }^{31} \mathrm{P}$ pode ser atribuído tentativamente à mudança na valência do tungstênio $\left(\mathrm{W}^{5+} \rightarrow\right.$ $\left.\mathrm{W}^{6+}\right)$.(33) De acordo com os espectros medidos um dia após a irradiação, figura 6.58 .c, há uma redução destas espécies reduzidas, indicando uma reversibilidade do processo de redução dos poliânions de HPW. Embora macroscopicamente a amostra tenha mudado de cor, a área da linha correspondente ao HPW irradiado é muito pouco intensa quando comparada à linha central $(0,7 \%)$. Isto indica baixa eficiência em escala molecular do processo de irradiação realizado neste experimento, atingindo uma fração pequena de todos os poliânions disponíveis na amostra. 


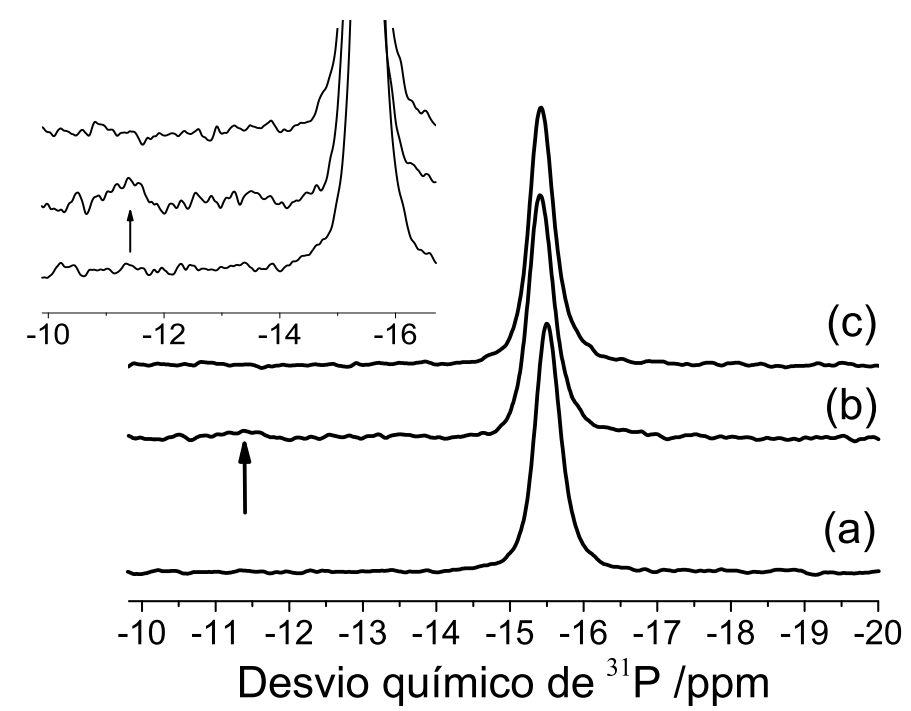

Figura 6.58-Espectros de ${ }^{31} \mathrm{P}$ RMN para a amostra HGAT-N2 antes e após irradiação com lâmpada de Xe. Fonte: Elaborada pelo autor.

Pela primeira vez foram realizados experimentos de ${ }^{1} \mathrm{H}$ RMN em xerogeis irradiados. A figura 6.59 mostra espectros de PD (a) e spin-eco (b) (com $2 \tau=800 \mu s){ }^{1} \mathrm{H}$ RMN obtidos em temperatura ambiente para a amostra HGAT-Amb, antes e após irradiação com luz UV. O espectro de PD (figura 6.59. a) é majoritariamente composto pela ressonância correspondente à moléculas de $\mathrm{H}_{2} \mathrm{O}$ relativamente móveis, conforme mostrado na seção 6.2.6. Uma mudança apreciável na largura da linha central é observada após a irradiação da amostra, indicando um rearranjo estrutural para a maioria das espécies $\mathrm{H}_{2} \mathrm{O}$ presentes na amostras, de forma que haja um aumento do acoplamento dipolar ${ }^{1} \mathrm{H}-{ }^{1} \mathrm{H}$. Os espectros de spin-eco para esta amostra (figura 6.59. a) confirmam o aumento no acoplamento dipolar ${ }^{1} \mathrm{H}-{ }^{1} \mathrm{H}$ para os ${ }^{1} \mathrm{H} \mathrm{em}$ $\mathrm{H}_{2} \mathrm{O}$, a ressonância correspondente às espécies de hidratação é completamente suprimida no experimento realizado após a irradiação da amostra. É interessante notar que a reorganização das espécies de hidratação ocorre incluindo a maioria das moléculas de $\mathrm{H}_{2} \mathrm{O}$ na amostra, inclusive as que se encontram distantes do poliânion. Uma possível explicação seria que há uma reorganização das espécies de hidratação no ambiente de coordenação do poliânion, de forma a contrabalancear a carga do mesmo após a redução, e uma consequente reorganização em cadeia das espécies de hidratação nas esferas superiores de coordenação. O tempo de retorno para as amostras na forma de pó é substancialmente longo, da ordem de semanas. Portanto, para avaliar o retorno da amostra ao estado inicial foram realizados experimentos de ${ }^{1} \mathrm{H}$ RMN após 30 dias. Neste período a amostra esteve estocada em dissecador sem vácuo. Os espectros obtidos após 30 dias mostram uma linha intensa e relativamente estreita por volta de $6 \mathrm{ppm}$, que corresponde à espécies de hidratação intersticiais na amostra, mostrando que houve hidratação da amostra. Esta hidratação torna difícil a avaliação da reversibilidade do processo fotocrômico para as amostras preparadas em condições ambientes. 

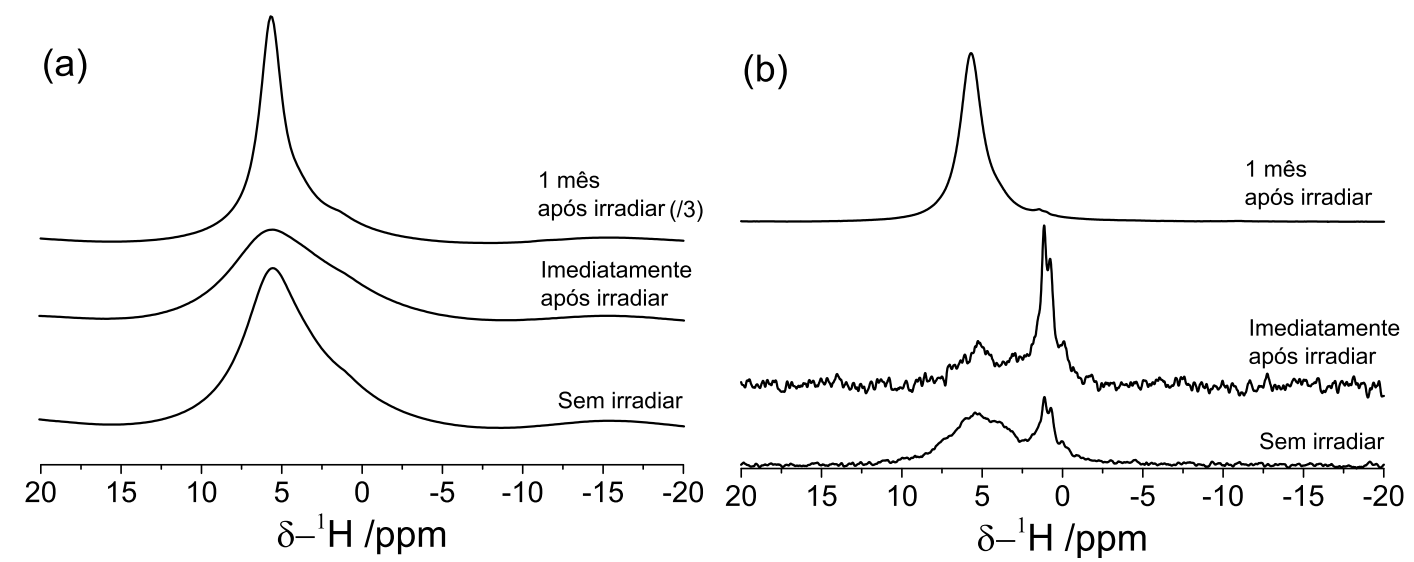

Figura 6.59-Espectros de ${ }^{1} \mathrm{H}$ RMN em polarização direta (a) e spin-eco com $\tau=800 \mu s$ (b) para a amostra HGAT-Amb, antes e após passar por irradiação com lâmpada de Xe. Fonte: Elaborada pelo autor.

Experimentos de ${ }^{1} \mathrm{H}$ RMN também foram realizados para a amostra HGAT-N2 antes e após a irradiação, os resultados de PD e spin-eco são mostrados nas figuras 6.60 a e 6.60.b respectivamente. Esta amostra possui menor nível de hidratação do que a amostra HGAT-Amb, e o espectro de polarização direta apresenta ressonâncias relativamente intensas na região atribuída aos ${ }^{1} \mathrm{H}$ da matriz ormosil, como $\mathrm{SiOH}$ e $\mathrm{H}_{2} \mathrm{O}$ adsorvida na matriz e um ombro menos intenso correspondente às espécies de hidratação menos móveis, identificadas na seção 6.2.4. A comparação entre os espectros de $\mathrm{PD}{ }^{1} \mathrm{H}$ antes e após a irradiação mostra pouca alteração na região de frequências correspondente a grupos $\mathrm{SiOH}$, e um alargamento das ressonâncias correspondentes às espécies de hidratação. Portanto, similarmente ao que ocorre para a amostra HGAT-Amb, nesta amostra também há uma reorganização das espécies de hidratação, de forma que haja uma redução na mobilidade e o consequente aumento no acoplamento dipolar homonuclear. Após a irradiação a amostra foi estocada em câmara com fluxo de $\mathrm{N}_{2}$ durante 30 dias, e os esperimentos de ${ }^{1} \mathrm{H}$ RMN foram repetidos. Na figura 6.60. a é possível observar que o espectro de PD obtido após 30 dias é muito próximo ao obtido para a amostra não irradiada, mostrando que o processo é reversível para a maioria das espécies ${ }^{1} \mathrm{H}$. Os espectros de spin-eco (figura 6.60.a), por sua vez, mostra uma alteração nas ressonâncias, anteriormente atribuídas à grupos $\mathrm{OH}$, após a irradiação da amostra, mostrando que estes grupos participam do ambiente de coordenação do poliânion. O espectro obtido após 30 dias mostra uma reversão parcial da organização estrutural destes grupos, no entanto o espectro original não é completamente recuperado, mostrando que mudanças irreversíveis podem ter ocorrido. É importante destacar que estes grupos correspondem à menor parte das espécies protônicas presentes na amostra, uma vez que apenas podem ser observados em experimentos de spin-eco devido ao seu baixo acoplamento dipolar homonuclear, comparado com as outras espécies protônicas da amostra. 
Não foi observada evidência de hidratação durante o periodo de estocagem desta amostra, portanto as condições utilizadas são ideais para estudos futuros da reversibilidade a nível molecular do efeito fotocrômico.
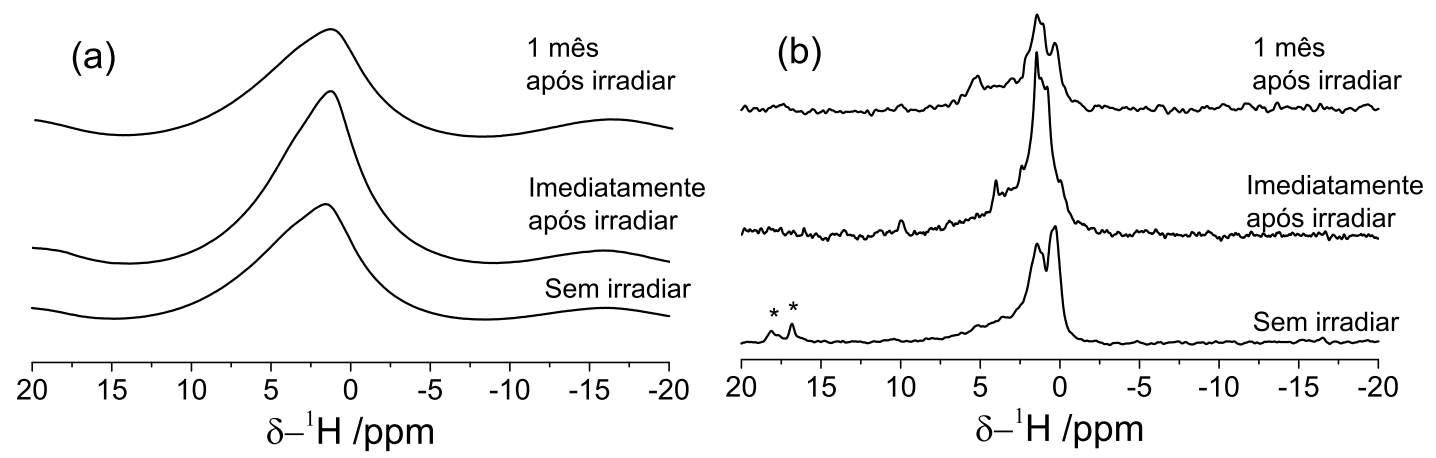

Figura 6.60-Espectros de ${ }^{1} \mathrm{H}$ RMN em polarização direta (a) e spin-eco com $\tau=800 \mu s$ (b) para a amostra HGAT-N2, antes e após passar por irradiação com lâmpada de Xe. 
Capítulo 7

\section{Discussão}

\subsection{HPW hidratado}

Os resultados de ${ }^{1} \mathrm{H}$ e ${ }^{31} \mathrm{P}$ mostram que a secagem do $\mathrm{HPW} \cdot \mathrm{nH}_{2} \mathrm{O}$ a $85^{\circ} \mathrm{C}$ por $2 \mathrm{~h}$ produz a amostras mais homogêneas. Os dados de TGA mostram que esta amostra possui a estequiometria, dentro da sensibilidade da técnica, consistente com o $\mathrm{HPW} \cdot 6 \mathrm{H}_{2} \mathrm{O}$. A secagem em $95^{\circ} \mathrm{C}$ por $1 \mathrm{~h}$ também leva à mesma estequiometria, no entanto o ambiente de coordenação do HPW nesta amostra é heterogêneo, mostrando ambientes com diferentes níveis de hidratação para o HPW. Secagens em temperaturas maiores desidratam excessivamente a amostra, resultando em estequiometrias mais baixas, tais como $\mathrm{HPW} \cdot 5,2 \mathrm{H}_{2} \mathrm{O}$ e HPW $\cdot 2,6 \mathrm{H}_{2} \mathrm{O}$. Para esta amostra foram identificados desvios de ${ }^{31} \mathrm{P}$ fora da faixa esperada para poliânions de HPW hidratados, levando à conclusão de que o poliânion passa a realizar ligações covalentes com um ou dois prótons $\left(\delta_{-}{ }^{31} \mathrm{P} \approx-13 \mathrm{ppm}\right)$. Para a amostra HPW $2,6 \mathrm{H}_{2} \mathrm{O}$ espécies de HPW completamente desidratado também foram identificadas $\left(\delta-{ }^{31} \mathrm{P} \approx-12 \mathrm{ppm}\right)$.

Dados de TGA e DRX mostram que a estequiometria e a estrutura cristalográfica tanto para a amostra HPW-I quanto para HPW-II são consistentes com os dados reportados na literatura.(23, 27) Transformações com a temperatura foram detectadas em ambas as amostras.

Os espectros de ${ }^{1} \mathrm{H}$ para a amostra HPW-I sofrem mudanças substanciais acima de $40^{\circ} \mathrm{C}$, que estão relacionadas com o rearranjo estrutural para as espécies de ${ }^{1} \mathrm{H}$ e a possível remoção de algumas moléculas de $\mathrm{H}_{2} \mathrm{O}$. Algumas destas transformações estão associadas com estados metaestáveis para as espécies de água. Os desvios químicos de ${ }^{1} \mathrm{H}$ e os diferentes valores de $\mathrm{T}_{1 \rho}$ obtidos de forma direta e indireta indica um excesso de água para esta amostra, provavelmente na forma de clusters $\mathrm{H}^{+}\left(\mathrm{H}_{2} \mathrm{O}\right)_{n}$. A ressonância estreita indica alta mobilidade para estas espécies de hidratação. Muitos destes prótons não contribuem para o sinal de $\mathrm{CP}\left\{{ }^{1} \mathrm{H}\right\}-{ }^{31} \mathrm{P}$, indicando distâncias maiores e/ou dinâmica rápida. O experimentos de SEDOR indicam que o regime de rede rígida não é atingido para os prótons no ambiente de coordenação do poliânion, mesmo em mais baixas temperaturas $\left(-95^{\circ} \mathrm{C}\right)$. Portanto, embora técnicas de DRX e TGA mostrem uma estrutura média consistente com o cristal de $\mathrm{HPW} \cdot 6 \mathrm{H}_{2} \mathrm{O}$, os resultados de RMN, 
com maior sensibilidade com relação aos ambientes locais do HPW, revelam que esta amostra apresenta um excesso de espécies de hidratação e/ou defeitos, que são responsáveis pelas transformações observadas, como será detalhado no final desta seção.

Por outro lado, a amostra HPW-II é termicamente mais estável do que a HPW-I, e os dados de RMN mostram uma estrutura mais consistente com a estrutura proposta para o HPW. $6 \mathrm{H}_{2} \mathrm{O}$. $\mathrm{O}$ valor de $\mathrm{M}_{2 H P}$ obtido para esta amostra indica que o acoplamento dipolar entre o ${ }^{31} \mathrm{P}$ e os ${ }^{1} \mathrm{H}$ ao redor é consistente com o valor calculado para um cristal de $\mathrm{HPW} \cdot 6 \mathrm{H}_{2} \mathrm{O}$, considerando que os prótons centrais do poliânion, altamente móveis, estão fracamente acoplados e não contribuem para $\mathrm{M}_{2 H P}$. Claramente o tratamento da amostra sob fluxo de $\mathrm{N}_{2}$ é mais eficiente para remover o excesso de $\mathrm{H}_{2} \mathrm{O}$ na amostra HPW. $\mathrm{nH}_{2} \mathrm{O}$ inicial. Mudanças contínuas para os parâmetros espectrais de ${ }^{1} \mathrm{H}$ e ${ }^{31} \mathrm{P}$ RMN foram observadas em função da temperatura, desde $-50^{\circ} \mathrm{C}$ até $85^{\circ} \mathrm{C}$ que são consistentes com a dissociação/associação do íon dioxônio, conforme o equilíbrio mostrado na equação 2.2.1.(26) Três regimes de dinâmica podem ser identificados:

(i) Baixas temperaturas $\left(\mathrm{T}<10^{\circ} \mathrm{C}\right)-\mathrm{A}$ maioria dos prótons pertencentes ao dioxônio se encontram em estado de baixa mobilidade, resultando em uma ressonância de ${ }^{1} \mathrm{H}$ extremamente alargada devido ao acoplamento dipolar ${ }^{1} \mathrm{H}-{ }^{1} \mathrm{H}$. É observada uma pequena fração de prótons em ligações de hidrogênio fortes (em torno de $10 \%$ em $-50^{\circ} \mathrm{C}$ ). Dados de difração de nêutrons (24) mostram que a distância entre as moléculas de $\mathrm{H}_{2} \mathrm{O}$ no poliânion decresce com a temperatura, possibilitando a atribuição destas espécies a prótons realizando saltos rápidos entre as duas posições equivalentes próximas aos $\mathrm{O}$ do dioxônio. $\mathrm{O}$ estado dos íons dioxônio podem então ser descritos por uma mistura de duas configurações, $\mathrm{H}_{5} \mathrm{O}_{2}{ }^{+}$e $\mathrm{H}_{3} \mathrm{O}^{+}+\mathrm{H}_{2} \mathrm{O}$.

(ii) Faixa de temperaturas intermediárias $\left(10^{\circ} \mathrm{C}\right.$ a $\left.40^{\circ} \mathrm{C}\right)-\mathrm{O}$ decréscimo do acoplamento dipolar ${ }^{1} \mathrm{H}-{ }^{1} \mathrm{H}$ com o aumento na temperatura indica maior mobilidade para os prótons em $\mathrm{H}_{3} \mathrm{O}^{+}$e $\mathrm{H}_{2} \mathrm{O}$. A ressonância correspondente a prótons em ligações fortes de hidrogênio deixa de ser resolvida, indicando que o equilíbrio das espécies $\mathrm{H}$ se desloca para o centro da equação 2.2.1. A mistura dinâmica entre as diferentes espécies protônicas indica a ativação de novos processos conforme a temperatura é aumentada, como o processo de troca entre os três prótons em $\mathrm{H}_{3} \mathrm{O}^{+}$e/ou inversões das moléculas $\mathrm{H}_{2} \mathrm{O}$, combinados com um processo mais lento de troca entre as espécies $\mathrm{H}_{3} \mathrm{O}^{+}$e $\mathrm{H}_{2} \mathrm{O}$.

(iii) Alta temperatura $\left(\mathrm{T}>50^{\circ} \mathrm{C}\right)-\mathrm{O}$ decréscimo do acoplamento dipolar ${ }^{1} \mathrm{H}-{ }^{1} \mathrm{H}$ é revertido nesta faixa de temperaturas, o que parece em contradição com o aumento na energia térmica do sistema. Este comportamento pode indicar uma mudança no equilíbrio das espécies protônicas para o lado direito da equação 2.2.1, formando $\mathrm{H}^{+}+2 \mathrm{H}_{2} \mathrm{O}$. Assim, 
o próton central do dioxônio é capaz de saltar para outros sítios, como por exemplo posições próximas aos $\mathrm{O}$ do poliânion. Este processo interrompe a dinâmica de troca ocorrendo em $\mathrm{H}_{3} \mathrm{O}^{+}+\mathrm{H}_{2} \mathrm{O}$, deixando apenas duas moléculas de $\mathrm{H}_{2} \mathrm{O}$. A presença de novas ressonâncias correspondentes a prótons móveis na faixa de desvios químicos característica de grupos $\mathrm{OH}$ confirma esta interpretação, uma vez que o próton pode migrar entre defeitos. Os movimentos mais lentos, como o de inversão das moléculas $\mathrm{H}_{2} \mathrm{O}$, seriam responsáveis por manter o acoplamento dipolar ${ }^{1} \mathrm{H}-{ }^{1} \mathrm{H}$ relativamente baixo, tornando possível resolver parcialmente as bandas laterais no espectro de ${ }^{1} \mathrm{H}$ mesmo em $85^{\circ} \mathrm{C}$

As mudanças observadas para os parâmetros espectrais em ${ }^{31} \mathrm{P}-\mathrm{RMN}$ para o HPW-II (desvio químico e largura a meia altura) são pequenas e bem correlacionadas com as mudanças observadas para os prótons. Portanto, os experimentos de ${ }^{31} \mathrm{P}$ parecem refletir as transformações das espécies de hidratação no ambiente de coordenação do poliânion de HPW, que perturbam o tensor de blindagem e o acoplamento dipolar ${ }^{1} \mathrm{H}_{-}{ }^{31} \mathrm{P}$ residual. Estas alterações não indicam distorções na geometria local dos tetraedros $\mathrm{PO}_{4}$, como proposto por Kremenovic et al.(23) Este comportamento essencialmente relacionado às alterações na dinâmica das espécies de hidratação contrastam com os resultados obtidos para o HPW-I. Nesta amostra as alterações observadas no espectro de ${ }^{31} \mathrm{P}$ RMN com a temperatura parecem ser devido à alterações estruturais, como a geração de defeitos e/ou desordem para as espécies de hidratação, de forma compatível com a transição por volta de $47^{\circ} \mathrm{C}$ observada na literatura.(23, 24) $\mathrm{O}$ ambiente de hidratação nesta amostra é muito complexo, e as alterações observadas são parcialmente irreversíveis. Estes resultados indicam que o grau de hidratação da amostra é crítico para a determinação do comportamento da estrutura local do poliânion em altas temperaturas $(T>$ $47^{\circ} \mathrm{C}$ ). Adicionalmente, a coincidência entre a temperatura de transição observada na literatura, com o deslocamento no equilíbrio das espécies protônicas para o lado direito da equação 2.2.1 na amostra HPW-II demonstra o importante papel da dinâmica dos prótons para a evolução estrutural com a temperatura.

\subsection{Xerogeis}

Os resultados de ${ }^{13} \mathrm{C}$ RMN mostram que as cadeias orgânicas dos precursores não sofrem reações durante o processo de preparo dos xerogeis, com exceção do GLYMO, cujo anel epóxi 
reage com moléculas água formando grupos diol.(20) De acordo com os resultados de ${ }^{13} \mathrm{C} \mathrm{e}$ ${ }^{29} \mathrm{Si} \mathrm{RMN}$ a matriz ormosil é completamente estável frente ao tratamento térmico em $85^{\circ} \mathrm{C}$. Por outro lado, o tratamento a $150^{\circ} \mathrm{C}$ provoca a quebra das cadeias orgânicas e a formação de grupos aldeídos e fragmentos contendo grupos $\mathrm{CO}, \mathrm{CH}_{3}, \mathrm{CH}_{2}$ e alcanos. Portanto, tratamentos térmicos nesta faixa de temperaturas não são convenientes para controlar o nível de hidratação nestes materiais.

As principais espécies de $\mathrm{H}$ identificadas nos xerogéis são: (i) aglomerados de moléculas de $\mathrm{H}_{2} \mathrm{O}$ com alta mobilidade (acoplamento homonuclear ${ }^{1} \mathrm{H}-{ }^{1} \mathrm{H}$ baixo), (ii) espécies de hidratação como $\mathrm{H}_{2} \mathrm{O}, \mathrm{H}_{3} \mathrm{O}^{+}, \mathrm{H}_{5} \mathrm{O}_{2}{ }^{+}$e $\mathrm{H}^{+}\left(\mathrm{H}_{2} \mathrm{O}\right)_{n}$ com mobilidade mais restrita, as quais participam do ambiente de coordenação do poliânion de HPW, (iii) grupos OH no ambiente de coordenação do poliânion (iv) $\mathrm{H}$ pertencentes à matriz ormosil, em grupos orgânicos, $-\mathrm{CH}_{2},-\mathrm{CH}_{3},-\mathrm{OCH}_{2} \mathrm{e}$ - $\mathrm{COH}$, e nos grupos de $\mathrm{Si} \mathrm{Q}_{n}(\mathrm{n}=3,2,1)$ e $\mathrm{T}_{2}$.

Os resultados de ${ }^{1} \mathrm{H}$ RMN mostram que as amostras preparadas em condições ambientes apresentam grandes concentrações de $\mathrm{H}_{2} \mathrm{O}$ móveis (espécies do tipo (i) acima). Estas espécies estão presentes em menor quantidade nas amostras HT-N2 e HGT-N2, e não são observadas para as amostras HGBT-N2 e HGAT-N2 nem nas amostras preparadas em glove-box. Portanto, o controle da atmosfera durante o preparo dos xerogeis é suficiente para reduzir a concentração de $\mathrm{H}_{2} \mathrm{O}$ nos xerogeis. Um grande aumento na mobilidade destes prótons é observado com o aumento da temperatura, e estas espécies são facilmente eliminadas por tratamento térmico em $85^{\circ} \mathrm{C}$. O espectro de HETCOR $\left\{{ }^{1} \mathrm{H}\right\}{ }^{31} \mathrm{P}$ para a amostra HGAT-Amb (figura 6.43 e projeção de ${ }^{1} \mathrm{H}$ na figura 6.44) mostra que não há acoplamento dipolar heteronuclear entre os prótons em $\mathrm{H}_{2} \mathrm{O}$ e o ${ }^{31} \mathrm{P}$ em HPW, indicando que estas espécies não participam do ambiente de coordenação do HPW, ou alternativamente, sua alta mobilidade reduz o acoplamento dipolar ${ }^{1} \mathrm{H}^{31} \mathrm{P}$, e os ${ }^{1} \mathrm{H}$ não transferem magnetização para ${ }^{31} \mathrm{P}$.

Nos espectros de ${ }^{1} \mathrm{H}$ para as amostras com menores concentrações de $\mathrm{H}_{2} \mathrm{O}$, é possível identificar uma ressonância larga e com centro em torno de $6 \mathrm{ppm}$ a 7,5ppm. O desvio químico e a largura desta linha são consistentes com espécies de hidratação com mobilidade reduzida, semelhantes às espécies observadas para as amostras de HPW hidratado (espécies do tipo (ii) acima). Adicionalmente, os resultados de spin-eco também mostram alto acoplamento dipolar ${ }^{1} \mathrm{H}-{ }^{1} \mathrm{H}$ para estas espécies, reforçando esta atribuição. De acordo com os resultados de HETCOR $\left\{{ }^{1} \mathrm{H}\right\}-{ }^{31} \mathrm{P}$, estes prótons estão acoplados dipolarmente com ${ }^{31} \mathrm{P}$ em HPW, mostrando a presença destas espécies na vizinhança do poliânion de HPW, provavelmente formando clusters do tipo $\mathrm{H}^{+}\left(\mathrm{H}_{2} \mathrm{O}\right)_{n}$ e estabilizando a carga do poliânion, como ocorre para o $\mathrm{HPW} \cdot 6 \mathrm{H}_{2} \mathrm{O}$. Os valores de $\mathrm{M}_{2 H P}$ para os xerogeis são maiores do que os observados para $\mathrm{HPW} \cdot 6 \mathrm{H}_{2} \mathrm{O}$, indicando que estes clusters apresentam número $n$ de moléculas de $\mathrm{H}_{2} \mathrm{O}$ maior do que o encontrado para o 
HPW hidratado. Esta afirmação é consistente com o desvio químico menor observado para estas espécies nos xerogeis.(30) Após a secagem da amostra HT-N2, estas espécies (ii) não são observadas, consistentemente com o surgimento de ressonâncias nos espectros de ${ }^{31} \mathrm{P}$ que sugerem a ligação covalente entre o poliânion e um ou dois $\mathrm{H}$. Para os outros xerogeis submetidos à secagem estas espécies são termicamente estáveis, indicando interação forte com o ambiente, consistentemente com a baixa mobilidade observada.

Nos espectros de ${ }^{1} \mathrm{H}$ RMN para todos os xerogeis são observadas linhas em torno de 3,8ppm, 2,5ppm e 1,5ppm. Estudos de ${ }^{1} \mathrm{H}$ RMN em sílicas mostram que linhas em 1,5ppm e 2,5ppm estão presentes para sílicas desidratadas, e correspondem respectivamente à $\mathrm{OH}$ em unidades $\mathrm{SiOH}$ isoladas e em unidades $\mathrm{SiOH}$ adjacentes, com interação fraca entre o $\mathrm{H}$ e o $\mathrm{OH}$ vizinho, conforme mostram os esquemas da figura 7.1.(91, 110) A ressonância em 3,8ppm pode ser atribuída a espécies de $\mathrm{H}_{2} \mathrm{O}$ adsorvidas na superfície dos poros da matriz $\mathrm{SiO}$, Caillerie et al. observaram um aumento contínuo na intensidade e desvio químico para ressonâncias de ${ }^{1} \mathrm{H}$ na faixa de 3,0ppm a 5ppm, conforme é aumentada a hidratação da sílica.(110) Estas atribuições para as três espécies de $\mathrm{H}$ são consistentes com os resultados mostrados neste estudo. Os $\mathrm{OH}$ ressoando em $1,5 \mathrm{ppm}$ apresentam linha estreita nos espectros de ${ }^{1} \mathrm{H}$, e os resultados de spin-eco indicam baixo acoplamento dipolar ${ }^{1} \mathrm{H}_{-}{ }^{1} \mathrm{H}$ para esta espécie, consistentemente com $\mathrm{OH}$ isolados. Os $\mathrm{OH}$ ressoando em 2,5ppm por sua vez experimentam acoplamento dipolar homonuclear ligeiramente mais intenso do que o observado para os $\mathrm{OH}$ isolados. $\mathrm{O}$ acoplamento ${ }^{29} \mathrm{Si}^{1}{ }^{1} \mathrm{H}$ é mais intenso para os $\mathrm{OH}$ em unidades $\mathrm{SiO}$ adjacentes, como mostram os resultados de HETCOR $\left\{{ }^{1} \mathrm{H}\right\}-{ }^{29} \mathrm{Si}$, consistentemente com o maior número de ${ }^{1} \mathrm{H}$ ao redor dos ${ }^{29} \mathrm{Si}$ (maior o valor de $\mathrm{M}_{2 H S i}$ ). Os ${ }^{1} \mathrm{H}$ ressoando em 3,8ppm apresentam acoplamento homonuclear ainda mais intenso do que as duas espécies citadas anteriormente, consistentemente com a atribuição à grupos de moléculas de $\mathrm{H}_{2} \mathrm{O}$ adsorvidas na matriz $\mathrm{SiO}$. Alternativamente, os resultados para a amostra HPW-II mostram a existência de grupos $\mathrm{OH}$ ressoando na mesma faixa de desvio, provenientes da difusão dos $\mathrm{H}$ em diferentes sítios $\mathrm{O}$ dos clusters $\mathrm{H}^{+}\left(\mathrm{H}_{2} \mathrm{O}\right)_{n}$ e/ou do poliânion. Os prótons pertencentes às cadeias orgânicas também apresentam ressonâncias nesta faixa de desvios, como os ${ }^{1} \mathrm{H}$ em $\mathrm{CNH}_{2}\left(\delta-{ }^{1} \mathrm{H} \approx 1 \mathrm{ppm}\right)$ do APTS e o os $\mathrm{COH}\left(\delta-{ }^{1} \mathrm{H} \approx 3 \mathrm{ppm}\right)$ resultantes da abertura do anel epóxi do GLYMO.

Os resultados de HETCOR $\left\{{ }^{1} \mathrm{H}\right\}-{ }^{31} \mathrm{P}$ mostram ressonâncias de ${ }^{1} \mathrm{H}$ em torno de 3,3ppm, $1,5 \mathrm{ppm}$ e um ombro em torno de 5-7ppm. O ombro na região de desvios maiores pode ser seguramente atribuído a espécies de hidratação no ambiente de coordenação do poliânion, como as espécies observadas para o $\mathrm{HPW} \cdot 6 \mathrm{H}_{2} \mathrm{O}, \mathrm{H}^{+}\left(\mathrm{H}_{2} \mathrm{O}\right)_{n}, \mathrm{H}_{5} \mathrm{O}_{2}{ }^{+}, \mathrm{H}_{3} \mathrm{O}^{+}$e $\mathrm{H}_{2} \mathrm{O}$. Os valores de $\mathrm{M}_{2 H P}$ e o desvio químico destas espécies é consistente com maiores níveis de hidratação do que os encontrados em HPW $6 \mathrm{H}_{2} \mathrm{O}$. Para a amostra mais hidratada (HGAT-Amb), a ressonância 


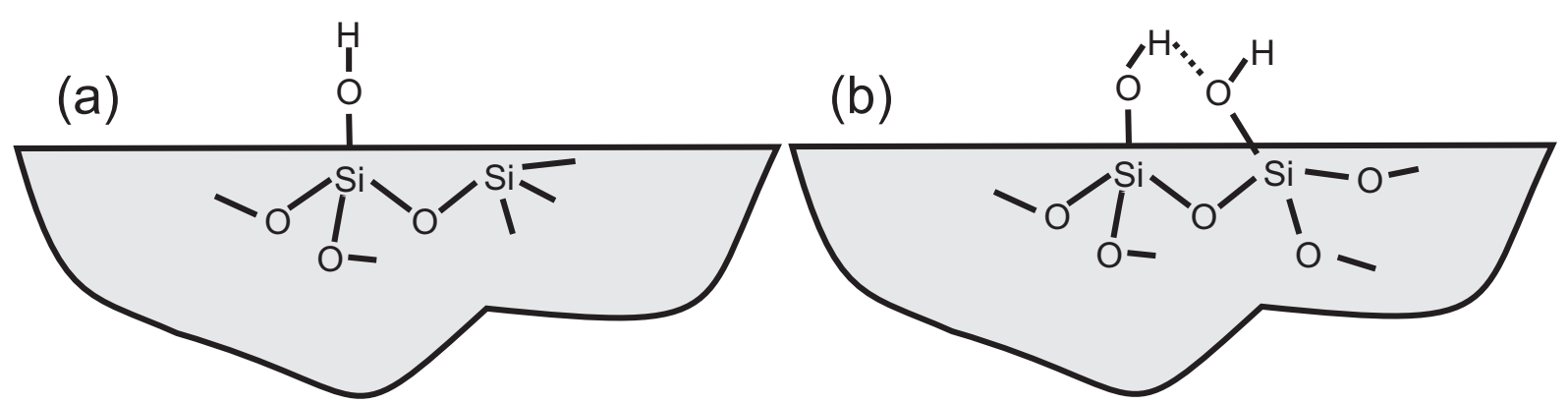

Figura 7.1-Representação esquemática de SiOH isolados (a) e adjacentes (b). Fonte: Adaptada de DELEPLANQUE.(91)

correspondente aos ${ }^{1} \mathrm{H}$ nestas espécies de hidratação é dominante no espectro indireto de ${ }^{1} \mathrm{H}$ obtido do experimento HETCOR, mostrando que o poliânion se coordena preferencialmente com as espécies de hidratação. Para as amostras mais secas (HT-N2, HGAT-N2 e HGAT-Box) os picos em 3,3ppm e 1,5ppm apresentam intensidade considerável no espectro indireto de ${ }^{1} \mathrm{H}$, mostrando um ambiente de coordenação diferente do observado para a amostra mais hidratada. A atribuição destas ressonâncias é ambígua, podendo ser os $\mathrm{H}$ difundindo entre grupos $\mathrm{OH}$ no ambiente de coordenação do poliânion, como observado para o HPW. $6 \mathrm{H}_{2} \mathrm{O}$, e/ou os grupos $\mathrm{OH}$ da matriz SiO. Resultados de HPW em sílica mostram que em amostras menos hidratadas, o poliânion, que é um ácido forte, tende a interagir preferencialmente com os $\mathrm{OH}$ isolados em grupos $\mathrm{SiOH}$, que apresentam caráter básico.(91, 111) Portanto não se pode descartar a interação entre o $\mathrm{HPW}$ com os $\mathrm{OH}$ e $\mathrm{H}_{2} \mathrm{O}$ da matriz de silicatos. Como as mesmas ressonâncias são observadas nos espectros HETCOR tanto para a amostra sem grupos orgânicos na composição (HT-N2) quanto para as amostras com grupos orgânicos (HGAT), não há evidência experimental que suporte a coordenação dos grupos orgânicos com o poliânion de HPW. Uma proposta para o esclarecimento destas ambiguidades seria a realização de experimentos utilizando técnica de desacoplamento homonuclear na dimensão indireta, como as técnicas de irradiação na condição de Lee-Goldburg .(112-114)

Os resultados de ${ }^{31} \mathrm{P}$ com variação de temperatura para a amostra HGAT-Box mostram uma alteração substancial de desvio químico para temperaturas abaixo de $0^{\circ} \mathrm{C}$. Os resultados de ${ }^{1} \mathrm{H}$, por outro lado, mostram uma variação na inclinação da curva de largura em função da temperatura por volta de $20^{\circ} \mathrm{C}$ e os resultados de spin-eco mostram um aumento significativo no acoplamento dipolar ${ }^{1} \mathrm{H}-{ }^{1} \mathrm{H}$, indicando uma redução considerável na dinâmica dos prótons, consistente com a variação observada nos espectros de ${ }^{31} \mathrm{P}$. Portanto, pode-se concluir que nesta amostra o desvio de ${ }^{31} \mathrm{P}$ é sensível às alterações dinâmicas ocorrendo no ambiente de coordenação do poliânion de HPW. Para a amostra HGAT-N2 variações apreciáveis nos desvios de ${ }^{31} \mathrm{P}$ não foram observadas, e a largura de ${ }^{1} \mathrm{H}$ mostra uma variação praticamente constante para toda a faixa de temperaturas analisadas. Conforme discutido na seção anterior, certa 
correlação entre os parâmetros espectrais de ${ }^{31} \mathrm{P}$ e as alterações no ambiente de prótons ao redor do poliânion também foram observadas para os hidratos de HPW, no entanto este efeito não é tão intenso quanto o observado para a amostra HGAT-Box, mostrando que nesta amostra menos hidratada o ambiente de coordenação do HPW é diferente do encontrado nas amostras mais hidratadas, e deve ser composto essencialmente de espécies protônicas da matriz ormosil.

Os resultados de RPE mostram que a interação entre o poliânion e as espécies protônicas ao redor altera a simetria do centro paramagnético $\mathrm{WO}_{6}$. Ao menos dois tipos de centros paramagnéticos $\mathrm{WO}_{6}$ em HPW foram observados para os diferentes xerogeis. Em amostras mais hidratadas apenas um sinal é observado, que pôde ser atribuído à centros $\mathrm{WO}_{6}$ interagindo mais fortemente com espécies de hidratação, podendo ser os aglomerados de $\mathrm{H}_{2} \mathrm{O}$ que compõem o ambiente de hidratação do HPW. Em amostras menos hidratadas, além deste centro coordenando-se com espécies de hidratação, foi observado um segundo centro, com simetria diferente do primeiro e consistente com interação mais fraca com os prótons no ambiente de coordenação do HPW. Este centro pode ser atribuído à $\mathrm{WO}_{6}$ interagindo mais fracamente com moléculas de $\mathrm{H}_{2} \mathrm{O}$ ou com outras espécies, como os grupos $\mathrm{SiOH}$ e/ou $\mathrm{H}_{2} \mathrm{O}$ adsorvida na superfície da sílica, como ocorre em sistemas de HPW suportado em sílica.(98, 111) Esta suposição é consistente com os diferentes ambientes de coordenação identificados para o HPW em função da hidratação das amostras. As propriedades do centro paramagnético formado após a irradiação dos xerogéis são muito similares dentre as composições estudadas, mostrando que a natureza dos grupos orgânicos da matriz ormosil não influencia na simetria do centro. Adicionando o fato de que não há evidências nos resultados de RMN que indiquem a participação dos grupos orgânicos no ambiente de coordenação do HPW, pode-se supor que os mesmos não influenciam de forma direta o processo de fotocromismo. Por outro lado, as espécies de hidratação participam efetivamente do processo de fotocromismo. 


\section{Conclusão}

Os estudos realizados neste trabalho mostram que a técnica de RMN é especialmente apropriada para a caracterização do ambiente de coordenação dos poliânions de HPW em diferentes amostras. As diferenças observadas para as amostras HPW-I e HPW-II não puderam ser observadas por outras técnicas, como TGA e DRX.

$\mathrm{O}$ controle da atmosfera durante a secagem do $\mathrm{HPW} \cdot \mathrm{nH}_{2} \mathrm{O}$ é determinante para a obtenção de amostras termicamente estáveis e com as características esperadas para HPW.6 $6 \mathrm{H}_{2} \mathrm{O} .(23,27)$ A amostra HPW-I, tratada sem controle de atmosfera, apresenta um excesso de espécies de hidratação. A estrutura destas espécies é muito complexa, sendo observadas transformações parcialmente irreversíveis, e estados metaestáveis após ciclagens térmicas. A temperatura de transição observada é consistente com o estudo de KREMENOVIC,(23, 24), que atribui este processo a uma transição de fase não-convergente. No entanto os resultados de RMN mostram que esses processos são devidos à remoção e/ou rearranjo de moléculas de $\mathrm{H}_{2} \mathrm{O}$ no material. Por outro lado, a amostra HPW-II, resultante do tratamento térmico sob fluxo de $\mathrm{N}_{2}$, possui estrutura mais estável, consistente com o cristal de HPW·6 $\mathrm{H}_{2} \mathrm{O}$. Transformações estruturais/dinâmicas reversíveis são observadas em função da temperatura. Estas transformações são consistentes com o processo de dissociação/associação do íon dioxônio, segundo o equilibrio da equação 2.2.1 $\left(\mathrm{H}_{5} \mathrm{O}_{2}^{+} \Longleftrightarrow \mathrm{H}_{3} \mathrm{O}^{+}+\mathrm{H}_{2} \mathrm{O} \Longleftrightarrow \mathrm{H}^{+}+2 \mathrm{H}_{2} \mathrm{O}\right)$, que se desloca para a direita com o aumento na temperatura. Tanto para HPW-I quanto para HPW-II, as transformações ocorrendo no ambiente local do ${ }^{31} \mathrm{P}$ no poliânion de HPW são pequenas, e correlacionadas em temperatura com as mudanças observadas para os prótons. Embora as amostras estudadas apresentem diferenças quanto à estrutura das espécies de hidratação, as variações ocorrem nas mesmas faixas de temperatura, mostrando que estas transformações estão associadas em parte aos mesmos processos dinâmicos locais de associação/dissociação dos íons $\mathrm{H}_{5} \mathrm{O}_{2}{ }^{+}$.

Considerando os xerogeis fotocrômicos, foram testadas diversas condições de atmosfera durante o preparo e tratamentos térmicos sobre o produto final. Os resultados mostram que a estrutura da matriz ormosil é praticamente invariante frente às diferentes condições de preparo. Tratamentos térmicos a até $85^{\circ} \mathrm{C}$ não alteram a estrutura dos grupos da matriz. A incorporação do HPW se da de forma uniforme para os xerogeis com grupos orgânicos na composição. Não foram observados indícios da degradação do poliânion de HPW em 
espécies lacunares. Por outro lado, nas amostras de composição HT, sem grupos orgânicos em sua composição, o ambiente de coordenação do HPW é heterogêneo. Ainda com esta diferença em relação ao outro conjunto de xerogeis fotocrômicos, os resultados de correlação $\left\{{ }^{1} \mathrm{H}\right\}-{ }^{31} \mathrm{P}$ foram comparáveis. Esta semelhança não permite afirmar que exista correlação entre os grupos orgânicos e o poliânion de HPW, diferente do que havia sido proposto em trabalhos anteriores.(16-20) Da mesma forma, os resultados de RPE em amostras irradiadas não são sensíveis à natureza dos grupos orgânicos.

Diferentes espécies de ${ }^{1} \mathrm{H}$ puderam ser identificadas para os xerogeis:

(i) aglomerados de moléculas de $\mathrm{H}_{2} \mathrm{O}$ móveis, provavelmente distantes de HPW,

(ii) grupos de hidratação como $\mathrm{H}_{2} \mathrm{O}, \mathrm{H}_{3} \mathrm{O}^{+}, \mathrm{H}_{5} \mathrm{O}_{2}{ }^{+}$e $\mathrm{H}^{+}\left(\mathrm{H}_{2} \mathrm{O}\right)_{n}$ no ambiente de coordenação do poliânion de HPW. A comparação com os resultados obtidos para amostras de $\mathrm{HPW} \cdot 6 \mathrm{H}_{2} \mathrm{O}$ indicam que o ambiente é majoritariamente constituído por clusters $\mathrm{H}^{+}\left(\mathrm{H}_{2} \mathrm{O}\right)_{n}$, mas a presença das outras espécies não pode ser descartada.

(iii) grupos $\mathrm{SiOH}$ e/ou $\mathrm{H}$ difundindo entre diferentes sítios $\mathrm{O}$.

(iv) espécies $\mathrm{CH}_{2}, \mathrm{CH}_{3}, \mathrm{OCH}_{2}$ e $\mathrm{COH}$ pertencentes às cadeias orgânicas dos organosilanos. Estas cadeias se mantém íntegras após a formação do ormosil, exceto pela reação do anel epóxi do GLYMO com $\mathrm{H}_{2} \mathrm{O}$, gerando grupos diol.

O controle de atmosfera durante o preparo é determinante para a estrutura final dos ambientes de hidratação ao redor do poliânion. A fração de $\mathrm{H}_{2} \mathrm{O}$ (i) nas amostras varia de acordo com a atmosfera de preparo, aparecendo em grandes quantidades para amostras preparadas em condições ambientes, em quantidades menores para amostras preparadas em câmara com fluxo de $\mathrm{N}_{2}$ e estão ausentes para amostras preparadas em glove-box. Em todas as amostras o ambiente de coordenação do HPW é constituído de espécies (ii) e (iii). As primeiras aparecem em maior quantidade em amostras mais hidratadas, enquanto frações semelhantes das duas espécies são observadas para amostras menos hidratadas. Os resultados de RPE em amostras mais hidratadas mostram forte interação entre moléculas de $\mathrm{H}_{2} \mathrm{O}$ e o poliânion de HPW, alterando distancias de ligações $\mathrm{W}=\mathrm{O}$ em $\mathrm{WO}_{6}$. Por outro lado, para amostras secas existem dois sítios $\mathrm{W}^{5+}$, interagindo de forma diferente com o ambiente. Um dos sítios é similar ao observado para as amostras mais hidratadas, $\mathrm{WO}_{6}$ interagindo fortemente com grupos de hidratação. $\mathrm{O}$ outro sítio corresponde à centros $\mathrm{WO}_{6}$ interagindo mais fracamente com o ambiente. Portanto, conclui-se as espécies de hidratação participam do processo de fotocromismo, provavelmente atuando como contra-íons fornecedores de elétrons para a redução do poliânion, assim como proposto por Chen et al.(62) 
Em resumo, o ambiente de coordenação do HPW nos xerogeis é basicamente constituído de espécies de hidratação, como $\mathrm{H}_{2} \mathrm{Oe} \mathrm{H}^{+}\left(\mathrm{H}_{2} \mathrm{O}\right)_{n}$, e espécies $\mathrm{OH}$, que provavelmente pertencem a grupos $\mathrm{SiOH}$ na matriz ormosil. A interação entre o poliânion e os grupos funcionais orgânicos não pôde ser confirmada pelos experimentos de RMN e RPE. Por outro lado, os resultados mostram grande participação das espécies de hidratação ao redor do poliânion no processo de fotocromismo.

Os experimentos preliminares em amostras irradiadas demonstram a sensibilidade da técnica de RMN frente às mudanças estruturais ocorrendo mediante a irradiação dos xerogéis. Foi observado um rearranjo estrutural reversível para as espécies de hidratação após a irradiação das amostras, reforçando a hipótese da participação ativa das espécies de hidratação no processo de fotocromismo. Estudos adicionais utilizando a abordagem desenvolvida neste projeto devem ser realizados em amostras irradiadas, para futuras investigações a respeito dos mecanismos envolvidos no fenômeno de fotocromismo.

Estudos adicionais precisam ser realizados para esclarecer certas ambiguidades na atribuição dos prótons próximos a HPW em amostras menos hidratadas:

- experimentos de HETCOR com desacoplamento da interação homonuclear ${ }^{1} \mathrm{H}-{ }^{1} \mathrm{H}$, para melhor resolução dos espectros indiretos de ${ }^{1} \mathrm{H}$;

- experimentos de ${ }^{1} \mathrm{H}$ e ${ }^{2} \mathrm{H}$ RMN em amostras deuteradas. A deuteração parcial das amostras reduz o número de spins ${ }^{1} \mathrm{H}$ acoplados, reduzindo o acoplamento dipolar ${ }^{1} \mathrm{H}-{ }^{1} \mathrm{H}$ e incrementando a resolução das linhas espectrais. Adicionalmente, $\mathrm{o}{ }^{2} \mathrm{H}$ apresenta spin $I=1$ e portanto momento quadrupolar diferente de zero. O acoplamento quadrupolar elétrico permite também a possibilidade de analisar a dinâmica destas espécies. 


\section{REFERÊNCIAS}

1 MARROT, L.; MEUNIER, J.-R. Skin DNA photodamage and its biological consequences. Journal of the American Academy of Dermatology, v. 58, n. 5, p. S139-148, 2008.

2 HIDALGO, M.; PESSOA, C.; FERNÁNDEZ, E.; CÁRDENAS, A. Comparative determination of photodegradation kinetics of quinolones. Journal of Photochemistry and Photobiology A: chemistry, v. 73, n. 2, p. $135-138,1993$.

3 DAVIS, A.; DEANE, G. H. W.; DIFFEY, B. L. Possible dosimeter for ultraviolet radiation. Nature, v. 261, n. 5556, p. $169-170,1976$.

4 MILLS, A.; MCFARLANE, M.; SCHNEIDER, S. A viologen-based UV indicator and dosimeter. Analytical and Bioanalytical Chemistry, v. 386, n. 2, p. 299-305, 2006.

5 PARISI, A. V.; KIMLIN, M. G.; TURNBULL, D. J.; MACARANAS, J. Potential of phenothiazine as a thin film dosimeter for UVA exposures. Photochemical and Photobiology Science, v. 4, n. 11, p. 907-910, 2005.

6 BROWN, G. H. Techniques of chemistry. New York, USA: Wiley-Interscience, 1971, v.3.

$7 \mathrm{HE}, \mathrm{T}$.; YAO, J. Photochromism in composite and hybrid materials based on transition-metal oxides and polyoxometalates. Progress in Materials Science, v. 51, n. 6, p. $810-879,2006$.

8 DEB, S. K.; CHOPOORIAN, J. A. Optical properties and color-center formation in thin films of molybdenum trioxide. Journal of Applied Physics, v. 37, n. 13, p. 4818-4825, 1966.

9 POPE, M.; MÜLLER, A. Polyoxometalates: from platonic solids to anti-retroviral activity. Dordrecht: Kluwer Academic Publishers, 1994.

10 HILL, C. L. Introduction: polyoxometalates multicomponent molecular vehicles to probe fundamental issues and practical problems. Chemical Reviews, v. 98, n. 1, p. 1-2, 1998.

11 LIN, S.; ZHANG, X.; LUO, M. A novel inorganic-organic hybrid compound constructed from copper(ii)-monosubstituted polyoxometalates and poly(amidoamine). Journal of Solid State Electrochemistry, v. 13, n. 10, p. 1585-1589, 2009. 
12 KATSOULIS, D. E. A survey of applications of polyoxometalates. Chemical Reviews, v. 98, n. 1, p. 359-388, 1998.

13 SANCHEZ, C.; LEBEAU, B.; CHAPUT, F.; BOILOT, J. P. Optical properties of functional hybrid organic-inorganic nanocomposites. Advanced Materials, v. 15, n. 23, p. 1969-1994, 2003.

14 ZAYAT, M.; PARDO, R.; LEVY, D. The role of organic groups in ormosil matrices in the photochromism of naphthopyrans in sol-gel thin films. Journal os Materials Chemistry, v. 13, n. 12, p. 2899-2903, 2003.

15 YAMASE, T. Photo- and electrochromism of polyoxometalates and related materials. Chemical Reviews, v. 98, n. 1, p. 307-326, 1998.

16 SOUZA, A. Aminoalcóxissilanos e ácido 12-tungstofosfórico: estudo de filmes híbridos orgânicos-inorgânicos automontados e avaliaçcão do comportamento fotocrômico dos seus xerogéis. 2005. 98p. Dissertação (Mestrado em Ciências) - Instituto de Química de São Carlos, Universidade de São Paulo, São Carlos, 2005.

17 CARVALHO, F. L. S. Efeito da matriz no comportamento fotocrômico de fosfotungstato. 2008. 85p. Dissertação (Mestrado em Ciências) - Instituto de Química de São Carlos, Universidade de São Paulo, São Carlos, 2008.

18 DE OLIVEIRA, M.; DE SOUZA, A. L.; SCHNEIDER, J.; RODRIGUES-FILHO, U. P. Local structure and photochromic response in ormosils containing dodecatungstophosphoric acid. Chemistry of Materials, v. 23, n. 4, p. 953-963, 2011.

19 FERREIRA-NETO, E.; CARVALHO, F.; ULLAH, S.; ZOLDAN, V.; PASA, A.; SOUZA, A.; BATTIROLA, L.; RUDOLF, P.; BILMES, S.; RODRIGUES-FILHO, U. Surface structure and reactivity study of phosphotungstic acid-nitrogenated ormosils. Journal of Sol-Gel Science and Technology, v. 66, n. 3, p. 363-371, 2013.

20 OLIVEIRA JUNIOR, M. Estudo de complexos fotocrômicos de xerogéis de ormosil através de ressonância magnética nuclear em estado sólido. 2009. 118p. Dissertação (Mestrado em Ciências) - Instituto de Física de São Carlos, Universidade de São Paulo, São Carlos, 2009.

21 GOUZERH, P.; PROUST, A. Main-group element, organic, and organometallic derivatives of polyoxometalates. Chemical Reviews, v. 98, n. 1, p. 77-112, 1998.

22 BROWN, G. M.; NOE-SPIRLET, M.-R.; BUSING, W. R.; LEVY, H. A. Dodecatungstophosphoric acid hexahydrate, $\left(\mathrm{H}_{5} \mathrm{O}_{2}^{+}\right)_{3}\left(\mathrm{PW}_{1} 2 \mathrm{O}_{40}^{3-}\right)$. the true structure of Keggin's 'pentahydrate' from single-crystal $\mathrm{X}$-ray and neutron diffraction data. Acta Crystallographica Section B, v. 33, n. 4, p. 1038-1046, 1977. 
23 KREMENOVIC, A.; DE BIRÉ, A. S.; DIMITRIJEVIC, R.; SCIAU, P.; MIOC, U.; COLOMBAN, P. Keggin's ion structural modification and expansion of dodecatungstophosphoric acid hexahydrate induced by temperature treatment: in situ X-ray powder diffraction and Raman investigations. Solid State lonics, v. 132, n. 1-2, p. 39-53, 2000.

24 KREMENOVIC, A.; DE BIRÉ, A. S.; BOURÉE, F.; COLOMBAN, P.; DIMITRIJEVIC, R.; DAVIDOVIC, M.; MIOC, U. Structural modifications of dodecatungstophosphoric acid hexahydrate induced by temperature in the $10-358 \mathrm{~K}$ range. in situ high-resolution neutron powder diffraction investigation. Solid State lonics, v. 150, n. 3 - 4, p. $431-442,2002$.

25 MIOC, U.; COLOMBAN, P.; NOVAK, A. Infrared and raman study of some heteropolyacid hydrates. Journal of Molecular Structure, v. 218, n. 0, p. 123-128, 1990.

26 MIOC, U.; DAVIDOVIC, M.; TJAPKIN, N.; COLOMBAN, P.; NOVAK, A. Equilibrium of the protonic species in hydrates of some heteropolyacids at elevated temperatures. Solid State lonics, v. 46, n. 1-2, p. $103-109,1991$.

27 MIOC, U.; DIMITRIJEVIC, R.; DAVIDOVIC, M.; NEDIC, Z.; MITROVIC, M.; COLOMBAN, $P$. Thermally induced phase transformations of 12-tungstophosphoric acid 29-hydrate: synthesis and characterization of $\mathrm{PW}_{8} \mathrm{O}_{26}$-type bronzes. Journal of Materials Science, v. 29, n. 14, p. 3705-3718, 1994.

28 MIOC, U.; TODOROVIC, M.; DAVIDOVIC, M.; COLOMBAN, P.; HOLCLAJTNERANTUNOVIC, I. Heteropoly compounds-from proton conductors to biomedical agents. Solid State lonics, v. 176, n. 39-40, p. $3005-3017,2005$.

29 MIOC, U. B.; PETKOVIC, M.; DAVIDOVIC, M.; PERIC, M.; ABDUL-REDAH, T. Proton and protonic entities in solid heteropoly compounds: An ab initio calculation of the environmental effect on the ion. Journal of Molecular Structure, v. 885, n. 1-3, p. $131-138$, 2008.

30 ESSAYEM, N.; TONG, Y.; JOBIC, H.; VEDRINE, J. Characterization of protonic sites in $\mathrm{H}_{3} \mathrm{PW}_{12} \mathrm{O}_{40}$ and $\mathrm{Cs}_{1} \cdot 9 \mathrm{H}_{1} \cdot 1 \mathrm{PW}_{12} \mathrm{O}_{40}$ : a solid-state ${ }^{1} \mathrm{H},{ }^{2} \mathrm{H},{ }^{31} \mathrm{P}$ MAS-NMR and inelastic neutron scattering study on samples prepared under standard reaction conditions. Applied Catalysis A: general, v. 194 - 195, n. 0, p. $109-122,2000$.

31 PRESSMAN, H. A.; SLADE, R. C. Internal rotation in the $\mathrm{H}_{5} \mathrm{O}_{2}^{+}$ion: A quasielastic neutron scattering study of 12-tungstophosphoric acid hexahydrate. Chemical Physics Letters, v. 151, n. $4-5$, p. $354-361,1988$.

32 GANAPATHY, S.; FOURNIER, M.; PAUL, J. F.; DELEVOYE, L.; GUELTON, M.; AMOUREUX, J. P. Location of protons in anhydrous keggin heteropolyacids $\mathrm{H}_{3} \mathrm{PMo}_{12} \mathrm{O}_{40}$ and $\mathrm{H}_{3} \mathrm{PW}_{12} \mathrm{O}_{40}$ by ${ }^{1} \mathrm{H}\left\{{ }^{31} \mathrm{P}\right\} /{ }^{31} \mathrm{P}\left\{{ }^{1} \mathrm{H}\right\}$ REDOR NMR and DFT quantum chemical calculations. Journal of the American Chemical Society, v. 124, n. 26, p. 7821-7828, 2002. 
33 KAZANSKY, L.; MCGARVEY, B. NMR and EPR spectroscopies and electron density distribution in polyoxoanions. Coordination Chemistry Reviews, v. 188, n. 1, p. $157-210$, 1999.

34 VEGA, A. J. Heteronuclear chemical-shift correlations of silanol groups studied by twodimensional cross-polarization magic angle spinning nmr. Journal of the American Chemical Society, v. 110, n. 4, p. 1049-1054, 1988.

35 UEDA, T.; TATSUMI, T.; EGUCHI, T.; NAKAMURA, N. Structure and properties of acidic protons in anhydrous dodecatungstophosphoric acid, $\mathrm{H}_{3} \mathrm{PW}_{12} \mathrm{O}_{40}$, as studied by solid-state ${ }^{1} \mathrm{H},{ }^{2} \mathrm{H}$ NMR, and ${ }^{1} \mathrm{H}_{-}{ }^{3} 1 \mathrm{P}$ Sedor NMR. Journal of Physical Chemistry B, v. 105, n. 23, p. 5391-5396, 2001.

36 WANG, P.-K.; SLICHTER, C. P.; SINFELT, J. H. NMR study of the structure of simple molecules adsorbed on metal surfaces: $\mathrm{C}_{2} \mathrm{H}_{2}$ on Pt. Physical Review Letters, v. 53, n. 1, p. 82-85, 1984.

37 YANG, J.; JANIK, M. J.; MA, D.; ZHENG, A.; ZHANG, M.; NEUROCK, M.; DAVIS, R. J.; YE, C.; DENG, F. Location, acid strength, and mobility of the acidic protons in Keggin $12-\mathrm{H}_{3} \mathrm{PW}_{12} \mathrm{O}_{40}$ : a combined solid-state NMR spectroscopy and DFT quantum chemical calculation study. Journal of the American Chemical Society, v. 127, n. 51, p. 18274-18280, 2005.

38 BRIDGEMAN, A. J. Density functional study of the vibrational frequencies of $\alpha$-keggin heteropolyanions. Chemical Physics, v. 287, n. 1-2, p. $55-69,2003$.

39 JANIK, M. J.; CAMPBELL, K. A.; BARDIN, B. B.; DAVIS, R. J.; NEUROCK, M. A computational and experimental study of anhydrous phosphotungstic acid and its interaction with water molecules. Applied Catalysis A: general, v. 256, n. 1-2, p. 51-68, 2003.

40 HABER, J.; MATACHOWSKI, L.; MUCHA, D.; STOCH, J.; SARV, P. New evidence on the structure of potassium salts of 12-tungstophosphoric acid, $\mathrm{K}_{x} \mathrm{H}_{3-x} \mathrm{PW}_{12} \mathrm{O}_{40}$. Inorganic Chemistry, v. 44, n. 19, p. 6695-6703, 2005.

41 DEC, S. F.; HERRING, A. M. Structure and dynamics of disodium hydrogen 12tungstophosphoric acid. Journal of Physical Chemistry B, v. 108, n. 33, p. 12339-12351, 2004.

42 KUANG, W.; RIVES, A.; FOURNIER, M.; HUBAUT, R. Structure and reactivity of silica-supported 12-tungstophosphoric acid. Applied Catalysis A: general, v. 250, n. 2, p. 221 229, 2003.

43 SHIRRELL, C. D.; WILLIAMS, D. E. The crystal structure of 2,2,4,4-tetramethyl-3thio-I,3-cyclobutanedione. Acta Crystallographica Section B, v. 30, n. 8, p. 1974-1978, 1974. 
44 COTTON, F. A.; FAIR, C. K.; LEWIS, G. E.; MOTT, G. N.; ROSS, F. K.; SCHULTZ, A. J.; WILLIAMS, J. M. Precise structural characterizations of the hexaaquovanadium(iii) and diaquohydrogen ions. X-ray and neutron diffraction studies of $\left[\mathrm{V}\left(\mathrm{H}_{2} \mathrm{O}\right)_{6}\right]\left[\mathrm{H}_{5} \mathrm{O}_{2}\right]\left(\mathrm{CF}_{3} \mathrm{SO}_{3}\right)_{4}$. Journal of the American Chemical Society, v. 106, n. 18, p. 5319-5323, 1984.

45 ATTIG, R.; WILLIAMS, J. M. Das $\mathrm{h}_{5} \mathrm{O}_{2}^{+}$-ion in Bromwasserstoff-dihydrat. Angewandte Chemie, v. 88, n. 15, p. 507-508, 1976.

46 SPIRLET, M.-R.; BUSING, W. R. Dodecatungstophosphoric acid-21-water by neutron diffraction. Acta Crystallographica Section B, v. 34, n. 3, p. 907-910, 1978.

47 JEFFREY, G. A. An introduction to hydrogen bonding. New York: Oxford Univ. Press, 1997.

48 MARX, D.; TUCKERMAN, M. E.; HUTTER, J.; PARRINELLO, M. The nature of the hydrated excess proton in water. Nature, v. 397, n. 8, p. 601-604, 1999.

49 EBELMEN, P. M. Sur les combinaisons des acides et silicique avec les éthers. Annales de Chimie e Physique, v. 16, n. 3, p. 129-166, 1846.

50 GRAHAM, T. On the properties of silicic acid and other analogous colloidal substances. Journal of Chemical Society, v. 17, n. 0, p. 318-327, 1864.

51 HENCH, L. L.; WEST, J. K. The sol-gel process. Chemical Reviews, v. 90, n. 1, p. 33-72, 1990.

52 BONHOMME, C.; COELHO, C.; BACCILE, N.; GERVAIS, C.; AZAÏS, T.; BABONNEAU, $\mathrm{F}$. Advanced solid state $\mathrm{nmr}$ techniques for the characterization of sol-gel-derived materials. Accounts of Chemical Research, v. 40, n. 9, p. 738-746, 2007.

53 MELDE, B. J.; HOLLAND, B. T.; BLANFORD, C. F.; STEIN, A. Mesoporous sieves with unified hybrid inorganic/organic frameworks. Chemistry of Materials, v. 11, n. 11, p. 3302-3308, 1999.

54 ARAKAKI, L. N. H.; AIROLDI, C. O relevante papel do agente sililante na modificação de superfícies de polímeros. Química nova, v. 22, n. 2, p. 246-253, 1999.

55 SCHUBERT, U.; HUESING, N.; LORENZ, A. Hybrid inorganic-organic materials by sol-gel processing of organofunctional metal alkoxides. Chemistry of Materials, v. 7, n. 11, p. 2010-2027, 1995.

56 PEETERS, M.; WAKELKAMP, W.; KENTGENS, A. A ${ }^{29}$ Si solid-state magic angle spinning nuclear magnetic resonance study of TEOS-based hybrid materials. Journal of Non-Crystalline Solids, v. 189, n. 1-2, p. $77-89,1995$. 
57 YAMASE, T. Photochemical studies of the alkylammonium molybdates. part 4. electron spin resonance study of an irradiated single crystal of hexakis-(isopropylammonium) dihydrogen octamolybdate dihydrate. Journal of Chemical Society, Dalton Transactions, , n. 4, p. 283-285, 1978. doi:10.1039/DT9780000283.

58 YAMASE, T. Photochemical studies of the alkylammonium molybdates. part 6. photoreducible octahedron site of $\left[\mathrm{Mo}_{7} \mathrm{O}_{24}\right]^{6-}$ as determined by electron spin resonance. Journal of Chemical Society, Dalton Transactions, , n. 10, p. 1987-1991, 1982. doi: 10.1039/DT9820001987.

59 YAMASE, T. Photochemical studies of the alkylammonium molybdates. part 7. octahedral sites for multi-electron reduction of $\left[\mathrm{Mo}_{8} \mathrm{O}_{26}\left(\mathrm{MoO}_{4}\right)_{2}\right]^{8-}$. Journal of Chemical Society, Dalton Transactions, , n. 12, p. 2585-2590, 1985. doi: 10.1039/DT9850002585.

60 YAMASE, T.; SUGA, M. Photochemical studies of alkylammonium molybdates. part 8. location of protons interacting with the paramagnetic electron in a single crystal of photoirradiated $\left[\mathrm{NH}_{3} \mathrm{Pr}_{i}\right] 6\left[\mathrm{Mo}_{8} \mathrm{O}_{26}(\mathrm{OH})_{2}\right] \cdot 2 \mathrm{H}_{2} \mathrm{O}$. Journal of Chemical Society, Dalton Transactions, , $\mathrm{n}$. 4, p. 661-669, 1989, doi:10.1039/DT9890000661.

61 YAMASE, T.; SUGETA, M. Charge-transfer photoluminescence of polyoxo-tungstates and -molybdates. Journal of Chemical Society, Dalton Transactions, , n. 5, p. 759-765, 1993. doi:10.1039/DT9930000759.

62 CHEN, Y.; YU, G.; LI, F.; XIE, C.; TIAN, G. Synthesis and visible-light photochromism of a new composite based on magadiite containing polytungstate. Journal os Materials Chemistry C, v. 1, p. 3842-3850, 2013. doi: 10.1039/C3TC30309H.

$63 \mathrm{HE}, \mathrm{T}$.; YAO, J. Photochromic materials based on tungsten oxide. Journal of Material Chemistry, v. 17, n. 43, p. 4547-4557, 2007.

64 AVELLANEDA, C. O.; BULHÕES, L. O. Photochromic properties of $\mathrm{WO}_{3}$ and $\mathrm{WO}_{3}: \mathrm{X}$ $(\mathrm{X}=\mathrm{Ti}, \mathrm{Nb}, \mathrm{Ta}$ and $\mathrm{Zr}$ ) thin films. Solid State lonics, v. 165, n. 1-4, p. $117-121,2003$.

65 YANG, Y.; CAO, Y.; CHEN, P.; LOO, B.; YAO, J. Visible-light photochromism in electrolytically pretreated $\mathrm{WO}_{3}$ thin films. Journal of Physics and Chemistry of Solids, v. $59, \mathrm{n}$. 9, p. $1667-1670,1998$.

66 BERNARDINI, G.; ZHAO, C.; WEDD, A. G.; BOND, A. M. Ionic liquid-enhanced photooxidation of water using the polyoxometalate anion $\left[\mathrm{P}_{2} \mathrm{~W}_{1} 8 \mathrm{O}_{6} 2\right]^{6-}$ as the sensitizer. Inorganic Chemistry, v. 50, n. 13, p. 5899-5909, 2011.

67 SLICHTER, C. P. Principles of magnetic resonance. New York: Springer, 1996.

68 ABRAGAM, A. The principles of nuclear magnetism. Oxford: Oxford Univ. Press, 1961. 
69 SCHIMIDT-ROHR, K.; SPIESS, H. W. Multidimensional solid-state NMR and polymers. London, UK: Academic Press Limited, 1996.

70 MEHRING, M. High resolution NMR of solids. Berlin: Springer-Verlag, 1983.

71 GERSTEIN, B. C.; DYBOWSKI, C. R. Transient techniques in NMR of solids. New York, USA: Academic Press, 1985.

72 DUER, M. J. Solid-state NMR spectroscopy. Oxford, USA: Blackwell Science, 2002.

73 HARRIS, R. K.; MANN, B. E. NMR and the periodic table. London, UK: Elsevier Science \& Technology Books, 1978.

74 BRYANT, R. G. The NMR time scale. Journal of Chemical Education, v. 60, n. 11, p. 933, 1983.

75 VAN VLECK, J. H. The dipolar broadening of magnetic resonance lines in crystals. Physical Review, v. 74, n. 9, p. 1168-1183, 1948.

76 MARICQ, M.; WAUGH, J. S. NMR in rotating solids. Journal of Chemical Physics, v. 70, n. 7, p. 3300-3316, 1979.

77 WAUGH, J. Theory of broadband spin decoupling. Journal of Magnetic Resonance, v. 50, n. 1 , p. $30-49,1982$.

78 HARTMANN, S. R.; HAHN, E. L. Nuclear double resonance in the rotating frame. Physical Review, v. 128, n. 5, p. 2042-2053, 1962.

79 TEKELY, P.; GÉRARDY, V.; PALMAS, P.; CANET, D.; RETOURNARD, A. Measurement of hartmann-hahn cross-polarization dynamics with quenching of proton $t_{1 \rho}$ relaxation dependence. Solid State Nuclear Magnetic Resonance, v. 4, n. 6, p. 361 - 367, 1995.

80 KLUR, I.; JACQUINOT, J.-F.; BRUNET, F.; CHARPENTIER, T.; VIRLET, J.; SCHNEIDER, C.; TEKELY, P. NMR cross-polarization when $\mathrm{t}_{I S}>\mathrm{t}_{1 \rho}$; examples from silica gel and calcium silicate hydrates. Journal of Physical Chemistry B, v. 104, n. 44, p. 10162-10167, 2000.

81 ERNST, R. R.; BODENHAUSEN, G.; WOUKAUN, A. Principles of nuclear magnetic resonance in one and two dimensions. Oxford, USA: Oxford University Press, 1997.

82 MARION, D.; WÜTHRICH, K. Application of phase sensitive two-dimensional correlated spectroscopy (COSY) for measurements of ${ }^{1} \mathrm{H}-{ }^{1} \mathrm{H}$ spin-spin coupling constants in proteins. Biochemical and Biophysical Research Communications, v. 113, n. 3, p. 967 - 974, 1983. 
83 KEELER, J.; NEUHAUS, D. Comparison and evaluation of methods for two-dimensional NMR spectra with absorption-mode lineshapes. Journal of Magnetic Resonance, v. 63, n. 3, p. $454-472,1985$.

84 HAHN, E. L. Spin echoes. Physical Review, v. 80, n. 4, p. 580-594, 1950.

85 HAYASHI, S.; HAYAMIZU, K.; YAMASAKI, S.; MATSUDA, A.; TANAKA, K. Nuclearmagnetic-resonance study of amorphous silicon-hydrogen-phosphorus alloys. Physical Review $B$, v. 38, n. 1, p. 31-38, 1988.

86 FUKUSHIMA, E.; ROEDER, S. B. W. Experimental pulse NMR: a nuts and bolts approach. London, UK: Addison-Wesley Publishing Company, Inc., 1981.

87 BRUSTOLON, M.; GIAMELLO, E. Eletron paramagnetic ressonance - a practioner's toolkit. New York, USA: John Wiley \& Sons, Inc., 2008.

88 CORY, D.; RITCHEY, W. Suppression of signals from the probe in Bloch decay spectra. Journal of Magnetic Resonance, v. 80, n. 1, p. 128 - 132, 1988.

89 STOLL, S.; SCHWEIGER, A. Easyspin, a comprehensive software package for spectral simulation and analysis in EPR. Journal of Magnetic Resonance, v. 178, n. 1, p. 42 - 55, 2006.

90 VARGA, G. M.; PAPACONSTANTINOU, E.; POPE, M. T. Heteropoly blues. IV. spectroscopic and magnetic properties of some reduced polytungstates. Inorganic Chemistry, v. 9, n. 3, p. 662-667, 1970.

91 DELEPLANQUE, J.; HUBAUT, R.; BODART, P.; FOURNIER, M.; RIVES, A. ${ }^{1} \mathrm{H}$ and ${ }^{31} \mathrm{P}$ solid-state NMR of trimethylphosphine adsorbed on heteropolytungstate supported on silica. Applied Surface Science, v. 255, n. 9, p. 4897 - 4901, 2009.

92 YESINOWSKI, J. P.; ECKERT, H.; ROSSMAN, G. R. Characterization of hydrous species in minerals by high-speed proton MAS-NMR. Journal of the American Chemical Society, v. 110, n. 5, p. $1367-1375,1988$.

93 KEARLEY, G.; WHITE, R.; FORANO, C.; SLADE, R. An analysis of the vibrational frequencies and amplitudes of the $\mathrm{H}_{5} \mathrm{O}_{2}^{+}$ion in $\mathrm{H}_{4} \mathrm{SiW}_{12} \mathrm{O}_{40} \cdot 6 \mathrm{H}_{2} \mathrm{O}\left(\mathrm{TSA} \cdot 6 \mathrm{H}_{2} \mathrm{O}\right)$ and $\mathrm{H}_{3} \mathrm{PW}_{12} \mathrm{O}_{40} \cdot 6 \mathrm{H}_{2} \mathrm{O}$ (TPA.6 $\mathrm{H}_{2} \mathrm{O}$ ). Spectrochimica Acta Part A: molecular spectroscopy, v. 46, n. 3, p. $419-424$, 1990.

94 BRUNNER, E.; STERNBERG, U. Solid-state NMR investigations on the nature of hydrogen bonds. Progress in Nuclear Magnetic Resonance Spectroscopy, v. 32, n. 1, p. $21-57,1998$.

95 TEMPLIN, M.; WIESNER, U.; SPIESSS, H. W. Multinuclear solid-state-NMR studies of hybrid organic-inorganic materials. Advanced Materials, v. 9, n. 10, p. 814-817, 1997. 
96 ENGELHARDT, G.; RADEGLIA, R. A semi-empirical quantum-chemical rationalization of the correlation between siosi angles and ${ }^{29} \mathrm{Si}$ NMR chemical shifts of silica polymorphs and framework aluminosilicates (zeolites). Chemical Physics Letters, v. 108, n. 3, p. $271-274$, 1984.

97 SMITH, B. J.; PATRICK, V. A. Quantitative determination of aqueous dodecatungstophosphoric acid speciation by nmr spectroscopy. Australian Journal of Chemistry, v. 57, n. 3, p. 261-268, 2004.

98 KOZHEVNIKOV, I.; SINNEMA, A.; JANSEN, R.; BEKKUM, H. ${ }^{17} \mathrm{O}$ NMR determination of proton sites in solid heteropoly acid $\mathrm{H}_{3} \mathrm{P} W_{12} \mathrm{O}_{40} \cdot{ }^{31} \mathrm{P},{ }^{29} \mathrm{Si}$ and ${ }^{17} \mathrm{O}$ NMR, FT-IR and XRD study of $\mathrm{H}_{3} \mathrm{PW}_{12} \mathrm{O}_{40}$ and $\mathrm{H}_{4} \mathrm{Si}_{12} \mathrm{O}_{40}$ supported on carbon. Catalysis Letters, v. 27, n. 1-2, p. 187-197, 1994.

99 CHAUMETTE, H.; GRANDCLAUDE, D.; BRONDEAU, J.; WERBELOW, L.; CANET, D. Rotating-frame spin-lattice relaxation measurements with weak spin-locking fields in the presence of homonuclear dipolar coupling. Molecular Physics, v. 101, n. 12, p. 1919-1926, 2003.

100 SANCHEZ, C.; LIVAGE, J.; LAUNAY, J. P.; FOURNIER, M. Electron delocalization in mixed-valence tungsten polyanions. Journal of the American Chemical Society, v. 105, n. 23, p. 6817-6823, 1983.

101 SANCHEZ, C.; LIVAGE, J.; LAUNAY, J. P.; FOURNIER, M.; JEANNIN, Y. Electron delocalization in mixed-valence molybdenum polyanions. Journal of the American Chemical Society, v. 104, n. 11, p. 3194-3202, 1982.

102 CARL, P. J.; ISLEY, S. L.; LARSEN, S. C. Combining theory and experiment to interpret the epr spectra of vo2+-exchanged zeolites. Journal of Physical Chemistry A, v. 105, n. 18, p. 4563-4573, 2001.

103 PAGANINI, M. C.; DALL'ACQUA, L.; GIAMELLO, E.; LIETTI, L.; FORZATTI, P.; BUSCA, G. An EPR study of the surface chemistry of the $\mathrm{V}_{2} \mathrm{O}_{5}-\mathrm{WO}_{3} / \mathrm{TiO}_{2}$ catalyst: redox behaviour and state of V(IV). Journal of Catalysis, v. 166, n. 2, p. $195-205,1997$.

104 PATCHKOVSKII, S.; ZIEGLER, T. Prediction of electron paramagnetic resonance gtensors of transition metal complexes using density functional theory: first applications to some axial d ${ }^{1}$ MEX 4 systems. Journal of Chemical Physics, v. 111, n. 13, p. 5730-5740, 1999.

105 RODELLA, C.; FRANCO, R.; MAGON, C.; DONOSO, J.; NUNES, L.; SAEKI, M.; AEGERTER, M.; SARGENTELLI, V.; FLORENTINO, A. $\mathrm{V}_{2} \mathrm{O}_{5} / \mathrm{TiO}_{2}$ catalytic xerogels Raman and EPR studies. Journal of Sol-Gel Science and Technology, v. 25, n. 1, p. 83-88, 2002.

106 PRAKASH, A. M.; KEVAN, L. Structure and adsorbate interactions of vanadium in a vanadium silicate (VS-1) molecular sieve. Journal of Physical Chemistry B, v. 104, n. 29, p. 6860-6868, 2000. 
107 MOVAGHAR, B.; SCHWEITZER, L.; OVERHOF, H. Electron spin resonance in amorphous germanium and silicon. Philosophical Magazine Part B, v. 37, n. 6, p. 683-702, 1978.

108 WEEKS, R. A.; NELSON, C. M. Trapped electrons in irradiated quartz and silica: li, electron spin resonance. Journal of the American Ceramic Society, v. 43, n. 8, p. 399-404, 1960.

109 GRISCOM, D. L. Optical properties and structure of defects in silica glass. Journal of the Ceramic Society of Japan, v. 99, n. 1154, p. 923-942, 1991.

110 D'ESPINOSE DE LA CAILLERIE, J.-B.; AIMEUR, M. R.; KORTOBI, Y. E.; LEGRAND, A. P. Water adsorption on pyrogenic silica followed by ${ }^{1} \mathrm{H}$ MAS NMR. Journal of Colloid and Interface Science, v. 194, n. 2, p. $434-439,1997$.

111 ZENG, Z.-X.; CUI, L.; XUE, W.-L.; MA, N.-K. Study on adsorption behavior of 12phosphotungstic acid on silica gel. Industrial \& Engineering Chemistry Research, v. 52, n. 23, p. 8070-8078, 2013.

112 LEE, M.; GOLDBURG, W. I. Nuclear-magnetic-resonance line narrowing by a rotating rf field. Physical Review, v. 140, n. 4A, p. A1261-A1271, 1965.

113 BIELECKI, A.; KOLBERT, A.; LEVITT, M. Frequency-switched pulse sequences: Homonuclear decoupling and dilute spin NMR in solids. Chemical Physics Letters, v. 155, n. 4-5, p. $341-346,1989$.

114 VAN ROSSUM, B.-J.; FÖRSTER, H.; DE GROOT, H. High-field and high-speed CPMAS ${ }^{13} \mathrm{C}$ NMR heteronuclear dipolar-correlation spectroscopy of solids with frequency-switched lee-goldburg homonuclear decoupling. Journal of Magnetic Resonance, v. 124, n. 2, p. 516 519, 1997. 